2. To: (Receiving Organization)

Distribution

5. Proj./Prog./Dept./Div.:

73500

8. Originator Remarks:

This document provides an Estimation of SX-Earm Vadose Zone Cs-137

Inventories Erom Geostatistical Analysis of Drywell and Soil Core Data

\section{Receiver Remarks: \\ 11A. Design Baseline Document? $\bigcirc$ Yes \\ For clearance, release, and RMIS processing.}

3. From: (Originating Organization)

RPP Vadose Zone Characterization

6. Design Authority/Design Agent/Cog. Engr.:

T. E. Jones
4. Related EDT No

$\mathrm{N} / \mathrm{A}$

7. Purchase Order No.:

$\mathrm{N} / \mathrm{A}$

9. Equip./Component No.

$\mathrm{N} / \mathrm{A}$

10. System/B/dg./Facility:

$\mathrm{N} / \mathrm{A}$

12. Major Assm. Dwg. No.:

$\mathrm{N} / \mathrm{A}$

13. Permit/Permit Application No.:

$\mathrm{N} / \mathrm{A}$

14. Required Response Date

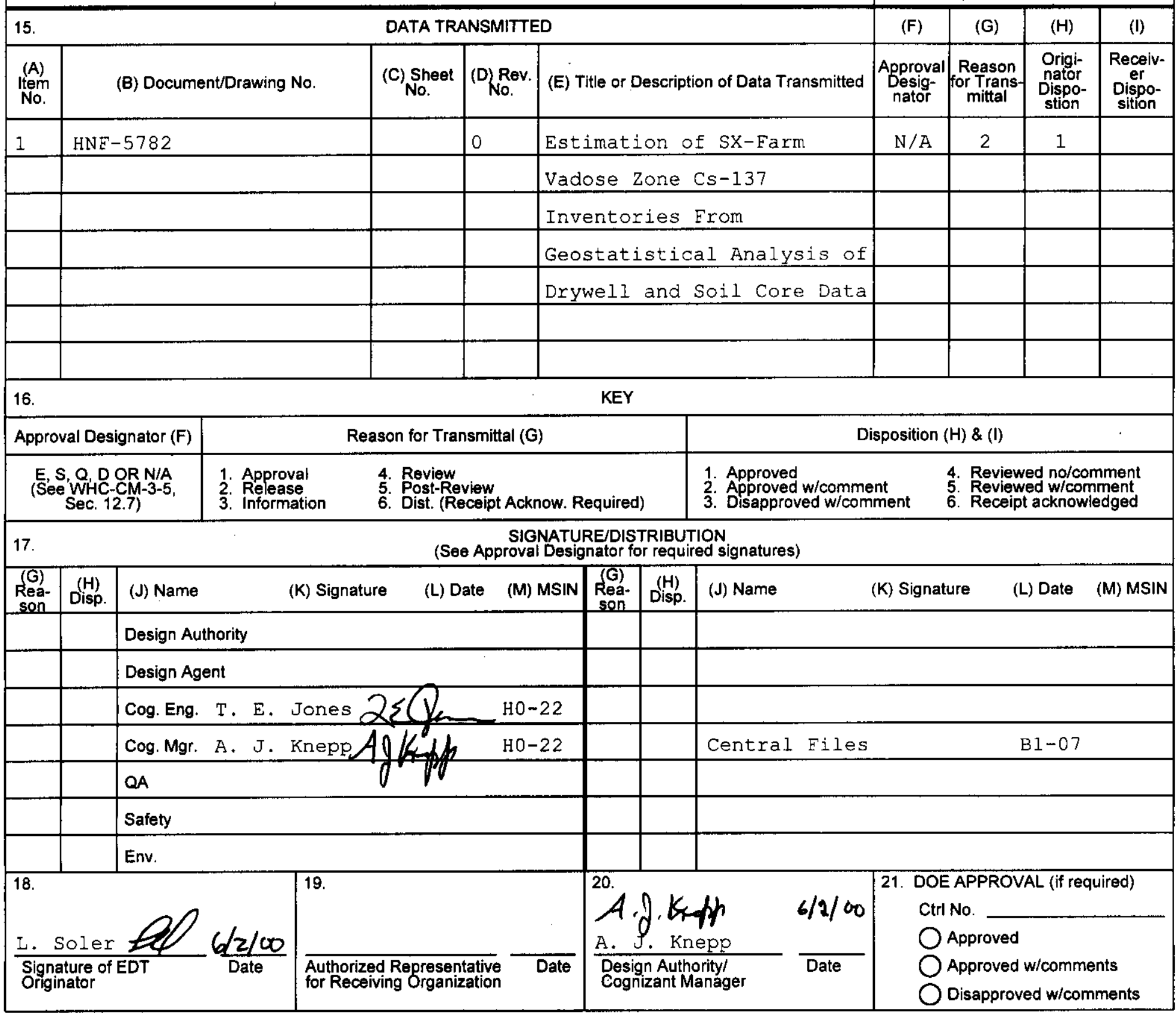




\section{DISTRIBUTION SHEET}

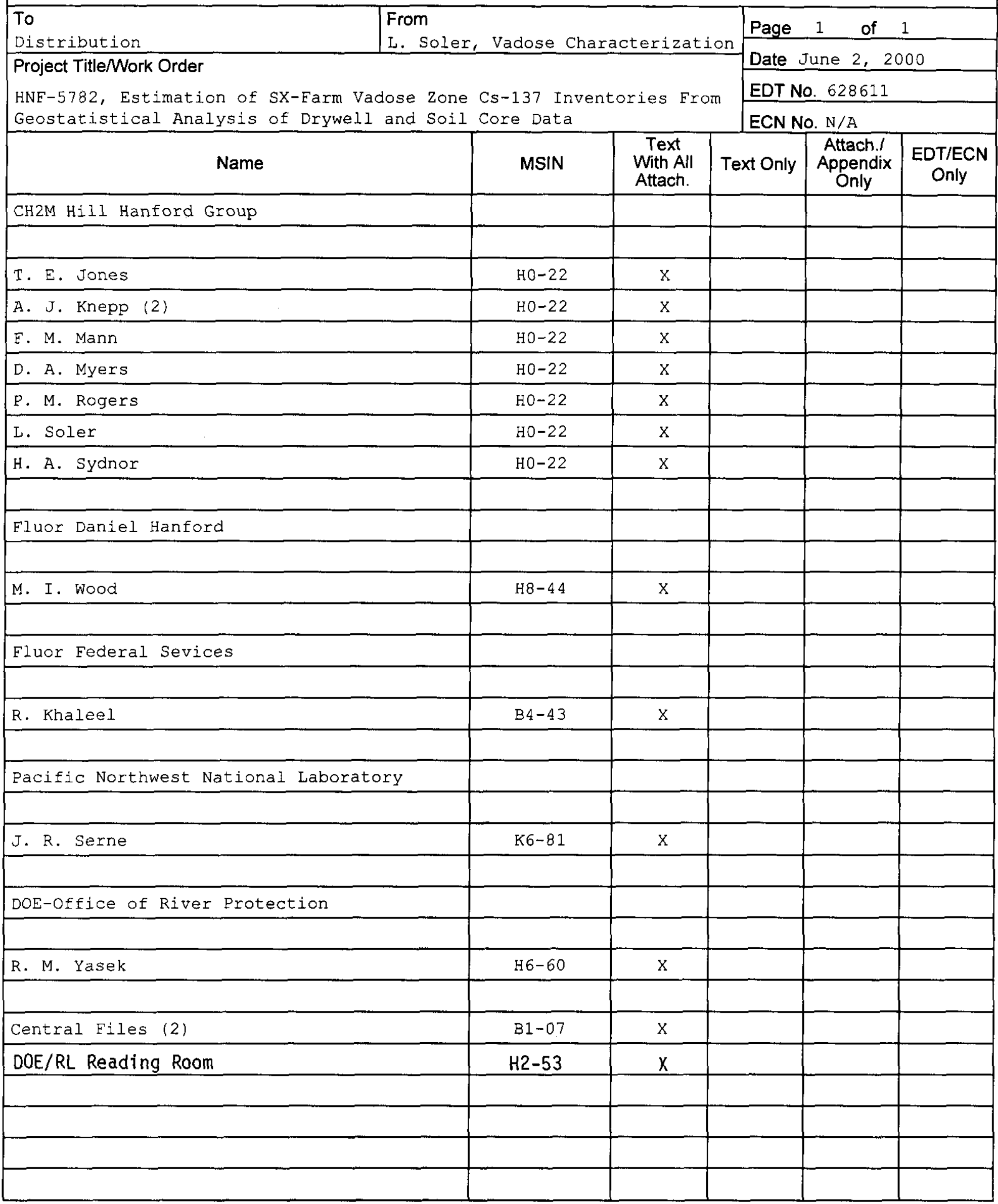




\section{Estimation of SX-Farm Vadose Zone Cs-137 Inventories from Geostatistical Analysis of Drywell and Soil Core Data}

Prepared for the U.S. Department of Energy

Assistant Secretary for Environmental Management

Project Hanford Management Contractor for the

U.S. Department of Energy under Contract DE-AC06-96RL13200

Fuor Hanford

P.o. Box 1000

Richland, Washington 


\section{Estimation of SX-Farm Vadose Zone Cs-137 Inventories from Geostatistical Analysis of Drywell and Soil Core Data}

T. E. Jones MACTEC
A. J. Knepp
CH2M HILL Hanford Group, Inc.

Date Published

June 2000

Prepared for the U.S. Department of Energy

Assistant Secretary for Environmental Management

Project Hanford Management Contractor for the

U.S. Department of Energy under Contract DE-AC06-96RL13200

\section{Fuor Hanford}

P.O. Box 1000

Richland, Washington
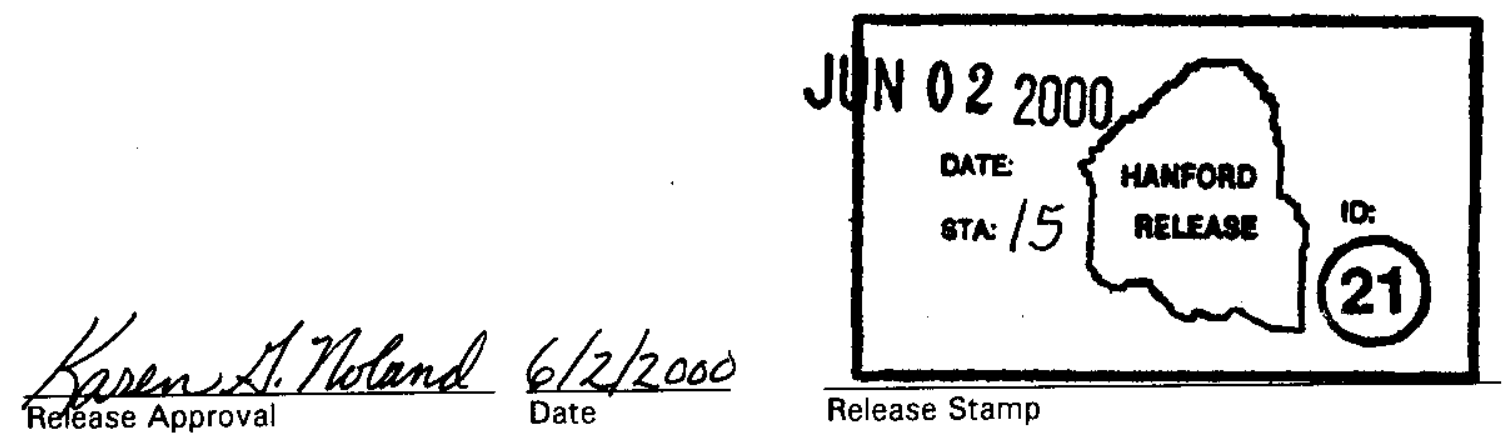
TRADEMARK DISCLAIMER

Reference herein to any specific commercial product, process,

or service by trade name, trademark, manufacturer, or

otherwise, does not necessarily constitute or imply its

endorsement, recommendation, or favoring by the United

States Government or any agency there of or its contractors or

subcontractors.

This report has been reproduced from the best available copy.

Printed in the United States of America

Total Pages: $125 \mathrm{kN}$ 
HNF-5782, Rev. 0

\title{
Estimation of SX-Farm Vadose Zone Cs-137 Inventories from Geostatistical Analysis of Drywell and Soil Core Data
}

\section{Keywords:}

Cs-137 inventory, SX Tank Farm, single-shell tanks, vadose zone characterization, TWRS, drywell and soil core samples

\begin{abstract}
:
This report provides an estimation of the Cs-137 inventories in the soil under the SX Tank Farm based on measurements obtained from drywell and soil cores. The Cs-137 inventories are estimated separately for distinct volumes of soil associated with each tank in the SX-Farm. The geostatistical method used is the second-order-stationary Gaussian process.
\end{abstract}




\title{
ESTIMATION OF SX-FARM VADOSE ZONE Cs-137 INVENTORIES FROM GEOSTATISTICAL ANALYSIS OF DRYWELL AND SOIL CORE DATA
}

\author{
Daniel Goodman \\ Environmental Statistics Group \\ Biology Department \\ Montana State University \\ Bozeman, MT 59717 \\ January 28,2000
}


HNF-5782 Rev. 0

\title{
ESTIMATION OF SX-FARM VADOSE ZONE Cs-137 INVENTORIES FROM GEOSTATISTICAL ANALYSIS OF DRYWELL AND SOIL CORE DATA*
}

\author{
Daniel Goodman \\ Environmental Statistics Group \\ Biology Department \\ Montana State University \\ Bozeman, MT 59717 \\ January 28,2000
}

\section{INTRODUCTION}

The SX tank farm comprises 15 tanks, some of which have been involved in significant leak events. For many years, the tank farm was monitored by gross gamma logging in 99 vertical drywells, most of which were located near the perimeters of the tanks. More recently, most of these vertical drywells were re-measured by spectral gamma logging. Early in the history of the monitoring, gross gamma logging was carried out in lateral drywells under ten of the tanks (though the lateral logging data available to us were only from eight of these tanks). Additionally, samples were analyzed from soil cores taken near two of the tanks, mostly from positions closer to the tank wall than the perimeter drywells. Figure 1 shows the locations of all wells with data.

* This is a report to MACTEC Inc., under agreement 3751.119.376 with Montana State University. Portions of the work reported here were supported by DOE cooperative agreement DE-FC07-94ID13317 to Montana State University, Daniel Goodman, Principal Investigator. 


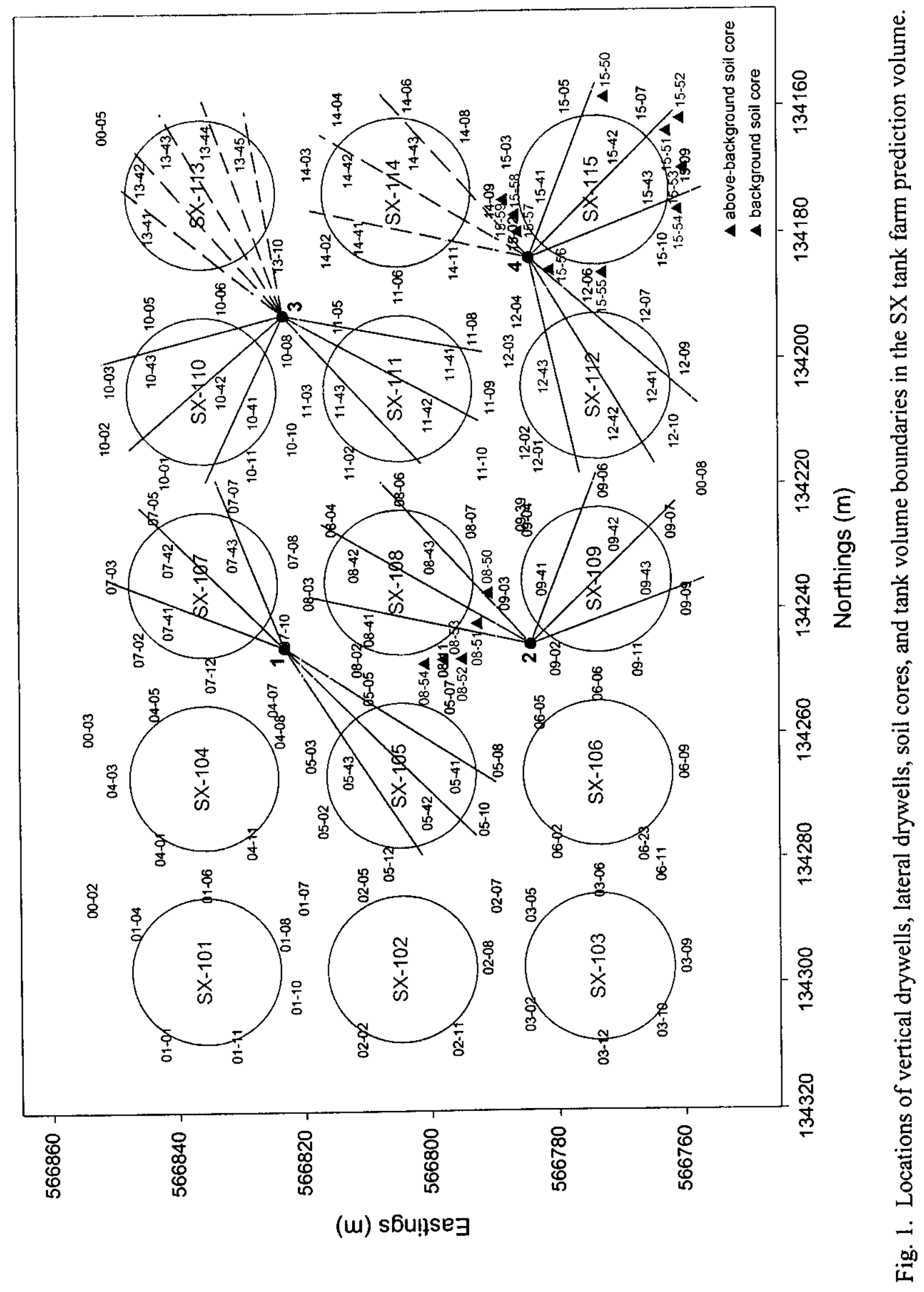


The objective of the present analysis is to estimate Cs-137 inventories in the soil volume under the tanks, from the measurement data from the drywells and soil cores. More specifically, the inventories are to be estimated separately for distinct volumes of soil associated with each tank. Further, the soil volume included in the inventory will be defined by exceedance of specified concentration thresholds.

The geostatistical method used is to be the second-order-stationary Gaussian process, as developed for this type of application in our previous report (Goodman, 1999). This method has the advantage of being comparatively simple and "purely statistical," so it intrudes a minimal number of assumptions into the analysis. In particular, it does not require specification of the physical process responsible for the spatial pattern. We have previously determined that this method exhibits very good stability for predicting point estimates of contamination, for the estimates "track the data." Further, when the "background" contamination level is specified for one of the parameters of the model, this precludes the creation of "phantom hot areas" which can be a disconcerting feature of other geostatistical techniques. For this reason, the inventory estimates will be realistic, but conservative, in the sense of defaulting to predictions of low contamination in locations that are too far from data.

The behavior of this geostatistical method for quantifying the uncertainty (e.g., confidence limits) on inventory estimates in this type of application has not be explored previously, so a secondary objective in the work reported here is to determine the properties, reasonableness, and sensitivity to assumptions of the mathematically computed uncertainty measures.

The data set spans a very large soil volume. The volume within which predictions could be made is 175 (N-S) x 120 (E-W) x 50 meters (depth), for a total of slightly over one million cubic meters. Data were available for about 19,610 distinct locations in this volume. For reasons that will be explained later, the data were aggregated into averages within each cubic meter that contained data, resulting in 3,962 cells that contained data which could be used for interpolation or prediction. This may seem like a lot of data, yet at the resolution of 1 cubic meter, we see that only $0.4 \%$ of the cells in the total volume actually had data in them, and the remaining $99.6 \%$ of the cells needed to have their value estimated by geostatistical interpolation.

Furthermore, the cells that contain data are not randomly or uniformly dispersed through the volume. The data are confined to horizontal or vertical strings of cells, with the consequence that a large fraction of the cells in the total volume can be more than 5 meters from the nearest data location. 
The combination of large prediction volume, large numbers of data locations, and large fraction of the prediction volume being distant from data locations, strains the predictive ability of geostatistical theory, and strains the computational machinery for implementing the geostatistics. Accordingly, there was a premium on using credible geostatistical methods that were, to the extent possible, simple, transparent, and robust, both with respect to the calculation of point estimates and with respect to the quantification of uncertainty. Our general approach for geostatistical analysis, but not including inventory estimation, is documented in the September 1999 report to MACTEC (Goodman, 1999).

The data available spanned a long history and involved measurements with a substantial variety of instruments for which specific cross-calibration information was not available to us. Some of these instruments had very different sensitivities, so that some were incapable of much resolution at low concentrations, while others would saturate at high concentrations. Of the values used to compute cell averages for the $\mathrm{m}^{3}$ cells that had data, 7,721 were obtained as spectral gamma measurements reported as $\mathrm{pCi} / \mathrm{g}$ Cs-137, 11,591 were obtained as spectral gamma total gamma reported as counts, 177 were obtained as measured Cs- 137 from soil samples reported in $\mathrm{pCi} / \mathrm{g}$, and 3,583 were either gross gamma reported in counts with various historical instruments or values that we set to "background" because a soil sample reported "not above trace" but was not quantified further. Thus, assembly of a comprehensive merged data set for the geostatistical analysis required a complicated sequence of decisions about data selection and data conversion.

In the present report package we:

1. document the assembly of the data set used for inventory estimation (Appendix 1),

2. deliver a copy of the data set (electronic file, on disk),

3. document the specific approach used for inventory estimation (Appendix 2), and

4. present the results of the inventory calculations (Appendix 3).

The method used, as documented in Appendix 2, involved minimal assumptions, but not all these assumptions were necessarily consistent with all the features of the data. The assumptions allowed the estimates to track the actual data very well, so the inventory estimates were robust and reasonable. If anything, the inventory estimates are perhaps underestimates, because of the absence of data 
directly under the tanks at depths deeper than the laterals (some of the vertical drywells show that substantial contamination can be found at much greater depth in some locations). The uncertainty quantification, using these methods and assumptions, was not as robust, because of sensitivity to some of the assumptions that were not entirely consistent with the data.

Refinement of the inventory estimate to better correct for the effect of the "data holes" under the laterals, and development of more stable quantification of uncertainty, could both be accomplished by a more complicated modeling approach, that takes into account more of the physical properties of the plume geometry, as described in Appendix 2. This would entail more assumptions than the model used in the present report, but those assumptions could be tailored to be more consistent with the actual process and the data.

The logical next step to pursue in the vadose zone geostatistical analysis is to extend the methodology specifically to cope with the inventory estimation in the other tank farms that do not have laterals. The absence of lateral data creates larger "data holes" under the tanks, which might create a significant bias in inventory estimates if it were not corrected. The SX-Farm data set presents an opportunity to develop a calibration of effects of presence or absence of lateral data, and this calibration could then be extrapolated to other tank farms where there are no lateral data.

\section{REFERENCES}

Goodman, D. 1999. Documentation of Geostatistical Approach for the Analysis of SX-Farm Vadose Zone Gamma Data. September 27, 1999, report to MACTEC Inc., under agreement 3751.119.376 with Montana State University. 


\section{Table of Contents}

I. Estimation Of SX-Farm Vadose Zone Cs-137 Inventories From Geostatistical Analysis Of Drywell And Soil Core Data

II. Appendix 1 - Assembly Of The Composite Data Sets

III. Appendix 2-Geostatistical Approach Used In Estimation Of SX-Farm Vadose Zone Cs-137 Inventories

IV. Appendix 3-Results Of The SX Inventory Calculation 


\section{List of Figures - Appendix 1}

1. Locations of vertical drywells, lateral drywells, soil cores, and tank volume boundaries $\ldots \ldots \ldots \ldots \ldots \ldots \ldots \ldots \ldots \ldots \ldots \ldots \ldots \ldots \ldots \ldots \ldots \ldots \ldots \ldots \ldots, 1-2$

2. Histogram of 1995 gamma-logging values less than $50 \mathrm{cps} \ldots \ldots \ldots \ldots \ldots$. . . .

3. Historical gamma logging values vs. spectral gamma total counts . . . . . . $1-5$

4. Drywell 09-39 gamma logging with spectral gamma and LVMS detectors .... 1-6

5. Historical gamma logging values vs. Cs-137 concentrations . . . . . . . 1-10

6. Histograms of all values in the composite $\mathrm{SX}$ data set, broken down by probe

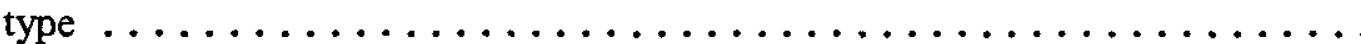

7. Histogram of all values less than $100 \mathrm{cps} \ldots \ldots \ldots \ldots \ldots \ldots \ldots \ldots, 1-12$

8. Histograms of vertical drywell gamma counts $\ldots \ldots \ldots \ldots \ldots \ldots \ldots \ldots$

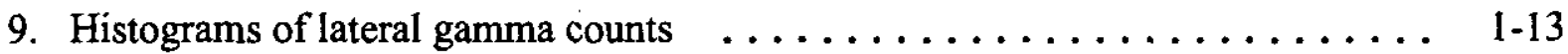

10. Distributions of maximum counts per well $\ldots \ldots \ldots \ldots \ldots \ldots \ldots \ldots, 1-14$

11. Histogram of soil core values and distribution of maximum values $\ldots \ldots \ldots, 1-15$

12. Histograms of vertical, lateral, and all gamma logging values and binning $\ldots \ldots \quad 1-16$

13. Spectral gamma total counts $\ldots \ldots \ldots \ldots \ldots \ldots \ldots \ldots \ldots \ldots \ldots \ldots . \ldots \ldots$

14. Spectral gamma Cs- $137 \mathrm{pCi}^{-1}$ vs. spectral gamma total counts $\ldots \ldots \ldots \ldots \quad 1-18$

15. Spectral gamma Cs- $137 \mathrm{pCi} \mathrm{g}^{-1}$ vs. spectral gamma total counts in type 4 units and SX-108 soil core Cs-137 $\mathrm{pCig}^{-1}$ vs. kriging-predicted type $4 \mathrm{cps} \ldots \ldots \ldots \quad$ I-19

16. SX-115 soil core $\mathrm{Cs}-137 \mathrm{pCi} \mathrm{g}^{-1}$ vs. kriging-predicted type $4 \mathrm{cps} \ldots \ldots \ldots \ldots \quad 1-20$

17. Histograms of all values in the composite Cs-137 data set, broken down by probe type

18. Histograms of vertical drywell values in the composite Cs-137 data set, broken

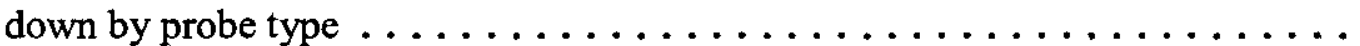

19. Histograms of lateral drywell values in the composite Cs-137 data set, broken

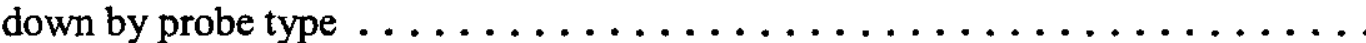

20. Histograms of the binned composite Cs- 137 data set, bin sample variance and

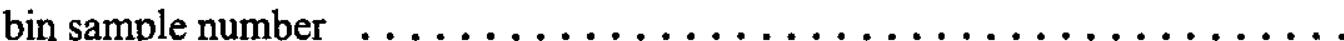

21. Drywell 09-39 Cs-137 $\mathrm{pCi} \mathrm{g}^{-1}$ from gamma logging and soil cores

List of Tables - Appendix 1

1. Conversion of gamma counts from four different detectors $\ldots \ldots \ldots \ldots \ldots$ 1-6

2. Patches applied to vertical drywells in the SX spectral gamma data set $\ldots \ldots \ldots$ 1-7

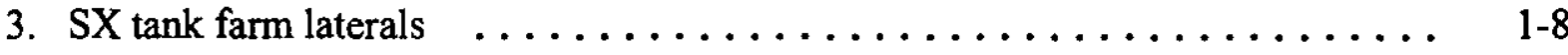

4. Soil core labels in Fig. 1 and Raymond and Shdo (1966) . . . . . . . . . . 1-9

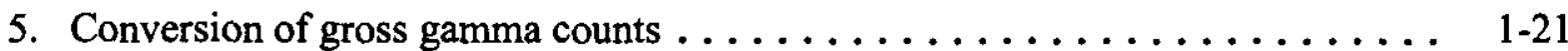


List of Figures - Appendix $2 \quad$ Page

1. Cell sample variance vs. cell mean . . . . . . . . . . . . . . . 2-4

2. Histogram of 1994 gamma-logging values less than $50 \mathrm{cps} \ldots \ldots \ldots$. . . . . 2-6

3. Histogram of type 2 gamma logging $\ldots \ldots \ldots \ldots \ldots \ldots \ldots$

4. Histogram of all gross gamma counts $\ldots \ldots \ldots \ldots \ldots \ldots \ldots \ldots \ldots$

5. Histogram of $\log \left(\mathrm{Cs}-137 \mathrm{pCi}^{-1}\right) \ldots \ldots \ldots \ldots \ldots \ldots \ldots \ldots \ldots \ldots$

6. Jack-knife residual surface $\ldots \ldots \ldots \ldots \ldots \ldots \ldots \ldots \ldots \ldots \ldots \ldots$

7. Spectral gamma Cs-137 $\mathrm{pCi} \mathrm{g}^{-1}$ vs. spectral gamma total counts $\ldots \ldots \ldots$. . . 21

8. Drywell 09-39 $\mathrm{Cs}-137 \mathrm{pCi} \mathrm{g}^{-1}$ from gamma logging . . . . . . . . . . 2-22

9. SX-115 soil core $\mathrm{Cs}-137 \mathrm{pCi}^{-1}$ vs. kriging-predicted $\ldots \ldots \ldots \ldots \ldots \ldots \ldots$

10. Six-tank subset of SX tank farm . . . . . . . . . . . . . . 2-27 


\section{List of Figures - Appendix 3}

1. SX Kriging point predictions exceeding $5 \times 10^{1} \mathrm{pCi} / \mathrm{g} \ldots \ldots \ldots \ldots \ldots$

2. SX Kriging point predictions exceeding $5 \times 10^{2} \mathrm{pCi} / \mathrm{g} \ldots \ldots \ldots \ldots \ldots$

3. SX Kriging point predictions exceeding $5 \times 10^{3} \mathrm{pCi} / \mathrm{g} \ldots \ldots \ldots \ldots \ldots \ldots$

4. SX Kriging point predictions exceeding $5 \times 10^{4} \mathrm{pCi} / \mathrm{g} \ldots \ldots \ldots \ldots \ldots$. . . . . . . . .

5. SX Kriging point predictions exceeding $5 \times 10^{5} \mathrm{pCi} / \mathrm{g} \ldots \ldots \ldots \ldots \ldots$. . . . . . .

6. SX Kriging point predictions exceeding $5 \times 10^{6} \mathrm{pCi} / \mathrm{g} \ldots \ldots \ldots \ldots \ldots \ldots$

7. SX Kriging point predictions exceeding $5 \times 10^{7} \mathrm{pCi} / \mathrm{g} \ldots \ldots \ldots \ldots \ldots \ldots$

\section{List of Tables - Appendix 3}

1. SX tank farm inventory of soil volumes . . . . . . . . . . . . . . 3-2

2. SX-101 inventory of soil volumes . . . . . . . . . . . . . . 3-4

3. $\mathrm{SX}-102$ inventory of soil volumes $\ldots \ldots \ldots \ldots \ldots \ldots \ldots \ldots \ldots \ldots$

4. SX-103 inventory of soil volumes $\ldots \ldots \ldots \ldots \ldots \ldots \ldots \ldots \ldots$ 3-10

5. $\mathrm{SX}-104$ inventory of soil volumes . . . . . . . . . . . . . . 3-13

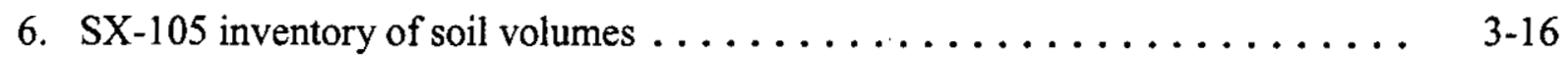

7. SX-106 inventory of soil volumes $\ldots \ldots \ldots \ldots \ldots \ldots \ldots \ldots \ldots$. . . . . . . . . .

8. SX-107 inventory of soil volumes . . . . . . . . . . . . . 3-22

9. SX-108 inventory of soil volumes . . . . . . . . . . . . . . 3-25

10. SX-109 inventory of soil volumes . . . . . . . . . . . . . 3-28

11. SX-110 inventory of soil volumes $\ldots \ldots \ldots \ldots \ldots \ldots \ldots \ldots \ldots \ldots$ 3-31

12. SX-111 inventory of soil volumes . . . . . . . . . . . . . 3-34

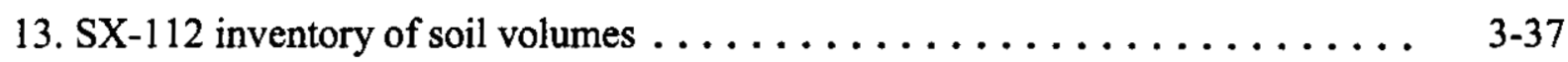

14. SX-113 inventory of soil volumes . . . . . . . . . . . . . . 3-40

15. SX-114 inventory of soil volumes . . . . . . . . . . . . 3-43

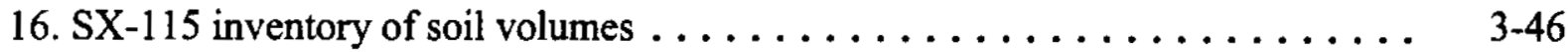




\section{APPENDIX 1. ASSEMBLY OF THE COMPOSITE DATA SETS}

Two data sets were compiled over the course of the SX tank farm inventory project. Both data sets are composites of spectral gamma and historical gamma logging values from 99 vertical drywells in combination with historical gamma logging at 24 lateral wells and a small number of core samples. The first data set, the "composite gamma counts data set", is composed of gamma activities in counts per second (cps) while the second data set, the "composite Cs-137 data set", contains Cs-137 concentrations in $\mathrm{pCi}^{-1}$ of soil. The composite gamma counts data set was initially used in exploratory parameter estimation and later used in a slightly modified form to derive a conversion from gross gamma logging in cps to Cs-137 concentrations. Importantly, the composite Cs-137 data set was the data set actually used to geostatistically calculate the SX tank farm inventory.

\section{The soil volume of interest}

All values in the two composite data sets were collected within a $175 \mathrm{~m}$ (north-south) by $120 \mathrm{~m}$ (east-west) by $50 \mathrm{~m}$ soil volume encompassing the fifteen SX storage tanks (Fig. 1). The southern boundary of the volume is located at northing $134145 \mathrm{~m}$ with the western boundary at easting $566745 \mathrm{~m}$. The top of the volume was set at the elevation of the top of the highest drywell in the SX-farm (well 01-07 at $203.61 \mathrm{~m}$ ). The soil volume was further subdivided into 15 equally sized subvolumes ( $31 \mathrm{~m}$ by $31 \mathrm{~m}$ by $50.5 \mathrm{~m}$ deep) approximately centered around each tank in the SX farm (Fig. 1). Cs-137 inventories assigned to each of the fifteen tanks were compiled within these subvolumes.

\section{Drywell and lateral locations}

In reconciling discrepancies between drywell $x-y$ coordinates provided by Mactec-Meier (Steve Anderson, pers. comm., 10/5/98) and the geologic strata data set obtained from Dave Meyers (pers. comm., 11/24/98), we used drywell coordinates contained in the Bechtel Hanford, Inc. GIS (Dave Meyers, pers. comm., 2/6/99). However, the Bechtel database did not contain a complete record of drywell elevations at the SX farm. Since the complete set of drywell elevations provided by Mactec-Meier closely resembled Bechtel elevations where comparisons could be made, the Mactec-Meier elevations were combined with the Bechtel $\mathrm{x}-\mathrm{y}$ coordinates. Two recently bored drywells, 09-39 and 12-01, were not included in the Bechtel database, thus requiring use of Mactec-Meier x-y coordinates. Lateral locations were assigned using caisson coordinates in tandem with well lengths, orientations, and depths summarized in Hanford drawing number H-2-31881, "241-SX tank farm leak detection system plan." Assignment of X$y-z$ coordinates to lateral data was complicated by the manner in which that data was reported, i.e. in distances from recording points to the surface via individual laterals and the caisson from which they originated. Using Hanford drawing number H-2-31882, "241 A \& 241 SX tank farms leak detection system: sections \& details", we calculated a total distance of $62.11 \mathrm{ft}$. from the surface to where laterals exit their respective caissons. Any gamma counts recorded at distances smaller than this value were treated as internal to a caisson and ignored. Vertical and lateral drywell locations are plotted in Fig. 1. Vertical drywell labels are identical to designations commonly used at Hanford minus the leading " 41 " typically designating the SX 


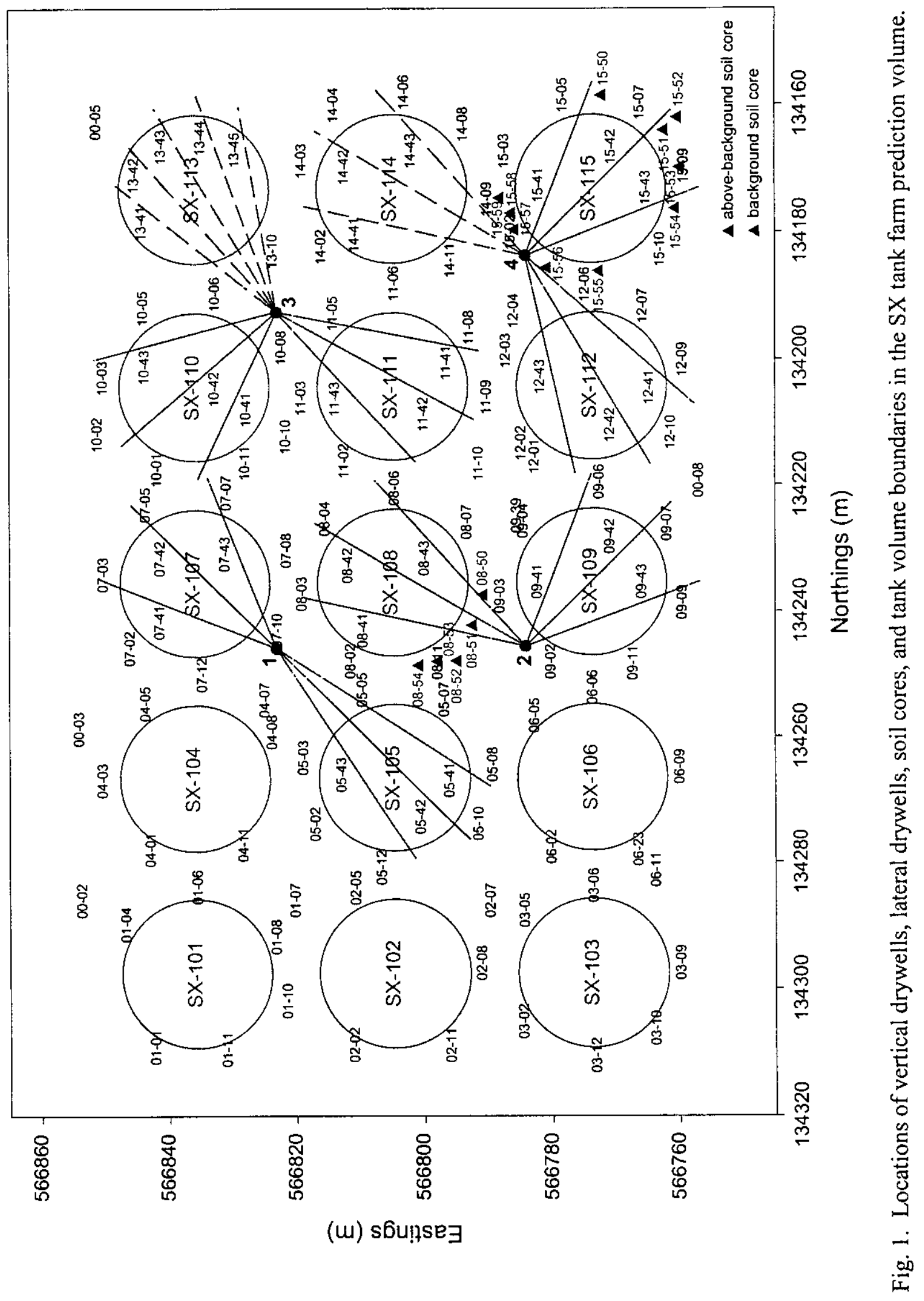


tank farm. At Hanford, lateral drywells are commonly identified by their tank number followed by a lateral number, 1-3 (WHC, 1992a; WHC, 1992b). In our naming scheme, laterals are identified by their tank number followed by an integer, 41 through 43 , corresponding to laterals 1-3. One exception to this rule is SX-113 with five laterals labeled 13-41 through 13-45. Where gamma logging data was available, laterals are plotted with solid lines in Fig. 1. Data from eight laterals associated with SX-113 and SX-114 was unavailable and thus these laterals are drawn with dashed lines.

\section{The composite gamma counts data set}

\section{Gamma logging probes and their cross-calibration}

Gamma logging values included in the composite gamma counts data set were acquired with six different instruments. Typically, gamma logging at vertical drywells in the SX tank farm was conducted with the type 4 (NaI-scintillation) probe. At higher levels of radiation, the type 14 (shielded NaI-scintillation), type 1 (green Geiger-Muller), or type 2 (red Geiger-Muller) probes were used (Isaccson, 1982). Laterals were logged with probe types 1 and 2 (WHC, 1992a; WHC 1992b). Spectral gamma-ray logging system (SGLS) counts were recorded with the high-purity germanium detector (DOE, 1996). A new instrument, the Leak Verification and Monitoring System (LVMS) NaI detector was used at one vertical drywell, 09-39, in January of 1997 (DOE, 1997). All historical gamma logging values (probe types 1, 2, 4, and 14) from vertical drywells were compiled in a Microsoft Access database received from Mactec-Meier (James Kelly, pers. comm., 7/17/98). Spectral gamma counts from all vertical drywells and LVMS data from well 09-39 were received from Mactec-ERS via Mactec-Meier (James Kelly, pers. comm., 9/19/98). Lateral gamma counts (probe types 1 and 2) were compiled by Russ Randall (pers. comm., 5/14/99).

The composite gamma data set was assembled largely from counts logged in 1995 since that was the year spectral gamma logging was conducted at the SX farm (DOE, 1996). All other values in the data set recorded prior to 1995 were half-life corrected to nominal 1995 values using the half-life of Cs-137, 30.17 years. Thus geostatistical analysis of the composite data set can be interpreted as the nominal "best estimate" of the spatial distribution of radioactive contamination at the SX tank farm, circa 1995. Importantly, any improvement in our nominal 1995 "best estimate" resulting from inclusion of data collected prior to 1995 rests on the assumption that radioactive decay is the most important or only process responsible for changes in Cs-137 activity at specific locations over the time interval of half-life correction. This is likely a reasonable assumption given that all values in the composite data set, with the exception of soil core data collected in 1966 (Raymond and Shdo,1966), were collected after the documented leak events at the SX-farm (DOE, 1996) and given the low mobility of Cs-137 (Jones et al., 1998).

Zero values recorded by the six gamma detectors were problematic in that geostatistical calculations were conducted after log-transformation of the data. For clarity, whenever we mention log-transformation or a log value within this report, we are referring to a natural 
logarithm. To allow reasonable log-transformation, we translated zeroes to a nominal "background" value of $25 \mathrm{cps}$ in type 4 units. This "background" value was based on a previous analysis of a six-tank neighborhood surrounding SX-108 and SX-109. A histogram of 1994 gamma counts from all drywells logged with the type 4 probe within this neighborhood indicates that $25 \mathrm{cps}$ is the most likely level of nominal "background" gamma radiation (Fig. 2). Note that translation of zero values to "background" level counts had no effect on the final SX inventories, given that inventories were calculated for Cs-137 activities well above "background."

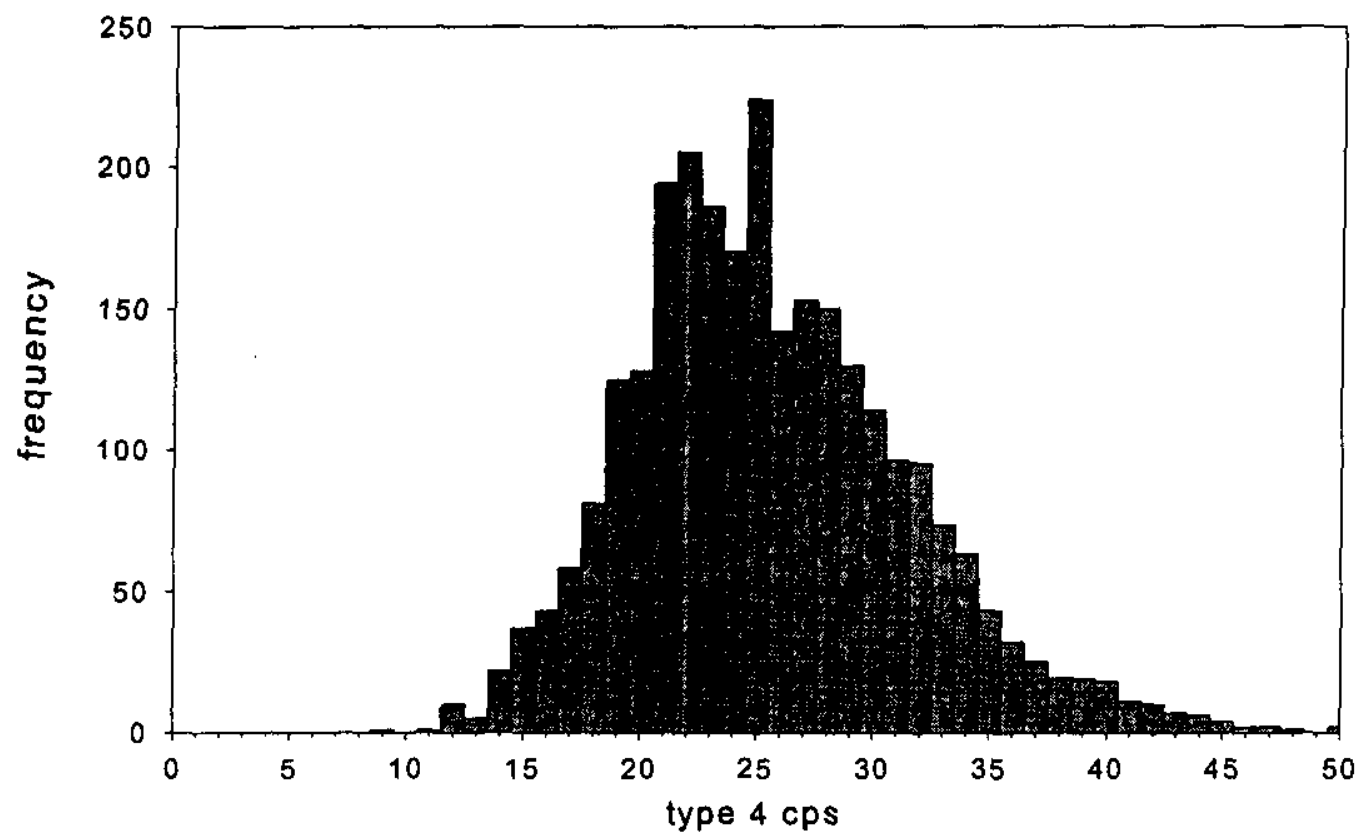

Fig. 2. Histogram of 1995 gamma-logging values less than $50 \mathrm{cps}$ recorded with the type 4 detector in the SX-108, SX-109 six-tank neighborhood.

In assembling the composite gamma data set, all values reported with various instruments were converted to probe type 4 units. Type 1 and type 2 counts were converted using the 1980 "Dry well survey probe calibration" received from Russ Randall (pers. comm., 7/31/67). Per Russ Randall's recommendation (pers. comm., 9/16/98), all type 14 gross gamma values were multiplied by seven. Spectral gamma total counts were converted to gross gamma counts in type 4 units using a calibration relationship fit to a scatter plot of historical gamma logging counts versus spectral gamma total counts (Fig. 3). In creating this plot, spectral gamma data from all vertical drywells in the SX farm was paired with historical gamma values from locations (well/depth) where both types of data were collected. Our search of the historical gamma logging record was restricted to values collected after January 1, 1990. Where location matches could be made, the most recent gross gamma counts were paired with the corresponding spectral gamma value. A maximum of ten historical gamma values were paired with each spectral gamma value with the intention that up to ten repeated measures would be matched with individual spectral gamma counts. Type 1, 2, and 14 counts were converted to type 4 units and 


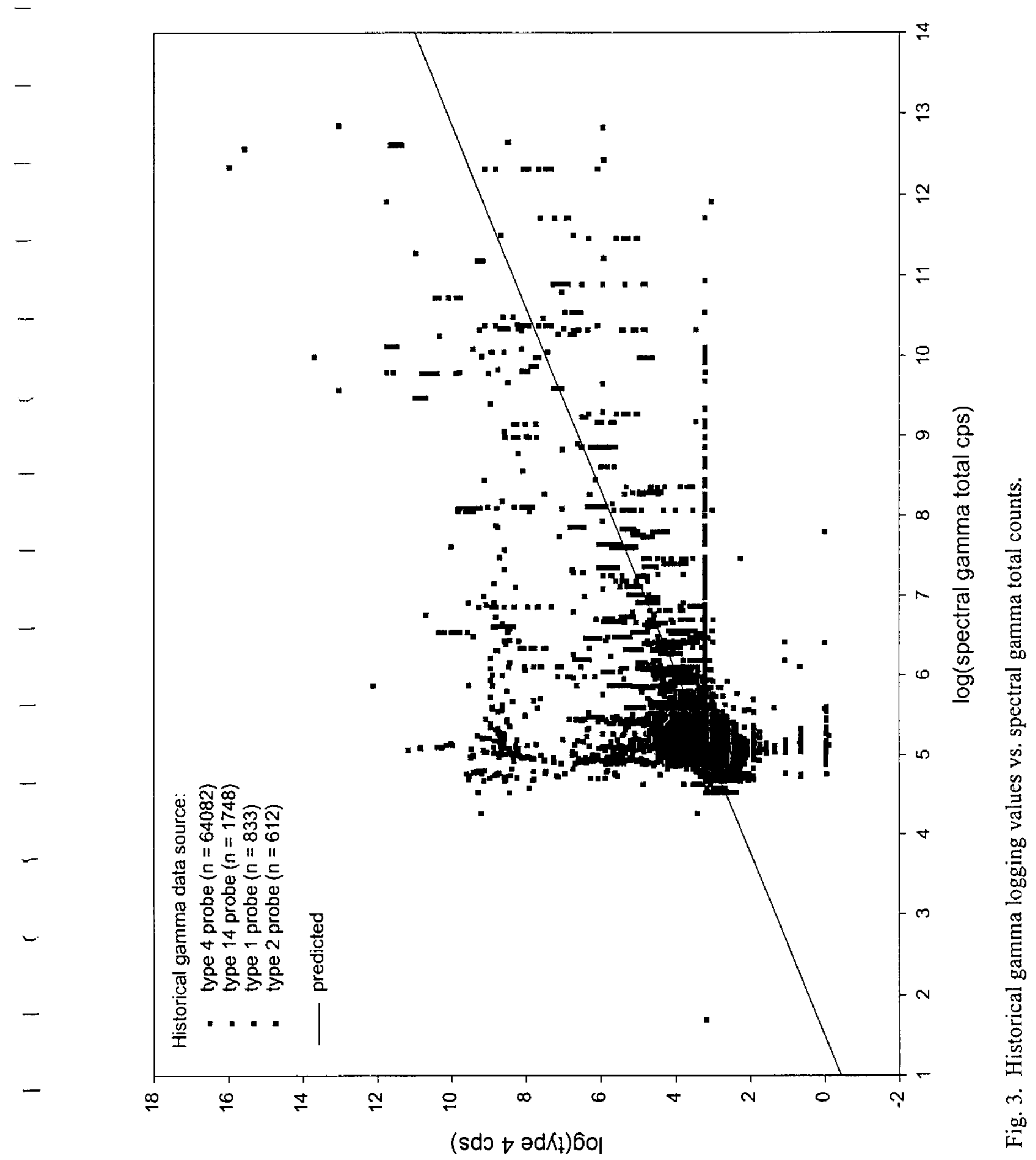


all historical values were half-life corrected to 1995 values. Because the type 2 detector recorded a relatively large number of zero values, type 2 counts were averaged before being paired with spectral gamma values. If the type 2 probe recorded only zeroes, the average was set at the nominal "background" of $25 \mathrm{cps}$.

Formulas used in cross-calibration of gamma detectors are summarized in Table 1. Note that the LVMS detector has not been cross-calibrated with other instruments used at the SX tank farm. However, spectral gamma counts (in type 4 units) at this well correspond closely to LVMS data (Fig. 4) and so the LVMS data were used without conversion.

Table 1. Conversion of gamma counts from four different detectors to probe type 4 units.

\begin{tabular}{|l|l|}
\hline Gamma logging source & Conversion to probe type 4 cps \\
\hline spectral gamma & $\exp \{-1.3164+0.8784 * \log ($ spectral gamma cps $)\}$ \\
\hline probe type 1 & $\exp \{2.7518+0.9720 * \log ($ type $1 \mathrm{cps})\}$ \\
\hline probe type 2 & $\exp \{8.2745+0.9720 * \log ($ type $2 \mathrm{cps})\}$ \\
\hline probe type 14 & $7 *($ type $14 \mathrm{cps})$ \\
\hline
\end{tabular}

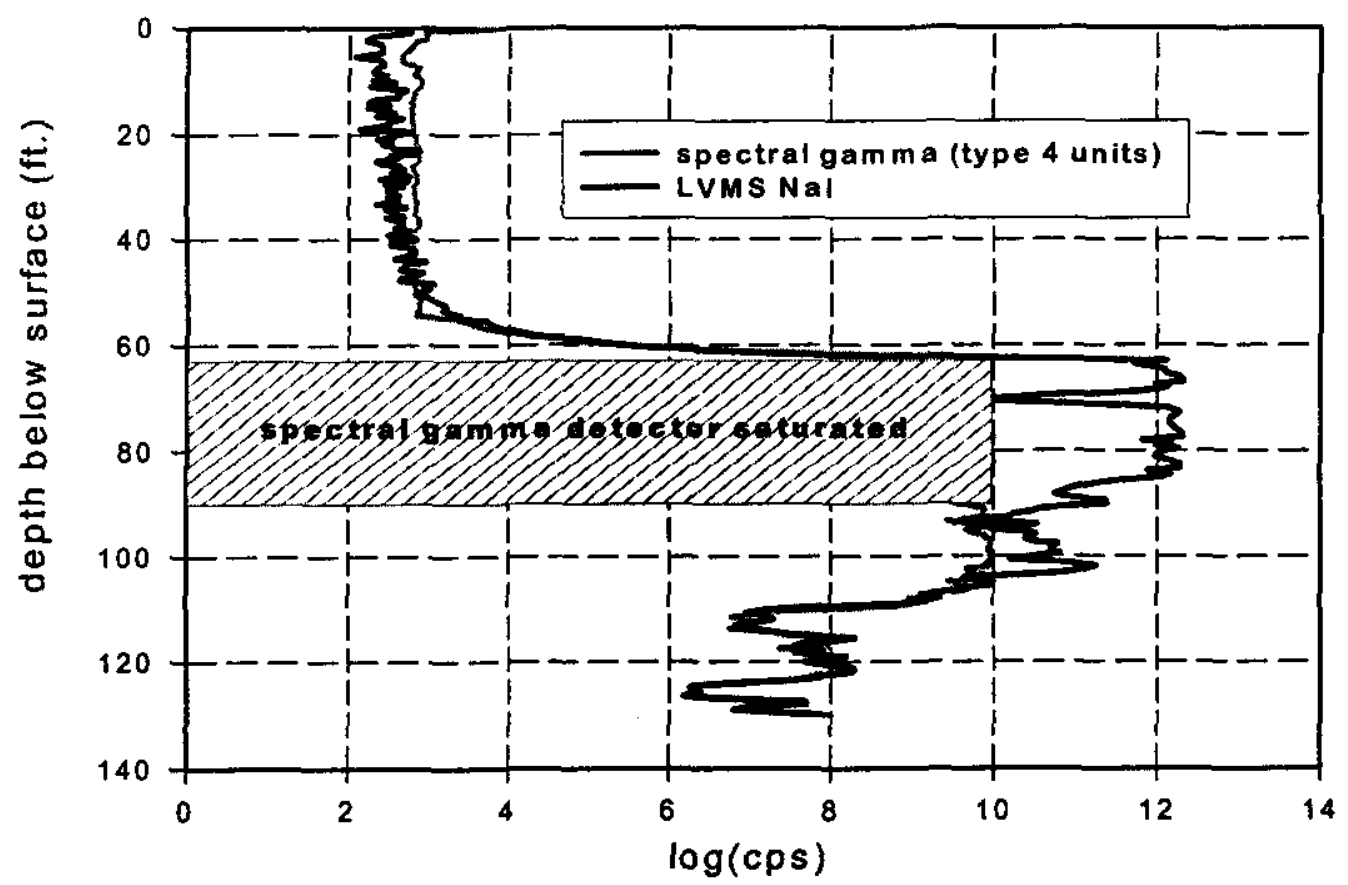

Fig. 4. Drywell 09-39 gamma logging with spectral gamma and LVMS detectors. 


\section{Vertical and lateral gamma logging values}

\section{Vertical drywells}

The vast majority of values $(82 \%)$ in the composite gamma data set are spectral gamma total counts logged by Mactec-ERS at vertical drywells from August to November of 1995 (DOE, 1996). Drywell 12-01, a companion to well 12-02, was drilled and sampled with the spectral gamma detector in July, 1996 (Brodeur, 1996). Drywell 09-39, a companion to well 0904, was drilled in December, 1996 and subsequently logged with both the spectral gamma and LVMS detectors (DOE, 1997). All zero values (six in total) were transformed to the nominal "background" of 25 type $4 \mathrm{cps}$. Where the spectral gamma data was incomplete due to detector saturation, high dead times, or other reasons, historical gamma logging data was patched into gaps. Details of these patches are summarized in Table 2. At each data gap, the most recent gross gamma logging values were substituted. Where patches composed of type 2 counts contained zero values, the most recent data from a type 1 or type 4 detector was inserted. All patch values were normalized to type 4 units and then half-life corrected to 1995 values.

Table 2. Patches applied to vertical drywells in the SX spectral gamma data set.

\begin{tabular}{|l|l|l|l|l|}
\hline Drywell ID \# & $\begin{array}{l}\text { Reason for data } \\
\text { gap }\end{array}$ & Patch depth(s) & $\begin{array}{l}\text { Patch } \\
\text { date }\end{array}$ & $\begin{array}{l}\text { Probe } \\
\text { type }\end{array}$ \\
\hline $41-00-03$ & well not logged & entire well & $11 / 3 / 93$ & 4 \\
\hline $41-00-05$ & well not logged & entire well & $6 / 11 / 93$ & 4 \\
\hline $41-00-08$ & none provided & $3-61,86-123 \mathrm{ft}$. & $10 / 19 / 93$ & 4 \\
\hline $41-05-08$ & none provided & $6-9 \mathrm{ft}$. & $10 / 25 / 93$ & 4 \\
\hline $41-07-05$ & detector saturated & $55-58 \mathrm{ft}$. & $6 / 10 / 94$ & 2 \\
\hline $41-07-07$ & detector saturated & $56-65 \mathrm{ft}$. & $6 / 10 / 94$ & 2 \\
\hline $41-07-10$ & well not logged & entire well & $6 / 10 / 94$ & 4 \\
\hline $41-08-07$ & detector saturated & $63-72 \mathrm{ft}$. & $6 / 10 / 94$ & 2 \\
\hline $41-08-11$ & detector saturated & $49-61 \mathrm{ft}$. & $6 / 10 / 94$ & 2 \\
& & $62 \mathrm{ft}$. & $12 / 18 / 91$ & 4 \\
\hline $41-09-07$ & high dead time & $64-72 \mathrm{ft}$. & $6 / 10 / 94$ & 1 \\
\hline $41-09-09$ & high dead time & $72-73 \mathrm{ft}$. & $6 / 9 / 94$ & 14 \\
\hline $41-11-10$ & high dead time & $66-70 \mathrm{ft}$. & $6 / 10 / 94$ & 1 \\
\hline $41-12-02$ & high dead time & $68-69,114,116-117,119 \mathrm{ft}$. & $5 / 27 / 94$ & 4 \\
& & $70-106,115,118,120-122 \mathrm{ft}$. & $6 / 10 / 94$ & 2 \\
\hline $41-12-03$ & high dead time & $65 \mathrm{ft}$. & $6 / 10 / 94$ & 14 \\
\hline
\end{tabular}


$\underline{\text { Lateral drywells }}$

SX lateral counts were recorded both electronically and on strip charts. At the 12 laterals where electronically recorded data was available, the most recent set of gamma counts was included in the data set. Otherwise, we used strip chart values from 1975 and 1976 digitized by Russ Randall. All pre-1978 type 2 counts were multiplied by 0.36 to compensate for instrument design changes in sensitivity (Randall, 1999). This re-scaling was limited to lateral data as the vertical drywell data did not contain any pre-1978 type 2 counts. All zero values were replaced with the nominal "background" of 25 type $4 \mathrm{cps}$ and all pre-1995 values were half-life corrected. The sampling date, detector type, recording method, and number of data points from each lateral are summarized in Table 3.

Table 3. SX tank farm laterals.

\begin{tabular}{|l|l|l|l|l|l|l|}
\hline Tank & $\begin{array}{l}\text { Lateral } \\
\text { ID }\end{array}$ & $\begin{array}{l}\text { Sample } \\
\text { date }\end{array}$ & $\begin{array}{l}\text { Detector } \\
\text { type }\end{array}$ & $\begin{array}{l}\text { Recording } \\
\text { method }^{1}\end{array}$ & $\begin{array}{l}\text { \# data } \\
\text { points }\end{array}$ & $\begin{array}{l}\text { \# points set to } \\
\text { "background" }\end{array}$ \\
\hline SX-105 & $05-41$ & $9 / 19 / 89$ & l & e & 122 & 14 \\
\hline & $05-42$ & $9 / 19 / 89$ & 1 & e & 131 & 13 \\
\hline & $05-43$ & $9 / 19 / 89$ & 1 & e & 122 & 19 \\
\hline SX-107 & $07-41$ & $6 / 11 / 86$ & 2 & e & 89 & 63 \\
\hline & $07-42$ & $6 / 11 / 86$ & 2 & e & 98 & 60 \\
\hline & $07-43$ & $6 / 11 / 86$ & 2 & e & 89 & 48 \\
\hline SX-108 & $08-41$ & 1976 & 2 & s & 180 & 5 \\
\hline & $08-42$ & 1976 & 2 & s & 228 & 0 \\
\hline & $08-43$ & 1976 & 2 & s & 149 & 1 \\
\hline SX-109 & $09-41$ & $2 / 2 / 76$ & 2 & s & 135 & 7 \\
\hline & $09-42$ & $2 / 2 / 76$ & 2 & s & 114 & 3 \\
\hline & $09-43$ & $2 / 2 / 76$ & 2 & s & 79 & 2 \\
\hline SX-110 & $10-41$ & $8 / 7 / 89$ & 1 & e & 88 & 13 \\
\hline & $10-42$ & $8 / 7 / 89$ & 1 & e & 100 & 10 \\
\hline & $10-43$ & $8 / 7 / 89$ & 1 & e & 89 & 16 \\
\hline SX-111 & $10-41$ & $8 / 7 / 89$ & 1 & e & 98 & 11 \\
\hline & $10-42$ & $8 / 7 / 89$ & 1 & e & 108 & 8 \\
\hline & $10-43$ & $8 / 7 / 89$ & 1 & e & 98 & 22 \\
\hline SX-112 & $10-41$ & $1 / 7 / 76$ & 1 & s & 32 & 2 \\
\hline & $10-42$ & $2 / 5 / 76$ & 2 & s & 35 & 9 \\
\hline & $10-43$ & $2 / 5 / 76$ & 1 & s & 118 & 8 \\
\hline SX-115 & $10-41$ & $2 / 10 / 75$ & 2 & s & 83 & 1 \\
\hline & $10-42$ & $2 / 3 / 75$ & 1 & s & 85 & 0 \\
\hline & $10-43$ & $2 / 25 / 75$ & 2 & s & 29 & 2 \\
\hline e=electronically recorded, s $=$ strip chart digitized by Russ Randall (Three Rivers Scientific) \\
\hline
\end{tabular}




\section{Soil Cores}

In addition to the gamma logging data described above, measurements from fifteen core samples associated with SX-108 and SX-115 were incorporated into the composite gamma data set. This data is not available in digital form and thus we were forced to rely exclusively on the 1966 Battelle-Northwest report (Raymond and Shdo, 1966) summarizing soil sampling at SX108 and SX-115. However, the authors only published results from cores recording "abovetrace" Cs- 137 concentrations where they defined the "trace" level as $1.0 \mathrm{pCi} / \mathrm{g}$. This included all five soil cores drilled in the vicinity of SX-108 and four cores at SX-115. Cs-137 concentrations from these nine cores were digitized from graphs plotted in Appendix A of Raymond and Shdo (1966). At the six other cores, we assigned "background" level counts ( 25 type $4 \mathrm{cps)}$ at one foot intervals to a depth of 70 feet, the approximate depth to which data was reported from the nine "above-trace" cores. Soil core locations were assigned by triangulation from known coordinates of neighboring vertical drywells using distances estimated from Figures 2 and 3 in Raymond and Shdo (1966). Estimated locations are plotted in Fig. 1. The naming convention used for soil cores in Fig. 1 is entirely our own. Corresponding labels from Figures 2 and 3 in Raymond and Shdo (1966) are included in Table 4.

Table 4. Soil core labels in Fig. 1 and corresponding labels in Raymond and Shdo (1966).

\begin{tabular}{|l|l|l|l|l|l|}
\hline Fig. 1 label & 1966 label & Fig. 1 label & 1966 label & Fig. 1 label & 1966 label \\
\hline $08-50$ & $32 \mathrm{~A}$ & $15-50$ & $47 \mathrm{~A}$ & $15-55$ & $41 \mathrm{~B}$ \\
\hline $08-51$ & $32 \mathrm{~B}$ & $15-51$ & $48 \mathrm{~B}$ & $15-56$ & $41 \mathrm{~A}$ \\
\hline $08-52$ & 29C & $15-52$ & $48 \mathrm{C}$ & $15-57$ & $45 \mathrm{~A}$ \\
\hline $08-53$ & 29A & $15-53$ & $48 \mathrm{~A}$ & $15-58$ & $45 \mathrm{~B}$ \\
\hline $08-54$ & 29B & $15-54$ & $49 \mathrm{~A}$ & $15-59$ & $17 \mathrm{~A}$ \\
\hline
\end{tabular}

Soil core Cs-137 concentrations were converted to gross gamma counts in type 4 units using a calibration relationship derived from a scatter plot of historical gamma logging values versus Cs-137 concentrations measured with the SGLS (Fig. 5). Calculation of Cs-137 concentrations from analysis of SGLS spectra is described in the SX Tank Farm Report (DOE, 1996). In creating this plot, we used a methodology identical to that described for the conversion of spectral gamma total counts to type 4 units (Fig. 3). Cs-137 concentrations from vertical drywells in the SX farm were paired with historical gamma values from locations (well/depth) where both types of data were collected. Once again, our search of the historical gamma logging record was restricted to values collected after January 1,1990. Where location matches could be made, the most recent gross gamma counts (up to a maximum of ten values) were paired with the corresponding Cs-137 concentration. Type 1, 2, and 14 counts were converted to type 4 units as summarized in Table 1 and all historical values were half-life corrected to 1995 values. A linear fit of the resulting scatter plot in log-space (Fig. 5) yields the conversion:

$$
\text { type } 4 \mathrm{cps}=\exp \{3.5709+0.4080 * \log (\mathrm{Cs}-137 \mathrm{pCi} / \mathrm{g})\}
$$

After conversion to type 4 counts, all soil core data was half-life corrected to 1995 values. 


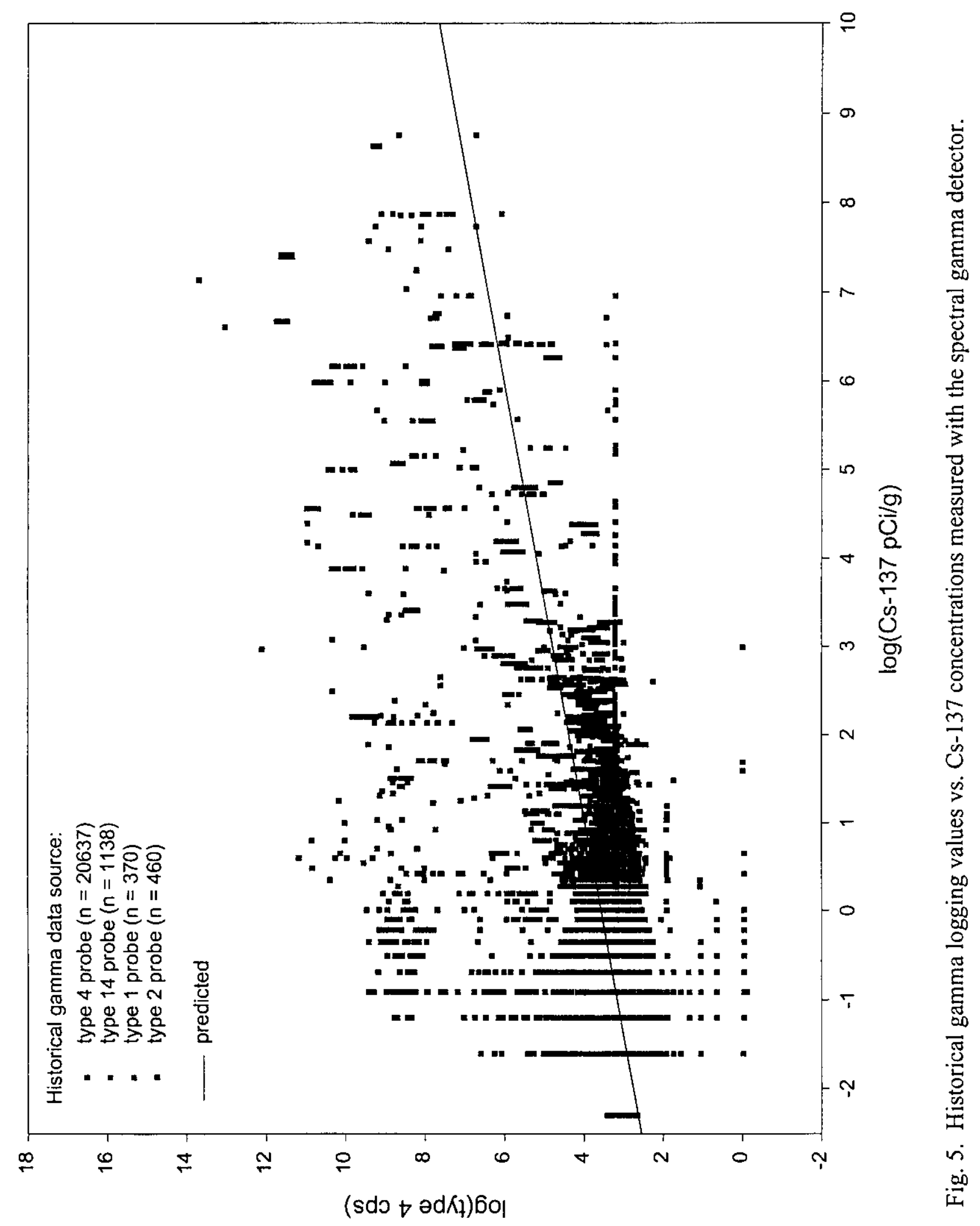




\section{Histograms}

Histograms of all values in the composite gamma data set and broken down among five different detectors used at the SX tank farm are plotted in Fig. 6. The distribution of all gamma logging values following conversion to consistent units is highly left-skewed. Most of these values $(18,635$ out of 22,616 total) were recorded with the spectral gamma detector over low to intermediate levels of contamination (gross gamma counts between 1.0 and 12.0 in log-space). The LVMS, type 1, and type 4 probes logged counts over a similar range. At intermediate and high levels of contamination, the type 2 probe recorded the majority of values, logging all counts in the composite data set greater than 13.0. Note that the conversion-to-"background" of 192 zero values recorded with the type 2 probe within lateral drywells caused the spike in type 2 counts between 3.0 and 4.0. Conversion of lateral zeroes did not have as pronounced an effect in the histogram of type 1 counts where 145 zeroes were set to "background."
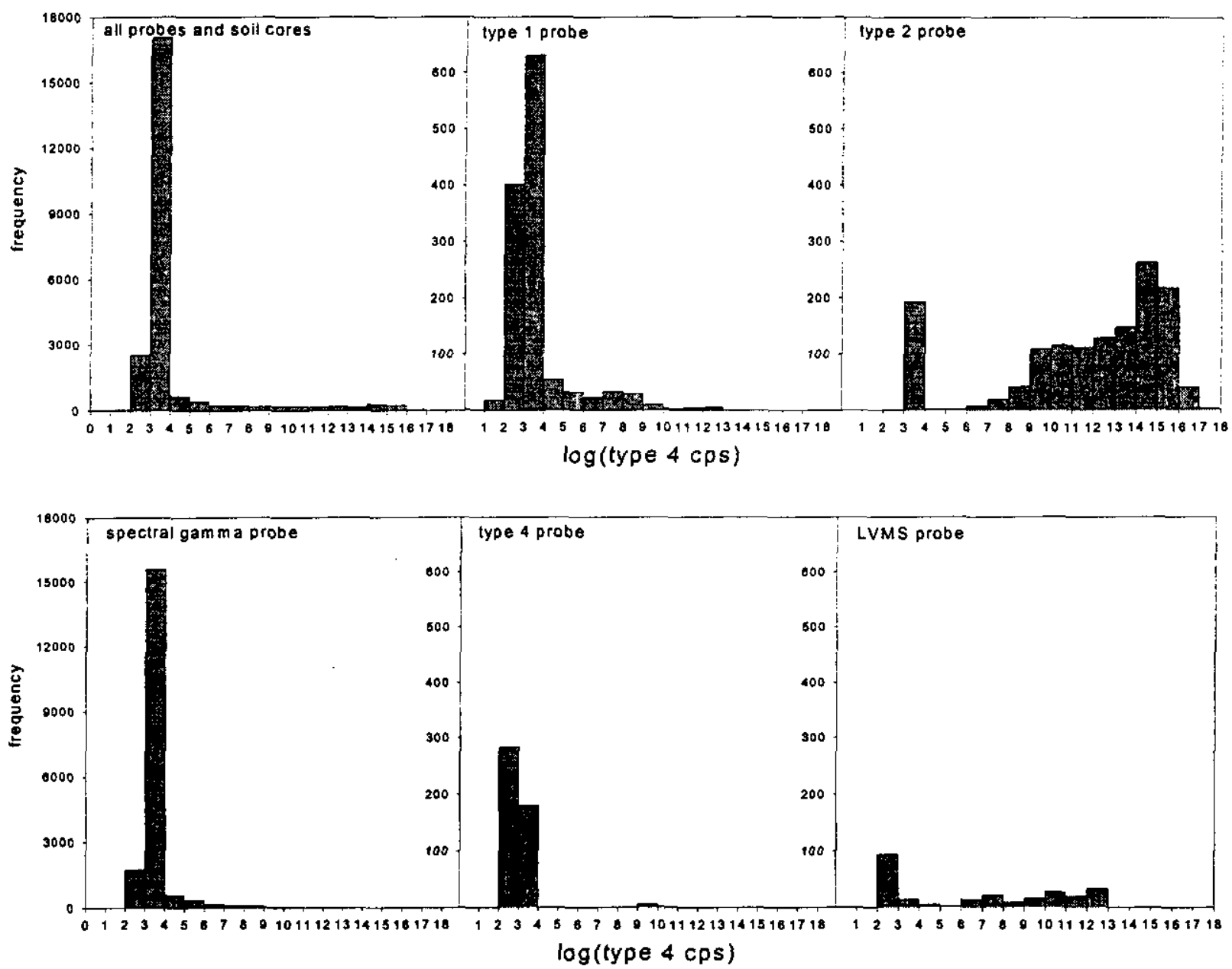

Fig. 6. Histograms of all values in the composite SX data set after conversion to consistent units and broken down by probe type. 
The histogram of all gamma logging values less than $100 \mathrm{cps}$ (Fig. 7) illustrates the distribution of "background"-level counts. This histogram supports the definition of a nominal "above-background" threshold of 4.0 in log-space (approximately 55 cps untransformed). Within the full composite data set, 19,611 values (out of 22,616) fall below this threshold. Thus, approximately $87 \%$ of the data is nominally "clean."

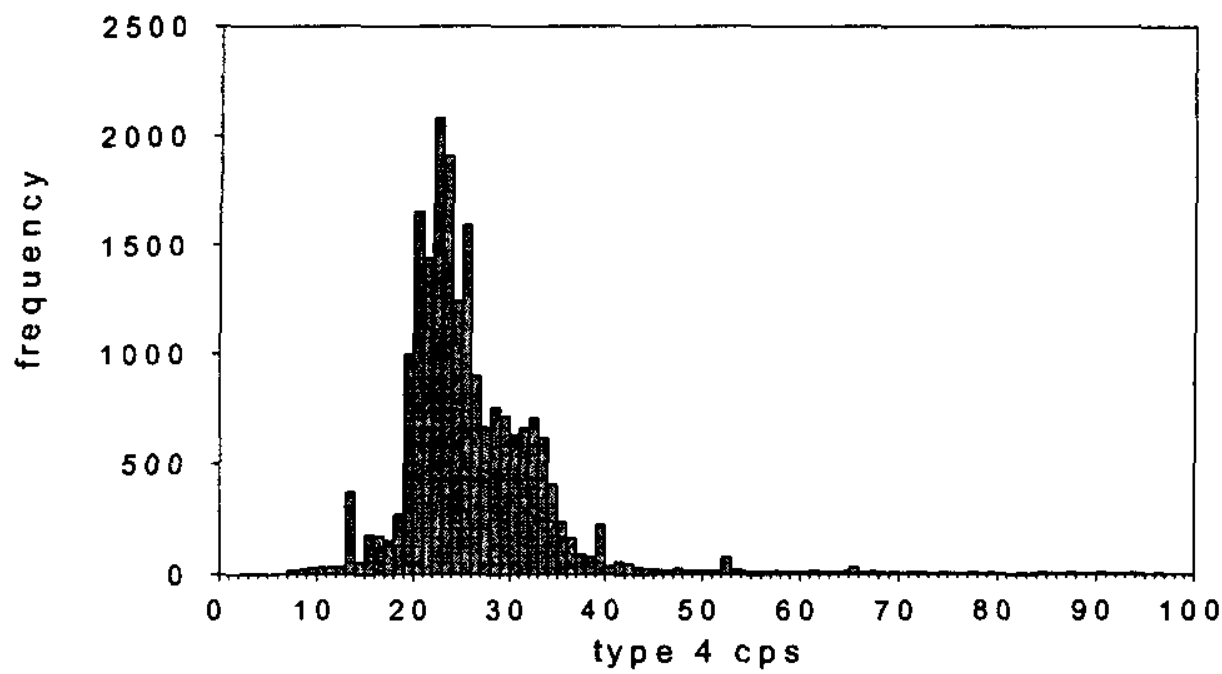

Fig. 7. Histogram of all values less than $100 \mathrm{cps}$ after conversion to consistent units.

Histograms of gamma counts within vertical and lateral drywells are plotted in Fig. 8 and Fig. 9, respectively. Compared to the complete composite gamma data set (Fig. 6), the distribution of all vertical drywell counts (Fig. 8) is similarly skewed but is not as flat at "abovebackground" levels of contamination. Lateral gamma logging values are bimodally distributed with $50 \%$ of all lateral counts greater than 4.0 in log-space (Fig. 9), revealing the importance of lateral data in defining "above-background" regions within the prediction volume.

The type 4, LVMS, and spectral gamma detectors were only used in vertical drywells and thus the histograms of vertical drywell counts from these probes (Fig. 8) are identical to those plotted in Fig. 6. Only three values from the type 14 probe were included in the data set and thus a type 14 histogram is not plotted. Recall that values from all probes other than the spectral gamma detector represent patches where the spectral gamma detector saturated, exceeded deadtime limits, or was not used. Type 1 counts cluster at intermediate values. Note that relatively few type 2 values define the highest levels of contamination measured in vertical drywells. Only 64 type 2 values are greater than 13.0 in log-space.

Within lateral drywells, type 1 data defines low and intermediate levels of contamination while type 2 counts are skewed toward intermediate and high values (Fig. 9). As noted above, the frequency of values between 3.0 and 4.0 in all three histograms in Fig. 9 reflects the conversion of zero values to the nominal "background" of $25 \mathrm{cps}$. 

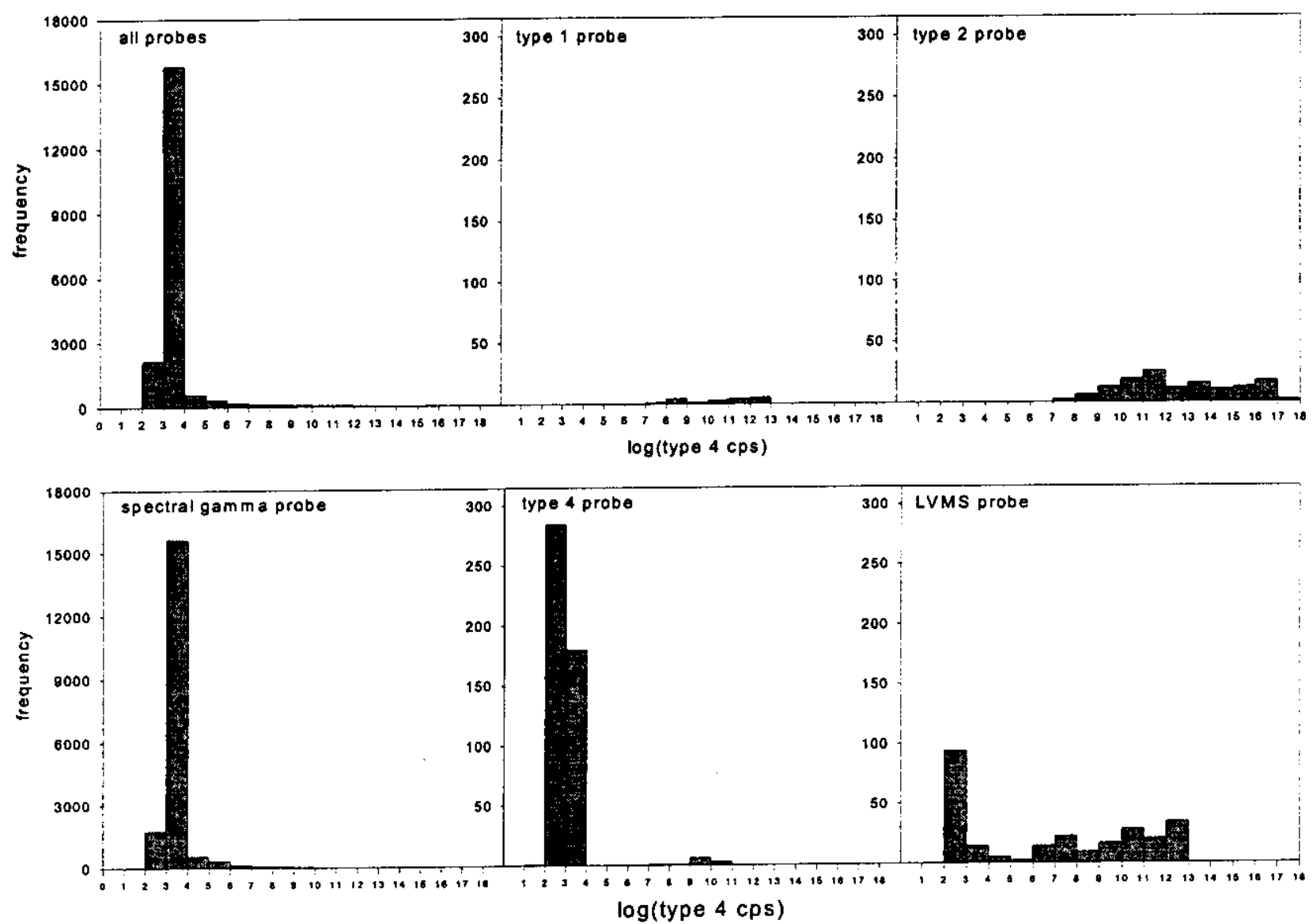

Fig. 8. Histograms of vertical drywell gamma counts recorded with five probe types. All values converted to consistent units.

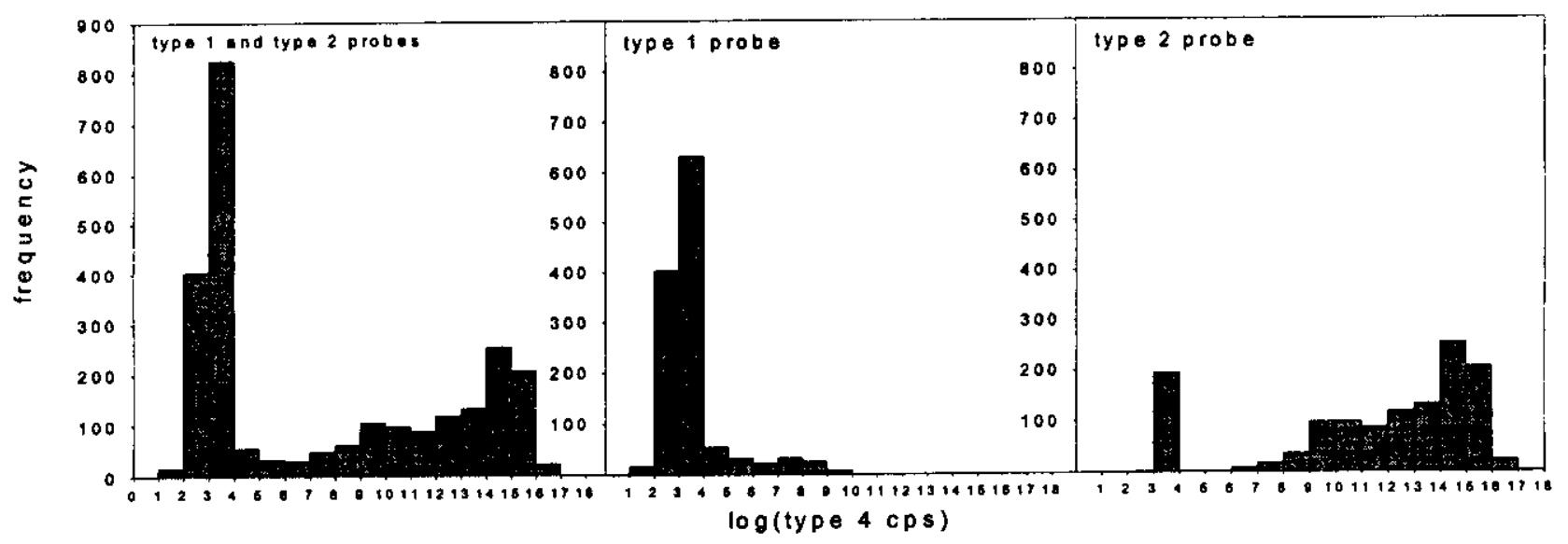

Fig. 9. Histograms of lateral gamma counts recorded with type 1 and type 2 probes. All values converted to consistent units. 
The distribution of maximum gamma counts by well among vertical and lateral wells also shows the dominance of lateral data at "above-background" levels of contamination (Fig. 10). All but one lateral out of 24 recorded a maximum value greater than 4.0 in log-space while 16 out of 99 vertical drywells logged maximums between 3.0 and 4.0. Note, as well, that 74 out of 99 vertical drywells recorded maximums between 3.0 and 6.0. The relatively modest levels of contamination found at most vertical drywells proved to be important in geostatistically defining the horizontal extent of contaminated plumes found at the SX farm. However, the importance of vertical wells in intercepting regions of high contamination should not be understated. At very high levels of contamination (between 12.0 and 18.0) equal numbers of vertical and lateral wells (10) recorded maximum values.
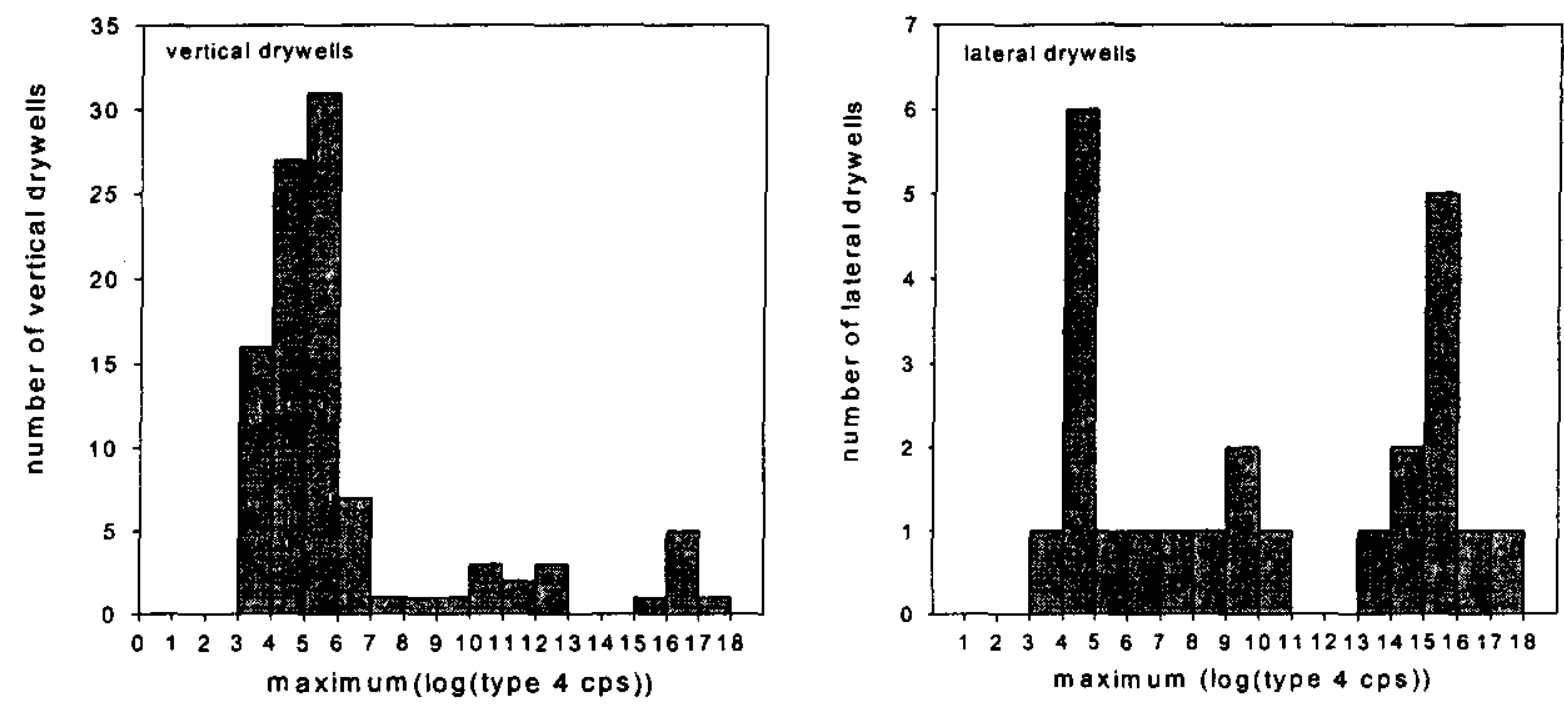

Fig. 10. Distribution of maximum counts per well recorded at vertical and lateral drywells.

The distribution of soil core data after conversion to consistent units is plotted in Fig. 11, revealing an intermediate level of contamination among the nine soil cores originally recording "above-trace" concentrations of Cs-137. The relatively large number of values between 3.0 and 4.0 in log-space (420 total) is the result of assigning "background" level counts at one foot intervals ( 70 per core) to the six cores where no "above-trace" Cs-137 concentrations were observed. The distribution of maximum values per core reflects this assignment of "background" level counts to six cores. The other maximums, once again, reveal an intermediate level of contamination with no maximum greater than 13.0 . 

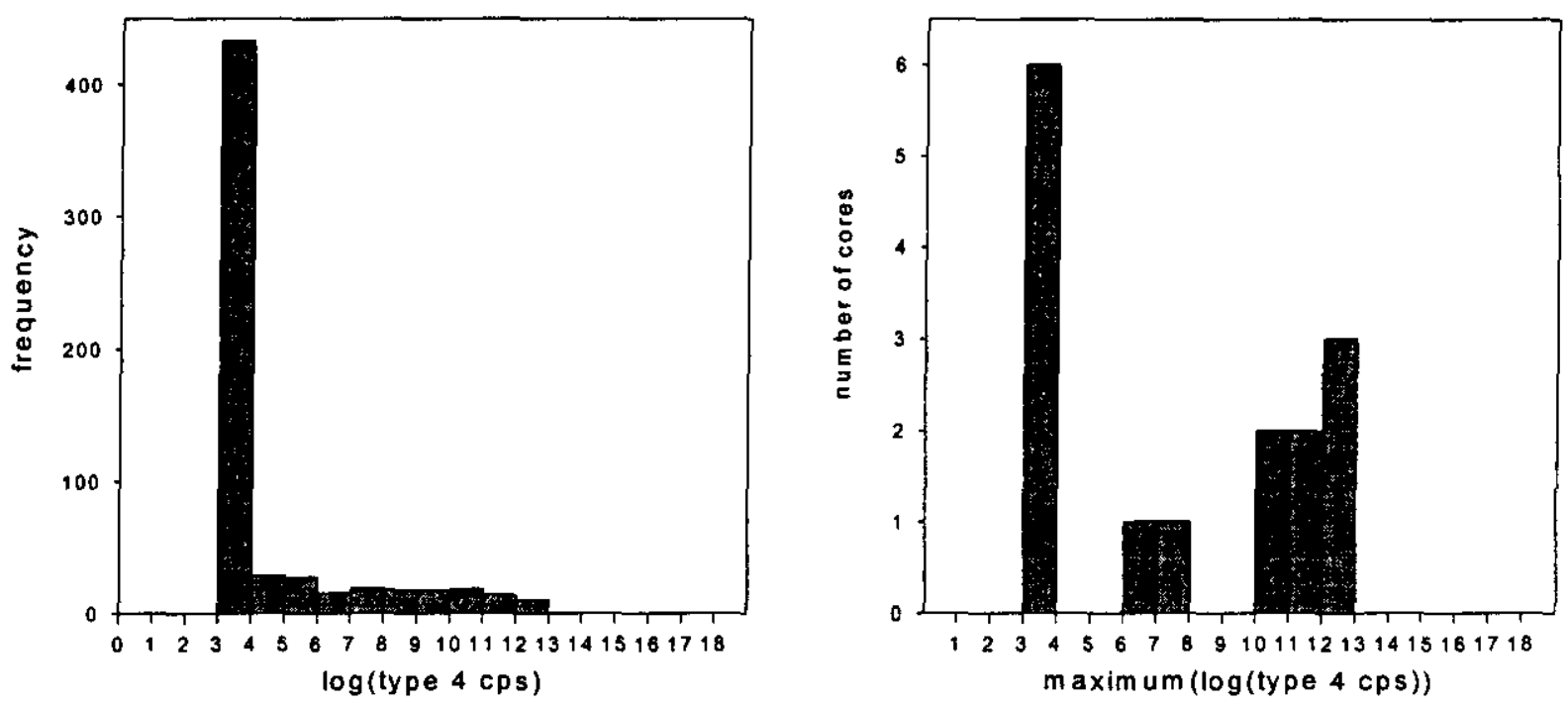

Fig. 11. Histogram of soil core values after conversion to consistent units and distribution of maximum values per core recorded at soil cores.

\section{Data binning}

In vertical and lateral drywells, gamma counts were recorded at short distance intervals. Vertical drywell data was typically spaced at $0.5 \mathrm{ft}$. intervals while lateral counts were generally recorded at one $\mathrm{ft}$. spacings. In reducing the size of the composite gamma data set $(n=22,616)$ to a more computationally tractable size, we used a binning procedure based on a 1-meter grid system established with vertex $(0,0,0)$ located at easting $566745 \mathrm{~m}$, northing $134145 \mathrm{~m}$, and the surface of the prediction volume. During binning, each data value was assigned to the nearest grid point in the prediction volume. The location of the center of mass and the mean of the logtransformed values in each non-empty bin $(n=3,957)$ were used as input in geostatistical analyses.

Histograms of binned data are plotted in Figure 12. Qualitatively, the binned distributions of all data and vertical drywell data closely resemble their unbinned analogues (Figs. 6 and 8). Relative to the distribution of unbinned lateral counts (Fig. 9), the histogram of binned lateral data is slightly flattened in the neighborhood of the upper mode between 14 and 15 in log-space. This result is not unexpected given the spatial averaging implicit in our binning method. However, the overall similarity between binned and unbinned distributions of the composite data set suggests that binning is an appropriate method for reducing the size of the data set. 

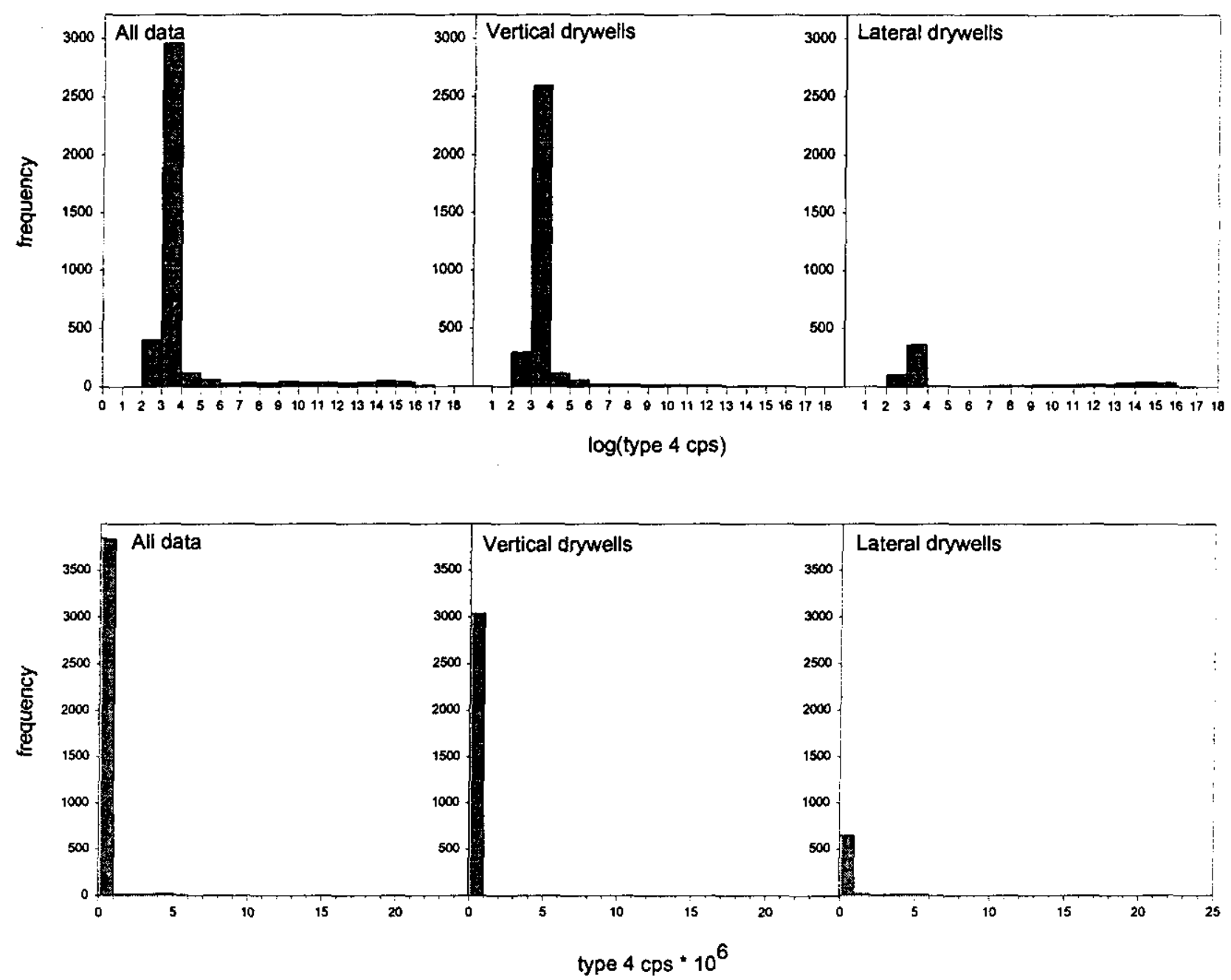

Fig. 12. Histograms of vertical, lateral, and all gamma logging values after conversion to consistent units and binning by 1 meter cubes. 


\section{The composite Cs-137 data set}

The Cs-137 data set is a composite of Cs-137 concentrations in $\mathrm{pCi} \mathrm{g}^{-1}$ including values derived from the analysis of SGLS spectra at vertical drywells, values predicted from spectral gamma and historical gamma counts logged at both vertical and lateral drywells, and Cs-137 concentrations measured directly from soil cores collected in the SX-108, SX-115 neighborhood.

\section{Spectral gamma Cs-137 gaps}

While spectral gamma Cs-137 concentrations were calculated from the same logging runs at vertical drywells where spectral gamma total counts were recorded ((DOE, 1996; DOE, 1997; Brodeur, 1996), fewer Cs-137 concentrations were reported by Mactec-ERS - 7,721 values over the entire SX farm versus 18,635 spectral gamma total counts over the entire SX farm. A histogram of spectral gamma total counts logged at locations (well/depth) where no Cs-137 concentrations were reported by Mactec-ERS is plotted in Fig. 13. Approximately $99 \%$ of these values are less than 6.0 in log-space, suggesting that gaps in the spectral Cs-137 data are concentrated in regions of "background-level" contamination. Additional gaps in the spectral gamma Cs-137 data due to detector saturation, high dead times, or other reasons are identical to gaps in the spectral gamma total counts data summarized in Table 2. At drywell 09-39 we did not use LVMS data over the entire well, but only over the interval where the spectral gamma detector saturated $(62-90 \mathrm{ft}$.).

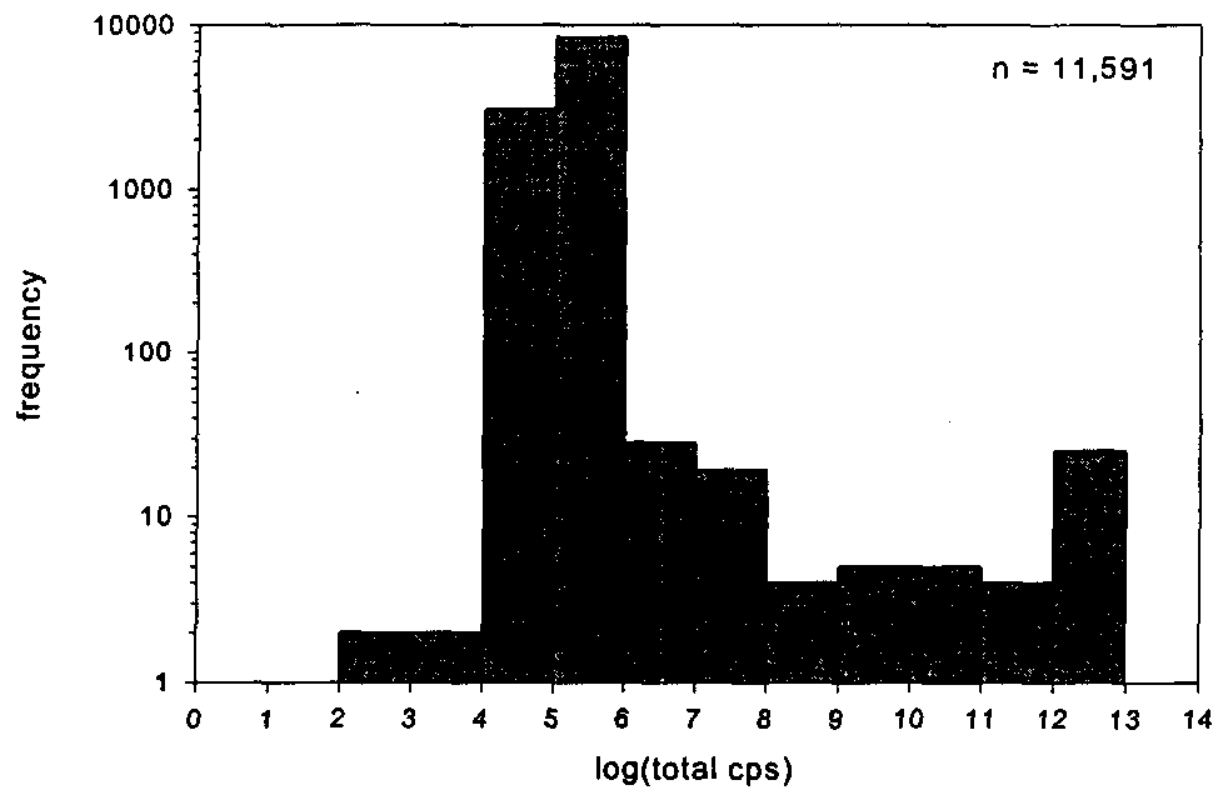

Fig. 13. Spectral gamma total counts recorded at locations (well/depth) in the SX farm where no spectral gamma Cs-137 concentration data was recorded 


\section{Vertical drywells, lateral drywells, and soil cores}

In filling gaps in the vertical drywell data, we converted gross gamma counts recorded with either the spectral or historical gamma detectors to $\mathrm{Cs}-137$ concentrations in $\mathrm{pCi} \mathrm{g}^{-1}$. The basis for the conversion of spectral gamma counts was a scatter plot of spectral gamma Cs- 137 concentrations versus spectral gamma total counts recorded at identical locations, i.e. the same well and depth. Note that in comparing well depths, depth values originally reported by MactecERS to the nearest one-hundreth of a foot were rounded to the nearest tenth. Following logtransformation of both variables, the resulting scatter plot was fit with a power curve (Fig. 14).

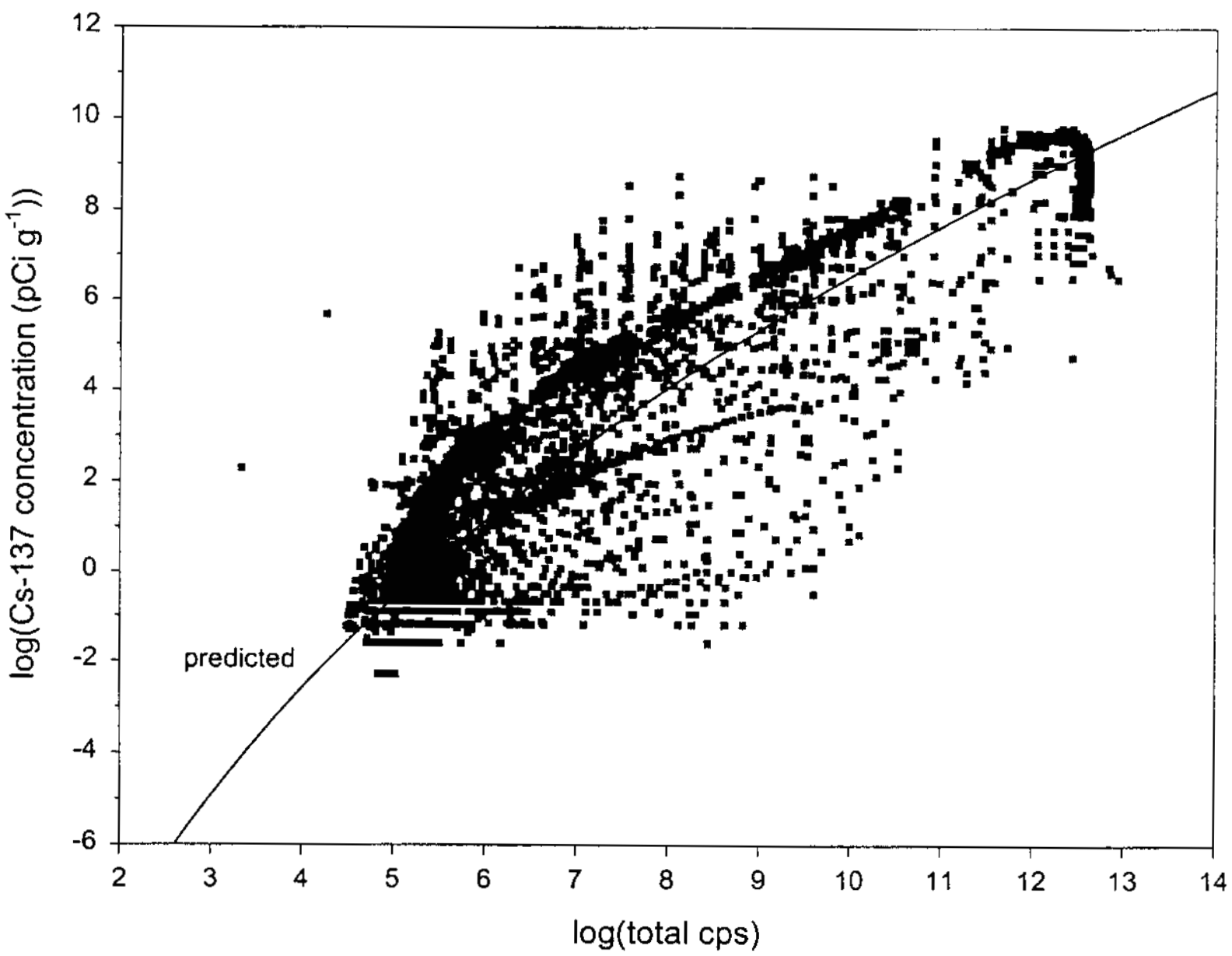

Fig. 14. Spectral gamma Cs-137 $\mathrm{pCi}^{-1}$ vs. spectral gamma total counts. 
A similar scatter plot was used to derive a calibration relationship between gamma counts in probe type 4 units and Cs-137 concentrations. In this case, spectral gamma total counts were first converted to type 4 units, as described in Table 1, before they were log-transformed and plotted against the log of spectral gamma Cs-137 concentrations (Fig. 15). Note that the maximum value in type 4 units among these pairs (the blue squares in Fig. 15) is approximately $\mathrm{e}^{10} \mathrm{cps}$. However, recall from the histograms of lateral gamma counts (Fig. 9), that a significant number of lateral gamma counts are greater than $\mathrm{e}^{10}$ in type $4 \mathrm{cps}$. Given that the laterals appear to be intercepting the most highly contaminated regions of the SX-farm, we were uncomfortable merely fitting a line to the paired spectral data and using that relationship to predict Cs- 137 concentrations from lateral counts of magnitudes beyond the range of the given scatter plot. Our solution was to use the composite gamma counts data set minus the soil core data to make kriging predictions of $\log ($ type $4 \mathrm{cps})$ at locations where $\mathrm{SX}-108$ soil core data was collected. The resulting pairs of soil core Cs-137 concentrations in $\log \left(\mathrm{pCi} \mathrm{g}^{-1}\right)$ versus $\log$ (predicted type 4 cps) are plotted with red squares in Fig. 15. A straight line conversion was fit to the combined scatter plot.(Fig. 15).

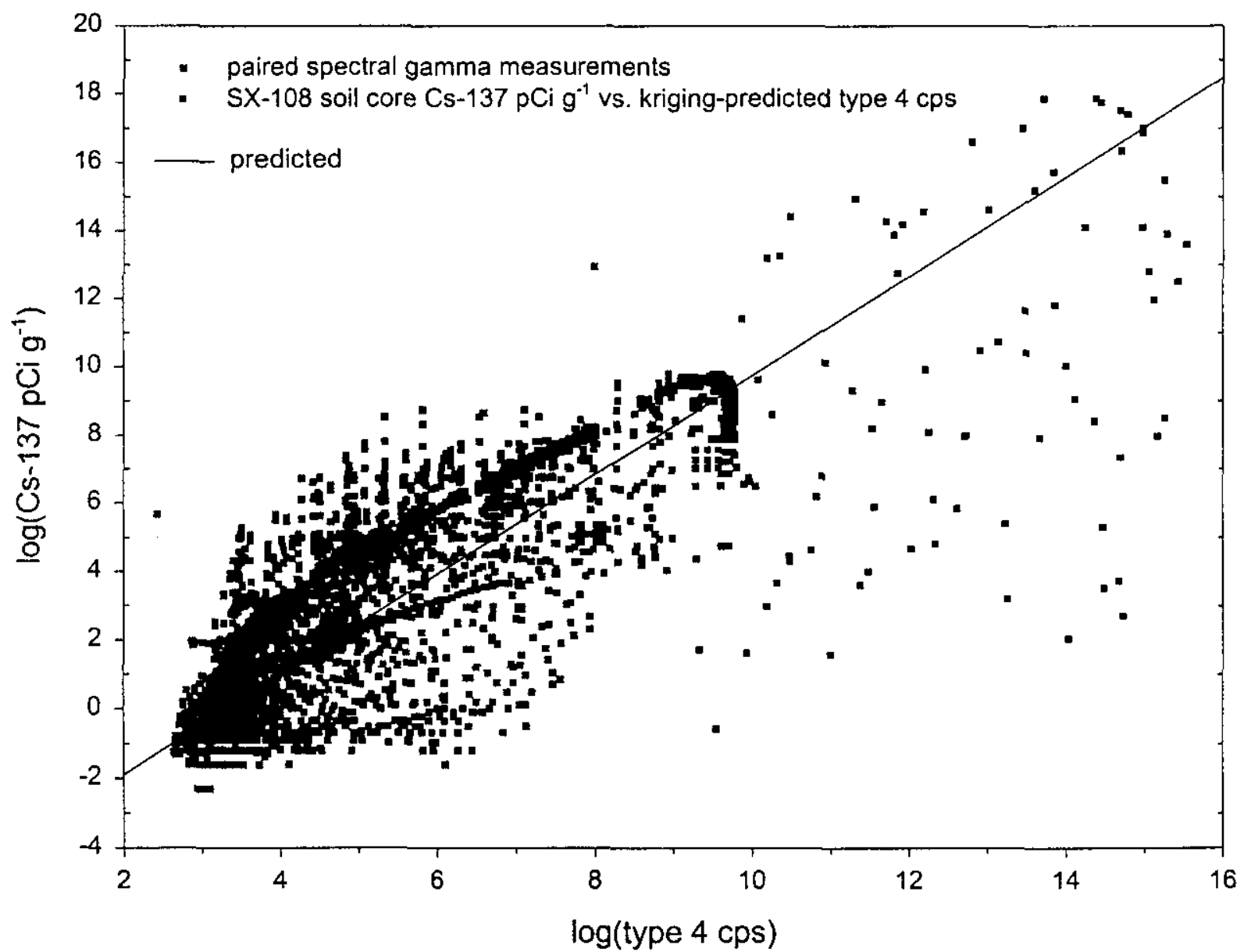

Fig. 15. Spectral gamma Cs- $137 \mathrm{pCi} \mathrm{g}^{-1}$ vs. spectral gamma total counts in type 4 units and SX-108 soil core Cs-137 $\mathrm{pCi} \mathrm{g}^{-1}$ vs. kriging-predicted type $4 \mathrm{cps}$. 
Note that results from the ten soil cores collected in the vicinity of SX-115 were not included in generating the conversion from historical gamma logging to Cs-137 concentrations. A plot of $\log \left(\mathrm{pCi}^{-1}\right.$ ) versus $\log$ (predicted type $4 \mathrm{cps}$ ) from $\mathrm{SX}-115$ soil cores (Fig. 16) reveals little correspondence between measured Cs-137 concentrations and kriging-predicted counts. At SX-115, the data do not appear to support the kriging model. Over a "background" range of predicted counts, $\mathrm{e}^{3}$ to $\mathrm{e}^{4} \mathrm{cps}$, measured Cs-137 concentrations range as high as $\mathrm{e}^{18} \mathrm{pCi} \mathrm{g}^{-1}$ (Fig. 16). Where a line of points is seen parallel to the $x$-axis of Fig. 16, counts slightly above "background" were predicted at soil cores originally assigned a "background" level of contamination. Given these inconsistencies, we chose to not include SX-115 values in Fig. 15.

Conversions from gross gamma counts in either spectral gamma or type 4 units to Cs-137 $\mathrm{pCi} \mathrm{g}^{1}$ are summarized in Table 5. Using the spectral gamma counts-to-pCi $\mathrm{g}^{-1}$ conversion, spectral gamma total counts filling gaps in the vertical drywell Cs-137 data, i.e. the values represented in Fig. 13, were converted to Cs 137 concentrations and added to the composite Cs137 data set. Similarly, the probe type 1,2, 4, and 14 historical gamma counts previously used to patch spectral gamma gaps in forming the composite gamma counts data set (Table 2), were converted to Cs-137 concentrations using the type 4 counts-to-pCi ${ }^{-1}$ conversion. All lateral drywell gamma counts from the composite gamma counts data set were converted to Cs-137 concentrations using the type 4 counts-to- $\mathrm{pCi} \mathrm{g}^{-1}$ conversion. The six soil cores previously assigned "background" level gamma counts were assigned Cs-137 concentrations using the same conversion while the nine soil cores recording "above-trace" Cs-137 concentrations were added to the composite Cs-137 data set without modification.

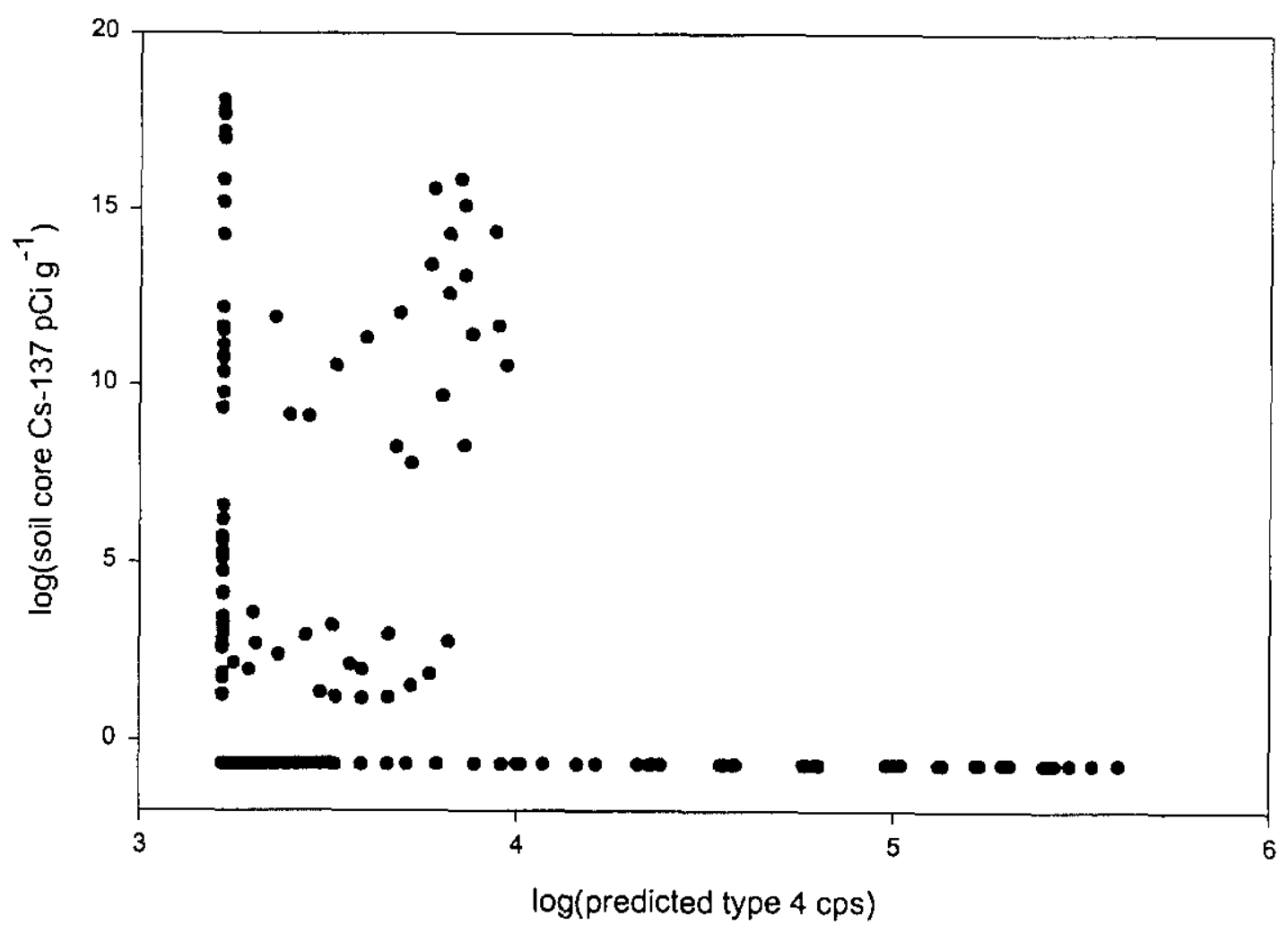

Fig. 16. SX-115 soil core Cs-137 pCi g $^{-1}$ vs. kriging-predicted type 4 cps. 
Table 5. Conversion of gross gamma counts in spectral gamma or type 4 units to $\mathrm{Cs}-137 \mathrm{pCi} \mathrm{g}^{-1}$.

\begin{tabular}{|l|l|}
\hline Gamma counts (units) & Conversion to Cs-137 pCi $^{-1}$ \\
\hline spectral gamma & $\exp \left\{-28.5363+16.4561 *(\log (\text { spectral gamma cps }))^{0.3287}\right\}$ \\
\hline type 4 & $\exp \{-4.7939+1.4547 * \log ($ type $4 \mathrm{cps})\}$ \\
\hline
\end{tabular}

\section{Histograms}

Histograms of all values in the composite Cs-137 data set and broken down by probe type are plotted in Fig. 17. Similar to the composite counts data set, the distribution of all values is left-skewed, even after log-transformation. The distribution of spectral gamma $\mathrm{pCi}^{-1}$ spans intermediate levels of contamination, while spectral gamma counts converted to $\mathrm{pCi}^{-1}$ are centered around "background" Cs-137 activities. While Cs-137 concentrations derived from type 1 and 2 counts are fewer in numbers, note their importance in defining the highest levels of contamination. The distribution of soil core values is fairly uniform between 1.0 and 18.0 in $\log$ space, with the spike between 0.0 and 1.0 the result of assigning "background" activities to six cores. Type 4, 14, and LVMS values are bimodally distributed, with one mode at "background" and a smaller mode between $\mathrm{e}^{12}$ and $\mathrm{e}^{13} \mathrm{pCi} \mathrm{g}^{-1}$.
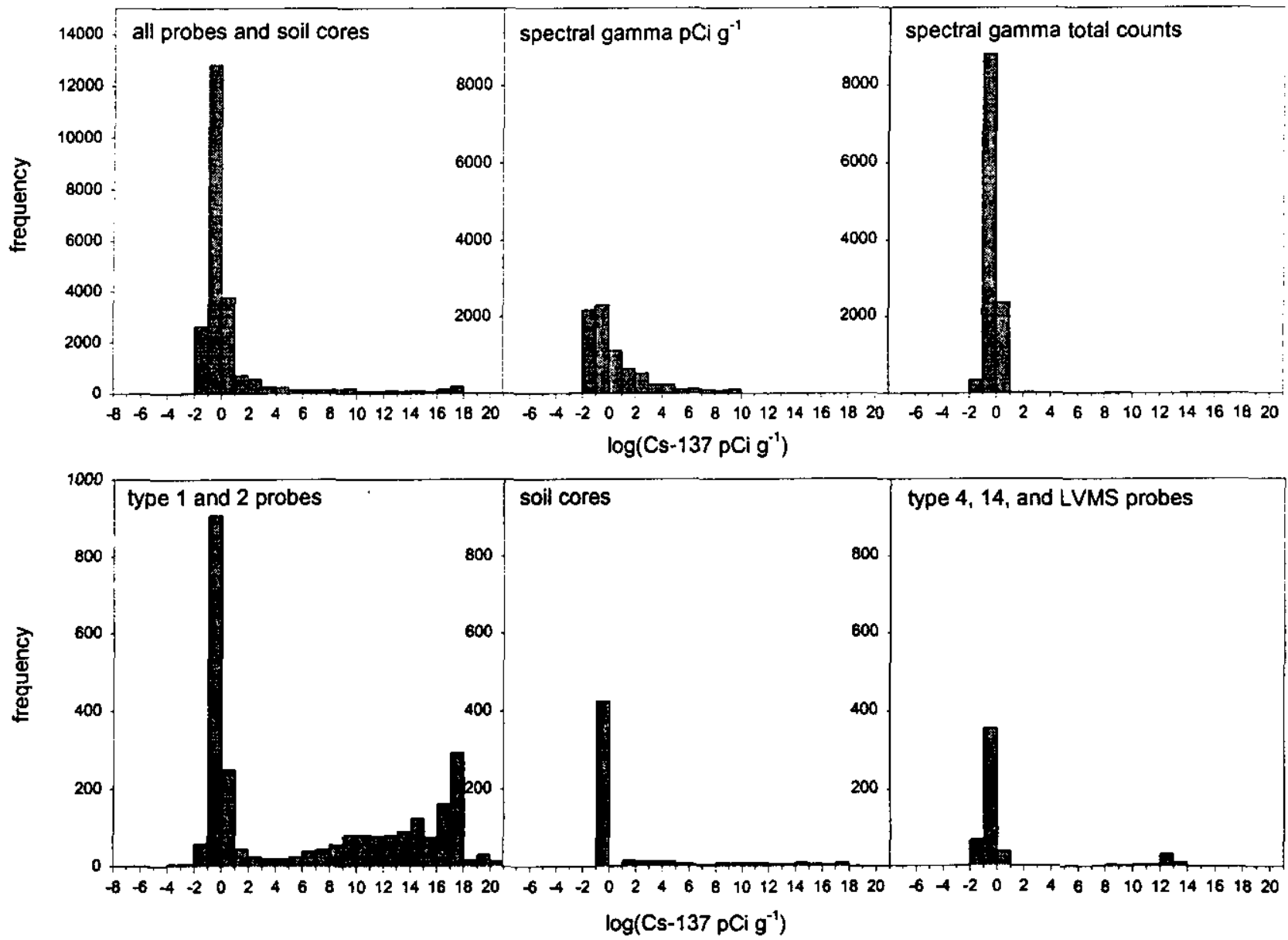

Fig. 17. Histograms of all values in the composite Cs-137 data set after conversion to $\mathrm{pCi}^{-1}$ and broken down by probe type. 
Histograms of Cs-137 concentrations measured at vertical drywells are plotted in Fig. 18 . Given that the spectral gamma detector was used only in vertical drywells, the spectral gamma distributions in Fig. 18 are identical to those plotted in Fig. 17. Once again, note that a relatively small number of type 2-derived values define the highest Cs-137 activities measured in vertical drywells.
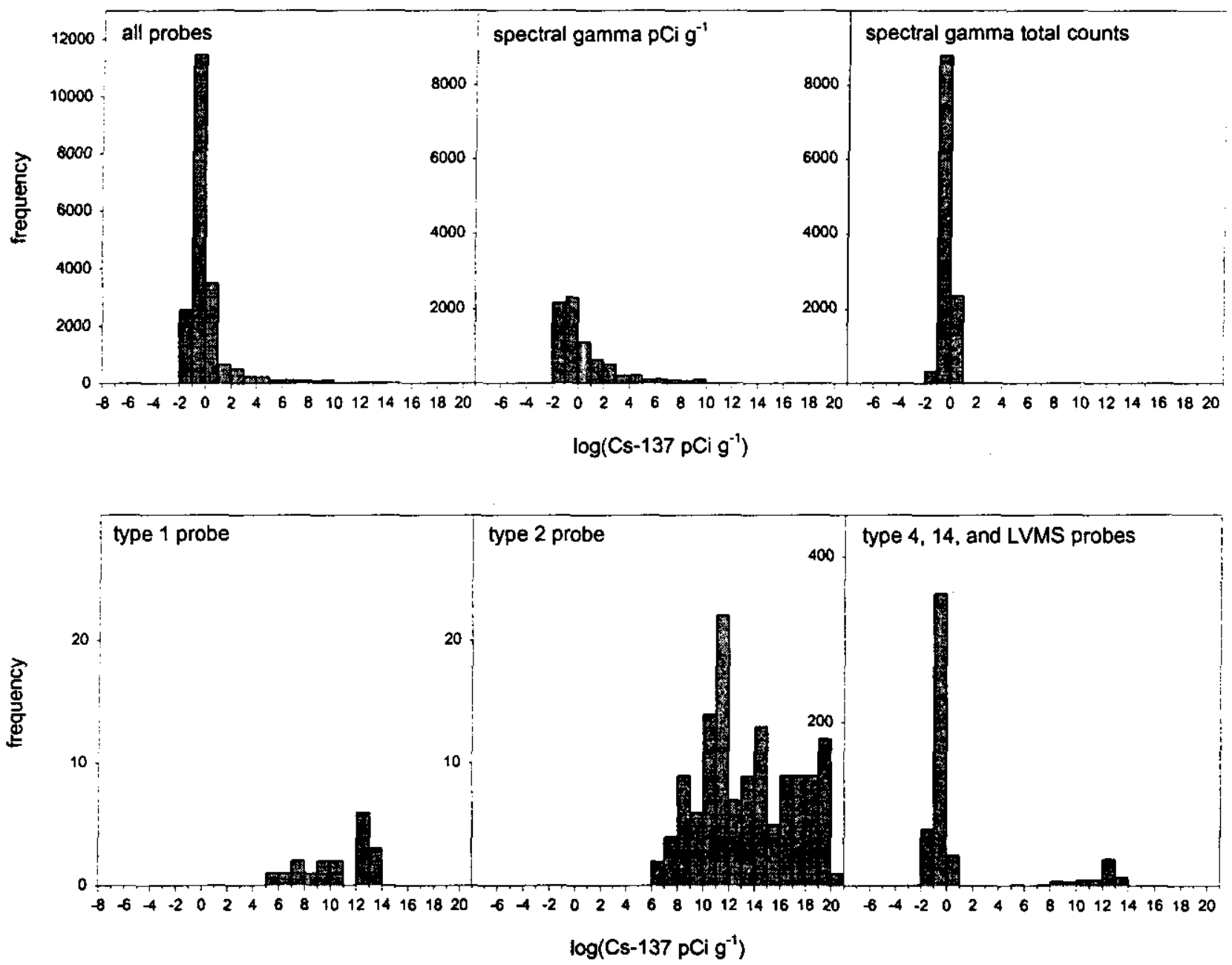

Fig. 18. Histograms of vertical drywell values in the composite Cs-137 data set after conversion to $\mathrm{pCi}^{-1}$ and broken down by probe type.

Histograms of Cs-137 concentrations derived from conversion of type 1 and 2 counts to $\mathrm{pCi}^{-1}$ in lateral drywells are plotted in Fig. 19. Type 1 values span low to intermediate Cs-137 concentrations while type 2 values dominate the intermediate to high range of Cs-137 concentrations. Recall that the type 2 peak between $\mathrm{e}^{-1}$ and $\mathrm{e}^{0} \mathrm{pCi} \mathrm{\textrm {g } ^ { - 1 }}$ is the result of assigning "background" activities to zeroes logged by the type 2 probe (see Table 3 ): 


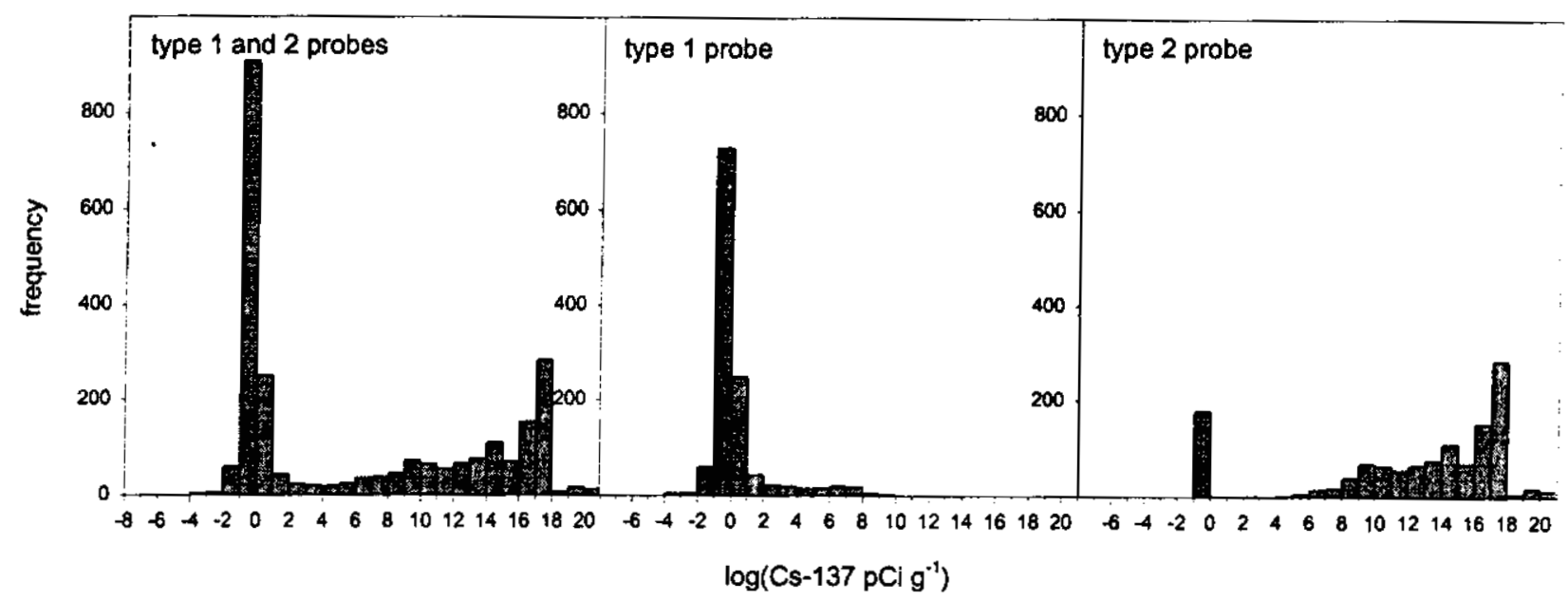

Fig. 19. Histograms of lateral drywell values in the composite Cs-137 data set after conversion to $\mathrm{pCi}^{-1}$ and broken down by probe type.

\section{Binning}

The same binning methodology described earlier was used to reduce the size of the composite Cs-137 data set from 23,072 values to a more computationally tractable size of 3,962 values. A histogram of the binned Cs-137 data is plotted in Fig. 20. Where bins contained more than one value, a bin sample variance was calculated. Histograms of bin sample variance and bin sample number (number of values per bin) are also plotted in Fig. 20.

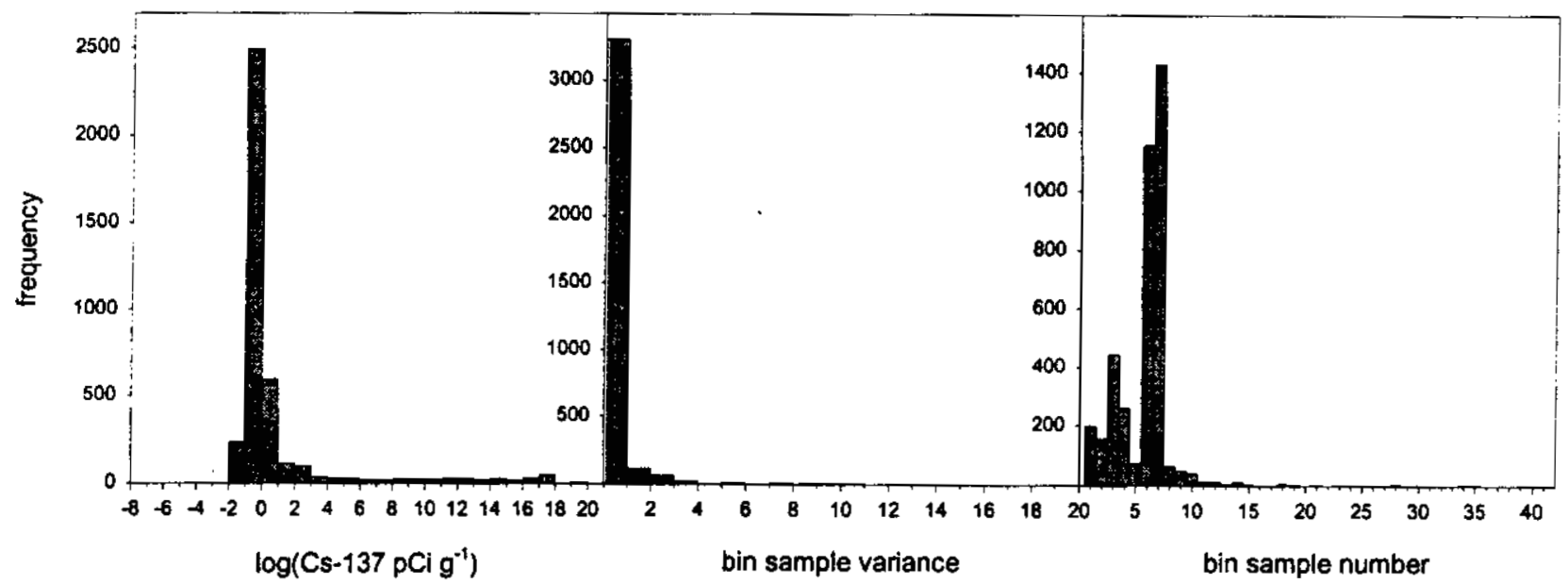

Fig. 20. Histograms of the binned composite Cs-137 data set, bin sample variance and bin sample number. 


\section{Drywell 09-39}

An opportunity to assess the accuracy of our counts-to-pCi $\mathrm{g}^{-1}$ conversions presents itself at drywell 09-39. Recall that well 09-39 was drilled in December, 1996 and logged with both spectral gamma and LVMS detectors (DOE, 1997). Additionally, a limited number of soil core samples were collected during drilling of the well (Dave Meyers, pers. comm., 11/15/99). A vertical profile of Cs-137 concentrations at well 09-39 is plotted in Fig. 21. Spectral gamma counts converted to $\mathrm{pCi} \mathrm{g}^{-1}$ are plotted only at depths where no spectral gamma Cs-137 measurements were recorded. LVMS counts were treated as equivalent to type 4 counts as discussed above (see Fig. 4), before conversion to pCi ${ }^{-1}$. LVMS-derived Cs-137 concentrations are plotted only at depths where the spectral gamma detector saturated.

Below a depth of $50 \mathrm{ft}$., the overall pattern of soil core values closely resembles the more continuous profile generated from drywell measurements (Fig. 21). However, soil core values are consistently greater than or equal to Cs-137 concentrations derived from gamma logging, suggesting that drywell measurements may be consistently underestimating the true Cs-137 concentration in the vadose zone. At $65.5,74.5$, and $79.5 \mathrm{ft}$. below surface, our type 4 cps-to$\mathrm{pCi} \mathrm{g}^{-1}$ conversion generates values approximately an order-of-magnitude smaller than soil core Cs-137 concentrations. At depths of 56.5, 102.5, and $108.5 \mathrm{ft}$, spectral gamma Cs-137 concentrations appear to underestimate true values by approximately, three, two, and one order(s)-of-magnitude, respectively. Note that Cs-137 concentrations derived from our spectral gamma cps-to-pCi $\mathrm{g}^{-1}$ conversion at depths of 90 and $103 \mathrm{ft}$ correspond closely to neighboring spectral gamma $\mathrm{pCi}^{-1}$, suggesting that this conversion may also underestimate $\mathrm{Cs}-137$ concentrations.

Consistent underestimation of Cs-137 concentrations may be the result of instrumentation operating at performance limits. While the spectral gamma detector was saturated from 62 to 68 $\mathrm{ft}$. and from 70 to $90 \mathrm{ft}$., assays from 90 to $110 \mathrm{ft}$. were deemed questionable because many of the spectra recorded over this interval were highly distorted (DOE, 1997). Similarly, the authors of the well 09-39 report (DOE, 1997) concluded that the LVMS detector was saturated from 63 to $68 \mathrm{ft}$. and from 72 to $85 \mathrm{ft}$. Aside from instrument shortcomings, it also seems unlikely that our type 4 cps-to-pCi g ${ }^{-1}$ conversion would tend to underestimate Cs-137 activities at high count rates. Note in Fig. 15, that soil core Cs-137 activities given predicted type $4 \mathrm{cps}$ (the red squares) tend to fall approximately two log cycles below the regression line, implying that our regression conversion is overestimating $\mathrm{pCi}^{-1}$ when we apply it in the range of high count rate, type 2 data.

We cannot explain the three orders-of-magnitude discrepancy between spectral gamma counts converted to $\mathrm{pCi}^{-1}$ and soil core measurements at 25.5 and $44.5 \mathrm{ft}$. However, it seems logical to assume that the reported soil core values are erroneous given that "background" level spectral gamma counts were recorded between 10 and $50 \mathrm{ft}$. 
HNF-5782 Rev. 0

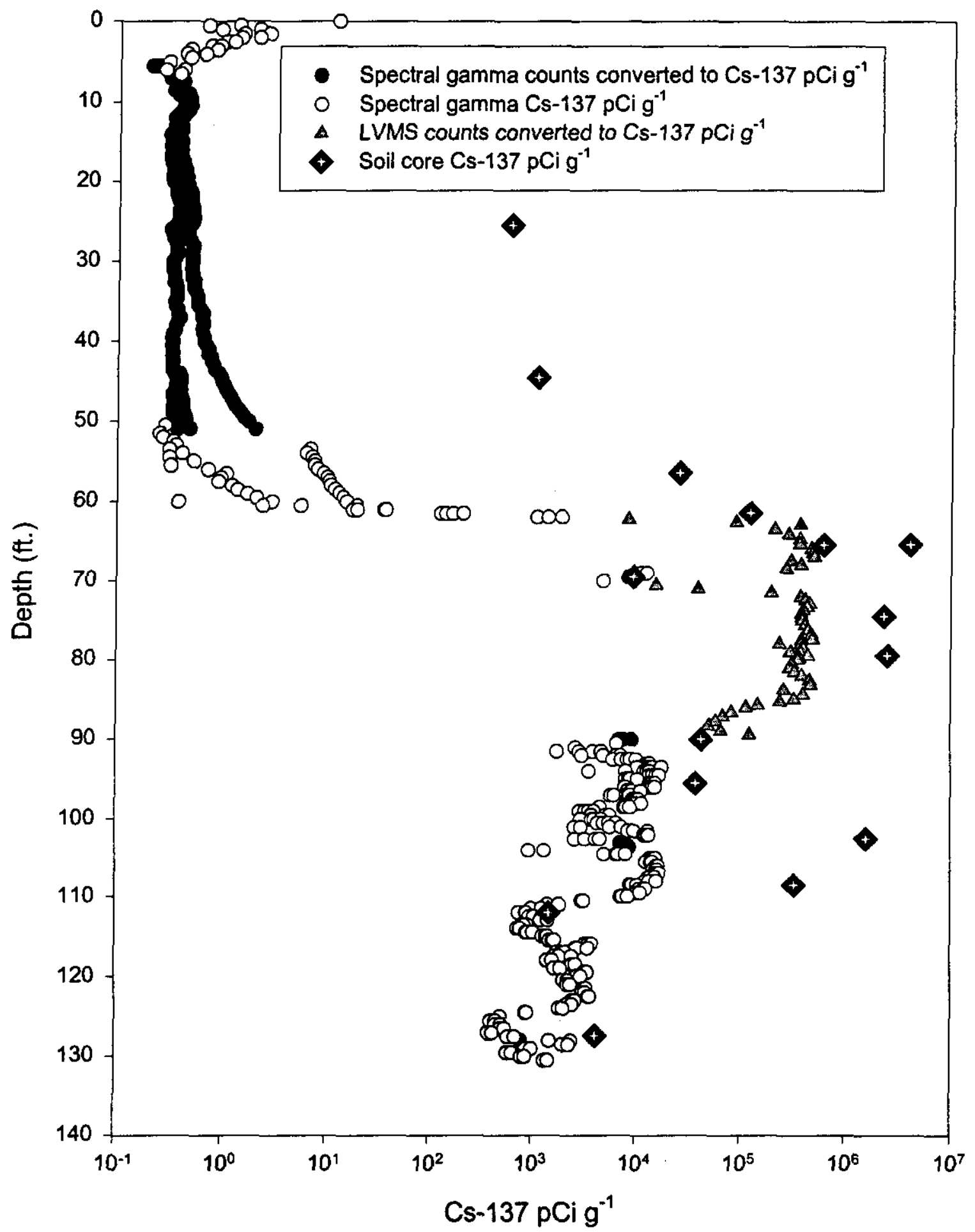

Fig. 21. Drywell 09-39 Cs-137 $\mathrm{pCi} \mathrm{g}^{-1}$ from gamma logging and soil cores. 


\section{References}

Brodeur, J. R. 1996. Unpublished letter report, Subject: "41-12-01 Borehole log report", Rust Geotech Inc., Richland, Washington.

Jones, T. E., Khaleel, R., Meyers, D. A., Shade, J. W., and M. I. Wood. 1998. A summary and evaluation of Hanford site tank farm subsurface contamination. HNF-2603, Lockheed Martin Hanford, Richland, WA.

Randall, R.R. 1999. Unpublished letter report, Subject: "SX red GM scaling for instrument sensitivity changes", Three Rivers Scientific, Richland, Washington.

Raymond, J. R. and E. G. Shdo. 1966. Characterization of subsurface contamination in the SX tank farm. BNWL-CC-701, Battelle-Northwest, Richland, Washington.

U.S. Department of Energy (DOE). 1997. Vadose zone characterization project at the Hanford tank farms, assessment of log data for borehole 41-09-39 and correlation with borehole 41-09-04 in the SX tank farm, GJO-HAN-9, prepared by MACTEC-ERS for the Grand Junction Projects Office, Grand Junction, Colorado.

U.S. Department of Energy (DOE). 1996. Vadose zone characterization project at the Hanford tank farms, SX tank farm report, GJPO-HAN-4, prepared by Rust Geotech for the Grand Junction Projects Office, Grand Junction, Colorado.

Westinghouse Hanford Company (WHC). 1992a. Tank 241-SX-108 leak assessment, WHC-MR300, Westinghouse Hanford Company, Richland, Washington.

Westinghouse Hanford Company (WHC). 1992b. Tank 241-SX-109 leak assessment, WHCMR-301, Westinghouse Hanford Company, Richland, Washington. 


\section{Addenda: ASCII data files}

Six ASCII text files are included with this report on diskette. The SX_counts_raw.txt, $S X \_$counts_processed.txt, and $S X \_$counts_binned.txt files correspond to the composite gamma counts data set. The $S X \_c u r i e s \_r a w . t x t, \bar{S} X$ _curies_processed.txt, and $S X$ curies_binned.txt files correspond to the composite Cs-137 data set.

\section{The composite gamma counts data set}

$S X \_c o u n t s \_r a w . t x t$

This file contains the vertical drywell counts, lateral drywell counts, and soil core Cs-137 concentrations used to create the composite gamma counts data set. All values in this file are included as they were found in either the spectral gamma dataset compiled by Mactec-ERS, the historical gamma logging record, or after digitizing Plates I-IX in the Raymond and Shdo (1966) report. The five fields are:

Field 1: a four-digit identification code unique to each vertical drywell, lateral drywell, or soil core. The first two digits identify the SX tank, 01 through 15, associated with each drywell or core. Vertical drywells not associated with a tank are designated with two leading zeroes, i.e. 00. The next two digits of the four-digit code designate individual wells or cores. Vertical drywells are labeled 01 through 39, lateral drywells are labeled 41 through 43 , and soil cores are labeled 50 through 59. All identification codes in this field are identical to labels used in Fig. 1.

Field 2: the depth (ft.) from the surface in the case of vertical drywells and soil cores or the distance (ft.) from the surface via caissons and individual laterals.

Field 3: historical or spectral gamma cps in vertical and lateral drywells or concentration of $\mathrm{Cs}-137(\mathrm{pCi} / \mathrm{g})$ in soil cores.

Field 4: the probe type used to acquire data. Probe types 1, 2, 4, and 14 correspond to the historical gamma logging instruments. The spectral gamma detector is designated probe type 5. The LVMS detector is assigned probe type 6 . Soil core values are designated type 7.

Field 5: the calendar year individual values were recorded.

SX_counts_processed.txt

This file contains the complete composite gamma counts data set following conversion of all raw data to consistent units as described in detail in the main body of this appendix. The first two fields are id and depth/distance fields identical to those described above. The third field is gross gamma counts in type $4 \mathrm{cps}$. 


\section{SX_counts_binned.txt}

This file contains the results of binning the composite gamma counts data set. The first three fields are the $x, y$, and $z$ coordinates of the center of mass of the values contained in each non-empty bin in eastings, northings, and depth below surface, respectively (all in meters). The fourth field is the arithmetic mean of the log-transformed values in each bin. The fifth field contains the number of values assigned to each bin. The sixth field is the bin sample variance. If a bin contained only one value, a sample variance was not calculated and an error code of -9.99999 is written.

\section{The composite Cs-137 data set}

SX_curies_raw.tot

This file contains all values used to assemble the composite Cs-137 data set. The five fields are identical in type to the five fields in the $S X$ counts_raw.txt file. All spectral gamma Cs137 concentrations reported by Mactec-ERS are included and identified as probe type 8 . At locations (well/depth) where spectral gamma total counts were logged but no spectral gamma Cs-137 concentrations were reported, spectral gamma total counts were added to the raw Cs-137 data set. Historical gamma counts from vertical and lateral drywells included in this file are identical to values found in the raw gamma counts data set. Similarly, soil core Cs-137 concentrations are identical to values found in the raw gamma counts data set. At drywell 09-39, LVMS total counts were included over the depth interval where the spectral gamma detector saturated $(62-90 \mathrm{ft}$.).

SX_curies_processed.txt

This file contains the complete composite Cs-137 data set following processing of the raw data as described in detail in the main body of this appendix. The first two fields are id and depth/distance fields. The third field is $\mathrm{Cs}-137$ concentration in $\mathrm{pCi}^{-1}$.

\section{SX_curies_binned.txt}

This file contains the results of binning the composite Cs-137 data set. The six fields are identical in type to those found in the $S X \_$counts_binned.txt file. 


\title{
APPENDIX 2. GEOSTATISTICAL APPROACH USED IN ESTIMATION OF SX-FARM VADOSE ZONE Cs-137 INVENTORIES *
}

\author{
Daniel Goodman \\ Environmental Statistics Group \\ Biology Department \\ Montana State University \\ Bozeman, MT 59717
}

January 28,2000

\section{GENERAL FEATURES OF THE MODEL}

\subsection{The Second-Order Stationary Gaussian Process}

The geostatistical model used in this analysis is the basic second-order stationary Gaussian process. It offers a good compromise of features with respect to relative transparency, interpretability, and computational speed in kriging (Goodman, 1999). This model has a long history in the context of time series analysis (Wiener, 1949), and it extends naturally to geostatistics (Cressie, 1991). This model treats the process mean as a distinct parameter, which can be set differently from the actual mean of the data, which may be a biased sample of the process, because of the tendency to sample in hot spots. The separation allows a reasonable "background" prediction value to be established, without detrending. In this sense the model is "purely geostatistical" since no ancillary models of a physical process

* This is a report to MACTEC Inc., under agreement 3751.119.376 with Montana State University. Portions of the work reported here were supported by DOE cooperative agreement DE-FC07-94ID13317 to Montana State University, Daniel Goodman, Principal Investigator. 
are invoked to account for a non-stationary mean. The model for the process is mathematically tractable, allowing a simple form for prediction, called "simple kriging," and for conditional simulation to calculate error distribution of decision quantities. The model can readily deal with observation error, both in prediction and in conditional simulation. The model has a natural likelihood function for the observations, should it be desired to use that approach for parameter estimation.

\subsection{The Exponential Variogram Model}

We chose the exponential variogram model because of its mathematical simplicity, and because it is a popular choice for applications in hydrogeology (Kitanidis, 1997). An exponential decay of correlation with distance seems to accord reasonably well both with intuition of the physical processes, and with the usual data sets.

To minimize the number of parameters, and complexity, we opted for isotropy in the horizontal dimensions. Because the movement of contamination in the vertical dimension in the vadose zone clearly is governed by physical mechanisms that are quite different from those controlling horizontal dispersion, we set a separate parameter for correlation with distance in the vertical dimension.

\subsection{Parameter Estimation}

This model structure requires that 5 parameters be determined. These are:

1. the process mean,

2. the process variance,

3. the correlation decay rate with distance in the horizontal,

4. the correlation decay rate with distance in the vertical,

5. the measurement error variance.

The volume of the tank farm vadose zone was subdivided in a grid system of cells that are cubes of $1 \mathrm{~m}$ on a side. After conversion of the data from various sources to estimated $\mathrm{pCi} / \mathrm{g}$ Cs-137, the log transformed values within each cell were averaged (in the log space, so these are actually geometric means of the concentrations), and the cell mean was employed to represent the contamination in that cell, and this log concentration value was assigned the nominal location of 
the log concentration weighted mean position (in 3-d) of the data locations that went into the mean for that cell. Later, when kriging predictions were made, these were assigned to the respective cell centers in this grid system.

For all cells with two or more data locations contributing to the mean, the within-cell sample variance was used to estimate a corresponding population variance, and the each such variance was graphed against the cell mean. A regression through this scatter plot (Figure 1) showed slight slope, due primarily to the low variances in the frequent cells reporting low contamination. These cells contributed little to the inventory, so their error variance was of little interest. Overall, and also in the subset of cells with higher concentration, the histogram of the variances was very skewed, as would be expected for variances that naturally have a chi-squared distribution. The median variance from this distribution was taken to represent the measurement error variance for a single measurement, and then the measurement error associated with the mean value used for each cell with data was computed as the standard error of that mean, using this estimate of the measurement error variance per measured value. It must be noted that this estimation of measurement error from replicability of measurements was dominated a large number of replications using the same probe type, which resulted in a much lower apparent measurement error than was revealed in comparing measurements, at the same location, with different probe types.

The process mean was set to duplicate the observed "background" in the tank farm as revealed by gross gamma logging with the type 4 instrument which has good resolution at the lower ranges of values, and was used for measurements at a large number of the locations. The gamma logging data with that probe showed a distinct normal mode at $25 \mathrm{cps}$ (Figure 2). The type 2 gross gamma instrument, which could not revolve such low activity levels, showed a second, definitely non-normal mode between $e^{14}$ and $e^{15}$ (shown in a histogram of the $\log$ counts in Figure 3). We took the distinct mode observed at $25 \mathrm{cps}$ with the type 4 instrument, which converts to $0.89 \mathrm{pCi} / \mathrm{g}$, to be the local "background," and used this value for the process mean. The very skewed shape of the hotter mode of the counts from the type 2 instrument (as revealed in the histogram of untransformed counts in Figure 4) indicated that some transformation of the data was required. We chose $\log$ transformation for the merged data, which resulted in a more normal-looking distribution than the original histogram, but the shape was still far from normal, with a long right-tail to very high, but infrequent values (Figure 5). 


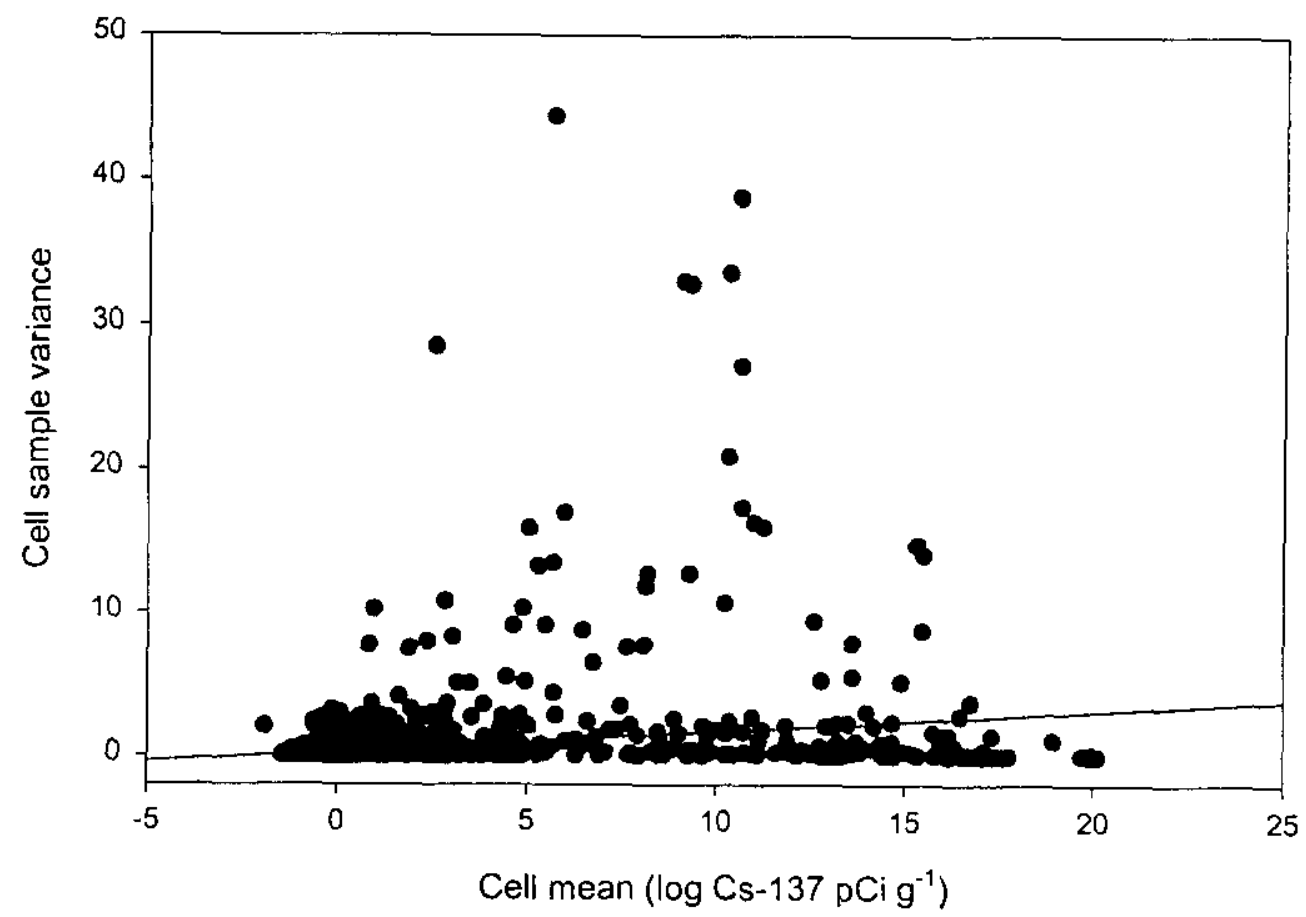

Fig. 1. Cell sample variance vs. cell mean for all cells containing two or more values.

The process variance plays only a minor role in computing the point estimate of the process at a location, as long as it is larger than the measurement error. Under these circumstances it serves only to scale the effect of the measurement error, weighting the data versus the process mean in the point prediction. If measurement error is zero, the process variance has no influence at all on the point prediction. For this same reason, the process variances has the same modest degree of influence on the point estimate of the inventory. However, the process variance plays a very large role in computing the prediction error variance, either for a single location, or for an inventory. The mathematics of the prediction error calculation are more sensitive to the underlying assumptions of the model than are the mathematics of the point prediction calculation. The assumption of normality is crucial to the applicability of the prediction error calculations for purposes of obtaining confidence intervals on the estimates.

The actual distribution of data from SX-farm was far from normal, even after log-transformation, for a long tail of rare but very high values persisted. This 
tail dominated the direct calculation of the variance of the data values, and gave very high values for the variance relative to the mean: the standard deviation was 3.93 in the log space, or $25 \times 10^{6}$ for the untransformed values, operating with data all converted to $\mathrm{pCi} / \mathrm{g}$. Since this very large empirical variance was owing to a severe departure from the assumptions of the model, use of the empirical variance as the process variance would lead to very unreasonable behavior of the prediction error calculation. The dominance of the high "outliers" in establishing such a high estimate of the process variance would result in reasonable estimates of prediction error only for the few data locations with very high concentrations of contamination, and would result in vastly inflated prediction error estimates for most of the rest of the volume.

Since the inventory calculations involve summing over much of the vadose zone volume, it was deemed that the reasonableness of the prediction error variance for the great preponderance of the volume that has relatively low contamination concentrations was more important than the correctness of the prediction error variance for the few high outliers. Accordingly, the process variance was estimated as the variance associated with the central mass of the distribution of the data, excluding the tail of high outliers, giving a value of 1.08 in the log space.

The remaining two parameters were the range of influence parameters (horizontal and vertical) that describe the rate at which correlation decays with increasing distance (in each direction). One conventional way (familiar to physicists) to report this parameter is as the $e$-folding distance: the separation distance at which the correlation between local contamination levels (true values, without measurement error) is $1 / e$ (roughly $37 \%$ ). We employed jack-knife cross-validation, in the kriging model itself, to adjust the two free range-of-influence parameters to minimize the jack-knife residual. Because this operation was carried out within a model that already embodied all the other assumptions we had made, and parameters we had set, the jack-knife parameter estimation had the further advantage of optimizing the two free parameters in context, so that any mis-specifications could be compensated to the extent possible. Similarly, the jack-knife predictions error would be representative of the actual prediction errors, at similar separation distances, in this application.

The parameter estimates from the final merged data set gave an $e$-folding distance of about 8.2 meters in the horizontal and 3.0 in the vertical. The residual response surface from the jack-knife cross validation was steep in the direction of smaller values of these parameters, but had a shallow slope in the direction of larger parameter values (see Figure 6). 


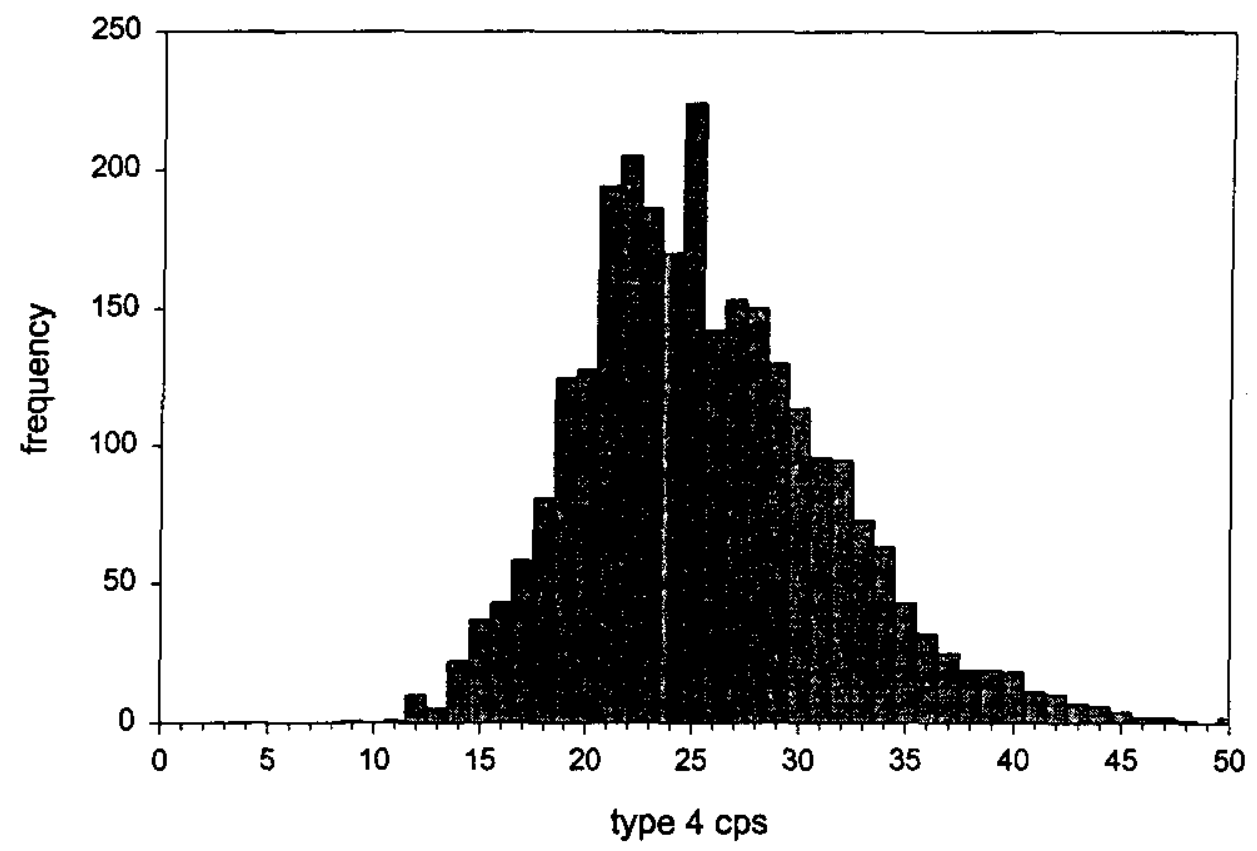

Fig. 2. Histogram of 1994 gamma-logging values less than $50 \mathrm{cps}$ recorded with the type 4 detector in the SX-108, SX-109 six-tank neighborhood.

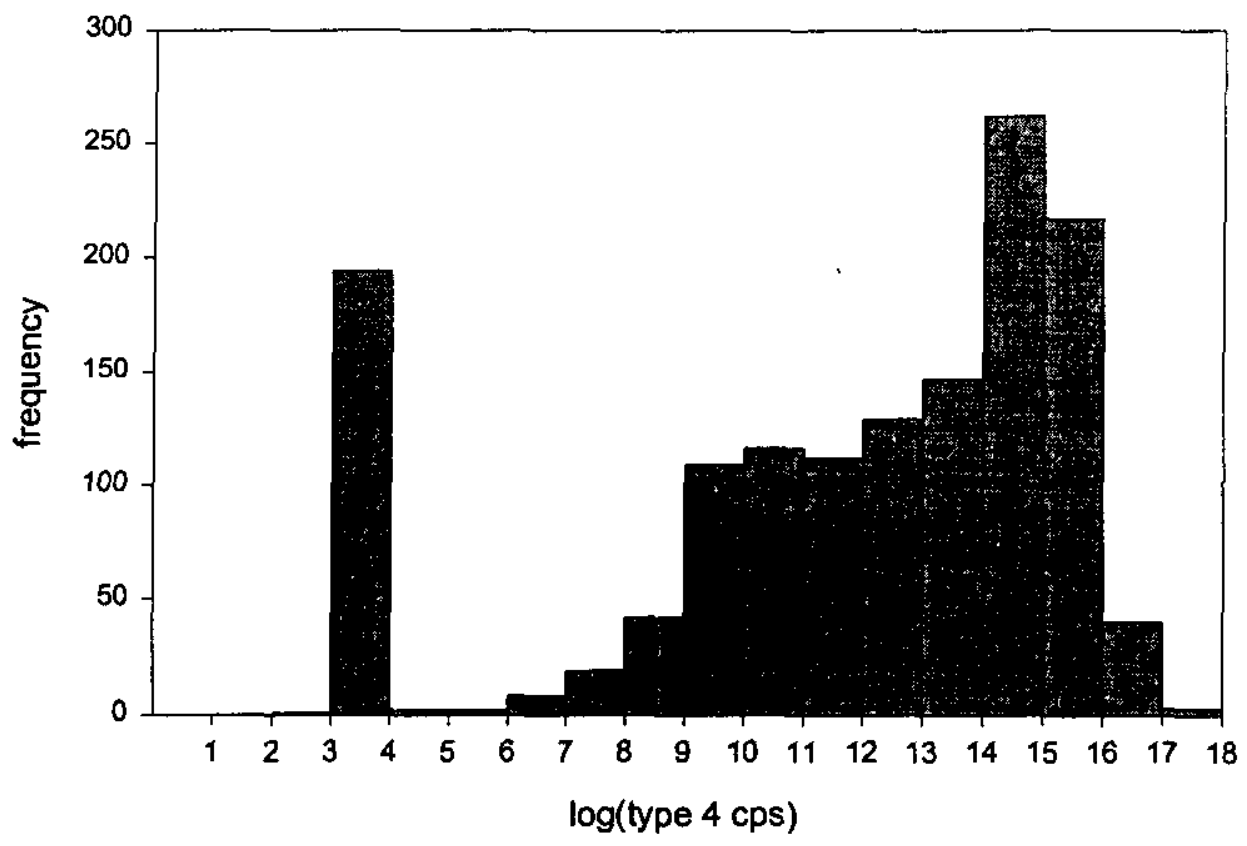

Fig. 3. Histogram of type 2 gamma logging converted to type 4 cps. 
HNF-5782 Rev. 0

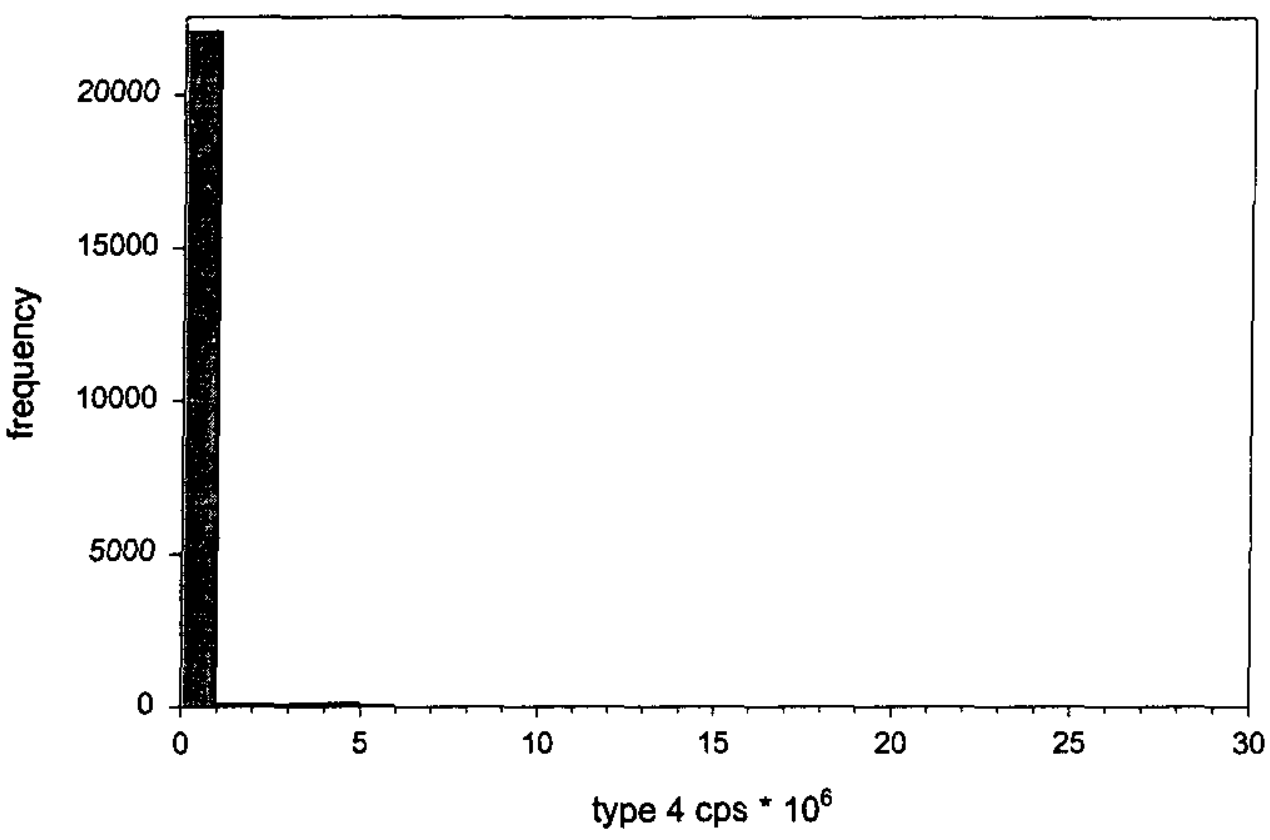

Fig. 4. Histogram of all gross gamma counts in type 4 units.

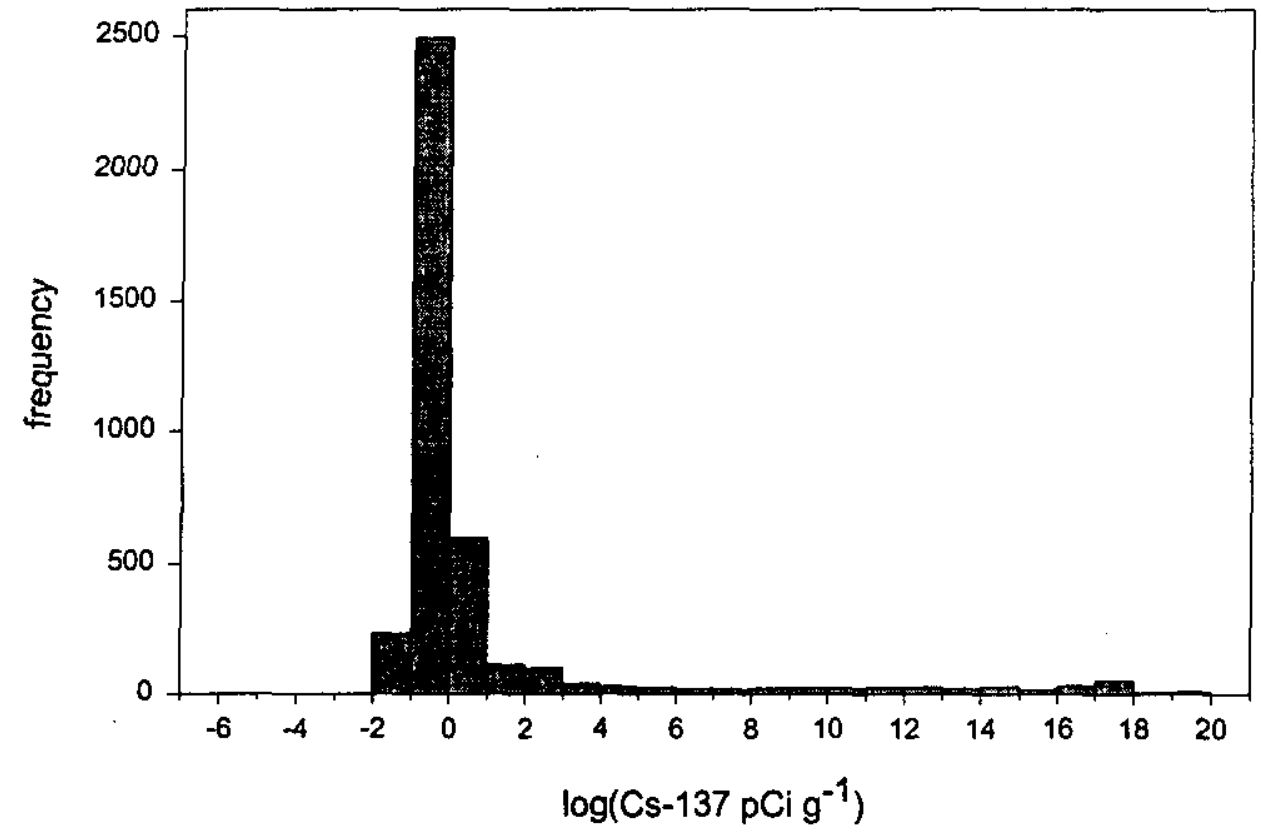

Fig. 5. Histogram of $\log \left(\mathrm{Cs}-137 \mathrm{pCi}^{-1}\right)$ in all cells. 


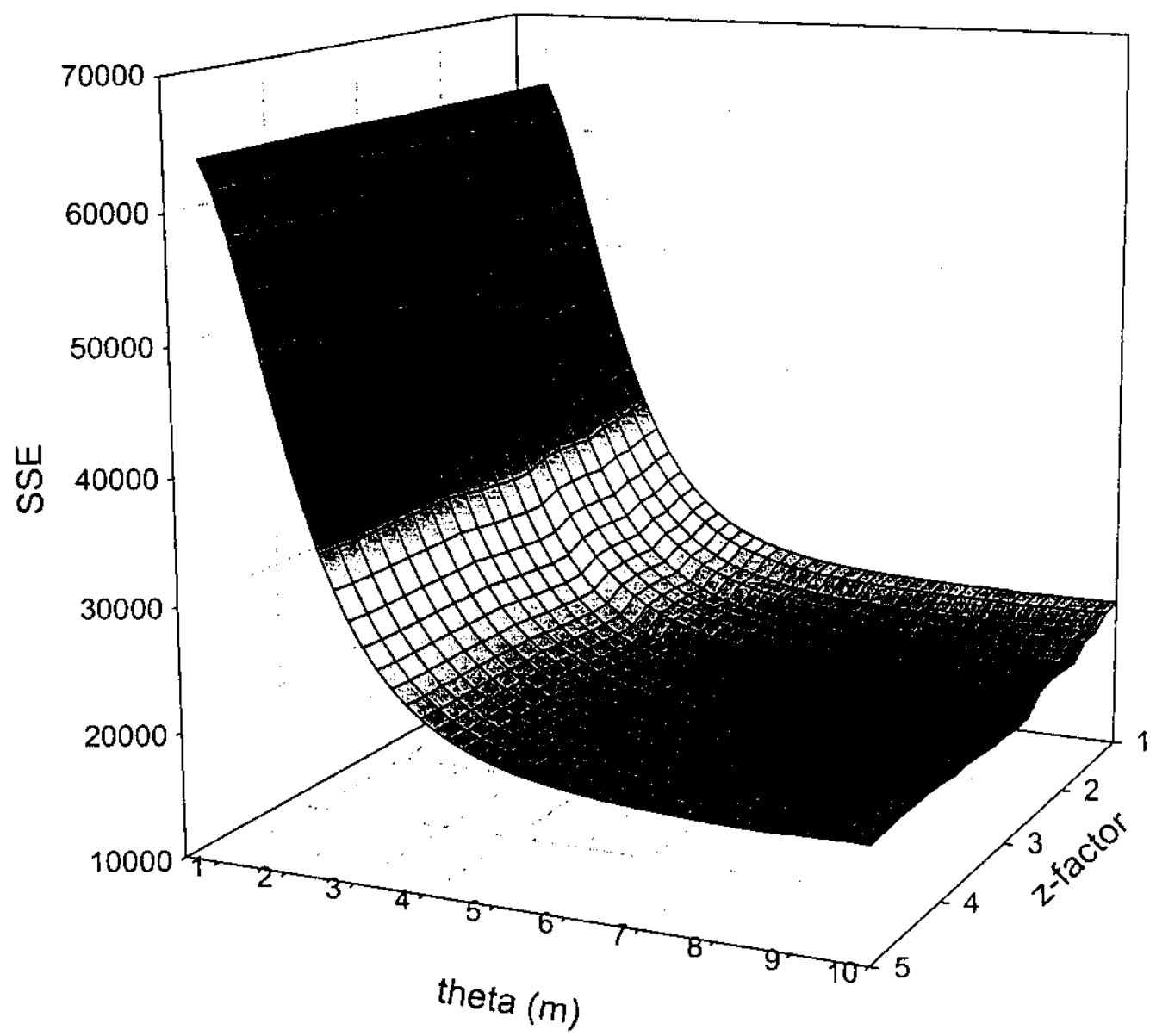

Fig. 6. Jack-knife residual surface resulting from jack-knifing the log-transformed and binned composite Cs-137 data set (SSE minimum at theta $=8.2 \mathrm{~m}, \mathrm{z}=2.7$ ). 


\section{MATHEMATICAL REPRESENTATION}

\subsection{Notation}

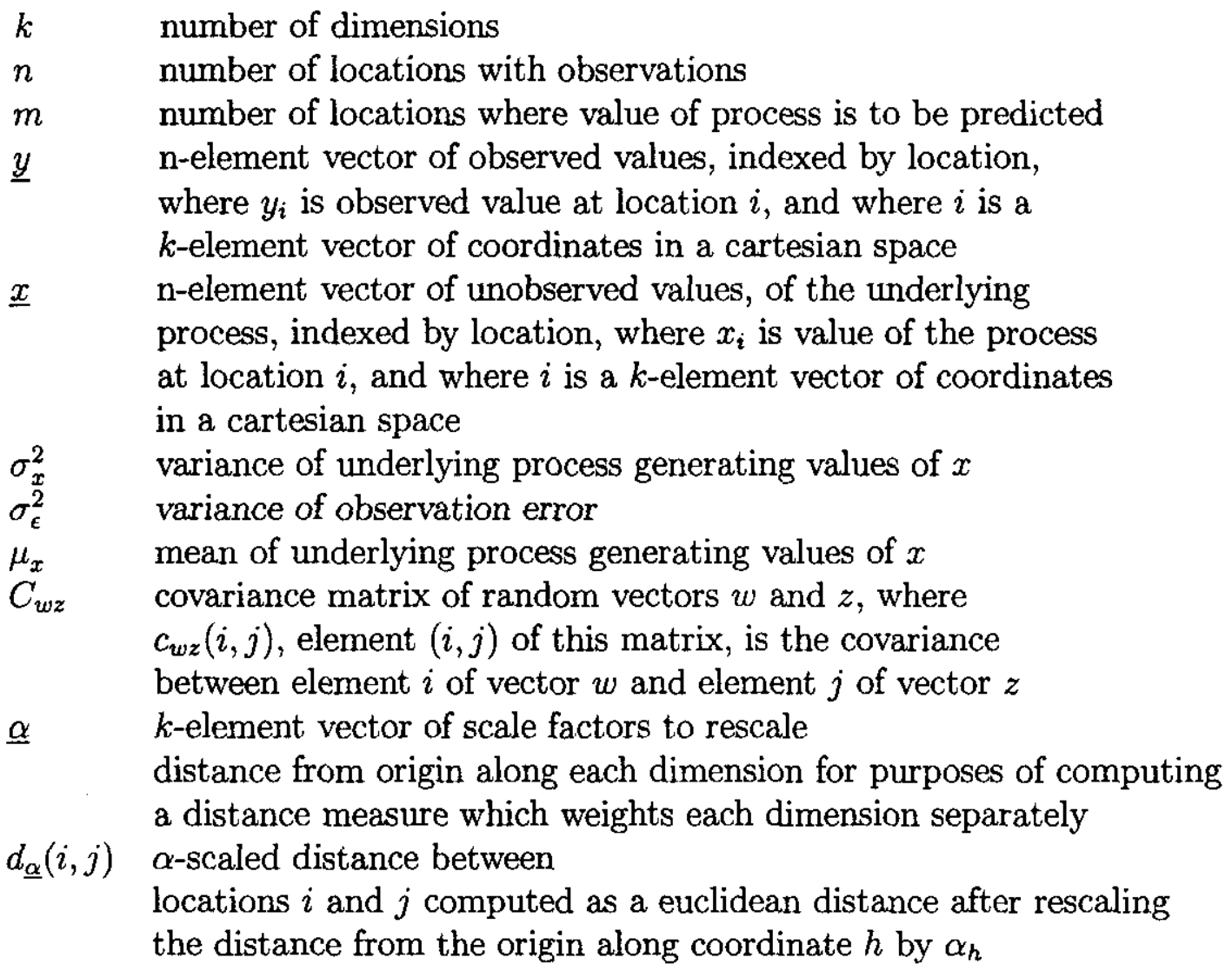

\subsection{Model of the Underlying Process}

$$
\begin{aligned}
& \underline{x} \sim N\left(\underline{\mu_{x}}, C_{x x}\right) \\
& x_{i} \sim N\left(\mu_{x}, \sigma_{x}^{2}\right)
\end{aligned}
$$

2.3. Spatial Structure of the Underlying Process

$$
\begin{gathered}
c_{x x}(i, j)=f\left(d_{\underline{\alpha}}(i, j)\right) \\
f\left(d_{\underline{\alpha}}(i, j)\right)=\sigma_{x}^{2} e^{-d_{\underline{\alpha}}(i, j)}
\end{gathered}
$$




$$
\begin{gathered}
c_{x x}(i, i)=\sigma_{x}^{2} \\
d_{\underline{\alpha}}(i, j)=\left(\sum_{h=1}^{n}\left(\frac{i_{h}}{\alpha_{h}}\right)^{2}\right)^{\frac{1}{2}}
\end{gathered}
$$

2.4. Relating Observations to the Underlying Process

$$
\begin{gathered}
y_{i}=x_{i}+\epsilon_{i} \\
\epsilon_{i} \sim N\left(0, \sigma_{\epsilon}^{2}\right)
\end{gathered}
$$

2.5. Spatial Structure of the Observations

$$
\begin{aligned}
& c_{y y}(i, j)=c_{x x}(i, j) \\
& c_{y y}(i, i)=\sigma_{x}^{2}+\sigma_{\epsilon}^{2}
\end{aligned}
$$

2.6. Joint Spatial Structure of Observations and the Underlying Process

$$
\begin{gathered}
c_{x y}(i, j)=c_{x x}(i, j) \\
c_{x y}(i, i)=\sigma_{x}^{2}
\end{gathered}
$$

2.7. Joint Distribution of Observations and the Underlying Process

$$
\begin{gathered}
\underline{v}=\left(\begin{array}{c}
\underline{y} \\
\underline{x}
\end{array}\right) \\
C_{v v}=\left(\begin{array}{ll}
C_{y y} & C_{y x} \\
C_{x y} & C_{x x}
\end{array}\right)
\end{gathered}
$$


2.8. Conditional Distribution of the Process, Given the Observations

$$
\begin{gathered}
(\underline{x} \mid \underline{y}) \sim N\left(\underline{\mu}_{(\underline{x} \mid \underline{y})}, C_{(\underline{x} \mid \underline{y})(\underline{x} \mid \underline{y})}\right) \\
\underline{\mu_{(\underline{x} \mid \underline{y})}}=\underline{\mu_{x}}+C_{x y} C_{y y}^{-1}\left(\underline{y}-\underline{\mu_{x}}\right) \\
\left.C_{(\underline{x} \mid \underline{y})(\underline{x} \mid \underline{y})}\right)=C_{x x}-C_{x y} C_{y y}^{-1} C_{y x}
\end{gathered}
$$

2.9. Point Estimate of the Process at a Location

$$
\widehat{x}_{i}=\mu_{x}+C_{x_{i} \underline{y}} C_{\underline{y y}}^{-1}\left(\underline{y}-\underline{\mu_{x}}\right)
$$

2.10. Prediction Error Variance of Point Estimate at a Location

$$
\begin{aligned}
\sigma_{\widetilde{x}_{i}}^{2} & =E\left(\widehat{x}_{i}-x_{i}\right)^{2} \\
& =\sigma_{x}^{2}-C_{x_{i} \underline{y}} C_{\underline{y} \underline{y}}^{-1} C_{\underline{y} x_{i}}
\end{aligned}
$$

2.11. Jack-knife Residual Variance at a Location

$$
E\left(\widehat{x}_{i}-y_{i}\right)^{2}=E\left(\widehat{x}_{i}-x_{i}\right)^{2}+\sigma_{\epsilon}^{2}
$$

2.12. Point Estimate of Inventory over $m$ Locations

$$
E\left(\sum_{i=1}^{m} x_{i}\right)=\sum_{i=1}^{m} \widehat{x}_{i}
$$

2.13. Prediction Error Variance of Inventory over $m$ Locations

$$
E\left(\sum_{i=1}^{m} \widehat{x}_{i}-\sum_{i=1}^{m} x_{i}\right)^{2}=\sum_{i=1}^{m} \sum_{j=1}^{m} c_{(\underline{x} \mid \underline{y})(\underline{x} \mid \underline{y})_{i j}}
$$

2.14. Likelihood Function

$$
\ln \left(L\left(\mu_{x}, \sigma_{x}, \underline{\alpha}\right)\right)=-\frac{n}{2} \ln (2 \pi)-\frac{1}{2} \ln \left(\left|C_{x x}\right|\right)-\frac{1}{2}\left(\underline{x}-\underline{\mu_{x}}\right)^{T} C_{x x}^{-1}\left(\underline{x}-\underline{\mu_{x}}\right)
$$




\subsection{Computational Demands and Computational Strategy}

For a data set with observations at $n$ locations, the kriging equation requires inversion of an $n \times n$ matrix, and this exacts a computational cost proportional to $n^{3}$. The inversion, however, only needs to be done once for obtaining the full set of $m$ point predictions for a given data set, once the process variance and spatial correlation parameter values are set.

A point estimate of the (predicted) process value at a given location requires, at each new location to be interpolated, an application of the $n \times n$ inverse matrix in multiplication to an $n$-element vector to obtain the vector of kriging weights, $w_{i}$, for the data relative to that location, and then a dot product of two $n$-element vectors to apply those weights to the data in order to obtain the prediction. The vector of kriging weights,

$$
\underline{w_{i}}=C_{x_{i} \underline{y}} C_{\underline{y y}}^{-1} \quad,
$$

again appears as an intermediate product in later calculations of prediction error variance, so an efficient computational scheme will use each set of kriging weights for all needed purposes, when first computed, rather than recompute them.

If we consider the basic computational unit in these various matrix operations to be the combination of a floating point multiplication and a floating point addition, then we see that the point estimate for each location to be predicted requires $n^{2}+n$ such units of floating point operation, plus two more floating point additions to remove and then restore the process mean. So, overall, a simple kriging prediction, without error analysis, for a field of $m$ points to be predicted, exacts a computational cost of $m \times n^{2}+m \times n$ basic units of floating operation, plus $2 \times m$ more floating point additions. In other words, the computational cost is approximately proportional to $m \times n^{2}$.

Embedding the kriging prediction in a jack-knife cross-validation for parameter estimation, further multiplies the computational cost by the number of combinations of parameter values explored, and multiplies the cost of the inversion of $n \times n$ matrix, since a new such matrix must be inverted for each new combination of parameters defining the process mean and the spatial correlation.

Embedding the kriging prediction in an inventory calculation does not involve appreciable additional expense for the point estimate of the inventory, since that is simply a sum of the point estimates for each cell in the volume.

A calculation of the prediction error variance for the point estimate of the (predicted) process value at a given location requires, at each new location to 
be interpolated, an application of the $n \times n$ inverse matrix in multiplication to an $n$-element vector to obtain the kriging weights for the data relative to that location, and then a dot product of two $n$-element vectors in order to obtain a quantity rather like a regression " $r$ squared," which finally is subtracted from the process variance to obtain the prediction error variance. Thus the prediction error variance at each location to be predicted requires $n^{2}+n$ basic units of floating point operation, plus one more floating point addition. Efficient programming can reduce the additional cost of the prediction error calculation over the cost of the prediction of the process at a given location, since the first $n^{2}$ operations duplicate the calculation of the kriging weights from the calculation of the point estimate of the process at that location.

A calculation of the prediction error variance for an inventory is much more expensive than the sum of the prediction errors for the cells in the volume. A substantial portion of the prediction error for a volume is owing to the correlation in prediction error across cells. Therefore the prediction error covariance matrix for all the cells in the volume must be computed. For a volume large enough that the number of cells it comprises is large, this becomes a significant cost. The prediction error covariance matrix, for a volume of $m$ cells, requires application of an $m \times n$ matrix in multiplication to the $n \times n$ inverse matrix, and the resulting $m \times n$ matrix is applied in multiplication to an $n \times n$ matrix to obtain an $m \times m$ matrix. This consumes $m^{3}+n^{2}+m$ basic units of floating point operation. The final substraction to obtain the $m \times m$ covariance matrix of the prediction error for all the cells in the volume adds $\mathrm{m}^{2}$ more floating point additions, and summing the elements of the prediction error covariance matrix to obtain the variance for the inventory adds another $m^{2}$ floating point additions. In other words, if the number of cells substantially exceeds the number of data locations, the cost of computing the prediction error for the inventory is approximately proportional to $m^{3}$.

A considerable computation savings can be achieved in computing the prediction error for the inventory by recognizing that the first intermediate matrix multiplication $C_{\underline{x y}} C_{\underline{x} y}^{-1}$ creates an $m \times m$ matrix, each row of which is simply the $m$-element vector of kriging weights for the prediction location corresponding to that index. Thus, all the elements of this $m \times n$ matrix, that exacts a computational cost of $m \times n^{2}$ units of floating point operation, will have already been calculated during the course of calculating the point estimates of the predicted value for each cell in the inventory volume (and the dot product of each kriging weight vector with the columns of $C_{\underline{y} \underline{\underline{x}}}$ can be cumulated on the fly). 
Conditional simulation of a field of $m$ points, conditioned on a data set of $n$ points, requires the initial cost of computing a point estimate for each location in the field and a prediction error covariance matrix for all the locations in the field (essentially equivalent to the cost of the point estimate and prediction error variance for an inventory of that field), followed by inversion of the $m \times m$ covariance matrix for the prediction error for all the locations in the field. Then, each realization of the field requires generation of $m$ normal variates and application of an $m \times m$ composition matrix in multiplication to the $m$-element vector. Generally, several thousand realizations will be required for satisfactory characterization of the distribution of a decision quantity. If $\ell$ is the number of realizations, conditional simulation exacts a computational cost proportional to $\ell \times m^{2}$ plus the initial cost proportional approximately to $\mathrm{m}^{3}$ and the inversion of an $m \times m$ matrix.

Two bottlenecks, therefore, can limit the feasibility of the application. One is the size of the matrices that must be inverted; the second is the brute number of basic floating point unit operations. The Cholesky decomposition offers efficiency and stability for the inversion of these positive-definite real symmetric matrices (Ripley, 1981; Ng \& Peyton, 1993). The brute number of multiplications can be controlled by a strategy of limiting the number of prediction points $m$ to the minimum needed to really answer the question (rather than just densely filling the field to get an attractive "picture"), and limiting the number of predictor points used for each prediction to a neighborhood of a small multiple of the $e$-folding distance around the location to be predicted (since more distant data will have little influence).

For the prediction error variance of an inventory, the brute number of floating point calculations can be excessive. If the volume is defined by a 3-d grid of 10 cells to a side, $m=10^{3}$ so the computational cost of the inventory is $m^{3}=10^{9}$ floating point unit operations. For a volume defined by a 3 -d grid of 20 cells to a side, the computational cost escalates to $512 \times 10^{9}$ floating point unit operations. On a current (1999) PC, a million floating point unit operations take from about 0.1 to 0.5 seconds. Therefore the prediction error variance for an inventory for the 3-d grid of 10 cells to a side will take a matter of minutes, but the 3-d grid of 20 cells to a side will take a matter of days. A good workstation is about 20 times faster than a PC, reducing the time to a matter of hours for calculating the prediction error variance of the inventory for a $3-\mathrm{d}$ grid of 20 cells to a side. Calculation of the prediction error variance of the inventory for a 3-d grid of much more than 20 cells to a side, in a reasonable amount of time, will require a class 
of computer substantially faster than a workstation.

\section{ILLUSTRATION FOR A SINGLE DATA LOCATION}

\subsection{Decay of Data Influence with Distance}

Consider a data set with data at a single location $i$. Then the point prediction for location $j$ at rescaled distance $d_{i j}$ is, following equation [8],

$$
\begin{aligned}
\widehat{x_{j}} & =\mu_{x}+\left(\sigma_{x}^{2} e^{-d_{i j}}\right)\left(\sigma_{x}^{2}+\sigma_{\epsilon}^{2}\right)^{-1}\left(y_{i}-\mu_{x}\right) \\
& =y_{i} \frac{\sigma_{x}^{2} e^{-d_{i j}}}{\sigma_{x}^{2}+\sigma_{\epsilon}^{2}}+\mu_{x}\left(1-\frac{\sigma_{x}^{2} e^{-d_{i j}}}{\sigma_{x}^{2}+\sigma_{\epsilon}^{2}}\right)
\end{aligned}
$$

which shows how the prediction is a weighted average of the process mean and the data value, where the weighting of the data value declines with separation distance and observation error. The weight of the data value goes to zero at large separation distance, and the maximum weight for the data value, $\frac{\sigma_{x}^{2}}{\sigma_{x}^{2}+\sigma_{\epsilon}^{2}}$, is achieved at zero separation distance.

If the observation error variance is zero, the point prediction simplifies to

$$
\widehat{x_{j}}=y_{i} e^{-d_{i j}}+\mu_{x}\left(1-e^{-d_{i j}}\right) \quad .
$$

With zero observation error variance, the weighting for the data value will be $1 / 2$, for example, at a separation distance of

$$
\begin{aligned}
d_{i j} & =-\ln \frac{1}{2} \\
& =0.6931
\end{aligned}
$$

The prediction error variance for the point prediction at location $j$ is, following equation [19],

$$
\begin{aligned}
\sigma_{\widehat{x_{j}}}^{2} & =\sigma_{x}^{2}-\left(\sigma_{x}^{2} e^{-d_{i j}}\right)\left(\sigma_{x}^{2}+\sigma_{\epsilon}^{2}\right)^{-1}\left(\sigma_{x}^{2} e^{-d_{i j}}\right) \\
& =\sigma_{x}^{2}\left(1-\frac{\sigma_{x}^{2} e^{-2 d_{i j}}}{\sigma_{x}^{2}+\sigma_{\epsilon}^{2}}\right)
\end{aligned}
$$


which shows how the prediction error variance increases with process variance, error variance, and separation distance, from a minimum of $\frac{\sigma_{x}^{2} \sigma_{c}^{2}}{\sigma_{x}^{2}+\sigma_{\epsilon}^{2}}$ at zero separation distance, to a maximum approaching the process variance at large separation distance.

If the observation error variance is zero, the prediction error variance simplifies to

$$
\sigma_{\widehat{x}_{j}}^{2}=\sigma_{x}^{2}\left(1-e^{-2 d_{i j}}\right)
$$

With zero observation error variance the prediction error variance will be half the process variance, for example, at a separation distance of

$$
\begin{aligned}
d_{i j} & =-\frac{1}{2} \ln \frac{1}{2} \\
& =0.3466
\end{aligned}
$$

\section{BACK-TRANSFORMING FROM THE LOG SPACE FOR INVENTORY CALCULATIONS}

In our kriging of the Cs-137 data from SX farm, we used log values (logarithm of $\mathrm{pCi} / \mathrm{g}$ ) to characterize the contamination at each location, because we found that the histogram of log values more nearly conformed to the assumption of a normal (Gaussian) process than did the values in original units (counts or $\mathrm{pCi} / \mathrm{g}$ ).

This commits us to assuming that the assumptions of the kriging model apply to this space for these data. I.e., we must assume that the set of values made up of logs of the $\mathrm{pCi} / \mathrm{g}$ values are a realization of a second order stationary Gaussian process characterized by a constant process mean and a constant process variance and a covariance structure determined entirely by separation distance, all in the log space.

Therefore the predicted values at each location, emerging from the kriging calculation are also in logarithms of $\mathrm{pCi} / \mathrm{g}$. Since there is a substantial prediction error associated with each such point prediction, the back-transformation to express the results in $\mathrm{pCi} / \mathrm{g}$ should treat this as back-transformation of a distribution rather than simple back-transformation of a value.

We chose to assume, as per the assumptions of the kriging model, that the distribution of the prediction error in the space of the kriging operation (which in this case was the log space) is normal, so that the point prediction and the 
prediction error variance actually reflect properties of the respective lognormal distribution of values in the space of $\mathrm{pCi} / \mathrm{g}$. Therefore, we take $\widehat{x}_{i}$ the point prediction delivered by the kriging operation for the process value at a given location to be the mean of the normal distribution of values obtained by log transforming the contamination value as measured in $\mathrm{pCi} / \mathrm{g}$, and we take $\sigma_{\hat{x}_{i}}^{2}$, the prediction error variance for that point prediction, to be the variance of the normal distribution of values obtained by log transforming the contamination value as measured in $\mathrm{pCi} / \mathrm{g}$. Then

Let $\widehat{x_{i}^{*}}$ designate the mean of the lognormal distribution of the values in $\mathrm{pCi} / \mathrm{g}$.

$$
\widehat{x_{i}^{*}}=e^{\widehat{x}_{i}+\sigma_{x_{i}}^{2} / 2}
$$

and we use this as the point prediction, at this location, in units of $\mathrm{pCi} / \mathrm{g}$.

Under the same assumptions, the prediction error variance for the value at a given location, in $\mathrm{pCi} / \mathrm{g}$, is expressed as the variance of the lognormal distribution of the values in $\mathrm{pCi} / \mathrm{g}$. Let $\sigma_{\widetilde{x}_{i}^{*}}^{2}$ designate variance of the lognormal distribution of the values in $\mathrm{pCi} / \mathrm{g}$. Then

$$
\sigma_{\widehat{x_{i}^{*}}}^{2}=e^{2 \widehat{x_{i}}} e^{\sigma_{\widetilde{x}_{i}}^{2}}\left(e^{\sigma_{\widetilde{x}_{i}}^{2}}-1\right)
$$

We note, of course, that this prediction error, in the space of $\mathrm{pCi} / \mathrm{g}$, now is assumed to be a non-standard lognormal distribution, so we would not compute a $95 \%$ confidence interval simply as the point estimate plus or minus twice the square root of the variance.

The inventory, in $\mathrm{pCi} / \mathrm{g}$, is a sum of point predictions in $\mathrm{pCi} / \mathrm{g}$. The point estimate for the inventory, in $\mathrm{pCi} / \mathrm{g}$, therefore is computed as the sum of the back-transformed point estimates for each cell in the inventory volume.

The prediction error variance for an inventory in $\mathrm{pCi} / \mathrm{g}$ is more complicated, and not approximated as satisfactorily. We ignore the effect of the transformation on the correlations between prediction error at different locations, assuming that the correlation is the same in the two spaces, and merely correct for the effect of transformation of the respective variances that normalize the covariance to a correlation. Letting $c_{i j}^{*}$ designate our approximation to the prediction error covariance in the space of the $\mathrm{pCi} / \mathrm{g}$ values, we thus replace each element $c_{i j}$ of the prediction error covariance matrix delivered by the standard calculation (carried out in the log space using equation [17]) according to 


$$
\begin{aligned}
c_{i j}^{*} & =c_{i j} \sqrt{\frac{c_{i i}^{*} c^{*} j j}{c_{i i} c_{j j}}} \\
& =c_{i j} \sqrt{\frac{\sigma_{\widehat{x}_{i}^{*}}^{2} \sigma_{\widehat{x_{j}^{*}}}^{2}}{\sigma_{\widehat{x}_{i}}^{2} \sigma_{\widehat{x}_{j}}^{2}}} .
\end{aligned}
$$

Then the prediction error variance for the inventory, in $\mathrm{pCi} / \mathrm{g}$, is computed as the sum of these approximate back-transformed elements of the prediction error covariance matrix. In this space, the prediction error variance of the inventory, will not be exactly normal, though it will be more normal than a lognormal, since it is a sum of many lognormals that are only partially correlated, and so some of the behavior underlying the central limit theorem will apply.

The approach, outlined in this section, of back-transforming the inventory calculation from logarithms to $\mathrm{pCi} / \mathrm{g}$ by trying to reconstruct the mean and variance of a lognormal distribution from the mean and variance of the normal distribution of the log values, uses formulas which assume that the distribution really is lognormal. We of course have no assurance that this is exactly true.

\section{EFFECTS OF THE BACK-TRANSFORMATION: ILLUSTRATION WITH ONE DATA LOCATION}

\subsection{Increase of Lognormal Mean of the Predictive Distribution with Distance}

If the process is assumed normal in the log space, then the normal prediction error in this space is actually a log-normal distribution in the space of the untransformed units. Then the point prediction in the space of the untransformed units should be computed as the expectation (mean) of the lognormal predictive distribution, according to equation [31]. In the worst case of separation distance so large that the prediction in the log space takes the limiting value of the process mean with the prediction error variance taking the limiting value of the process variance, then the point prediction in the space of the untransformed units is $e^{\mu_{x}+\sigma_{x}^{2}}$.

In the present application where $\mu$ was chosen to represent "background" in $\log$ units, $e^{\mu}$ recapitulates "background" in the original units, and so the backtransformation gives a point prediction that is $e^{\sigma_{x}^{2}}$ times "background." Is this reasonable? The answer depends upon what we mean by "background." 
If by "background" we mean the values within the area of the SX farm that could plausibly be contaminated, but where we don't have data, then a point prediction which responds to the possibility of contamination is not unreasonable. In the present application, where the process mean in the log space is -0.111 (corresponding to a "background" value of $0.89 \mathrm{pCi} / \mathrm{g}$ ) and the untruncated process variance in the log space is 15.5 , then the back-transformation for a point prediction at a location far from any data gives a mean for the log-normal of 2,322 $\mathrm{pCi} / \mathrm{g}$, which is 2,078 times the measured background. This is not unreasonable when the upper $95 \%$ tail on the process distribution in the log space is 7.76 , corresponding to $2,352 \mathrm{pCi} / \mathrm{g}$, and the largest measured values for contamination are in excess of $100 \times 10^{6} \mathrm{pCi} / \mathrm{g}$.

If, on the other hand, we mean by "background" the ground state at locations that are not contaminated, then of course the back-transformation will be viewed as creating a bias that raises this "background." The trouble, though, is justifying, in the absence of nearby measurements, that a given location really is in such an area of low contamination.

For a gauge of how close to a data location the prediction location must be in order for the back-transformation to raise the point prediction by an appreciably smaller multiple than the worst case, consider the illustration of a prediction at location $i$ from a single data location $j$. If the separation distance is 0.3466 , then in the log space the prediction error variance is half the process variance in the log space, so the multiple applied in the back-transformation is $e^{\sigma_{x}^{2} / 4}$, i.e., the square root of the multiple for the worst case. For the untruncated process variance in the present application, the multiple over this short distance is 48 .

\section{EFFECTS OF THE ASSUMPTIONS ON THE INVENTORY ESTIMATES}

\subsection{Point Estimate of the Inventory}

We see from equation [21] that the point estimate of the inventory is simply the sum of the point estimates of the cells in the selected volume. The kriging point estimate is a robust quantity, relatively insensitive to departures from assumptions of the model. For example, a process with local differences in the process mean (this is called a "trend" in the geostatistical literature) will still be fit reasonably well by the point predictions, if there is reasonable data density, since the point predictions track the data, and the data will track the local dif- 
ferences in the process mean. Also, our procedure for determining the $e$-folding distance parameters by jack-knife cross-validation automatically compensates to some degree for possible mistakes in specifying the other parameters, since it adjusts the $e$-folding distance in context for best fit to the data. And finally, when measurement error variance is small relative to the process variance, neither has appreciable influence on the point predictions. Thus we have strong reasons for expecting the point estimates of the inventory to behave reasonably, and to give good, and stable, values.

In the actual event, the inventory estimates for SX-Farm lived up to this expectation. Two features of the inventory estimates may strike some readers as anomalous, but even in these two respects we believe the estimates are correct within the limitations of the data. One apparent anomaly is the low inventory estimate for the plume under SX-115, relative either to the calculated leak loss inventory from the tank, or the vadose zone inventory estimate calculated by Raymond and Shdo (1966). The Raymond and Shdo estimate was calculated from much the same data that we used, but with a very different procedure for converting the gamma count data from the laterals to $\mathrm{pCi} / \mathrm{g}$ : they simply equated the highest counts in laterals to the highest $\mathrm{pCi} / \mathrm{g}$ measurements from their soil core samples around the perimeter of the tanks, some distance away from the hottest portions of the laterals. The Raymond and Shdo procedure is not unreasonable, but it gives a much different conversion factor than we obtained from comparing spectral gamma total count data and the spectral gamma Cs-137 values for the same location and from comparing the Cs-137 measurements reported by Raymond and Shdo for the cores around tank SX-108 and our kriged point predictions of the gamma counts in those locations based on the gamma counts measured elsewhere (Figure 7). The comparison of soil core sample measurements from drywell 09-39 with the co-located gamma logging data (Figure 8) suggests a higher conversion from counts to $\mathrm{pCi} / \mathrm{g}$, but this is still not high enough to obtain an inventory estimate for the SX-115 vadose zone that would be similar to the Raymond and Shdo estimate for that inventory. 


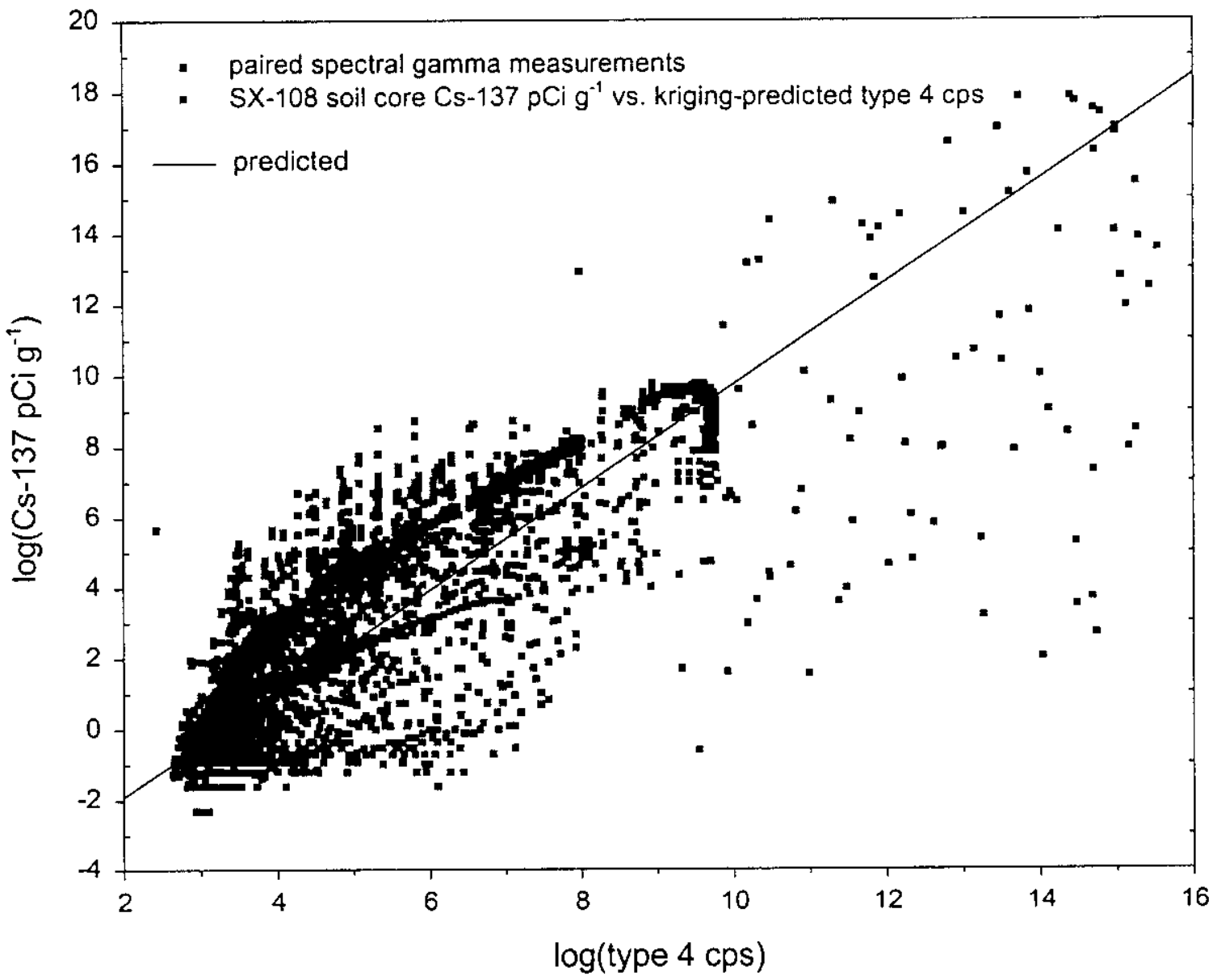

Fig. 7. Spectral gamma Cs- $137 \mathrm{pCi} \mathrm{g}^{-1}$ vs. spectral gamma total counts in type 4 units and SX-108 soil core Cs- $137 \mathrm{pCi} \mathrm{g}^{-1}$ vs. kriging-predicted type $4 \mathrm{cps}$. 


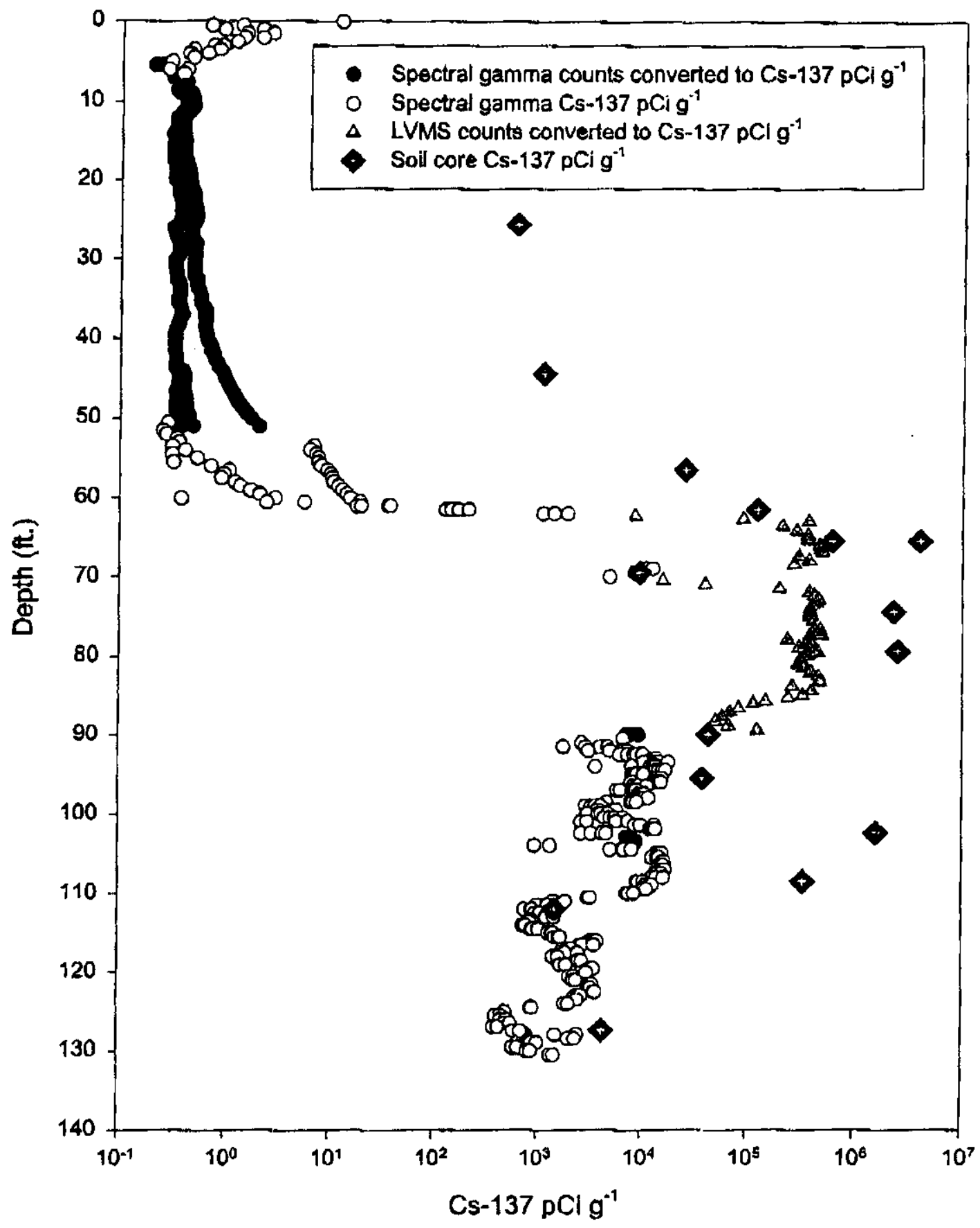

Fig. 8. Drywell 09-39 Cs-137 $\mathrm{pCi}^{-1}$ from gamma logging and soil cores. 
Incidentally, our inventory estirnate for the plume under SX-108 is in accord with the estimate that Raymond and Shdo computed for that tank. If our inventory estimate for SX-115 is not correct, this must be owing to some misinterpretation of the old gamma logging data. The gamma logging in the SX-115 laterals was done same tirne ago, and the reports available to us are sketchy. Our attempts to cross-calibrate the soil sample Cs-137 data from the SX-115 cores with kriging predictions at those same locations based on the nearby gamma logging data did not yield a plausible pattern (Figure 9).

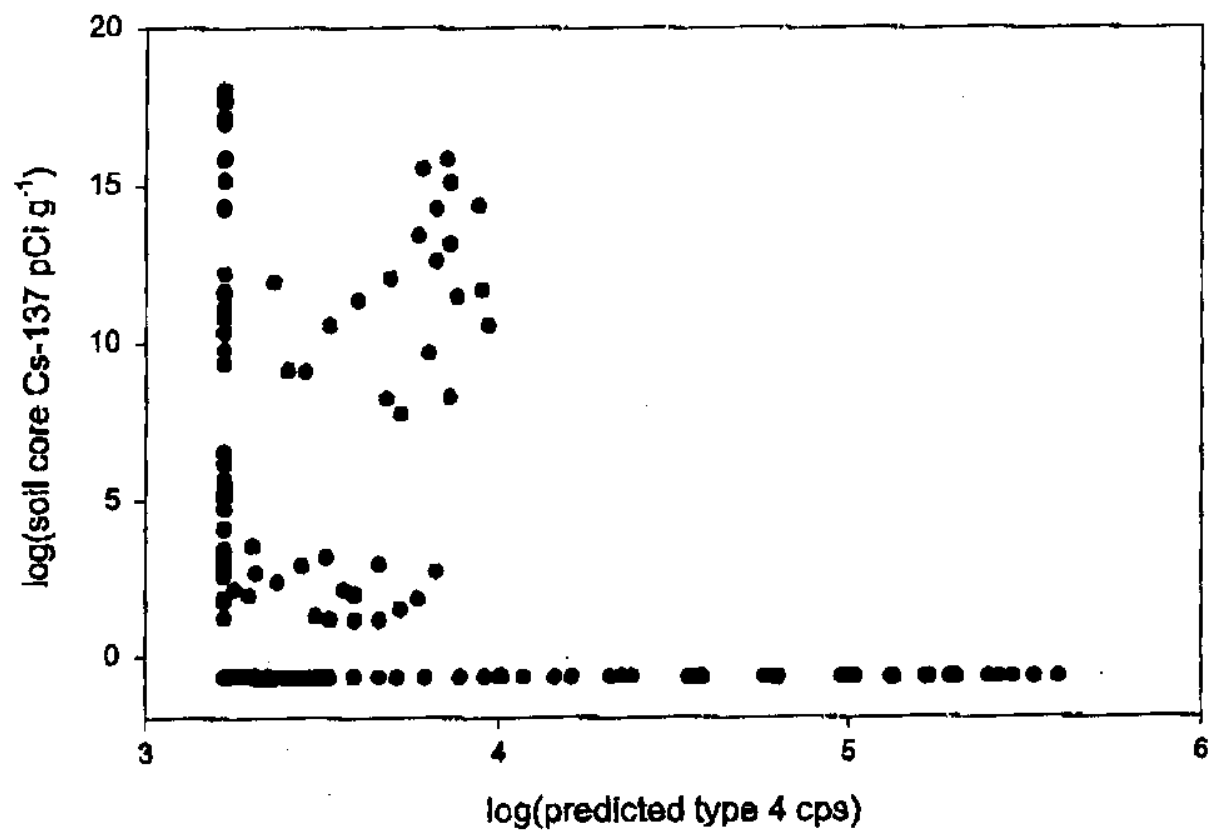

Fig. 9. SX-115 soil core $\mathrm{Cs}-137 \mathrm{pCi}^{-1}$ vs. kriging-predicted type $4 \mathrm{cps}$.

A second feature of our inventory estimates that may appear odd is the near constancy of the inventory under some tanks for different choices of threshold, except for the very hottest thresholds (above $10^{5} \mathrm{pCi} / \mathrm{g}$ ). The explanation of this pattern is very straight forward. The inventory is dominated by a very few 
cells with very high counts. The data from the hottest cells are many orders of magnitude hotter than the data from almost all the other cells. The hotspots that the kriging estimates construct around these hot data cells are a relatively small volume. So the kriging estimates, like the data themselves, involve a relatively small number of cells that are many orders of magnitude hotter than rest of the volume. As a simple arithmetic consequence, the total inventory in all the cells outside this hot volume is negligible compared to the inventory in the hot volume.

\subsection{Prediction Error Variance for the Inventory}

Unlike the point estimates of inventory, the prediction error variance estimates for the inventory are very sensitive to assumptions, and are sensicive to the values used for process variance and measurement error variance. Furthermore, the jackknife cross-validation procedure for adjusting the e-folding distance parameters to fit the point estimates to the data does not enforce any fit of the prediction error variance. For this reason, we do not consider the prediction error variances reported here to be robust, though they were calculated from operations on bycell prediction error variances that were computed with a mathematically correct formula, and returned values that are not implausible. More modeling work, of a more complicated nature than was done here, would be needed to attain a higher level of security in the prediction error variance estimates. In particular, a strongly smoothed plume dispersion and transport model should be used to "detrend" the data, to obtain a more normal distribution of residuals that could be kriged, thus allowing for variation in the spatially correlated process on either side of the local process mean, and also allowing for a considerably smaller process variance (and hence for smaller prediction error variance) since a good fraction of the variance of the data will be accounted for by the "trend." Further, we recommend for future more refined estimation of the prediction error variance of the inventories, that the prediction error variances be re-calibrated by jack-knife cross-validation of the prediction error variance itself.

One pattern in the prediction error variances we report that may seem puzzling, is, in fact, readily explained. It will be noted in the tables of results, that as one lowers the threshold concentration that defines the volume of interest, the point estimate of the inventory does not increase much once the threshold is below about $10^{5}$, though the volume included goes up appreciably, and the prediction error variance goes up dramatically. Indeed the coefficient of variation, which is the standard deviation expressed as a fraction of point estimate, increases with 
the number of cells. At first this may seem to be contrary to the elementary properties of the model for second-order stationary Gaussian process.

If an arbitrary volume is defined under this model, and we consider the process itself, unconditioned on any data, the expected inventory of that volume should be proportional to the number of cells: it is, in fact, $m \mu$, where $m$ is the number of cells in the volume, and $\mu$ is the process mean. Once the number of cells defines a volume of large enough extent (compared to the $e$-folding distance) to average out the effect of spatial correlation, the variance of the inventory for the volume will be proportional to $m \sigma^{2}$, where $\sigma^{2}$ is the process variance. Thus the standard deviation of the inventory for the volume will be $\sigma \sqrt{m}$, and so expressing the standard deviation of the inventory as a fraction of the inventory (coefficient of variation) gives $\frac{\sigma}{\mu \sqrt{m}}$, which declines as the number of cells increases, going to zero in the limit.

So why do we observe an increasing coefficient of variation with increasing volume in the tables in Appendix 3? Bear in mind that the volumes for which we compute inventories are not randomly or arbitrarily located in the field of the process. The volumes are defined as collections of cells that exceed a defined threshold, so they are invariably centered on hotspots, and as the threshold is lowered and the number of cells included increases, the new cells being added to the volume are cooler and cooler. Thus, for volumes specified in this way, the inventory does not increase in proportion to the number of cells. In choosing our model to predict low values when far from hot data, we set the process mean at "background" with is also the mode of the lowest data values. Therefore, any kriged hotspot must be centered on data, and therefore at the hotspot center the prediction error variance must be low (because of the proximity to data). As the threshold is lowered, and cooler cells are included in the volurne, a large fraction of the cells being added will be cells that are farther from data, and thus are cells with a larger prediction error variance than the point prediction for the core of the hotspot. Furthermore, if the typical spatial scale of a hotspot is similar to the e-folding distance, which is almost inevitable from the way we determined the value of that parameter, there will be considerable spatial correlation in error variation (contrary to the limiting assumption in the unconditional scenario), so the prediction error variance in the inventory will increase more than linearly with the sum of the prediction error variances of the cells (recall that the number of off-diagonal elements in the covariance matrix goes up almost with the square of the number of cells). For all these reasons, the square root of the prediction error variance of the inventory expressed as a fraction of the inventory can increase 
substantially as the number of cells in this selected volume increases: the inventory can increase much less than linearly with the number of cells, and the prediction error variance of the inventory can increase much more than linearly with the number of cells.

\section{FUTURE DIRECTIONS}

The gamma monitoring data set for SX farm is unusually rich. For the 15 tanks in this farm, we have data from 99 vertical far-perimeter drywells positioned the way most monitoring drywells are in the 200 area, plus 24 lateral drywells, plus soil sample data from one of the vertical drywells, and 15 soil cores from the tank close-perimeter (closer to the tank than the vertical drywells). For most of the vertical far-perimeter drywells, we have recent spectral gamma data.

We have gone to some effort to cross calibrate among readings from different gross gamma instruments (that differ in their sensitivity and shielding), and spectral gamma, spectral garnma C8-137, and Cs-137 measuremeats from soil core samples. With this cross calibration, and decay correction, we have merged gross gamma logging data, and soil core sample Cs-137 measurements from earlier periods, to complete the data for locations that do not have recent spectral gamma measurements (or where the spectral gamma saturated).

Most of the other tank farms do not have similar data richness. The gamma monitoring data for most farms is confined to vertical drywells. Our preliminary results have already shown that the lateral dato in SX farm make a considerable difference to the reconstructed plume and the estimate of plume inventory. Figure 10 shows a 6-tank subset of the farm, viewed from the East, with tank 108 in the center front. The lateral wells show as dark green horizontal lines under sorne of the tanks. The $e^{6} \mathrm{cps}$ (in probe type 4 units) iso-surface of the reconstruction of the plume from tanks 108 and 109 shows as the irregular shape. The reconstruction based just on the vertical drywell data appears as 4 disconnected opaque gray blobs; the transparent purple extension, that connects all the blobs into a single larger plume is the reconstruction that includes the lateral data with the vertical drywell data. 


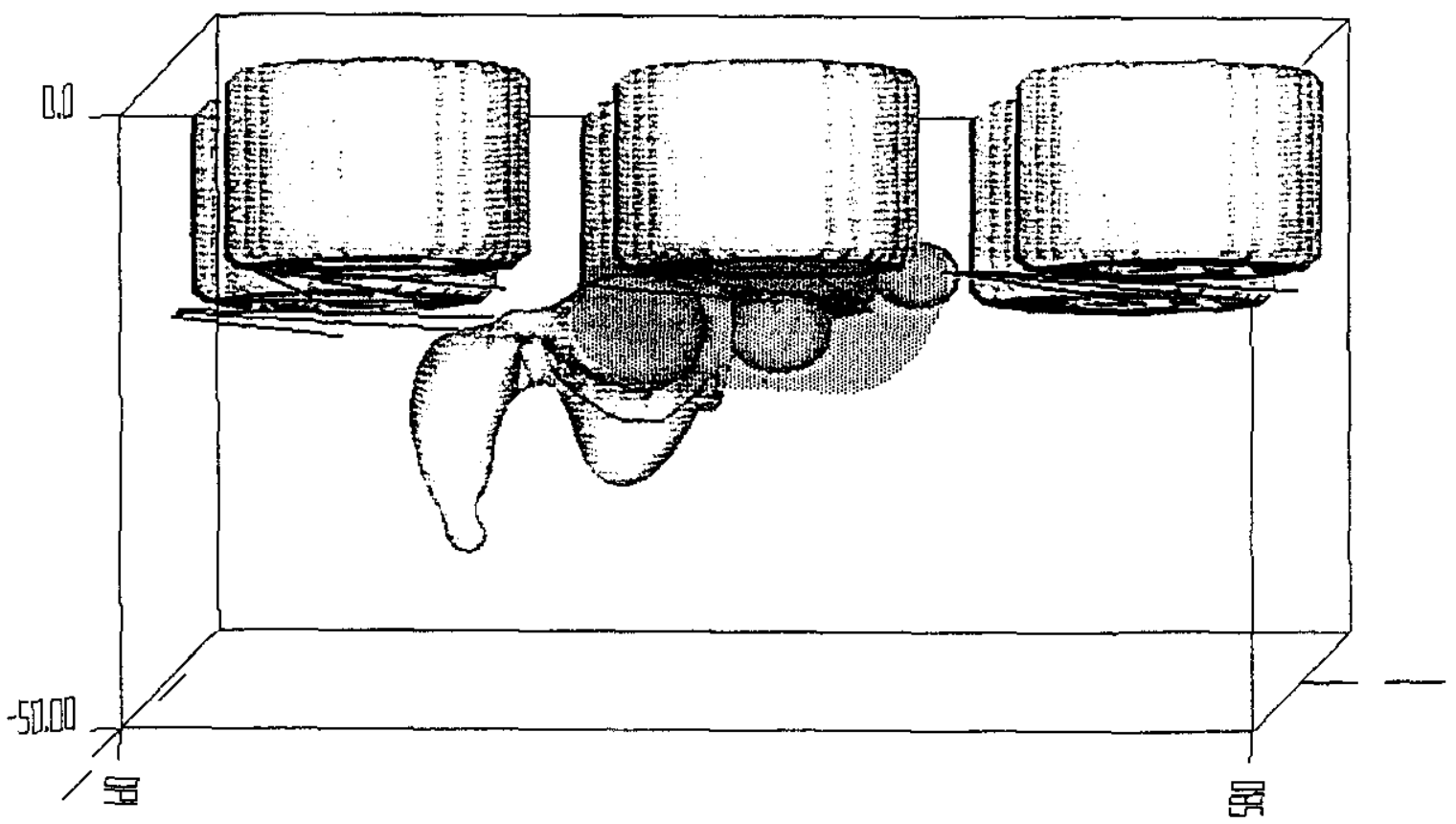

Fig 10. Six-tank subset of SX tank farm, east view.

\subsection{Calibrating Plume Estimates for Data Sets Without Laterals}

The composite Cs-137/gamma data from SX farm show definite contamination plumes under 5 of the tanks: 107, 108, 109, 112 and 115. For all 5 of these tanks, we have vertical drywell and lateral drywell data. For two of these tanks (108 and 115) we also have tank close-perimeter soil core sample data. This presents an opportunity to test the power and sensitivity of vertical drywell logging alone as a means to detect and quantify contamination plumes. In such an exercise, the geostatistical plume reconstruction from the merged data set, including laterals and perimeter soil cores, would be used as "ground truth," to investigate how accurately the plume can be reconstructed from vertical drywell data alone.

We have already noted, qualitatively, that the large plume under tanks 108 and 109 shows up clearly in the vertical drywell data (though it looks different when the lateral data are added). The smaller plumes under tanks 107 and 115 are not clearly delineated by the vertical drywell data, and need lateral and/or perimeter soil core data, closer to the actual plume, in order for the full extent of the plume to be evident. 
The point of a plume reconstruction calibration analysis would be to refine and quantify these observations, (1) to determine how large a plume inventory has to be in order for it to be detected with confidence using vertical drywell data alone, and (2) to calibrate the difference in plume inventory estimates using all the data versus vertical drywell data alone, to establish the reliability of a corrected estimate based on vertical drywell data alone.

These calibrations would be very important for interpreting the geostatistics from other tank farms which have only vertical drywell data.

\section{REFERENCES}

Cressie, N. 1991. Statistics for Spatial Data. John Wiley \& Sons, N.Y.

Goodman, D. 1999. Documentation of Geostatistical Approach for the Analysis of SX-Farm Vadose Zone Gamma Data. September 27, 1999, report to MACTEC Inc., under agreement 3751.119.376 with Montana State University.

Kitanidis, P.K. 1997. Introduction to Geostatistics. Cambridge University Press. Cambridge.

Ng, E.G., and B.W. Peyton. 1993. Block sparse Cholesky algorithms on advanced uniprocessor computers. SIAM-Journal of Scientific Computing 1034-1056.

Raymond, J.R., and E.G. Shdo. 1966. Characterization of Subsurface Contamination in the SX Tank Farm. BNWL-CC-701, Battelle-Northwest, Richland, Washington.

Ripley, B.D. 1981. Spatial Statistics. John Wiley \& Sons, N.Y.

Wiener, N. 1949. Extrapolation, Interpolation, and Smoothing of Stationary Time Series. Technology Press, MIT, and John Wiley \& Sons, N.Y. 


\section{APPENDIX 3. RESULTS OF THE SX INVENTORY CALCULATION}

Kriging point predictions in $\mathrm{Cs}-137 \mathrm{pCi} \mathrm{g}^{-1}$ were estimated at one meter spacings on a three dimensional grid filling the prediction volume (Fig. 1, Appendix 1.), where grid point $(0,0,0)$ was located at easting $566745 \mathrm{~m}$, northing $134145 \mathrm{~m}$, and a depth of $50 \mathrm{~m}$. Individual tank inventories were calculated from the kriging point predictions falling within the soil subvolume associated with each tank (Fig. 1, Appendix 1.). However, kriging predictions assigned to a soil subvolume, but actually located within a storage tank or lateral caisson, were ignored.

The Cs-137 inventory associated with each tank was broken down by soil volumes exceeding eight respective limits, $5 * 10^{1}, 5 * 10^{2}, 5 * 10^{3}, 5 * 10^{4}, 5 * 10^{5}, 5 * 10^{6}, 5 * 10^{7}$, and $5 * 10^{8}$ $\mathrm{pCi}^{-1}$. Individual tank inventories exceeding these thresholds were further broken down into 17 depth increments consisting of a $2.5 \mathrm{~m}$ layer from the surface of the prediction volume to a depth of $2.5 \mathrm{~m}$ and $16-3 \mathrm{~m}$ depth increments from $2.5 \mathrm{~m}$ to $50.5 \mathrm{~m}$. Given that the surface of the SX farm is not level, and given that the surface of the prediction volume was set at the surface elevation of the highest drywell in the SX-farm, the 0.0 to $2.5 \mathrm{~m}$ depth increment is somewhat artificial, containing a number of point predictions that are actually aboveground. However, relatively little Cs-137 contamination was predicted within this surface layer. Additionally, given that the vertical separation between the surface elevation of the highest and lowest drywells is approximately $2.2 \mathrm{~m}$, all artifactual predictions are restricted to this layer.

In calculating Cs-137 inventories, each kriging point prediction was considered to be at the center of a one cubic meter soil volume with an average Cs -137 concentration equal to the point prediction. Note that the tank subvolume boundaries in Fig. 1, Appendix 1. were located half way between neighboring vertical planes of kriging point predictions to accommodate this geometry. Given a soil bulk density of $1.8 \mathrm{~g} \mathrm{~cm}^{-3}$ at the SX tank farm (Raymond and Shdo, 1966), each point prediction in $\mathrm{pCi} \mathrm{g}^{-1}$ was converted to a total Cs-137 activity in pCi for a one cubic meter soil volume by multiplying by $1.8 * 10^{6}$. Once this conversion was made, individual Cs-137 inventories were calculated simply by summing the total activities of one cubic meter cubes. Given the conversion from $\mathrm{pCi} \mathrm{g}^{-1}$ to $\mathrm{pCi} \mathrm{m}^{-3}$ of soil, kriging prediction variances were scaled to one cubic meter soil volumes by multiplying by $\left(1.8^{*} 10^{6}\right)^{2}$.

Confidence intervals associated with individual inventories were calculated as described in Appendix 2. All inventories and their associated confidence intervals were decay corrected to January, 2000 values.

Cs-137 inventories over the entire soil volume associated with each SX storage tank are summarized in Table 1. Inventories broken down by depth increments are presented for individual tank volumes in Tables 2 through 16. Vis5D visualizations of the plumes exceeding seven activity thresholds (no kriging point predictions were greater than $5^{*} 10^{8} \mathrm{pCi} \mathrm{g}^{-1}$ ) are plotted in Figures 1 though 7. 
Table 1. SX tank farm inventory of soil volumes, total activities and upper 958 confidence limit, exceeding 8 activity thresholds.

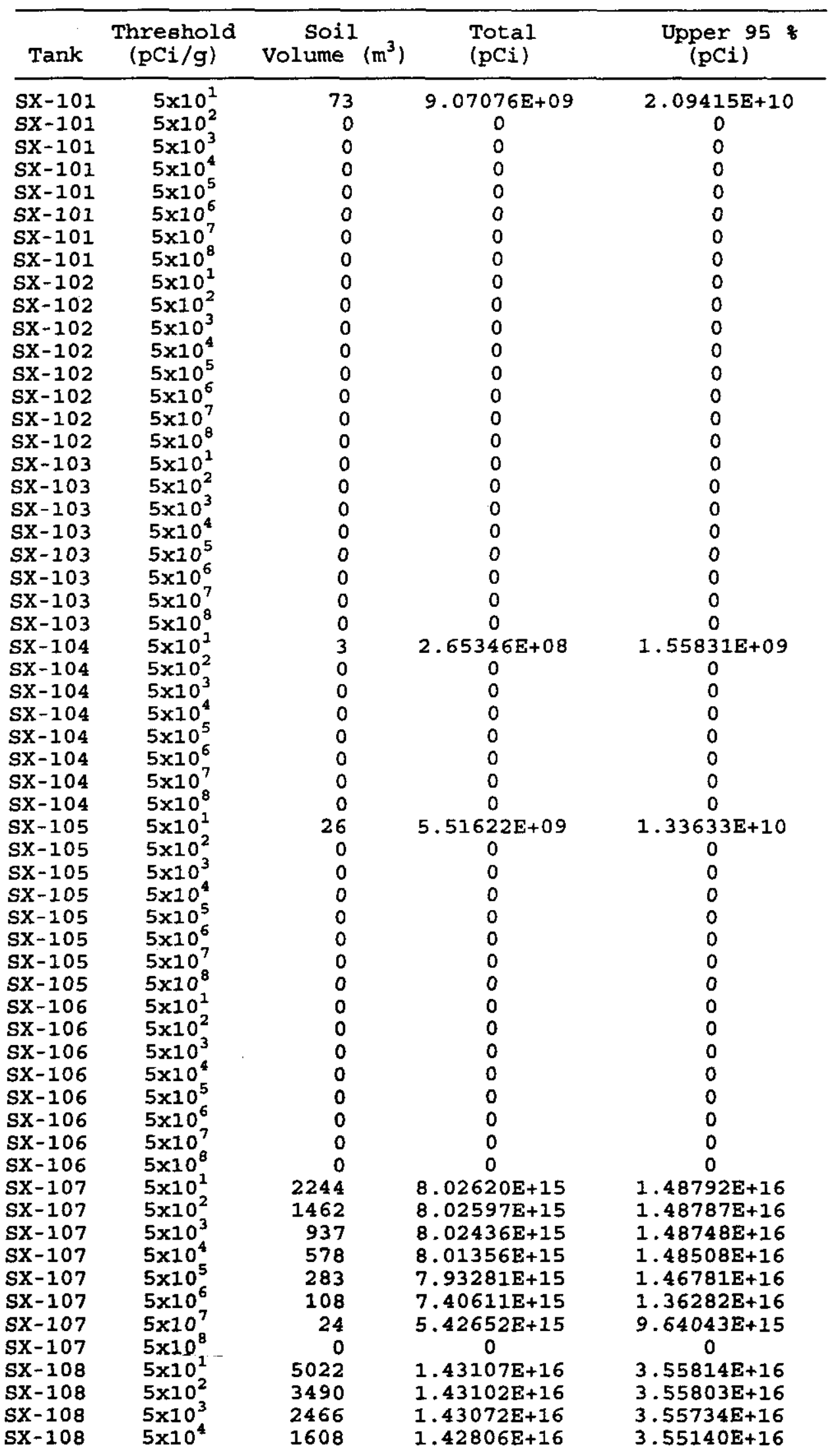


HNF-5782 Rev. 0

Table 1. Continued.

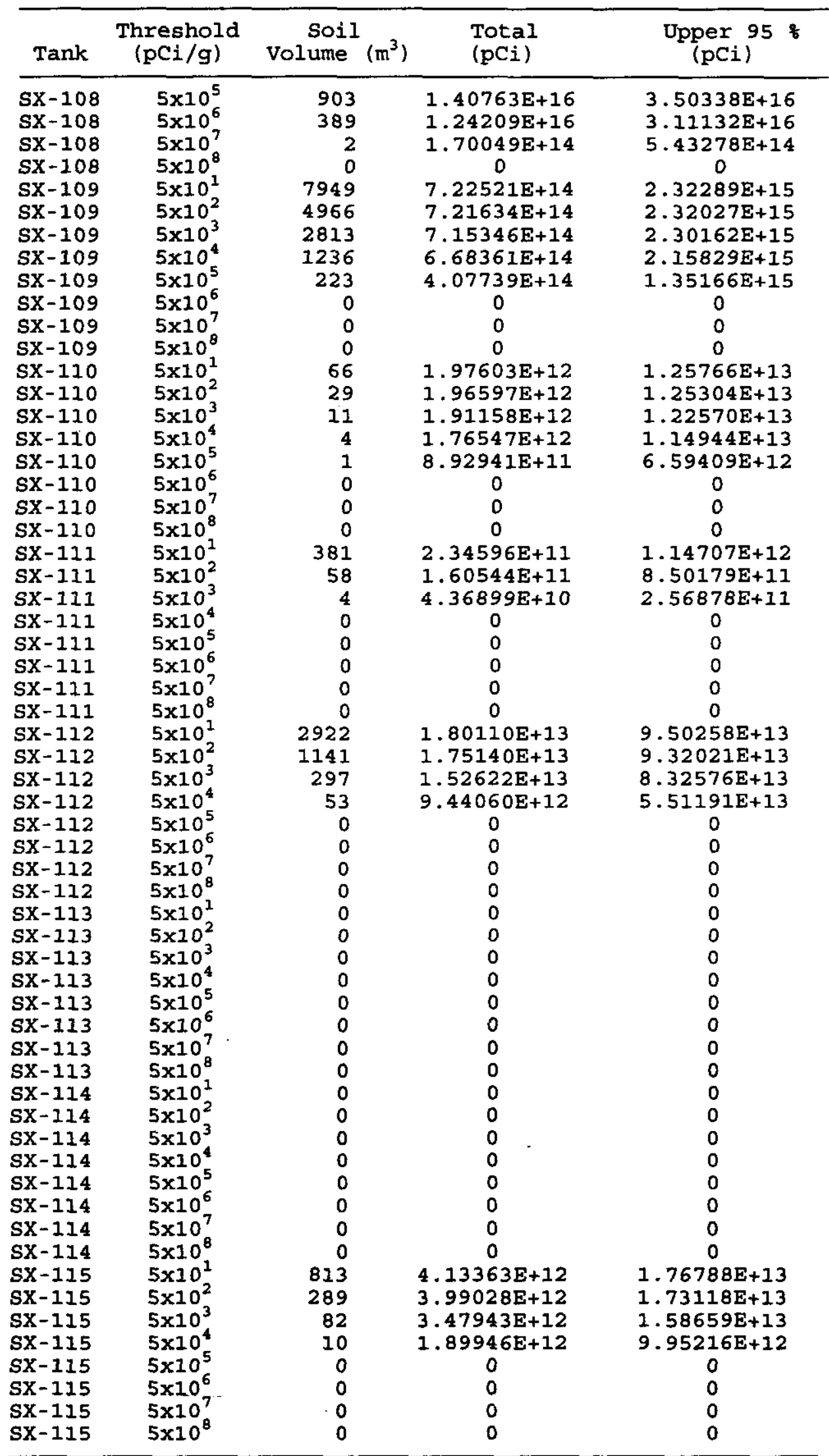


Table 2. SX-101 inventory of soil volumes, total activities and upper 958 confidence limit, exceeding 8 activity thresholds over 17 depth increments.

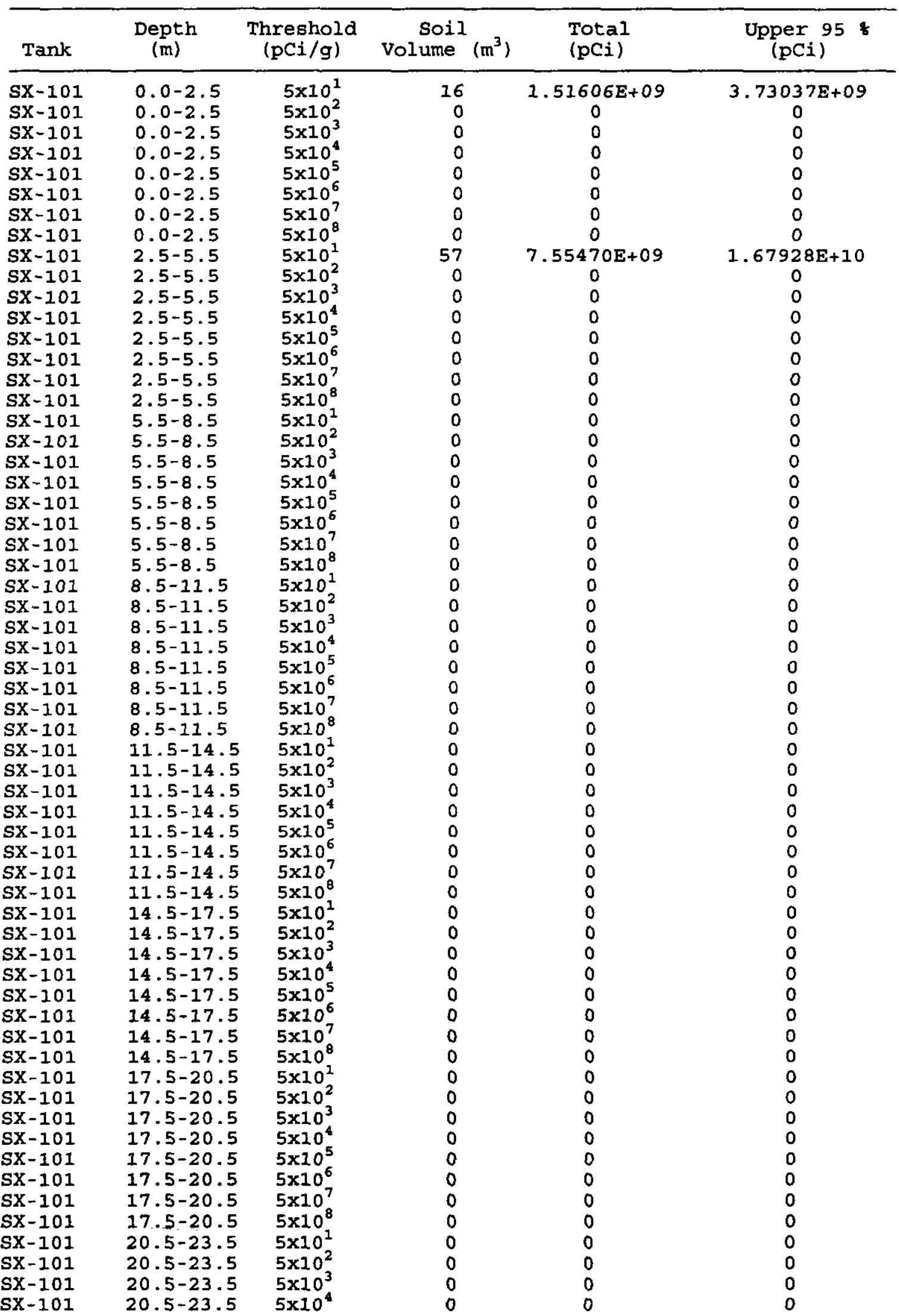


Table 2 . Continued.

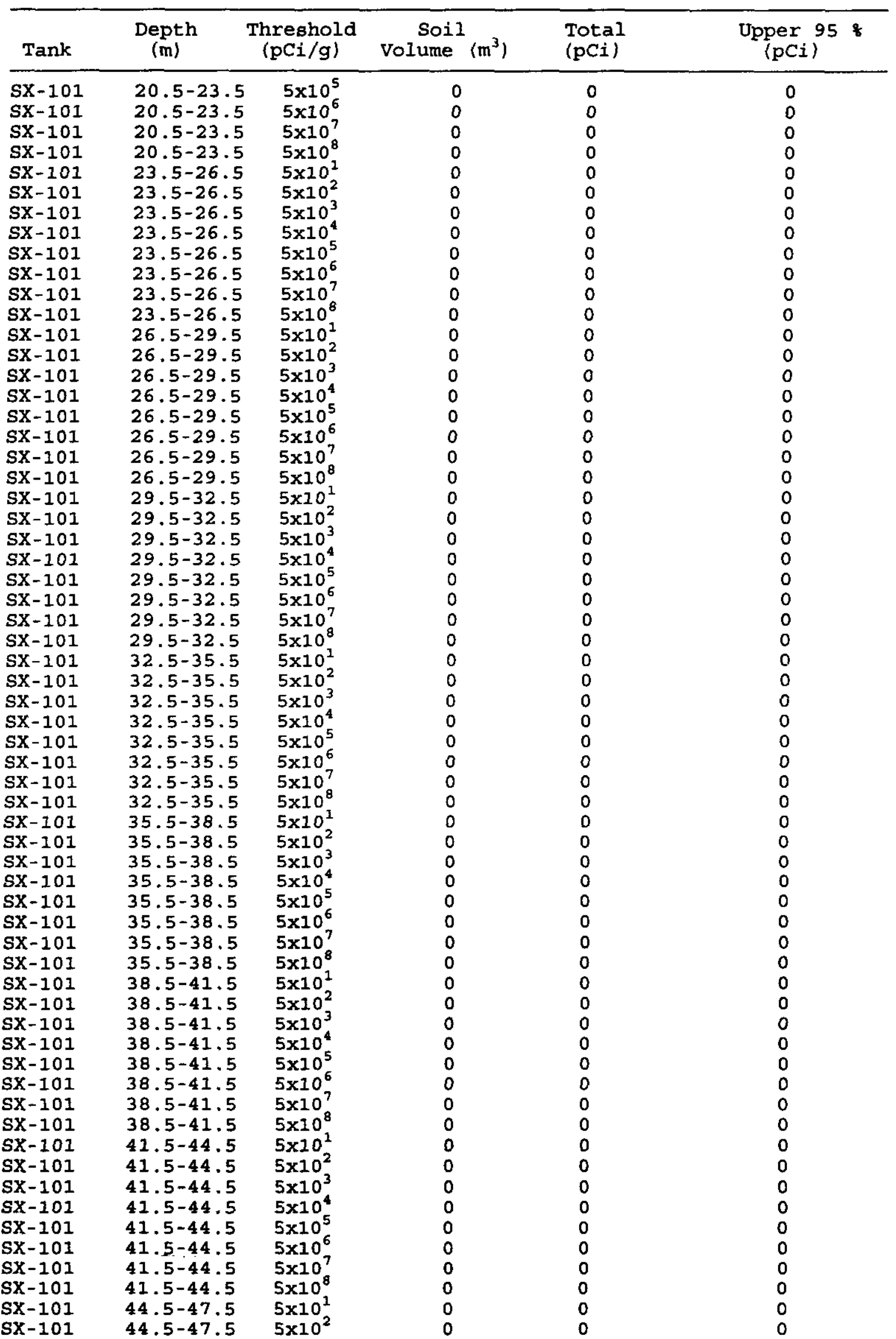


HNF-5782 Rev. 0

Table 2, Continued.

\begin{tabular}{|c|c|c|c|c|c|}
\hline Tank & $\underset{(\mathrm{m})}{\text { Depth }}$ & $\begin{array}{c}\text { Threshold } \\
\text { (pCi } / \mathrm{g})\end{array}$ & Soll & $\begin{array}{l}\text { Total } \\
\text { (pCi) }\end{array}$ & $\begin{array}{l}\text { Upper } \\
\text { (pCi) }\end{array}$ \\
\hline 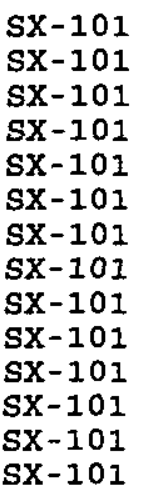 & $\begin{array}{l}44.5-47.5 \\
44.5-47.5 \\
44.5-47.5 \\
44.5-47.5 \\
44.5-47.5 \\
44.5-47.5 \\
47.5-50.5 \\
47.5-50.5 \\
47.5-50.5 \\
47.5-50.5 \\
47.5-50.5 \\
47.5-50.5 \\
47.5-50.5 \\
47.5-50.5\end{array}$ & $\begin{array}{l}5 \times 10^{3} \\
5 \times 10^{4} \\
5 \times 10^{5} \\
5 \times 10^{6} \\
5 \times 10^{7} \\
5 \times 10^{8} \\
5 \times 10^{1} \\
5 \times 10^{2} \\
5 \times 10^{3} \\
5 \times 10^{4} \\
5 \times 10^{5} \\
5 \times 10^{6} \\
5 \times 10^{7} \\
5 \times 10^{8}\end{array}$ & $\begin{array}{l}0 \\
0 \\
0 \\
0 \\
0 \\
0 \\
0 \\
0 \\
0 \\
0 \\
0 \\
0 \\
0 \\
0\end{array}$ & $\begin{array}{l}0 \\
0 \\
0 \\
0 \\
0 \\
0 \\
0 \\
0 \\
0 \\
0 \\
0 \\
0 \\
0 \\
0\end{array}$ & $\begin{array}{l}0 \\
0 \\
0 \\
0 \\
0 \\
0 \\
0 \\
0 \\
0 \\
0 \\
0 \\
0 \\
0 \\
0\end{array}$ \\
\hline
\end{tabular}


Table 3. SX-102 inventory of soil volumes, total activities and upper $95 \%$ confidence limit, exceeding 8 activity thresholds over 17 depth increments.

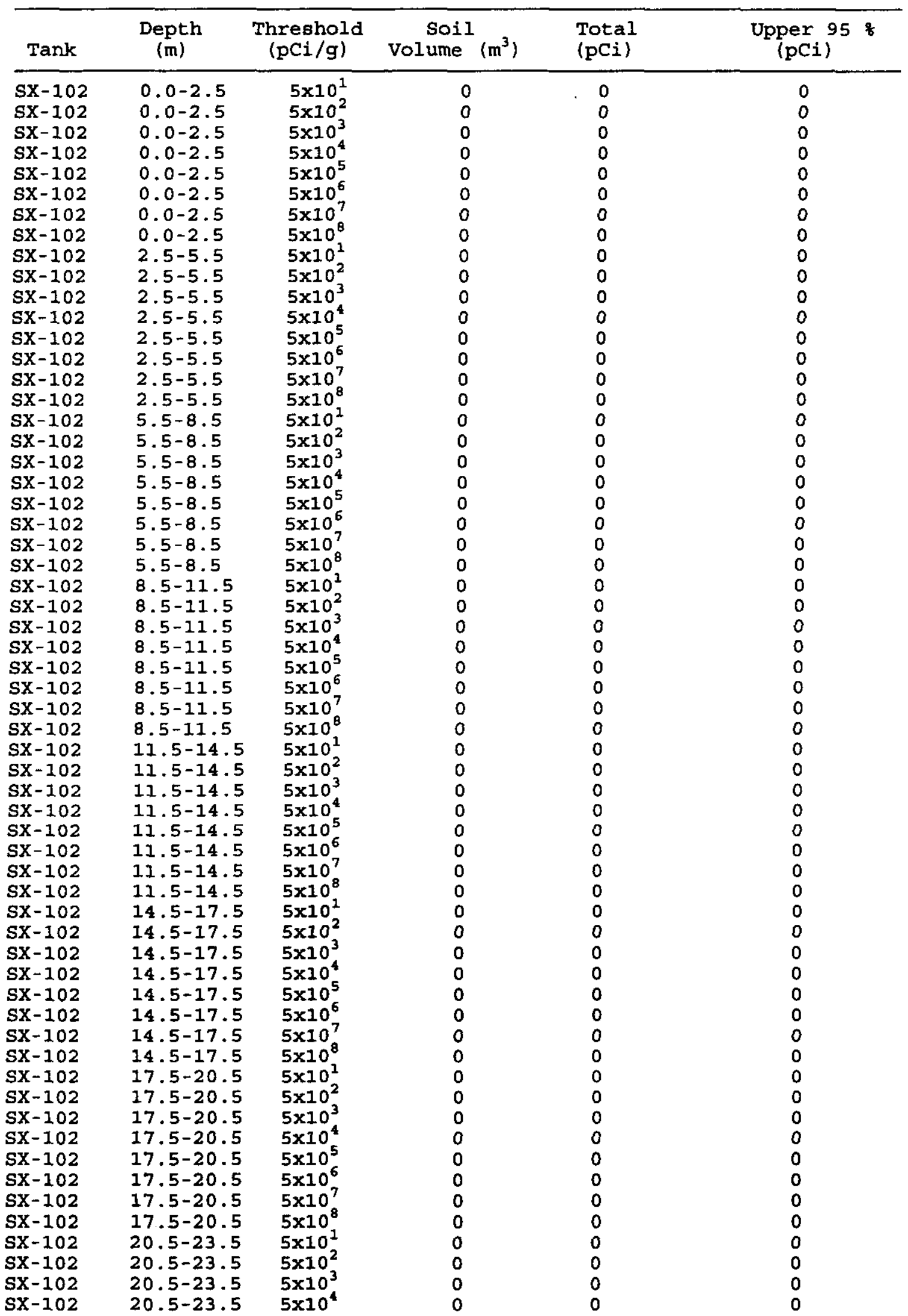


Table 3. Continued.

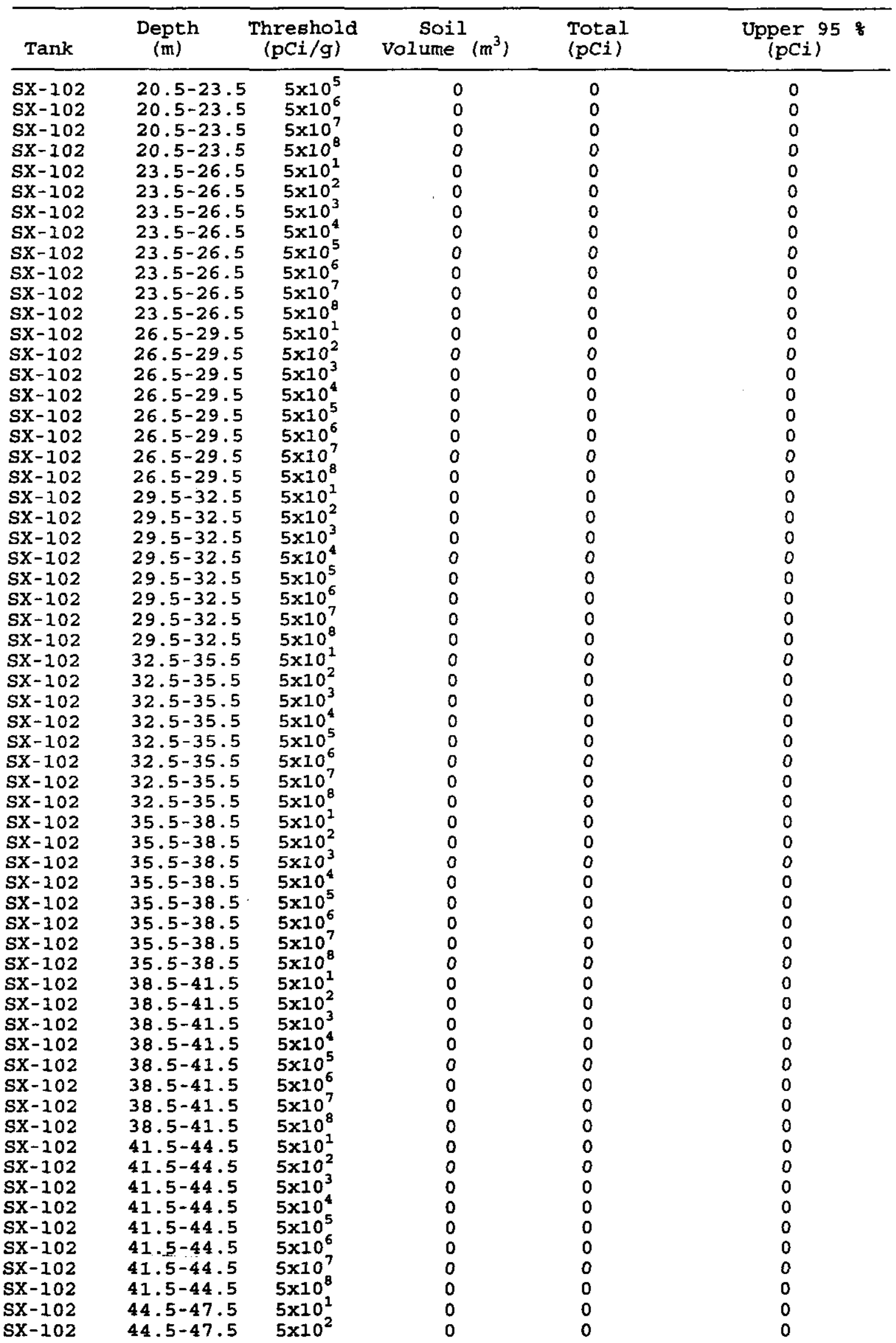


HNF-5782 Rev. 0

Table 3 . Continued.

\begin{tabular}{|c|c|c|c|c|c|}
\hline Tank & $\underset{(\mathrm{m})}{\text { Depth }}$ & $\begin{array}{l}\text { Threshold } \\
\text { (pCi/g) }\end{array}$ & Soil & $\begin{array}{l}\text { Total } \\
\text { (pCi) }\end{array}$ & $\begin{array}{c}\text { Upper } 95 \\
(\mathrm{pC} i)\end{array}$ \\
\hline $5 x-102$ & $44.5-47.5$ & $5 \times 10^{3}$ & 0 & 0 & 0 \\
\hline$s x-102$ & $44.5-47.5$ & $5 \times 10^{4}$ & 0 & 0 & 0 \\
\hline$S X-102$ & $44.5-47.5$ & $5 \times 10^{5}$ & 0 & 0 & 0 \\
\hline $5 x-102$ & $44.5-47.5$ & $5 \times 10^{6}$ & 0 & 0 & 0 \\
\hline $5 x-102$ & $44.5-47.5$ & $5 \times 10^{7}$ & 0 & 0 & 0 \\
\hline $5 x-102$ & $44.5-47.5$ & $5 \times 10^{8}$ & 0 & 0 & 0 \\
\hline sx-102 & $47.5-50.5$ & $5 \times 10^{1}$ & 0 & 0 & 0 \\
\hline$s x-102$ & $47.5-50.5$ & $5 \times 10^{2}$ & 0 & 0 & 0 \\
\hline$s x-102$ & $47.5-50.5$ & $5 \times 10^{3}$ & 0 & 0 & 0 \\
\hline $5 x-102$ & $47.5-50.5$ & $5 \times 10^{4}$ & 0 & 0 & 0 \\
\hline $5 x-102$ & $47.5-50.5$ & $5 \times 10^{5}$ & 0 & 0 & 0 \\
\hline SX-102 & $47.5-50.5$ & $5 \times 10^{6}$ & 0 & 0 & 0 \\
\hline $5 x-102$ & $47.5-50.5$ & $5 \times 10^{7}$ & 0 & 0 & 0 \\
\hline$S A-102$ & $47.5-50.5$ & $5 \times 10^{8}$ & 0 & 0 & 0 \\
\hline
\end{tabular}


Table 4. SX-103 inventory of soil volumes, total activities and upper 95t confidence limit, exceeding 8 activity thresholds over 17 depth increments.

\begin{tabular}{|c|c|c|c|c|c|}
\hline Tank & $\begin{array}{c}\text { Depth } \\
(\mathrm{m})\end{array}$ & $\begin{array}{l}\text { Threshold } \\
\text { (pCi/g) }\end{array}$ & Soil & $\begin{array}{l}\text { Total } \\
\text { (pci) }\end{array}$ & $\begin{array}{l}\text { Upper } 95: \\
\text { (pCi) }\end{array}$ \\
\hline 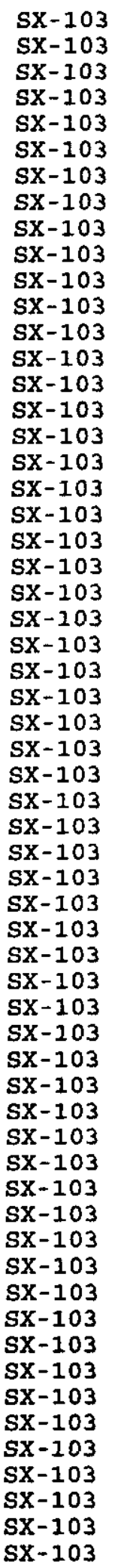 & 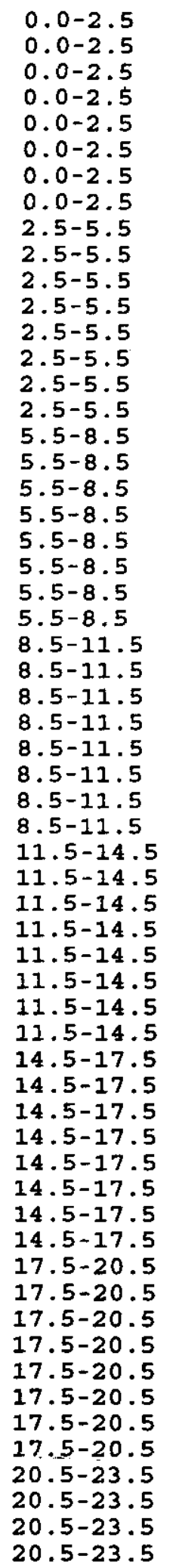 & $\begin{array}{l}5 \times 10^{1} \\
5 \times 10^{2} \\
5 \times 10^{3} \\
5 \times 10^{4} \\
5 \times 10^{5} \\
5 \times 10^{6} \\
5 \times 10^{7} \\
5 \times 10^{8} \\
5 \times 10^{1} \\
5 \times 10^{2} \\
5 \times 10^{3} \\
5 \times 10^{4} \\
5 \times 10^{5} \\
5 \times 10^{6} \\
5 \times 10^{7} \\
5 \times 10^{8} \\
5 \times 10^{1} \\
5 \times 10^{2} \\
5 \times 10^{3} \\
5 \times 10^{4} \\
5 \times 10^{5} \\
5 \times 10^{6} \\
5 \times 10^{7} \\
5 \times 10^{8} \\
5 \times 10^{1} \\
5 \times 10^{2} \\
5 \times 10^{3} \\
5 \times 10^{4} \\
5 \times 10^{5} \\
5 \times 10^{6} \\
5 \times 10^{7} \\
5 \times 10^{8} \\
5 \times 10^{1} \\
5 \times 10^{2} \\
5 \times 10^{3} \\
5 \times 10^{4} \\
5 \times 10^{5} \\
5 \times 10^{6} \\
5 \times 10^{7} \\
5 \times 10^{8} \\
5 \times 10^{1} \\
5 \times 10^{2} \\
5 \times 10^{3} \\
5 \times 10^{4} \\
5 \times 10^{5} \\
5 \times 10^{6} \\
5 \times 10^{7} \\
5 \times 10^{8} \\
5 \times 10^{1} \\
5 \times 10^{2} \\
5 \times 10^{3} \\
5 \times 10^{4} \\
5 \times 10^{5} \\
5 \times 10^{6} \\
5 \times 10^{7} \\
5 \times 10^{8} \\
5 \times 10^{1} \\
5 \times 10^{2} \\
5 \times 3\end{array}$ & $\begin{array}{l}0 \\
0 \\
0 \\
0 \\
0 \\
0 \\
0 \\
0 \\
0 \\
0 \\
0 \\
0 \\
0 \\
0 \\
0 \\
0 \\
0 \\
0 \\
0 \\
0 \\
0 \\
0 \\
0 \\
0 \\
0 \\
0 \\
0 \\
0 \\
0 \\
0 \\
0 \\
0 \\
0 \\
0 \\
0 \\
0 \\
0 \\
0 \\
0 \\
0 \\
0 \\
0 \\
0 \\
0 \\
0 \\
0 \\
0 \\
0 \\
0 \\
0 \\
0 \\
0 \\
0 \\
0 \\
0 \\
0 \\
0\end{array}$ & $\begin{array}{l}0 \\
0 \\
0 \\
0 \\
0 \\
0 \\
0 \\
0 \\
0 \\
0 \\
0 \\
0 \\
0 \\
0 \\
0 \\
0 \\
0 \\
0 \\
0 \\
0 \\
0 \\
0 \\
0 \\
0 \\
0 \\
0 \\
0 \\
0 \\
0 \\
0 \\
0 \\
0 \\
0 \\
0 \\
0 \\
0 \\
0 \\
0 \\
0 \\
0 \\
0 \\
0 \\
0 \\
0 \\
0 \\
0 \\
0 \\
0 \\
0 \\
0 \\
0 \\
0 \\
0 \\
0 \\
0 \\
0 \\
0\end{array}$ & $\begin{array}{l}0 \\
0 \\
0 \\
0 \\
0 \\
0 \\
0 \\
0 \\
0 \\
0 \\
0 \\
0 \\
0 \\
0 \\
0 \\
0 \\
0 \\
0 \\
0 \\
0 \\
0 \\
0 \\
0 \\
0 \\
0 \\
0 \\
0 \\
0 \\
0 \\
0 \\
0 \\
0 \\
0 \\
0 \\
0 \\
0 \\
0 \\
0 \\
0 \\
0 \\
0 \\
0 \\
0 \\
0 \\
0 \\
0 \\
0 \\
0 \\
0 \\
0 \\
0 \\
0 \\
0 \\
0 \\
0 \\
0 \\
0 \\
0 \\
0 \\
0 \\
0 \\
0 \\
0 \\
0 \\
0\end{array}$ \\
\hline
\end{tabular}


Table 4. Continued.

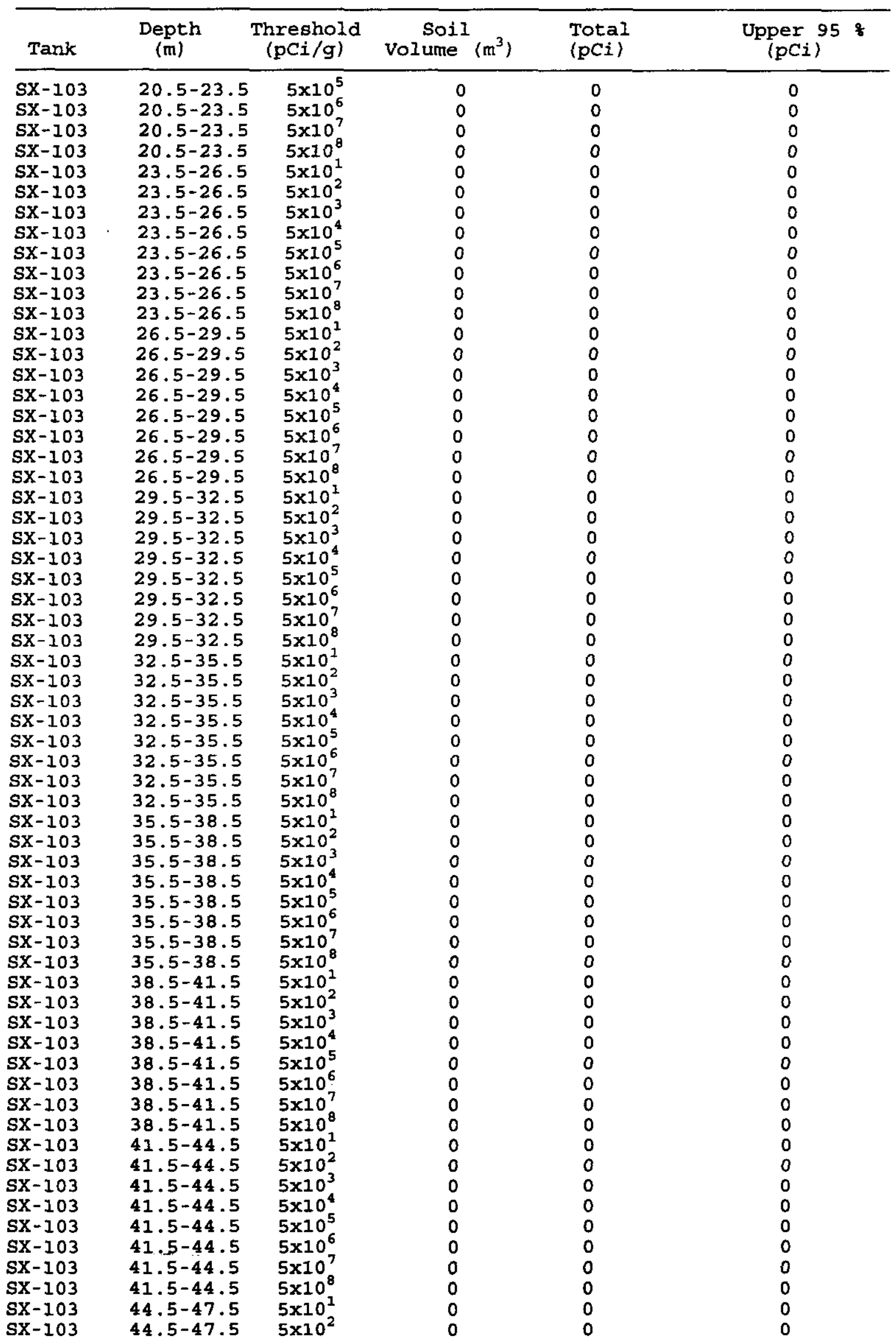


HNF-5782 Rev. 0

Table 4. Continued.

\begin{tabular}{|c|c|c|c|c|c|}
\hline Tank & $\underset{(m)}{\text { Depth }}$ & $\begin{array}{l}\text { Threshold } \\
\text { (pCi/g) }\end{array}$ & Soil & $\begin{array}{l}\text { Total } \\
\text { (pCi) }\end{array}$ & $\begin{array}{l}\text { Upper } 95 \% \\
\text { (pCi) }\end{array}$ \\
\hline $\begin{array}{l}s x-103 \\
s x-103 \\
s x-103 \\
s x-103 \\
s x-103 \\
s x-103 \\
s x-103 \\
s x-103 \\
s x-103 \\
s x-103 \\
s x-103 \\
s x-103 \\
s x-103 \\
s x-103\end{array}$ & $\begin{array}{l}44.5-47.5 \\
44.5-47.5 \\
44.5-47.5 \\
44.5-47.5 \\
44.5-47.5 \\
44.5-47.5 \\
47.5-50.5 \\
47.5-50.5 \\
47.5-50.5 \\
47.5-50.5 \\
47.5-50.5 \\
47.5-50.5 \\
47.5-50.5 \\
47.5-50.5\end{array}$ & $\begin{array}{l}5 \times 10^{3} \\
5 \times 10^{4} \\
5 \times 10^{5} \\
5 \times 10^{6} \\
5 \times 10^{7} \\
5 \times 10^{8} \\
5 \times 10^{1} \\
5 \times 10^{2} \\
5 \times 10^{3} \\
5 \times 10^{4} \\
5 \times 10^{5} \\
5 \times 10^{6} \\
5 \times 10^{7} \\
5 \times 10^{8}\end{array}$ & $\begin{array}{l}0 \\
0 \\
0 \\
0 \\
0 \\
0 \\
0 \\
0 \\
0 \\
0 \\
0 \\
0 \\
0 \\
0\end{array}$ & $\begin{array}{l}0 \\
0 \\
0 \\
0 \\
0 \\
0 \\
0 \\
0 \\
0 \\
0 \\
0 \\
0 \\
0 \\
0\end{array}$ & $\begin{array}{l}0 \\
0 \\
0 \\
0 \\
0 \\
0 \\
0 \\
0 \\
0 \\
0 \\
0 \\
0 \\
0 \\
0\end{array}$ \\
\hline
\end{tabular}


Table 5. Sx-104 inventory of soil volumes, total activities and upper 95\% confidence limit, exceeding 8 activity thresholds over 17 depth increments.

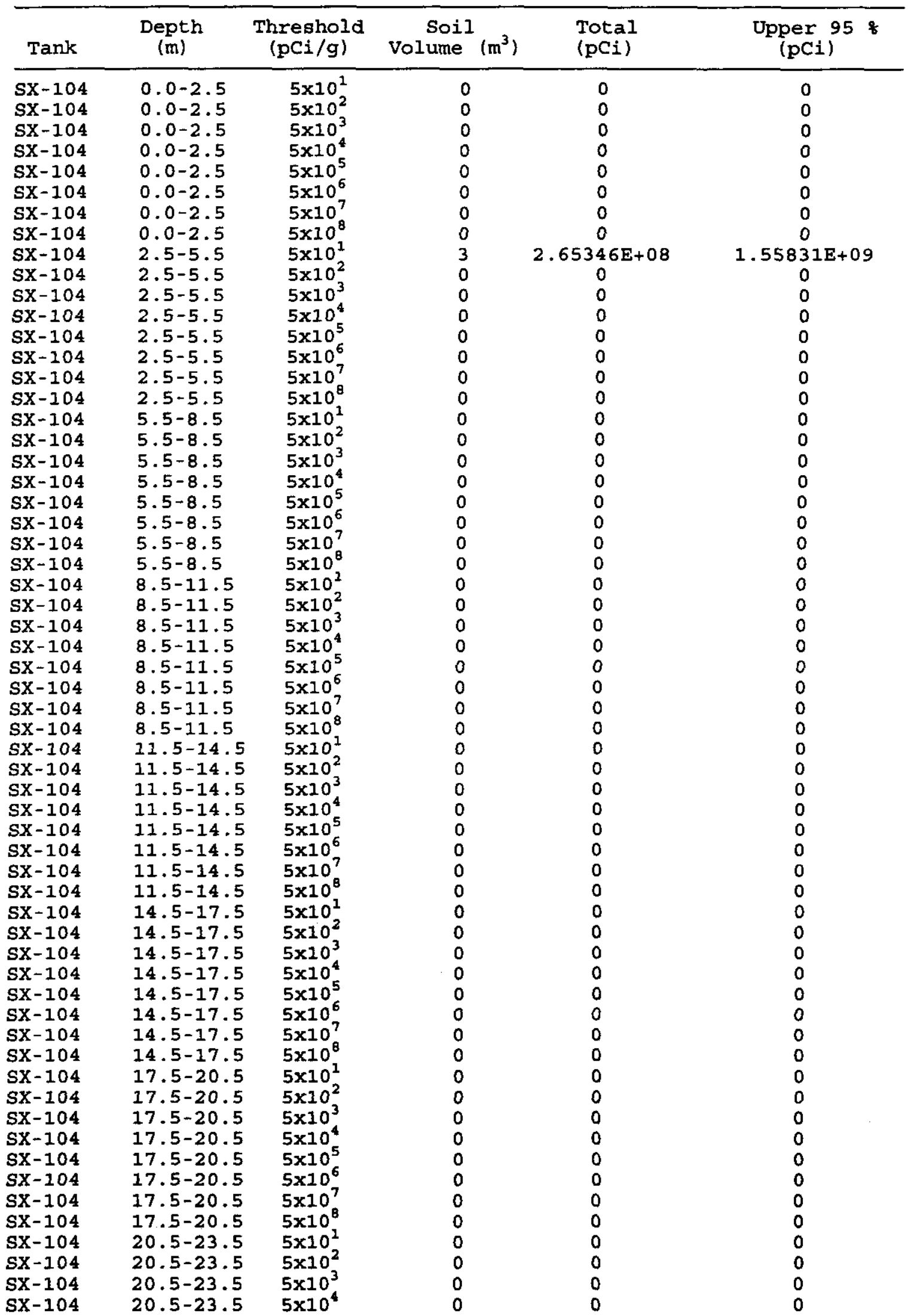


Table 5. Continued.

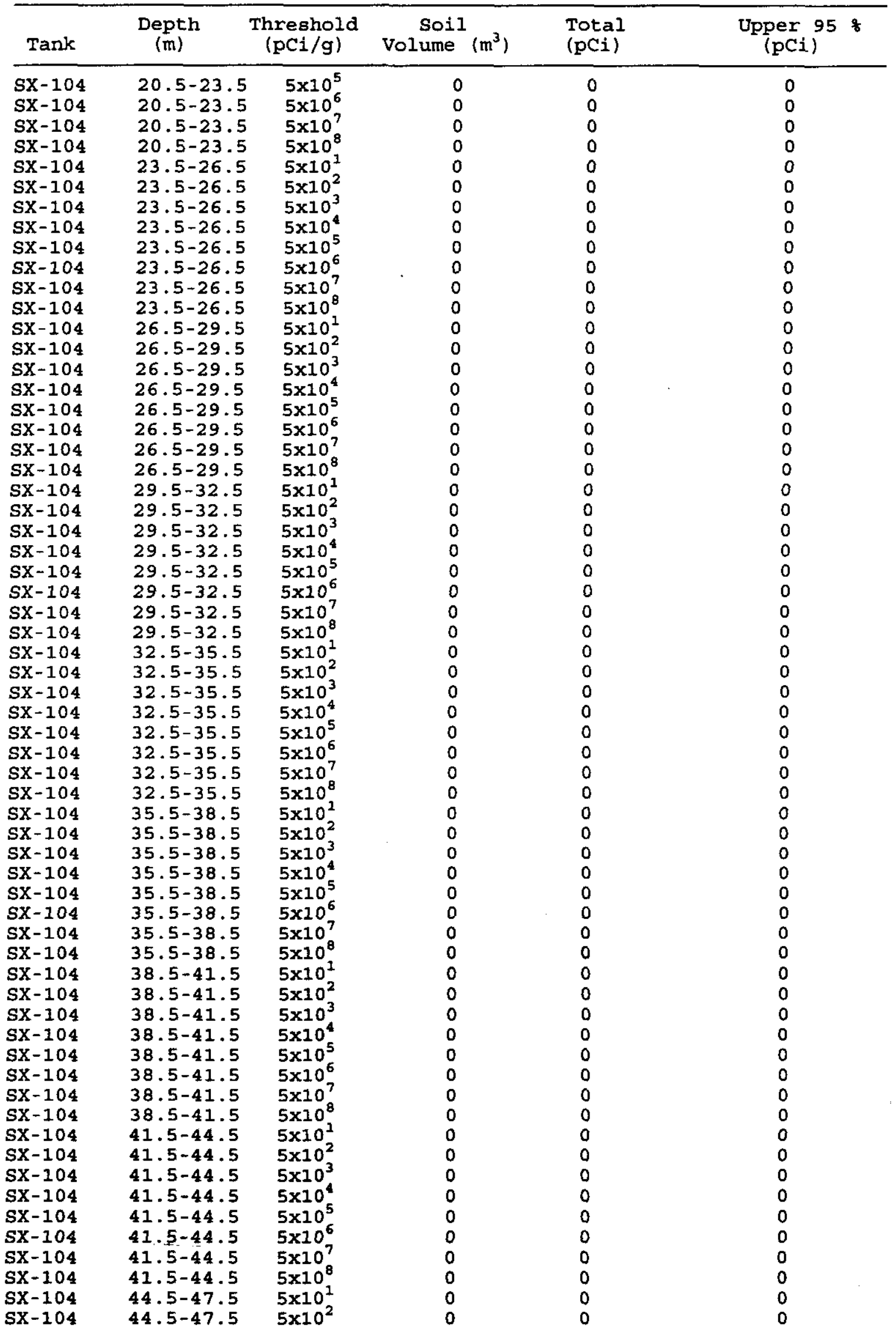


HNF-5782 Rev.0

Table 5. Continued.

\begin{tabular}{llcccc}
\hline Tank & $\begin{array}{c}\text { Depth } \\
(\mathrm{m})\end{array}$ & $\begin{array}{c}\text { Threshold } \\
(\mathrm{pCi} / \mathrm{g})\end{array}$ & $\begin{array}{c}\text { Soil } \\
\text { Volume }\left(\mathrm{m}^{3}\right)\end{array}$ & $\begin{array}{c}\text { Total } \\
(\mathrm{pCi})\end{array}$ & $\begin{array}{c}\text { Upper } 95 \\
(\mathrm{pCi})\end{array}$ \\
\hline SX-104 & $44.5-47.5$ & $5 \times 10^{3}$ & 0 & 0 & 0 \\
SX-104 & $44.5-47.5$ & $5 \times 10^{4}$ & 0 & 0 & 0 \\
SX-104 & $44.5-47.5$ & $5 \times 10^{5}$ & 0 & 0 & 0 \\
SX-104 & $44.5-47.5$ & $5 \times 10^{6}$ & 0 & 0 & 0 \\
SX-104 & $44.5-47.5$ & $5 \times 10^{7}$ & 0 & 0 & 0 \\
SX-104 & $44.5-47.5$ & $5 \times 10^{8}$ & 0 & 0 & 0 \\
SX-104 & $47.5-50.5$ & $5 \times 10^{1}$ & 0 & 0 & 0 \\
SX-104 & $47.5-50.5$ & $5 \times 10^{2}$ & 0 & 0 & 0 \\
SX-104 & $47.5-50.5$ & $5 \times 10^{3}$ & 0 & 0 & 0 \\
SX-104 & $47.5-50.5$ & $5 \times 10^{4}$ & 0 & 0 & 0 \\
SX-104 & $47.5-50.5$ & $5 \times 10^{5}$ & 0 & 0 & 0 \\
SX-104 & $47.5-50.5$ & $5 \times 10^{6}$ & 0 & 0 & 0 \\
SX-104 & $47.5-50.5$ & $5 \times 10^{7}$ & 0 & 0 & 0 \\
SX-104 & $47.5-50.5$ & $5 \times 10^{8}$ & 0 & 0 & 0 \\
\hline
\end{tabular}


Table 6. Sx-105 inventory of soil volumes, total activities and upper 95 confidence limit, exceeding 8 activity thresholds over 17 depth increments.

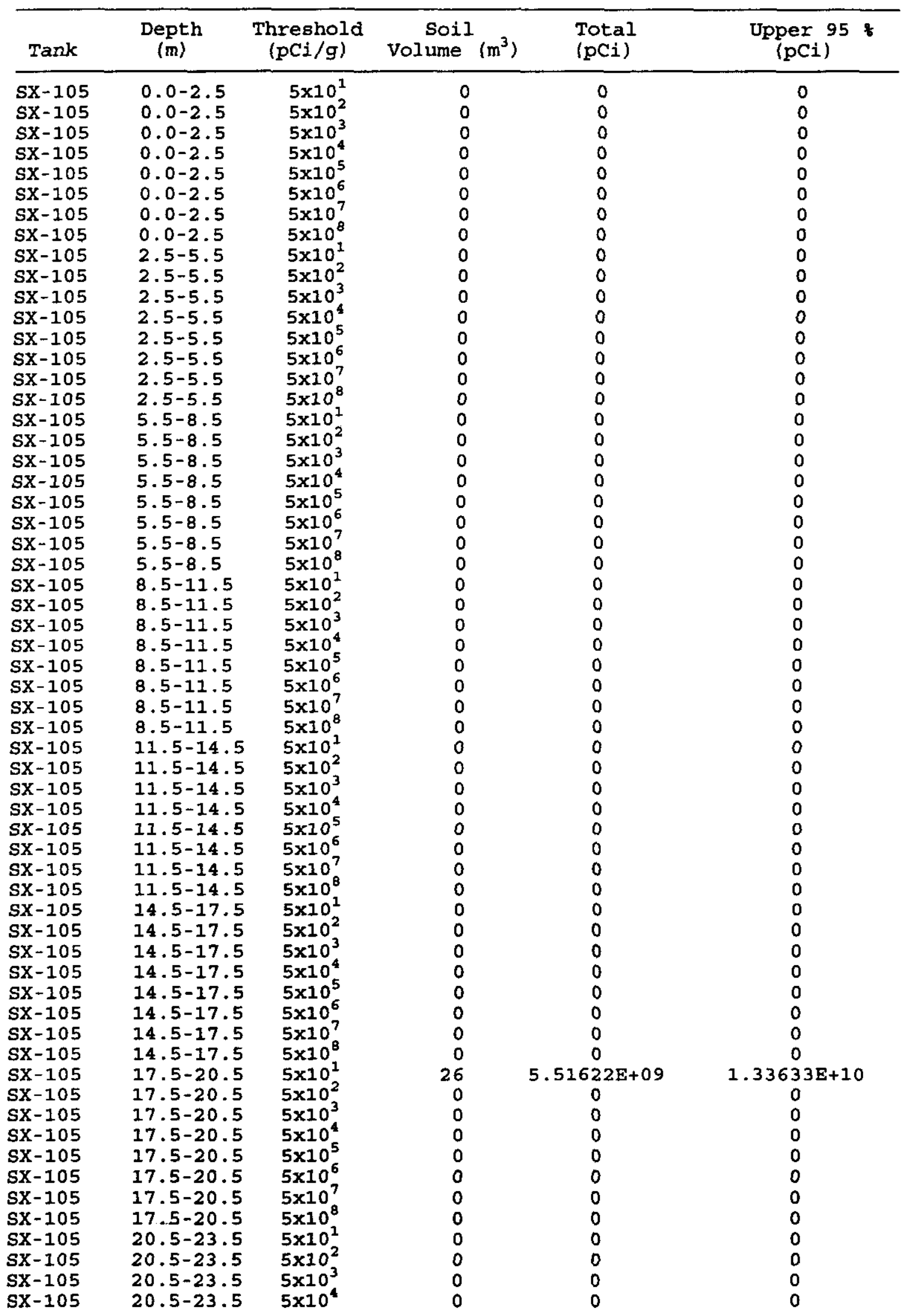


Table 6. Continued.

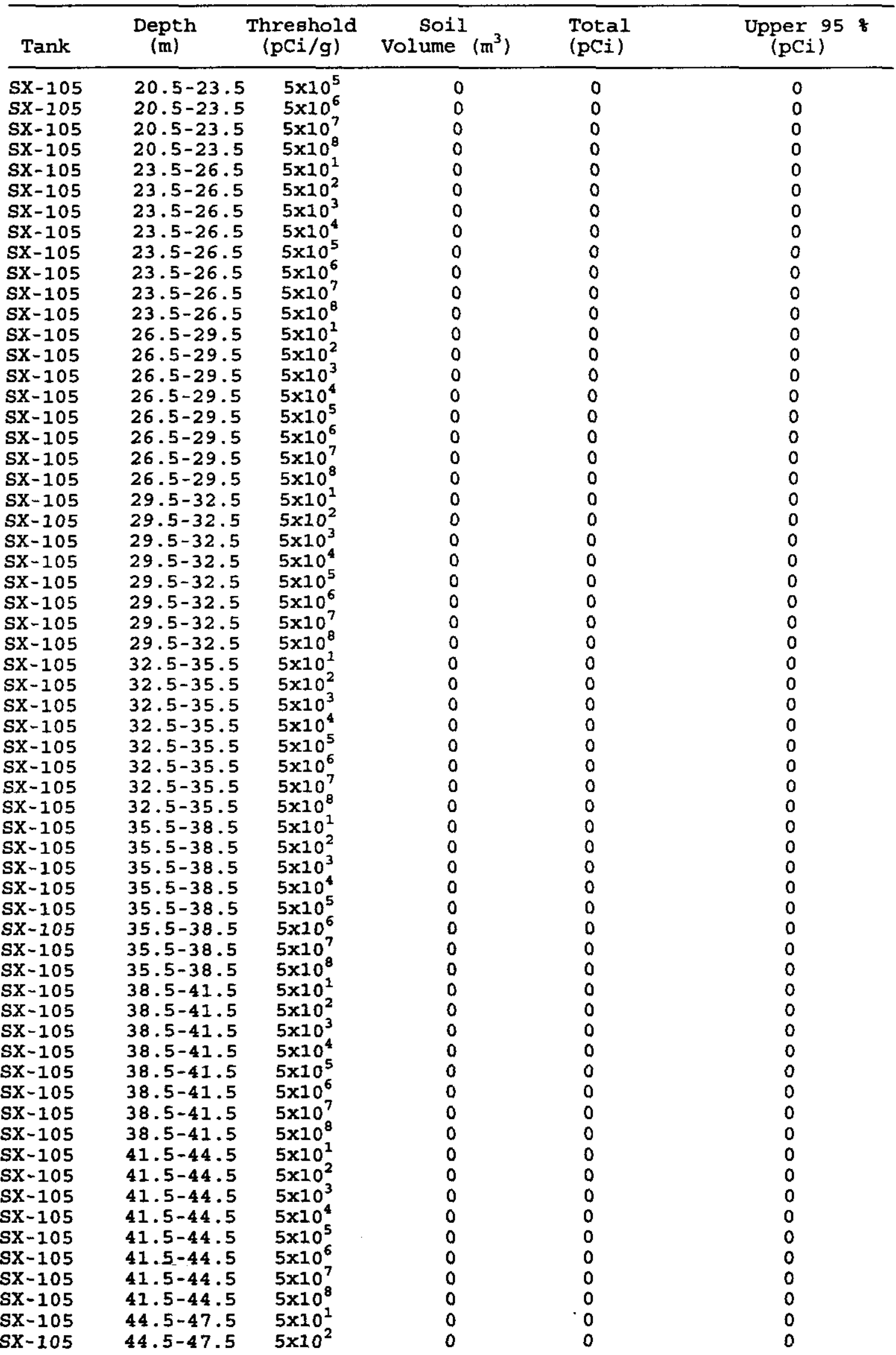


HNF-5782 Rev. 0

Table 6. Continued.

\begin{tabular}{cccccc}
\hline Tank & $\begin{array}{c}\text { Depth } \\
(\mathrm{m})\end{array}$ & $\begin{array}{c}\text { Threshold } \\
(\mathrm{pCi} / \mathrm{g})\end{array}$ & $\begin{array}{c}\text { Soil } \\
\text { Volume }\end{array}$ & $\begin{array}{c}\text { Total } \\
\text { (pCi) }\end{array}$ & $\begin{array}{c}\text { Upper 95 } \\
\text { (pCi) }\end{array}$ \\
\hline SX-105 & $44.5-47.5$ & $5 \times 10^{3}$ & 0 & 0 & 0 \\
SX-105 & $\mathbf{4 4 . 5 - 4 7 . 5}$ & $5 \times 10^{4}$ & 0 & 0 & 0 \\
SX-105 & $\mathbf{4 4 . 5 - 4 7 . 5}$ & $5 \times 10^{5}$ & 0 & 0 & 0 \\
SX-105 & $44.5-47.5$ & $5 \times 10^{6}$ & 0 & 0 & 0 \\
SX-105 & $44.5-47.5$ & $5 \times 10^{7}$ & 0 & 0 & 0 \\
SX-105 & $44.5-47.5$ & $5 \times 10^{8}$ & 0 & 0 & 0 \\
SX-105 & $47.5-50.5$ & $5 \times 10^{1}$ & 0 & 0 & 0 \\
SX-105 & $47.5-50.5$ & $5 \times 10^{2}$ & 0 & 0 & 0 \\
SX-105 & $47.5-50.5$ & $5 \times 10^{3}$ & 0 & 0 & 0 \\
SX-105 & $47.5-50.5$ & $5 \times 10^{4}$ & 0 & 0 & 0 \\
SX-105 & $47.5-50.5$ & $5 \times 10^{5}$ & 0 & 0 & 0 \\
SX-105 & $47.5-50.5$ & $5 \times 10^{6}$ & 0 & 0 & 0 \\
SX-105 & $47.5-50.5$ & $5 \times 10^{7}$ & 0 & 0 & 0 \\
SX-105 & $47.5-50.5$ & $5 \times 10^{8}$ & 0 & 0 & 0 \\
\hline
\end{tabular}


Table 7. Sx-106 inventory of soil volumes, total activities and upper 95\% confidence limit, exceeding 8 activity thresholds over 17 depth increments.

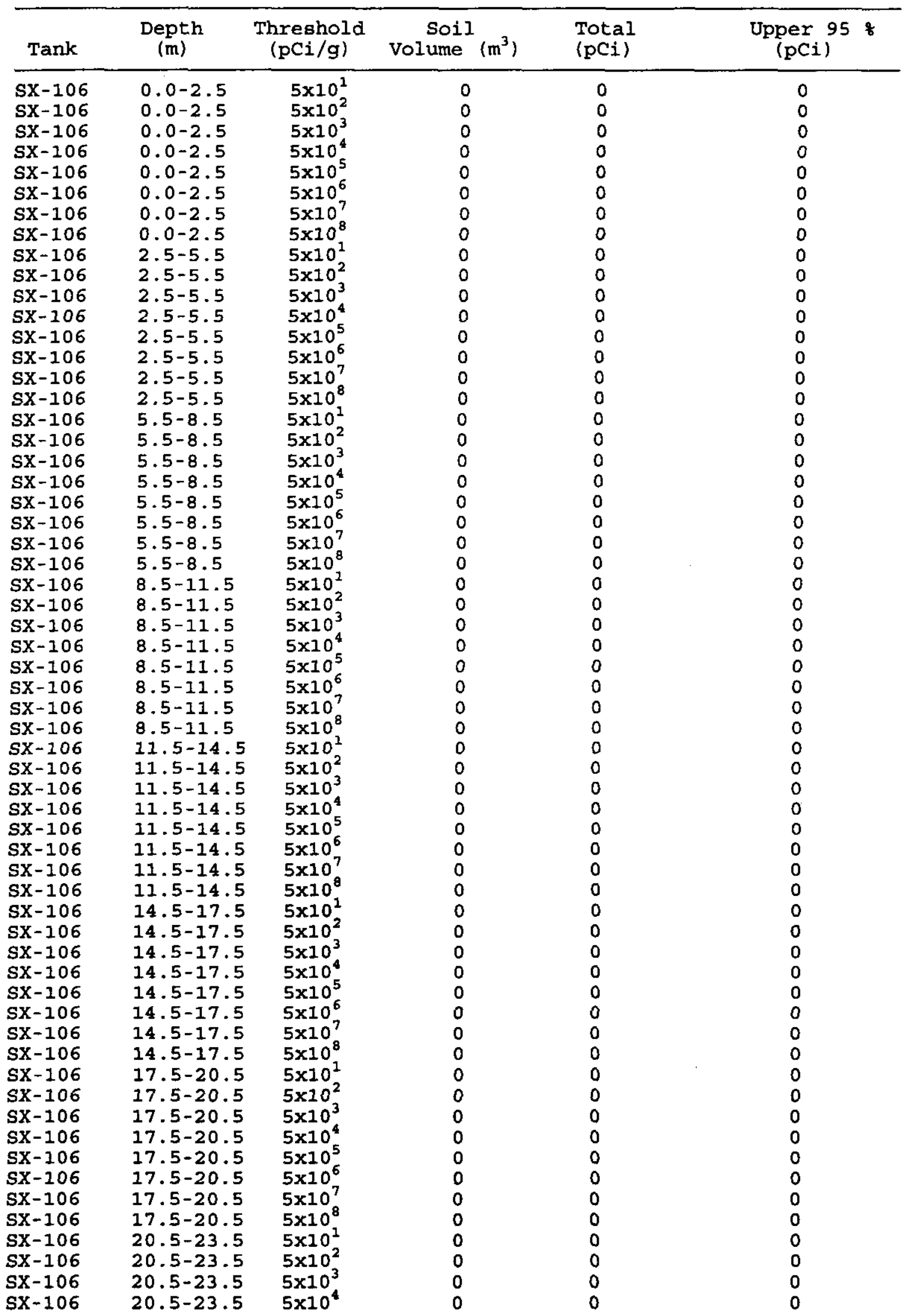


Table 7. Continued.

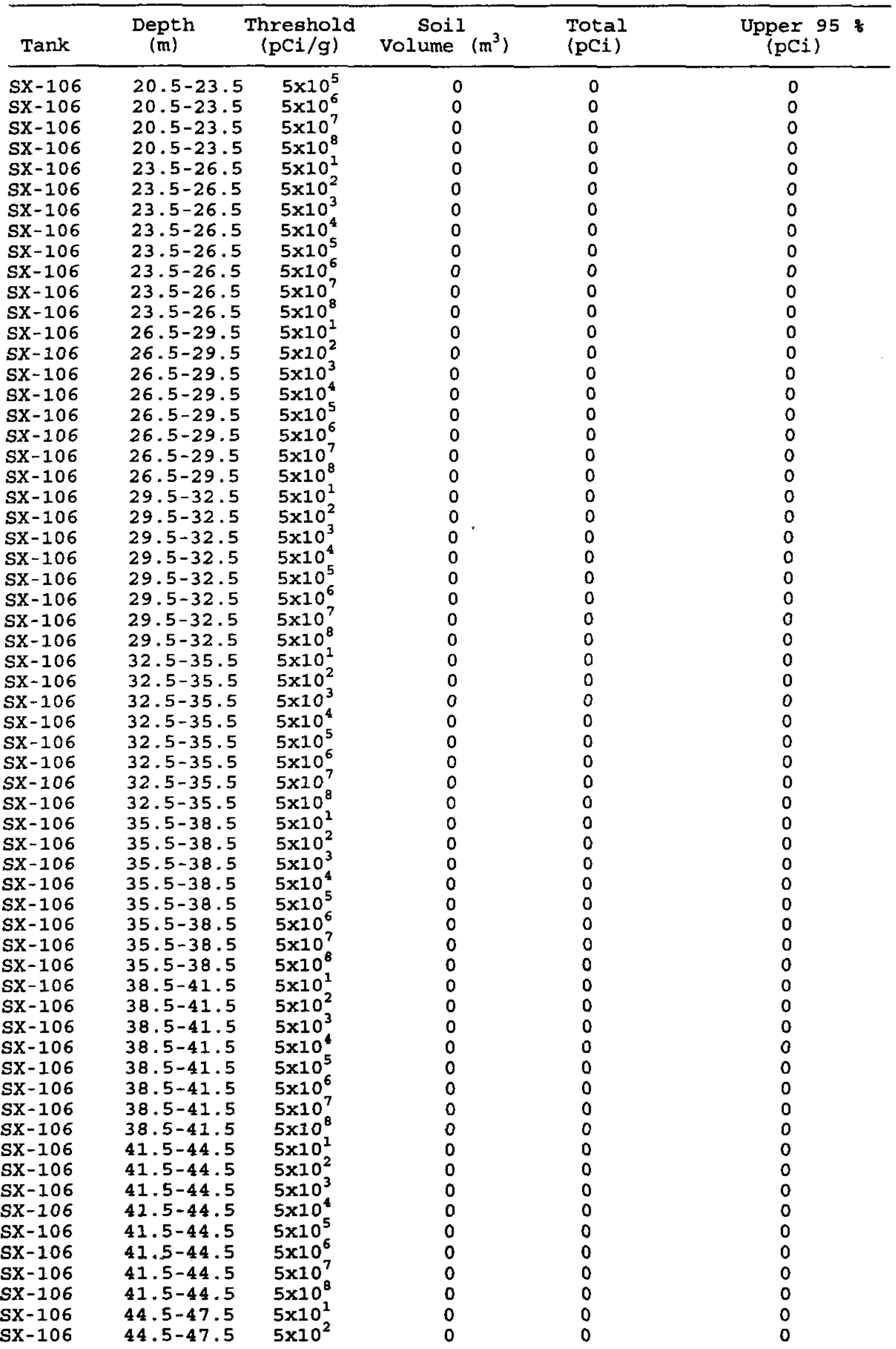


HNF-5782 Rev.0

Table 7. Continued.

\begin{tabular}{cccccc}
\hline Tank & $\begin{array}{c}\text { Depth } \\
(\mathrm{m})\end{array}$ & $\begin{array}{c}\text { Threshold } \\
(\mathrm{pCi} / \mathrm{g})\end{array}$ & $\begin{array}{c}\text { Soil } \\
\text { Volume }\end{array}$ & $\begin{array}{c}\text { Total } \\
\left(\mathrm{m}^{3}\right)\end{array}$ & $\begin{array}{c}\text { Upper } 95 \text { (pCi) } \\
(\mathrm{pCi})\end{array}$ \\
\hline SX-106 & $44.5-47.5$ & $5 \times 10^{3}$ & 0 & 0 & 0 \\
SX-106 & $44.5-47.5$ & $5 \times 10^{4}$ & 0 & 0 & 0 \\
SX-106 & $44.5-47.5$ & $5 \times 10^{5}$ & 0 & 0 & 0 \\
SX-106 & $44.5-47.5$ & $5 \times 10^{6}$ & 0 & 0 & 0 \\
SX-106 & $44.5-47.5$ & $5 \times 10^{7}$ & 0 & 0 & 0 \\
SX-106 & $44.5-47.5$ & $5 \times 10^{8}$ & 0 & 0 & 0 \\
SX-106 & $47.5-50.5$ & $5 \times 10^{1}$ & 0 & 0 & 0 \\
SX-106 & $47.5-50.5$ & $5 \times 10^{2}$ & 0 & 0 & 0 \\
SX-106 & $47.5-50.5$ & $5 \times 10^{3}$ & 0 & 0 & 0 \\
SX-106 & $47.5-50.5$ & $5 \times 10^{4}$ & 0 & 0 & 0 \\
SX-106 & $47.5-50.5$ & $5 \times 10^{5}$ & 0 & 0 & 0 \\
SX-106 & $47.5-50.5$ & $5 \times 10^{6}$ & 0 & 0 & 0 \\
SX-106 & $47.5-50.5$ & $5 \times 10^{7}$ & 0 & 0 & 0 \\
SX-106 & $47.5-50.5$ & $5 \times 10^{8}$ & 0 & 0 & 0 \\
\hline
\end{tabular}


Table 8. Sx-107 inventory of soil volumes, total activities and upper 958 confidence limit, exceeding 8 activity thresholds over 17 depth increments.

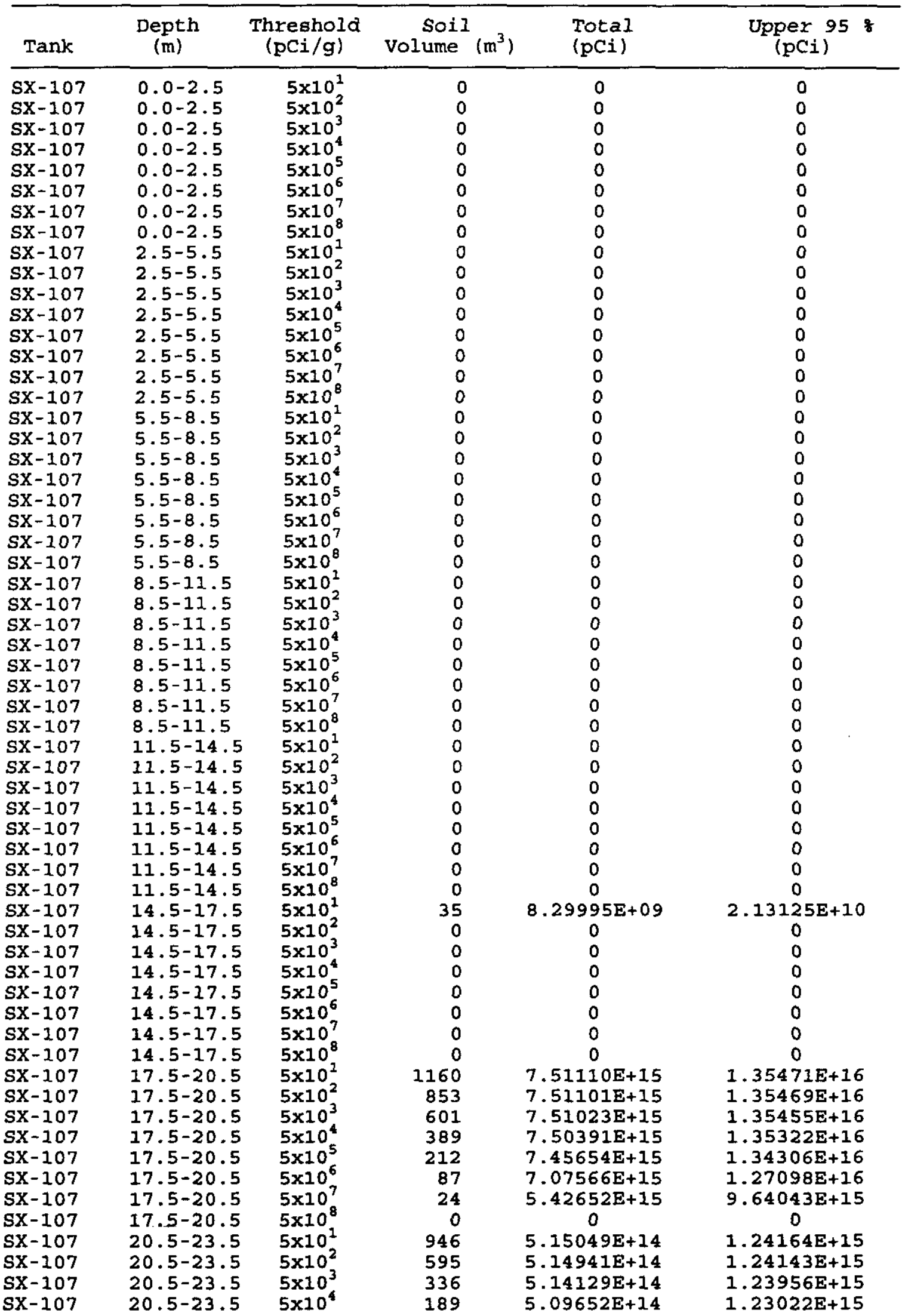


HNF-5782 Rev.0

Table 8. Continued.

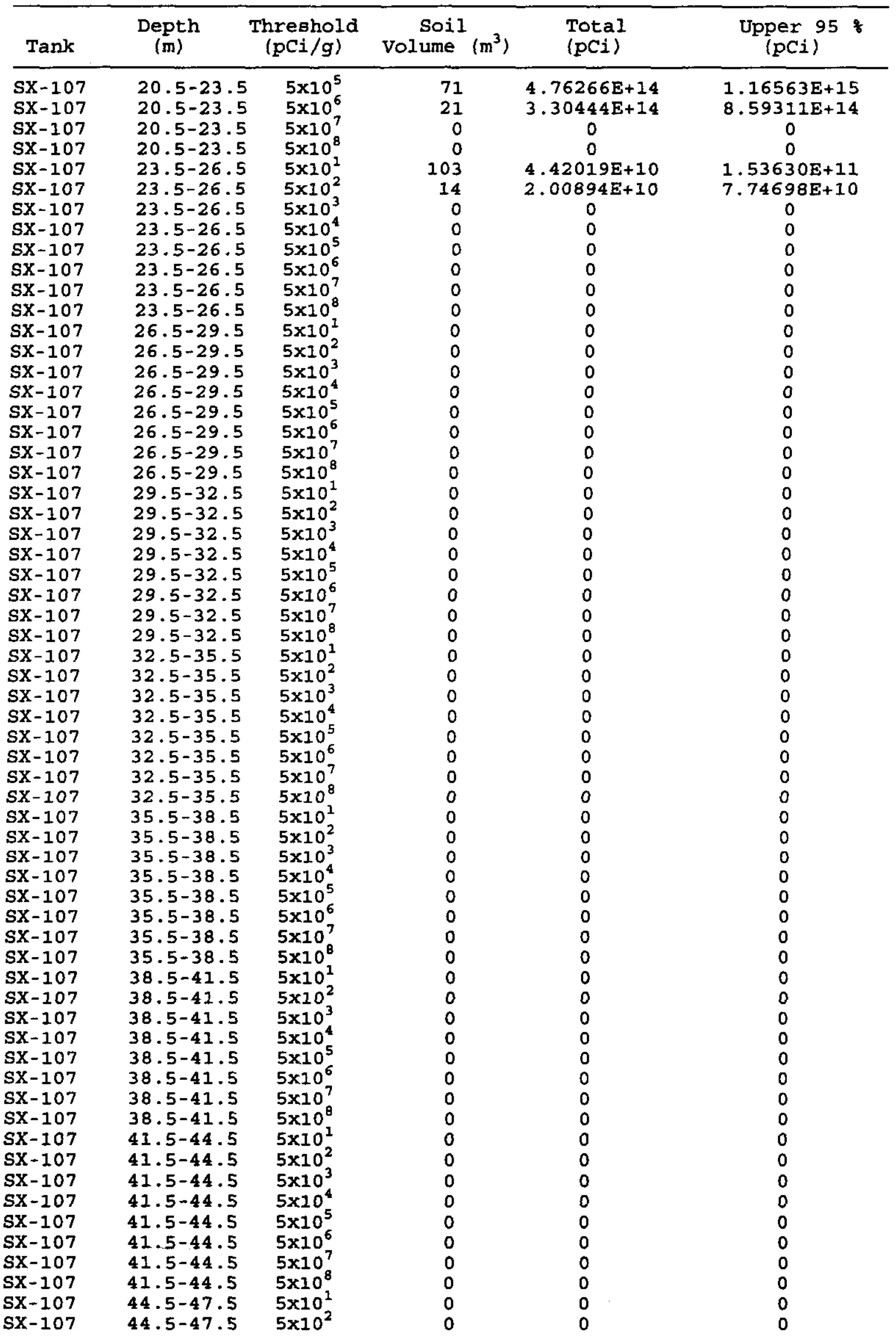


HNF-5782 Rev. 0

Table 8 . Continued.

\begin{tabular}{cccccc}
\hline Tank & $\begin{array}{c}\text { Depth } \\
(\mathrm{m})\end{array}$ & $\begin{array}{c}\text { Threshold } \\
(\mathrm{pCi} / \mathrm{g})\end{array}$ & $\begin{array}{c}\text { Soil } \\
\text { Volume }\left(\mathrm{m}^{3}\right)\end{array}$ & $\begin{array}{c}\text { Total } \\
(\mathrm{pCi})\end{array}$ & $\begin{array}{c}\text { Upper } 95 \% \\
\text { (pCi) }\end{array}$ \\
\hline sX-107 & $44.5-47.5$ & $5 \times 10^{3}$ & 0 & 0 & 0 \\
SX-107 & $44.5-47.5$ & $5 \times 10^{4}$ & 0 & 0 & 0 \\
SX-107 & $44.5-47.5$ & $5 \times 10^{5}$ & 0 & 0 & 0 \\
SX-107 & $44.5-47.5$ & $5 \times 10^{6}$ & 0 & 0 & 0 \\
SX-107 & $44.5-47.5$ & $5 \times 10^{7}$ & 0 & 0 & 0 \\
SX-107 & $44.5-47.5$ & $5 \times 10^{8}$ & 0 & 0 & 0 \\
SX-107 & $47.5-50.5$ & $5 \times 10^{1}$ & 0 & 0 & 0 \\
SX-107 & $47.5-50.5$ & $5 \times 10^{2}$ & 0 & 0 & 0 \\
SX-107 & $47.5-50.5$ & $5 \times 10^{3}$ & 0 & 0 & 0 \\
SX-107 & $47.5-50.5$ & $5 \times 10^{4}$ & 0 & 0 & 0 \\
SX-107 & $47.5-50.5$ & $5 \times 10^{5}$ & 0 & 0 & 0 \\
SX-107 & $47.5-50.5$ & $5 \times 10^{6}$ & 0 & 0 & 0 \\
SX-107 & $47.5-50.5$ & $5 \times 10^{7}$ & 0 & 0 & 0 \\
SX-107 & $47.5-50.5$ & $5 \times 10^{8}$ & 0 & 0 & 0 \\
\hline
\end{tabular}


Table 9. SX-108 inventory of soil volumes, total activities and upper 95\% confidence limit, exceeding 8 activity thresholds over 17 depth increments.

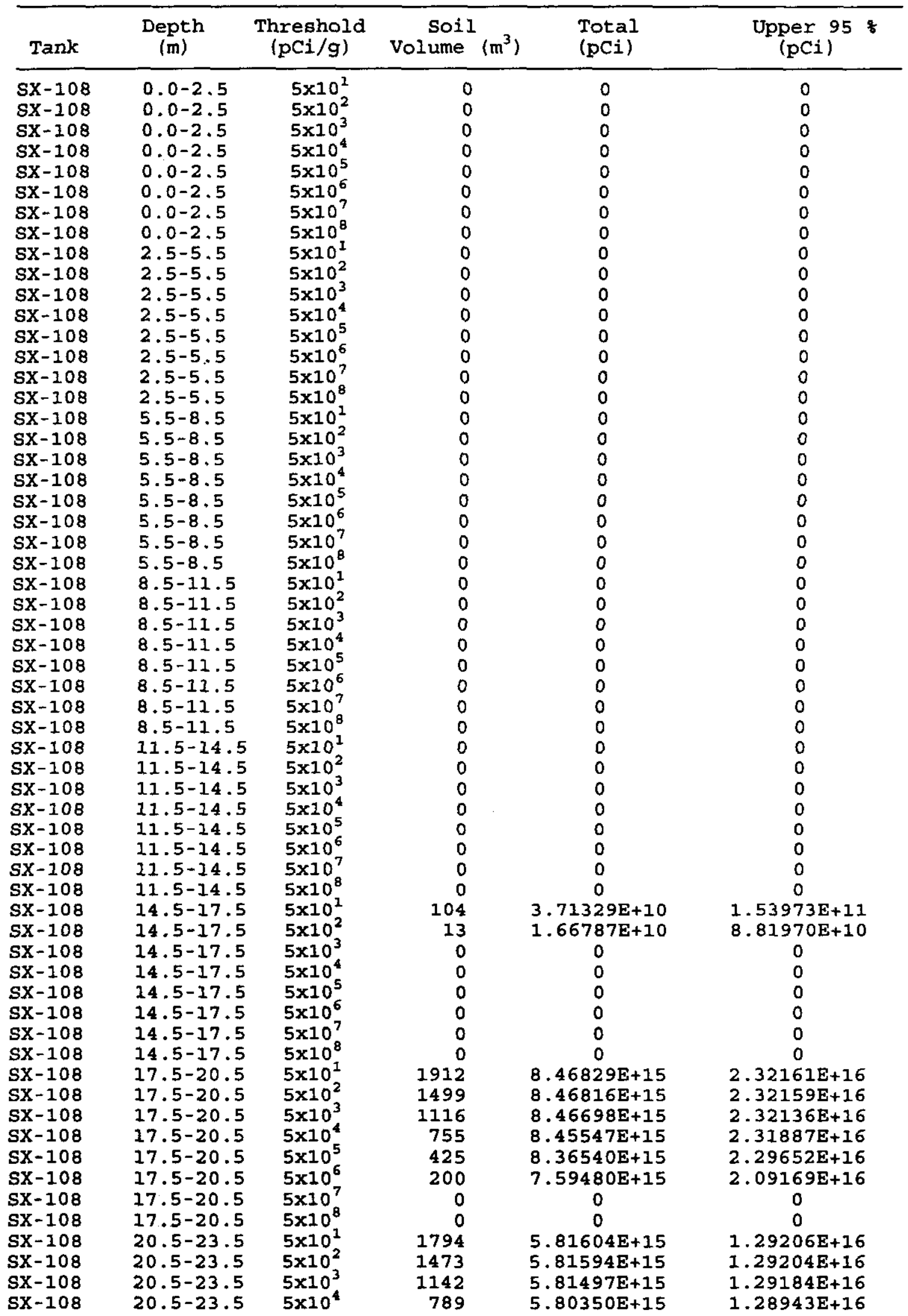


Table 9. Continued.

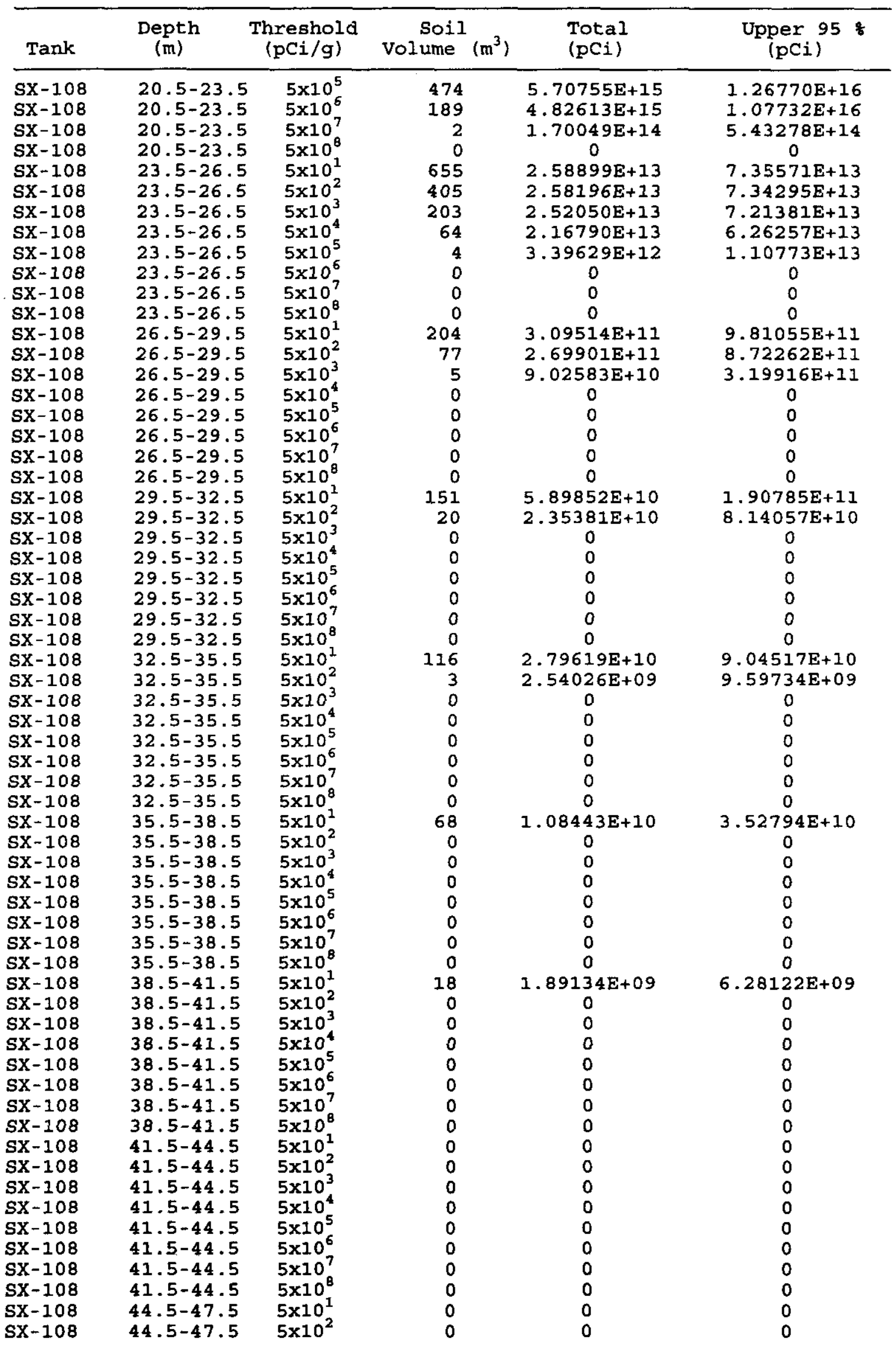


HNF - 5782 Rev . 0

Table 9. Continued.

\begin{tabular}{cccccc}
\hline Tank & $\begin{array}{c}\text { Depth } \\
(\mathrm{m})\end{array}$ & $\begin{array}{c}\text { Threshold } \\
(\mathrm{pCi} / \mathrm{g})\end{array}$ & $\begin{array}{c}\text { Soil } \\
\text { volume } \\
\left(\mathrm{m}^{3}\right)\end{array}$ & $\begin{array}{c}\text { Total } \\
(\mathrm{pCi})\end{array}$ & $\begin{array}{c}\text { Upper } \\
(\mathrm{pCi})\end{array}$ \\
\hline SX-108 & $44.5-47.5$ & $5 \times 10^{3}$ & 0 & 0 & 0 \\
SX-108 & $44.5-47.5$ & $5 \times 10^{4}$ & 0 & 0 & 0 \\
SX-108 & $44.5-47.5$ & $5 \times 10^{5}$ & 0 & 0 & 0 \\
SX-108 & $44.5-47.5$ & $5 \times 10^{6}$ & 0 & 0 & 0 \\
SX-108 & $44.5-47.5$ & $5 \times 10^{7}$ & 0 & 0 & 0 \\
SX-108 & $44.5-47.5$ & $5 \times 10^{8}$ & 0 & 0 & 0 \\
SX-108 & $47.5-50.5$ & $5 \times 10^{1}$ & 0 & 0 & 0 \\
SX-108 & $47.5-50.5$ & $5 \times 10^{2}$ & 0 & 0 & 0 \\
SX-108 & $47.5-50.5$ & $5 \times 10^{3}$ & 0 & 0 & 0 \\
SX-108 & $47.5-50.5$ & $5 \times 10^{4}$ & 0 & 0 & 0 \\
SX-108 & $47.5-50.5$ & $5 \times 10^{5}$ & 0 & 0 & 0 \\
SX-108 & $47.5-50.5$ & $5 \times 10^{6}$ & 0 & 0 & 0 \\
SX-108 & $47.5-50.5$ & $5 \times 10^{7}$ & 0 & 0 & 0 \\
SX-108 & $47.5-50.5$ & $5 \times 10^{8}$ & 0 & 0 & 0 \\
\hline
\end{tabular}


Table 10. Sx-109 inventory of soil volumes, total activities and upper 958 confidence limit, exceeding 8 activity thresholds over 17 depth increments.

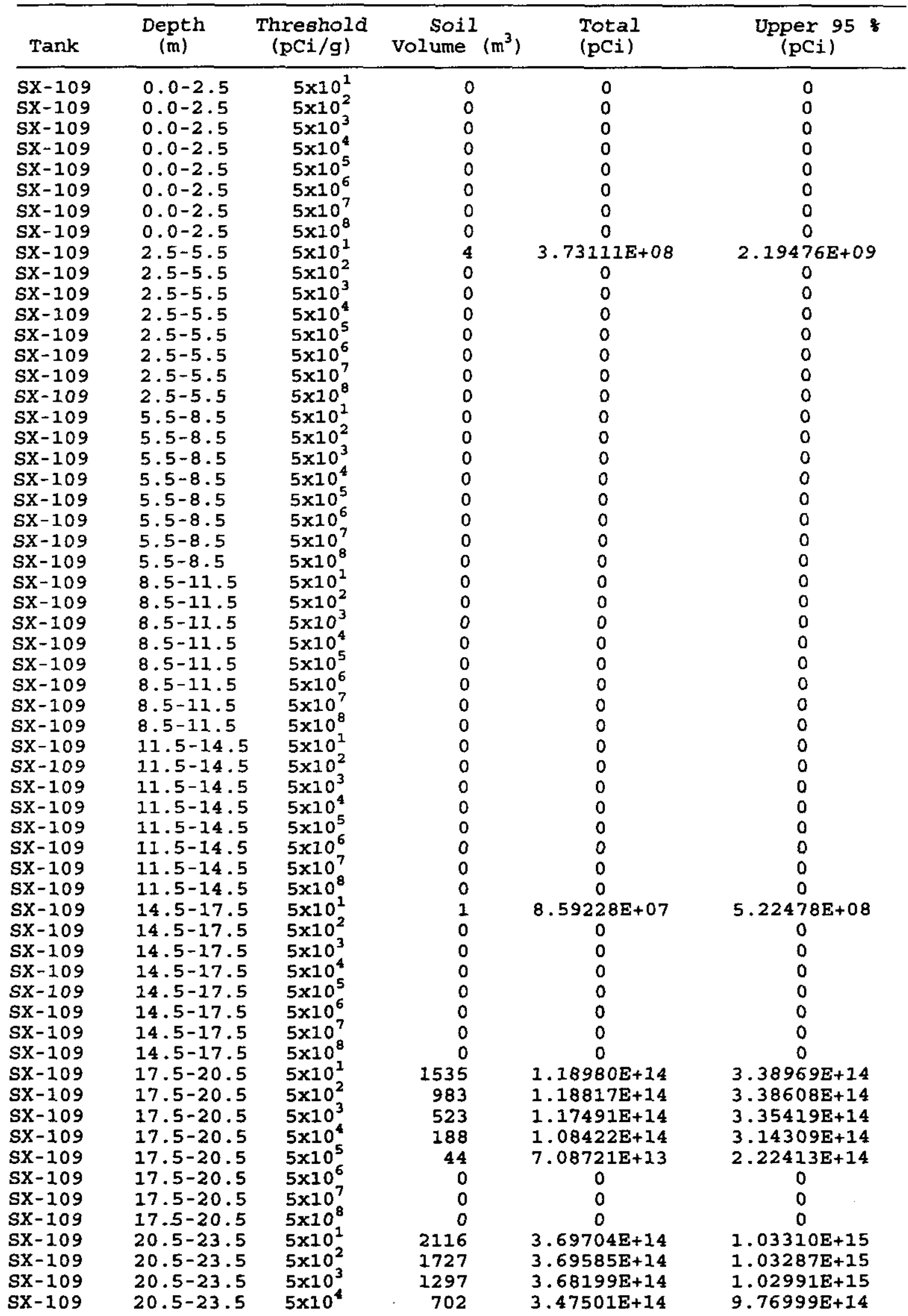


Table 10. Continued.

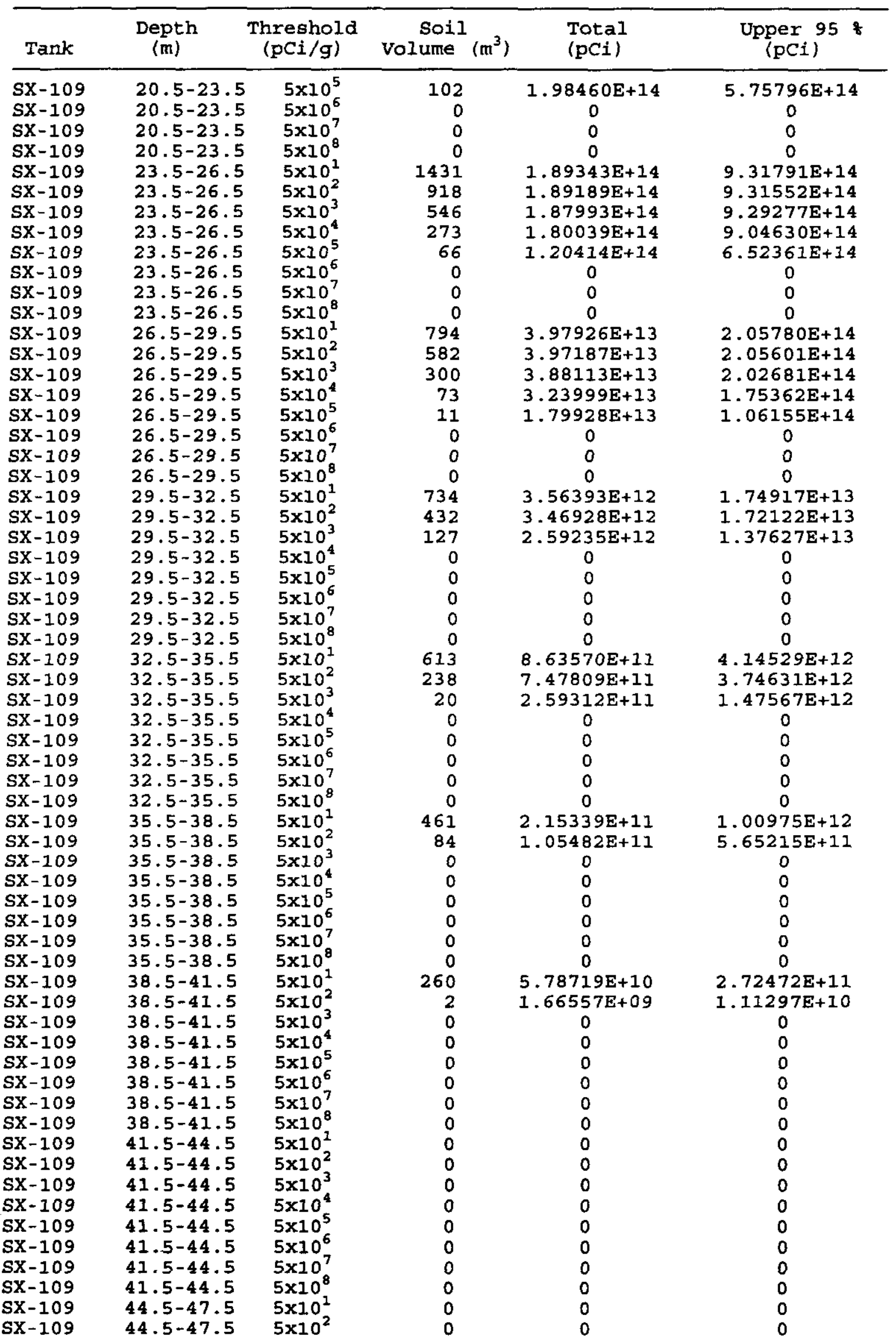


HNF-5782 Rev. O

Table 10. Continued.

\begin{tabular}{cccccc}
\hline Tank & $\begin{array}{c}\text { Depth } \\
(\mathrm{m})\end{array}$ & $\begin{array}{c}\text { Threshold } \\
(\mathrm{pCi} / \mathrm{g})\end{array}$ & $\begin{array}{c}\text { Soil } \\
\text { Volume }\left(\mathrm{m}^{3}\right)\end{array}$ & $\begin{array}{c}\text { Total } \\
(\mathrm{pCi})\end{array}$ & $\begin{array}{c}\text { Upper } 95 \text { \% } \\
\text { (pCi) }\end{array}$ \\
\hline SX-109 & $44.5-47.5$ & $5 \times 10^{3}$ & 0 & 0 & 0 \\
SX-109 & $44.5-47.5$ & $5 \times 10^{4}$ & 0 & 0 & 0 \\
SX-109 & $44.5-47.5$ & $5 \times 10^{5}$ & 0 & 0 & 0 \\
SX-109 & $44.5-47.5$ & $5 \times 10^{6}$ & 0 & 0 & 0 \\
SX-109 & $44.5-47.5$ & $5 \times 10^{7}$ & 0 & 0 & 0 \\
SX-109 & $44.5-47.5$ & $5 \times 10^{8}$ & 0 & 0 & 0 \\
SX-109 & $47.5-50.5$ & $5 \times 10^{1}$ & 0 & 0 & 0 \\
SX-109 & $47.5-50.5$ & $5 \times 10^{2}$ & 0 & 0 & 0 \\
SX-109 & $47.5-50.5$ & $5 \times 10^{3}$ & 0 & 0 & 0 \\
SX-109 & $47.5-50.5$ & $5 \times 10^{4}$ & 0 & 0 & 0 \\
SX-109 & $47.5-50.5$ & $5 \times 10^{5}$ & 0 & 0 & 0 \\
SX-109 & $47.5-50.5$ & $5 \times 10^{6}$ & 0 & 0 & 0 \\
SX-109 & $47.5-50.5$ & $5 \times 10^{7}$ & 0 & 0 & 0 \\
SX-109 & $47.5-50.5$ & $5 \times 10^{8}$ & 0 & 0 & 0 \\
\hline
\end{tabular}


HNF-5782 Rev.0

Table 11. Sx-110 inventory of soil volumes, total activities and upper 958 confidence limit, exceeding 8 activity thresholds over 17 depth increments.

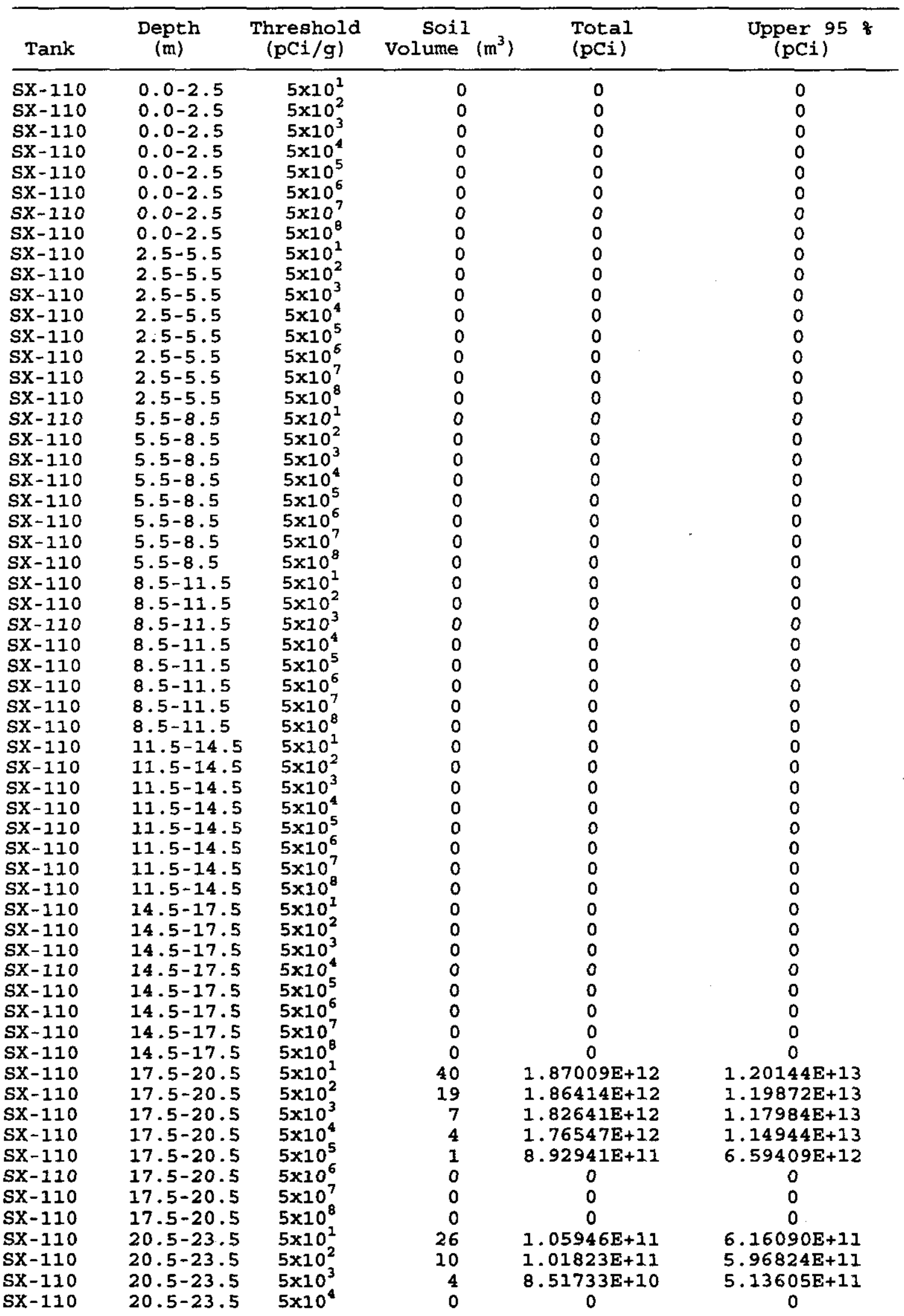


HNF-5782 ReV. 0

Table 11. Continued.

\begin{tabular}{|c|c|c|c|c|c|}
\hline Tank & $\begin{array}{c}\text { Depth } \\
(\mathrm{m})\end{array}$ & $\begin{array}{l}\text { Threshold } \\
(\mathrm{pCi} / \mathrm{g})\end{array}$ & $\begin{array}{c}\text { Soil } \\
\text { Volume }\left(\mathrm{m}^{3}\right)\end{array}$ & $\begin{array}{l}\text { Total } \\
\text { (pci) }\end{array}$ & $\underset{(\mathrm{pCi})}{\text { Upper }}$ \\
\hline$s x-110$ & $20.5-23.5$ & $5 \times 10^{5}$ & 0 & 0 & 0 \\
\hline$s x-110$ & $20.5-23.5$ & $5 \times 10^{6}$ & 0 & 0 & 0 \\
\hline$s x-110$ & $20.5-23.5$ & $5 \times 10^{7}$ & 0 & 0 & 0 \\
\hline$s X-110$ & $20.5-23.5$ & $5 \times 10^{8}$ & 0 & 0 & 0 \\
\hline$s x-110$ & $23.5-26.5$ & $5 \times 10^{1}$ & 0 & 0 & 0 \\
\hline$s x-110$ & $23.5-26.5$ & $5 \times 10^{2}$ & 0 & 0 & 0 \\
\hline$s x-110$ & $23.5-26.5$ & $5 \times 10^{3}$ & 0 & 0 & 0 \\
\hline $5 x-110$ & $23.5-26.5$ & $5 \times 10^{4}$ & 0 & 0 & 0 \\
\hline$s x-110$ & $23.5-26.5$ & $5 \times 10^{5}$ & 0 & 0 & 0 \\
\hline $5 x-110$ & $23.5-26.5$ & $5 \times 10^{6}$ & 0 & 0 & 0 \\
\hline $5 X-110$ & $23.5-26.5$ & $5 \times 10^{7}$ & 0 & - 0 & 0 \\
\hline$s x-110$ & $23.5-26.5$ & $5 \times 10^{8}$ & 0 & 0 & 0 \\
\hline$s x-110$ & $26.5-29.5$ & $5 \times 10^{1}$ & 0 & 0 & 0 \\
\hline $5 x-110$ & $26.5-29.5$ & $5 \times 10^{2}$ & 0 & 0 & 0 \\
\hline $5 x-110$ & $26.5-29.5$ & $5 \times 10^{3}$ & 0 & 0 & 0 \\
\hline$s x-110$ & $26.5-29.5$ & $5 \times 10^{4}$ & 0 & 0 & 0 \\
\hline$s X-110$ & $26.5-29.5$ & $5 \times 10^{5}$ & 0 & 0 & 0 \\
\hline$s x-110$ & $26.5-29.5$ & $5 \times 10^{6}$ & 0 & 0 & 0 \\
\hline$s \mathrm{X}-110$ & $26.5-29.5$ & $5 \times 10^{7}$ & 0 & 0 & 0 \\
\hline$s x-110$ & $26.5-29.5$ & $5 \times 10^{8}$ & 0 & 0 & 0 \\
\hline $5 x-110$ & $29.5-32.5$ & $5 \times 10^{1}$ & 0 & 0 & 0 \\
\hline$s x-110$ & $29.5-32.5$ & $5 \times 10^{2}$ & 0 & 0 & 0 \\
\hline$S X-110$ & $29.5-32.5$ & $5 \times 10^{3}$ & 0 & 0 & 0 \\
\hline$s x-110$ & $29.5-32.5$ & $5 \times 10^{4}$ & 0 & 0 & 0 \\
\hline$s x-110$ & $29.5-32.5$ & $5 \times 10^{5}$ & 0 & 0 & 0 \\
\hline $5 x-110$ & $29.5-32.5$ & $5 \times 10^{6}$ & 0 & 0 & 0 \\
\hline$s x-110$ & $29.5-32.5$ & $5 \times 10^{7}$ & 0 & 0 & 0 \\
\hline$s x-110$ & $29.5-32.5$ & $5 \times 10^{8}$ & 0 & 0 & 0 \\
\hline$s x-110$ & $32.5-35.5$ & $5 \times 10^{1}$ & 0 & 0 & 0 \\
\hline $5 X-110$ & $32.5-35.5$ & $5 \times 10^{2}$ & 0 & 0 & 0 \\
\hline$s x-110$ & $32.5-35.5$ & $5 \times 10^{3}$ & 0 & 0 & 0 \\
\hline$s x-110$ & $32.5-35.5$ & $5 \times 10^{4}$ & 0 & 0 & 0 \\
\hline$S X-110$ & $32.5-35.5$ & $5 \times 10^{5}$ & 0 & 0 & 0 \\
\hline$s x-110$ & $32.5-35.5$ & $5 \times 10^{6}$ & 0 & 0 & 0 \\
\hline$s x-110$ & $32.5-35.5$ & $5 \times 10^{7}$ & 0 & 0 & 0 \\
\hline$s x-110$ & $32.5-35.5$ & $5 \times 10^{8}$ & 0 & 0 & 0 \\
\hline$s X-110$ & $35.5-38.5$ & $5 \times 10^{1}$ & 0 & 0 & 0 \\
\hline$s x-110$ & $35.5-38.5$ & $5 \times 10^{2}$ & 0 & 0 & 0 \\
\hline$s x-110$ & $35.5-38.5$ & $5 \times 10^{3}$ & 0 & 0 & 0 \\
\hline sx-110 & $35.5-38.5$ & $5 \times 10^{4}$ & 0 & 0 & 0 \\
\hline$s x-110$ & $35.5-38.5$ & $5 \times 10^{5}$ & 0 & 0 & 0 \\
\hline$s x-110$ & $35.5-38.5$ & $5 \times 10^{6}$ & 0 & 0 & 0 \\
\hline $5 x-110$ & $35.5-38.5$ & $5 \times 10^{7}$ & 0 & 0 & 0 \\
\hline$S x-110$ & $35.5-38.5$ & $5 \times 10^{8}$ & 0 & 0 & 0 \\
\hline$s x-110$ & $38.5-41.5$ & $5 \times 10^{1}$ & 0 & 0 & 0 \\
\hline $5 x-110$ & $38.5-41.5$ & $5 \times 10^{2}$ & 0 & 0 & 0 \\
\hline$s x-110$ & $38.5-41.5$ & $5 \times 10^{3}$ & 0 & 0 & 0 \\
\hline $5 x-110$ & $38.5-41.5$ & $5 \times 10^{4}$ & 0 & 0 & 0 \\
\hline$s x-110$ & $38.5-41,5$ & $5 \times 10^{5}$ & 0 & 0 & 0 \\
\hline$s x-110$ & $38.5-41.5$ & $5 \times 10^{6}$ & 0 & 0 & 0 \\
\hline$s x-110$ & $38.5-41.5$ & $5 \times 10^{7}$ & 0 & 0 & 0 \\
\hline$s x-110$ & $38.5-41.5$ & $5 \times 10^{8}$ & 0 & 0 & 0 \\
\hline$s \mathrm{x}-110$ & $41.5-44.5$ & $5 \times 10^{1}$ & 0 & 0 & 0 \\
\hline$s x-110$ & $41.5-44.5$ & $5 \times 10^{2}$ & 0 & 0 & 0 \\
\hline$s x-110$ & $41.5-44.5$ & $5 \times 10^{3}$ & 0 & 0 & 0 \\
\hline $5 x-110$ & $41.5-44.5$ & $5 \times 10^{4}$ & 0 & 0 & 0 \\
\hline$S X-110$ & $41.5-44.5$ & $5 \times 10^{5}$ & 0 & 0 & 0 \\
\hline$s x-110$ & $41.5-44.5$ & $5 \times 10^{6}$ & 0 & 0 & 0 \\
\hline$s x-110$ & $41.5-44.5$ & $5 \times 10^{7}$ & 0 & 0 & 0 \\
\hline$s x-110$ & $41.5-44.5$ & $5 \times 10^{8}$ & 0 & 0 & 0 \\
\hline$s x-110$ & $44.5-47.5$ & $5 \times 10^{1}$ & 0 & 0 & 0 \\
\hline$S x-110$ & $44.5-47.5$ & $5 \times 10^{2}$ & 0 & 0 & 0 \\
\hline
\end{tabular}


HNF-5782 Rev.0

Table 11. Continued.

\begin{tabular}{cccccc}
\hline Tank & $\begin{array}{c}\text { Depth } \\
(\mathrm{m})\end{array}$ & $\begin{array}{c}\text { Threshold } \\
(\mathrm{pCi} / \mathrm{g})\end{array}$ & $\begin{array}{c}\text { Soil } \\
\text { Volume }\end{array}\left(\mathrm{m}^{3}\right)$ & $\begin{array}{c}\text { Total } \\
(\mathrm{pCi})\end{array}$ & $\begin{array}{c}\text { Upper } 95 \% \\
(\mathrm{pCi})\end{array}$ \\
\hline $\mathrm{SX}-110$ & $44.5-47.5$ & $5 \times 10^{3}$ & 0 & 0 & 0 \\
$\mathrm{SX}-110$ & $44.5-47.5$ & $5 \times 10^{4}$ & 0 & 0 & 0 \\
$\mathrm{SX}-110$ & $44.5-47.5$ & $5 \times 10^{5}$ & 0 & 0 & 0 \\
SX-110 & $44.5-47.5$ & $5 \times 10^{6}$ & 0 & 0 & 0 \\
SX-110 & $44.5-47.5$ & $5 \times 10^{7}$ & 0 & 0 & 0 \\
SX-110 & $44.5-47.5$ & $5 \times 10^{8}$ & 0 & 0 & 0 \\
SX-110 & $47.5-50.5$ & $5 \times 10^{1}$ & 0 & 0 & 0 \\
SX-110 & $47.5-50.5$ & $5 \times 10^{2}$ & 0 & 0 & 0 \\
SX-110 & $47.5-50.5$ & $5 \times 10^{3}$ & 0 & 0 & 0 \\
SX-110 & $47.5-50.5$ & $5 \times 10^{4}$ & 0 & 0 & 0 \\
SX-110 & $47.5-50.5$ & $5 \times 10^{5}$ & 0 & 0 & 0 \\
SX-110 & $47.5-50.5$ & $5 \times 10^{6}$ & 0 & 0 & 0 \\
SX-110 & $47.5-50.5$ & $5 \times 10^{7}$ & 0 & 0 & 0 \\
SX-110 & $47.5-50.5$ & $5 \times 10^{8}$ & 0 & 0 & 0 \\
\hline
\end{tabular}


Table 12. SX-111 inventory of soil volumes, total activities and upper 95\% confidence limit, exceeding 8 activity thresholds over 17 depth increments.

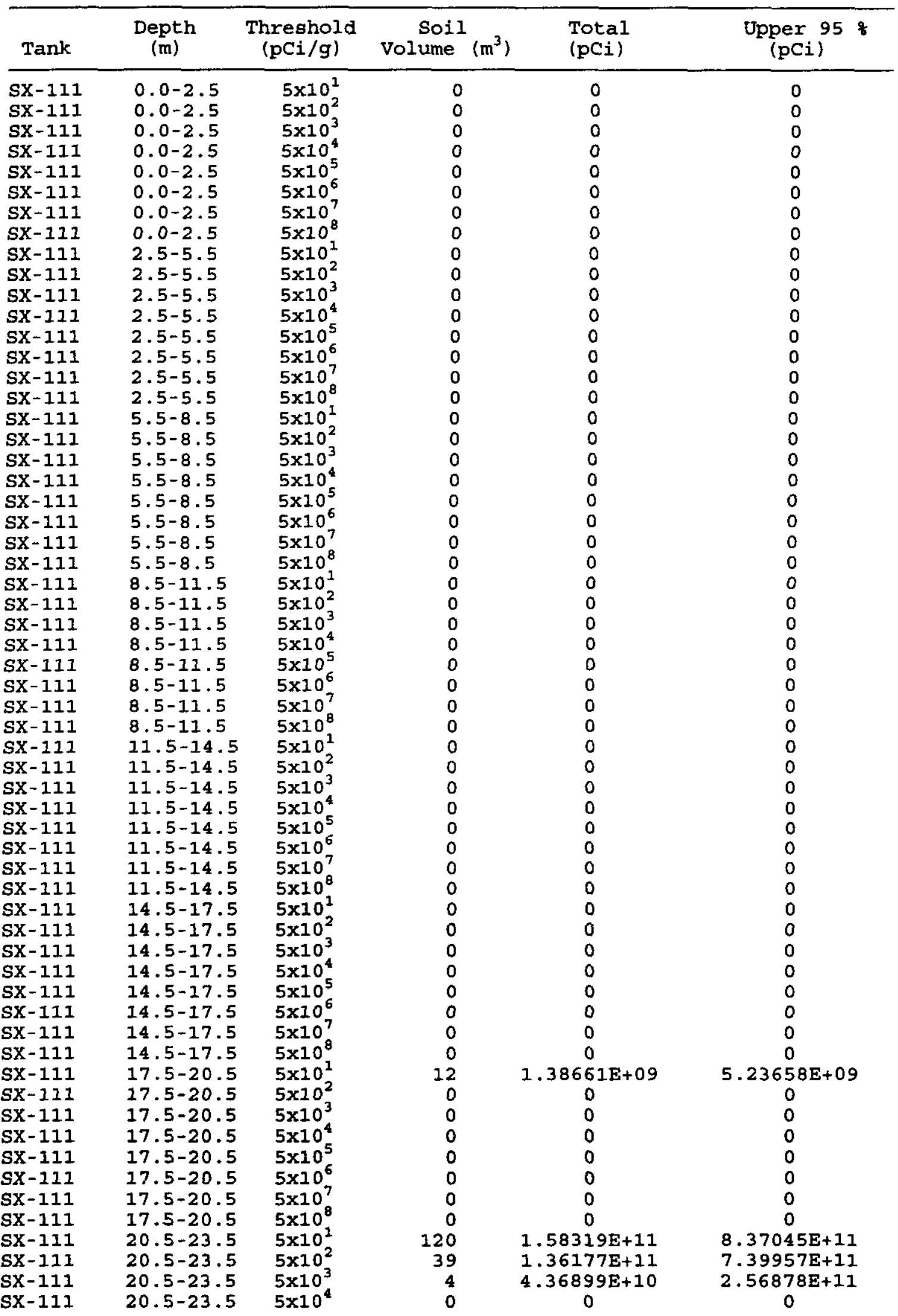


Table 12. Continued.

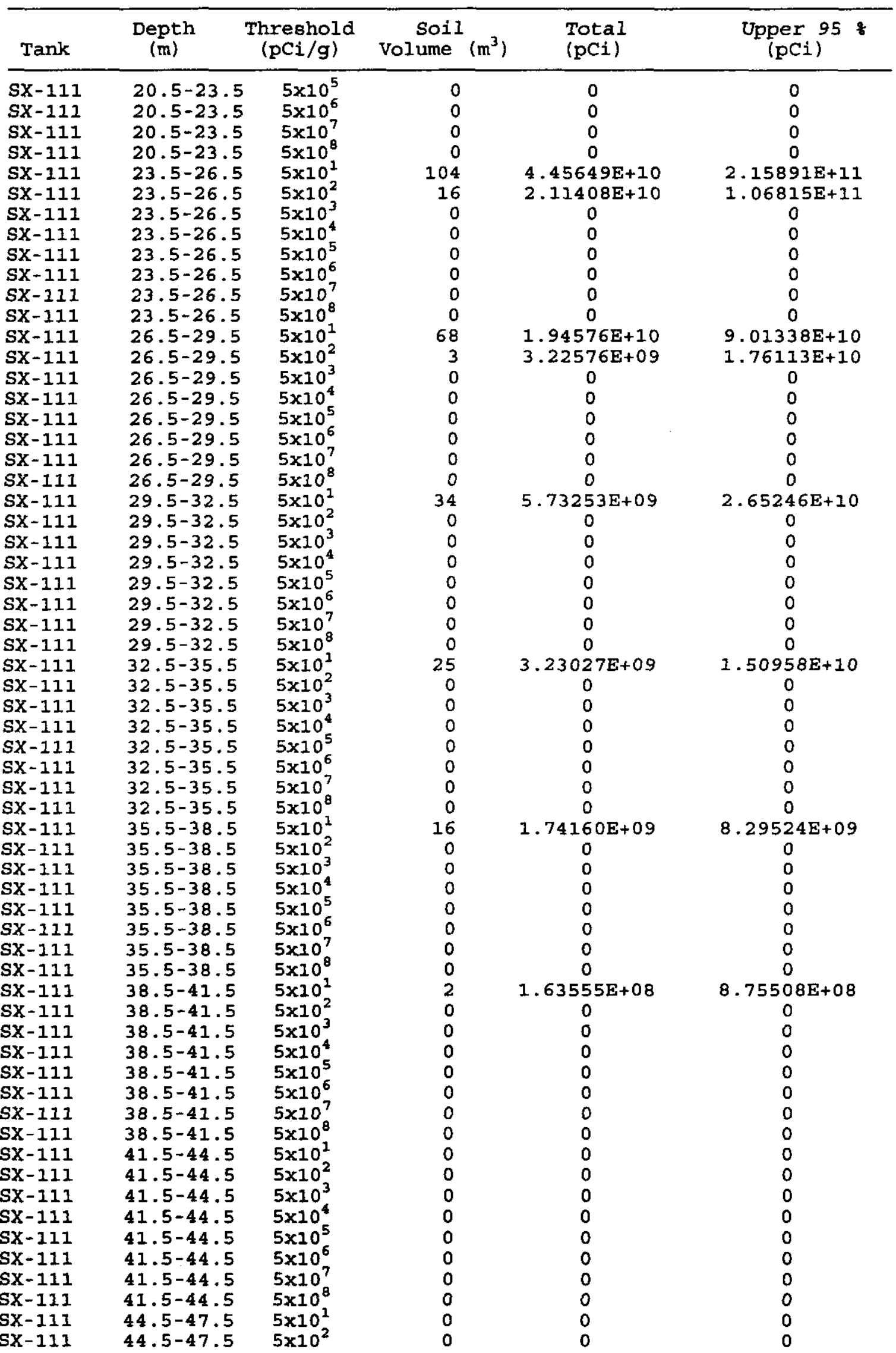


HNF-5782 Rev.0

Table 12. Continued.

\begin{tabular}{cccccc}
\hline Tank & $\begin{array}{c}\text { Depth } \\
(\mathrm{m})\end{array}$ & $\begin{array}{c}\text { Threshold } \\
(\mathrm{pCi} / \mathrm{g})\end{array}$ & $\left.\begin{array}{c}\text { Soil } \\
\text { Volume }\end{array} \mathrm{m}^{3}\right)$ & $\begin{array}{c}\text { Total } \\
(\text { pCi })\end{array}$ & $\begin{array}{c}\text { Upper } 95 \text { i } \\
(\text { pCi })\end{array}$ \\
\hline SX-111 & $\mathbf{4 4 . 5 - 4 7 . 5}$ & $5 \times 10^{3}$ & 0 & 0 & 0 \\
SX-111 & $\mathbf{4 4 . 5 - 4 7 . 5}$ & $5 \times 10^{4}$ & 0 & 0 & 0 \\
SX-111 & $\mathbf{4 4 . 5 - 4 7 . 5}$ & $5 \times 10^{5}$ & 0 & 0 & 0 \\
SX-111 & $\mathbf{4 4 . 5 - 4 7 . 5}$ & $5 \times 10^{6}$ & 0 & 0 & 0 \\
SX-111 & $44.5-47.5$ & $5 \times 10^{7}$ & 0 & 0 & 0 \\
SX-111 & $\mathbf{4 4 . 5 - 4 7 . 5}$ & $5 \times 10^{8}$ & 0 & 0 & 0 \\
SX-111 & $\mathbf{4 7 . 5 - 5 0 . 5}$ & $5 \times 10^{1}$ & 0 & 0 & 0 \\
SX-111 & $\mathbf{4 7 . 5 - 5 0 . 5}$ & $5 \times 10^{2}$ & 0 & 0 & 0 \\
SX-111 & $47.5-50.5$ & $5 \times 10^{3}$ & 0 & 0 & 0 \\
SX-111 & $47.5-50.5$ & $5 \times 10^{4}$ & 0 & 0 & 0 \\
SX-111 & $47.5-50.5$ & $5 \times 10^{5}$ & 0 & 0 & 0 \\
SX-111 & $47.5-50.5$ & $5 \times 10^{6}$ & 0 & 0 & 0 \\
SX-111 & $47.5-50.5$ & $5 \times 10^{7}$ & 0 & 0 & 0 \\
SX-111 & $47.5-50.5$ & $5 \times 10^{8}$ & 0 & 0 & 0 \\
\hline
\end{tabular}


Table 13. sx-112 inventory of soil volumes, total activities and upper $95 \%$ confidence limit, exceeding 8 activity thresholds over 17 depth increments.

\begin{tabular}{|c|c|c|c|c|c|}
\hline Tank & $\begin{array}{l}\text { Depth } \\
(\mathrm{m})\end{array}$ & $\begin{array}{l}\text { Threshold } \\
\text { (pCi/g) }\end{array}$ & Solume $\left(\mathrm{m}^{3}\right)$ & $\begin{array}{l}\text { Total } \\
\text { (pCi) }\end{array}$ & $\begin{array}{l}\text { Upper } 95 \% \\
\text { (pCi) }\end{array}$ \\
\hline$s x-112$ & $0.0-2.5$ & $5 \times 10^{1}$ & 0 & 0 & 0 \\
\hline$s x-112$ & $0.0-2.5$ & $5 \times 10^{2}$ & 0 & 0 & 0 \\
\hline$s x-112$ & $0.0-2.5$ & $5 \times 10^{3}$ & 0 & 0 & 0 \\
\hline SX-112 & $0.0-2.5$ & $5 \times 10^{4}$ & 0 & 0 & 0 \\
\hline$S X-112$ & $0.0-2.5$ & $5 \times 10^{5}$ & 0 & 0 & 0 \\
\hline $5 X-112$ & $0.0-2.5$ & $5 \times 10^{6}$ & 0 & 0 & 0 \\
\hline$S X-112$ & $0.0-2.5$ & $5 \times 10^{7}$ & 0 & 0 & 0 \\
\hline $5 X-112$ & $0.0-2.5$ & $5 \times 10^{8}$ & 0 & 0 & 0 \\
\hline $5 x-112$ & $2.5-5.5$ & $5 \times 10^{1}$ & 0 & 0 & 0 \\
\hline$S X-112$ & $2.5-5.5$ & $5 \times 10^{2}$ & 0 & 0 & 0 \\
\hline $\mathrm{sx}-112$ & $2.5-5.5$ & $5 \times 10^{3}$ & 0 & 0 & 0 \\
\hline $5 x-112$ & $2.5-5.5$ & $5 \times 10^{4}$ & 0 & 0 & 0 \\
\hline$s x-112$ & $2.5-5.5$ & $5 \times 10^{5}$ & 0 & 0 & 0 \\
\hline$s x-112$ & $2.5-5.5$ & $5 \times 10^{6}$ & 0 & 0 & 0 \\
\hline $\mathrm{SX}-112$ & $2.5-5.5$ & $5 \times 10^{7}$ & 0 & 0 & 0 \\
\hline$s x-112$ & $2.5-5.5$ & $5 \times 10^{8}$ & 0 & 0 & 0 \\
\hline$S X-112$ & $5.5-8.5$ & $5 \times 10^{1}$ & 0 & 0 & 0 \\
\hline$S X-112$ & $5.5-8.5$ & $5 \times 10^{2}$ & 0 & 0 & 0 \\
\hline$S X-112$ & $5.5-8.5$ & $5 \times 10^{3}$ & 0 & 0 & 0 \\
\hline$S X-112$ & $5.5-8.5$ & $5 \times 10^{4}$ & 0 & 0 & 0 \\
\hline$s x-112$ & $5.5-8.5$ & $5 \times 10^{5}$ & 0 & 0 & 0 \\
\hline$s X-112$ & $5.5-8.5$ & $5 \times 10^{6}$ & 0 & 0 & 0 \\
\hline$S X-112$ & $5.5-8.5$ & $5 \times 10^{7}$ & 0 & 0 & 0 \\
\hline$S x-112$ & $5.5-8.5$ & $5 \times 10^{8}$ & 0 & 0 & 0 \\
\hline$S X-112$ & $8.5-11.5$ & $5 \times 10^{1}$ & 0 & 0 & 0 \\
\hline$S X-112$ & $8.5-11.5$ & $5 \times 10^{2}$ & 0 & 0 & 0 \\
\hline$S X-112$ & $8.5-11.5$ & $5 \times 10^{3}$ & 0 & 0 & 0 \\
\hline$S X-112$ & $8.5-11.5$ & $5 \times 10^{4}$ & 0 & 0 & 0 \\
\hline$s X-112$ & $8.5-11.5$ & $5 \times 10^{5}$ & 0 & 0 & 0 \\
\hline$s X-112$ & $8.5-11.5$ & $5 \times 10^{6}$ & 0 & 0 & 0 \\
\hline$s x-112$ & $8.5-11.5$ & $5 \times 10^{7}$ & 0 & 0 & 0 \\
\hline SX-112 & $8.5-11.5$ & $5 \times 10^{8}$ & 0 & 0 & 0 \\
\hline$s X-112$ & $11.5-14.5$ & $5 \times 10^{1}$ & 0 & 0 & 0 \\
\hline$s X-112$ & $11.5-14.5$ & $5 \times 10^{2}$ & 0 & 0 & 0 \\
\hline$s x-112$ & $11.5-14.5$ & $5 \times 10^{3}$ & 0 & 0 & 0 \\
\hline$S X-112$ & $11.5-14.5$ & $5 \times 10^{4}$ & 0 & 0 & 0 \\
\hline $5 x-112$ & $11.5-14.5$ & $5 \times 10^{5}$ & 0 & 0 & 0 \\
\hline$s x-112$ & $11.5-14.5$ & $5 \times 10^{6}$ & 0 & 0 & 0 \\
\hline$s x-112$ & $11.5-14.5$ & $5 \times 10^{7}$ & 0 & 0 & 0 \\
\hline$S X-112$ & $11.5-14.5$ & $5 \times 10^{8}$ & 0 & 0 & 0 \\
\hline $\mathrm{SX}-112$ & $14.5-17.5$ & $5 \times 10^{1}$ & 0 & 0 & 0 \\
\hline$S X-112$ & $14.5-17.5$ & $5 \times 10^{2}$ & 0 & 0 & 0 \\
\hline$S X-112$ & $14.5-17.5$ & $5 \times 10^{3}$ & 0 & 0 & 0 \\
\hline SX-112 & $14.5-17.5$ & $5 \times 10_{5}^{4}$ & 0 & 0 & 0 \\
\hline$S x-112$ & $14.5-17.5$ & $5 \times 10^{5}$ & 0 & 0 & 0 \\
\hline$S X-112$ & $14.5-17.5$ & $5 \times 10^{6}$ & 0 & 0 & 0 \\
\hline $\mathrm{sX}-112$ & $14.5-17.5$ & $5 \times 10^{7}$ & 0 & 0 & 0 \\
\hline$s x-112$ & $14.5-17.5$ & $5 \times 10^{8}$ & 0 & 0 & 0 \\
\hline$S X-112$ & $17.5-20.5$ & $5 \times 10^{1}$ & 5 & $6.59550 E+08$ & $3.67724 \mathrm{E}+09$ \\
\hline$S X-112$ & $17.5-20.5$ & $5 \times 10^{2}$ & 0 & 0 & 0 \\
\hline $\mathrm{sX}-112$ & $17.5-20.5$ & $5 \times 10^{3}$ & 0 & 0 & 0 \\
\hline$S X-112$ & $17.5-20.5$ & $5 \times 10^{4}$ & 0 & 0 & 0 \\
\hline$S X-112$ & $17.5-20.5$ & $5 \times 10^{5}$ & 0 & 0 & 0 \\
\hline $5 x-112$ & $17.5-20.5$ & $5 \times 10^{6}$ & 0 & 0 & 0 \\
\hline$S x-112$ & $17.5-20.5$ & $5 \times 10^{7}$ & 0 & 0 & 0 \\
\hline$S X-112$ & $17.5-20.5$ & $5 \times 10^{8}$ & 0 & 0 & 0 \\
\hline$S X-112$ & $20.5-23.5$ & $5 \times 10^{1}$ & 236 & $3.97563 E+11$ & $1.96114 \mathrm{E}+12$ \\
\hline$S X-112$ & $20.5-23.5$ & $5 \times 10^{2}$ & 92 & $3.60181 E+11$ & $1.81149 \mathrm{E}+12$ \\
\hline$S X-112$ & $20.5-23.5$ & $5 \times 10^{3}$ & 9 & $1.03884 \mathrm{E}+11$ & $5.69996 \mathrm{E}+11$ \\
\hline $\mathrm{SX}-112$ & $20.5-23.5$ & $5 \times 10^{4}$ & 0 & 0 & 0 \\
\hline
\end{tabular}


Table 13. Continued.

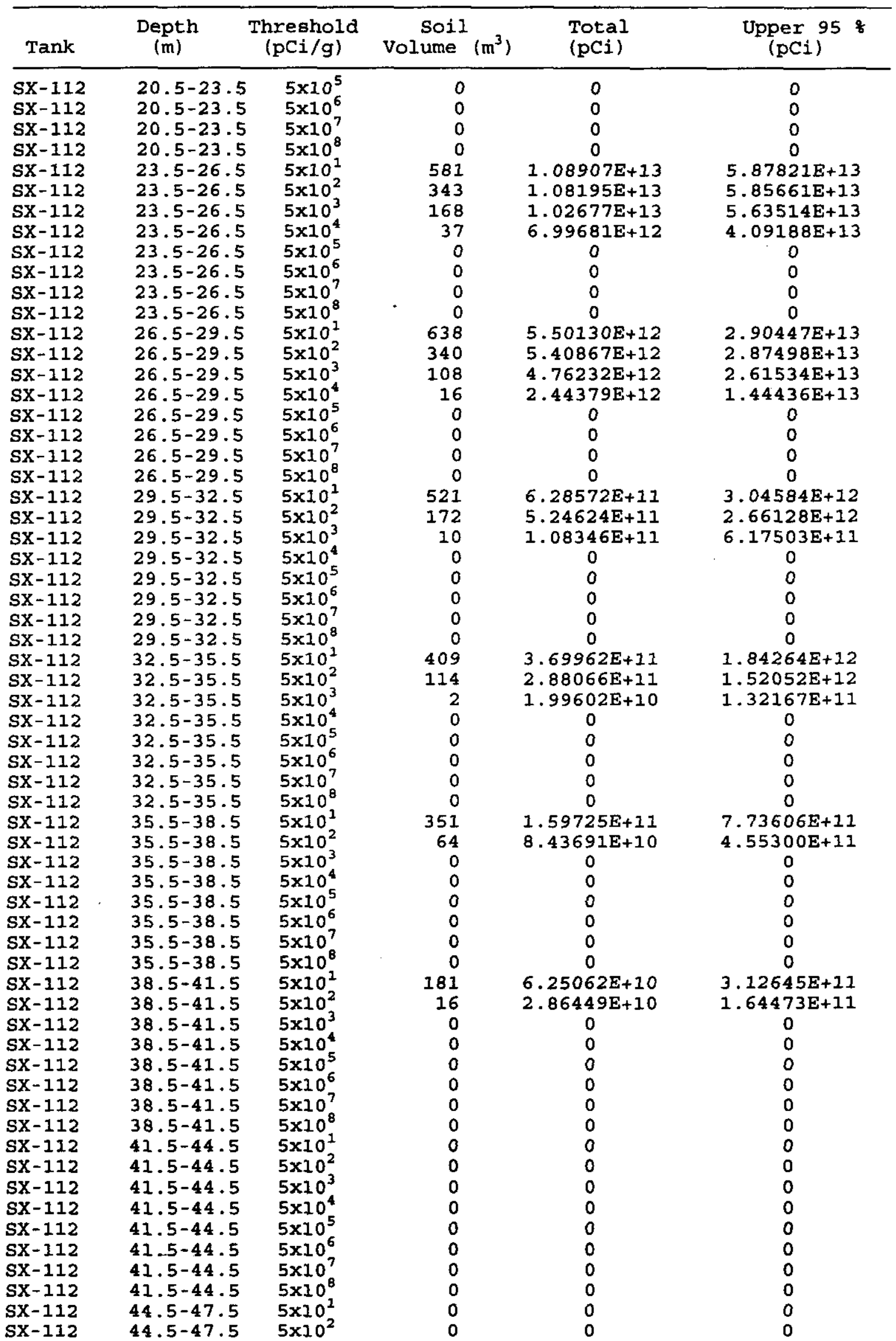


HNF-5782 Rev. 0

Table 13. Continued.

\begin{tabular}{cccccc}
\hline Tank & $\begin{array}{c}\text { Depth } \\
(\mathrm{m})\end{array}$ & $\begin{array}{c}\text { Threshold } \\
(\mathrm{pCi} / \mathrm{g})\end{array}$ & $\begin{array}{c}\text { Soil } \\
\text { Volume }\end{array}$ & $\begin{array}{c}\text { Total } \\
(\mathrm{pC})\end{array}$ & $\begin{array}{c}\text { Upper } 95 \text { \% } \\
(\mathrm{pCi})\end{array}$ \\
\hline SX-112 & $\mathbf{4 4 . 5 - 4 7 . 5}$ & $5 \times 10^{3}$ & 0 & 0 & 0 \\
SX-112 & $\mathbf{4 4 . 5 - 4 7 . 5}$ & $5 \times 10^{4}$ & 0 & 0 & 0 \\
SX-112 & $\mathbf{4 4 . 5 - 4 7 . 5}$ & $5 \times 10^{5}$ & 0 & 0 & 0 \\
SX-112 & $\mathbf{4 4 . 5 - 4 7 . 5}$ & $5 \times 10^{6}$ & 0 & 0 & 0 \\
SX-112 & $44.5-47.5$ & $5 \times 10^{7}$ & 0 & 0 & 0 \\
SX-112 & $44.5-47.5$ & $5 \times 10^{8}$ & 0 & 0 & 0 \\
SX-112 & $47.5-50.5$ & $5 \times 10^{1}$ & 0 & 0 & 0 \\
SX-112 & $47.5-50.5$ & $5 \times 10^{2}$ & 0 & 0 & 0 \\
SX-112 & $47.5-50.5$ & $5 \times 10^{3}$ & 0 & 0 & 0 \\
SX-112 & $47.5-50.5$ & $5 \times 10^{4}$ & 0 & 0 & 0 \\
SX-112 & $47.5-50.5$ & $5 \times 10^{5}$ & 0 & 0 & 0 \\
SX-112 & $47.5-50.5$ & $5 \times 10^{6}$ & 0 & 0 & 0 \\
SX-112 & $47.5-50.5$ & $5 \times 10^{7}$ & 0 & 0 & 0 \\
SX-112 & $47.5-50.5$ & $5 \times 10^{8}$ & 0 & 0 & 0 \\
\hline
\end{tabular}


Table 14. SX-113 inventory of soil volumes, total activities and upper 958 confidence limit, exceeding 8 activity thresholds over 17 depth increments.

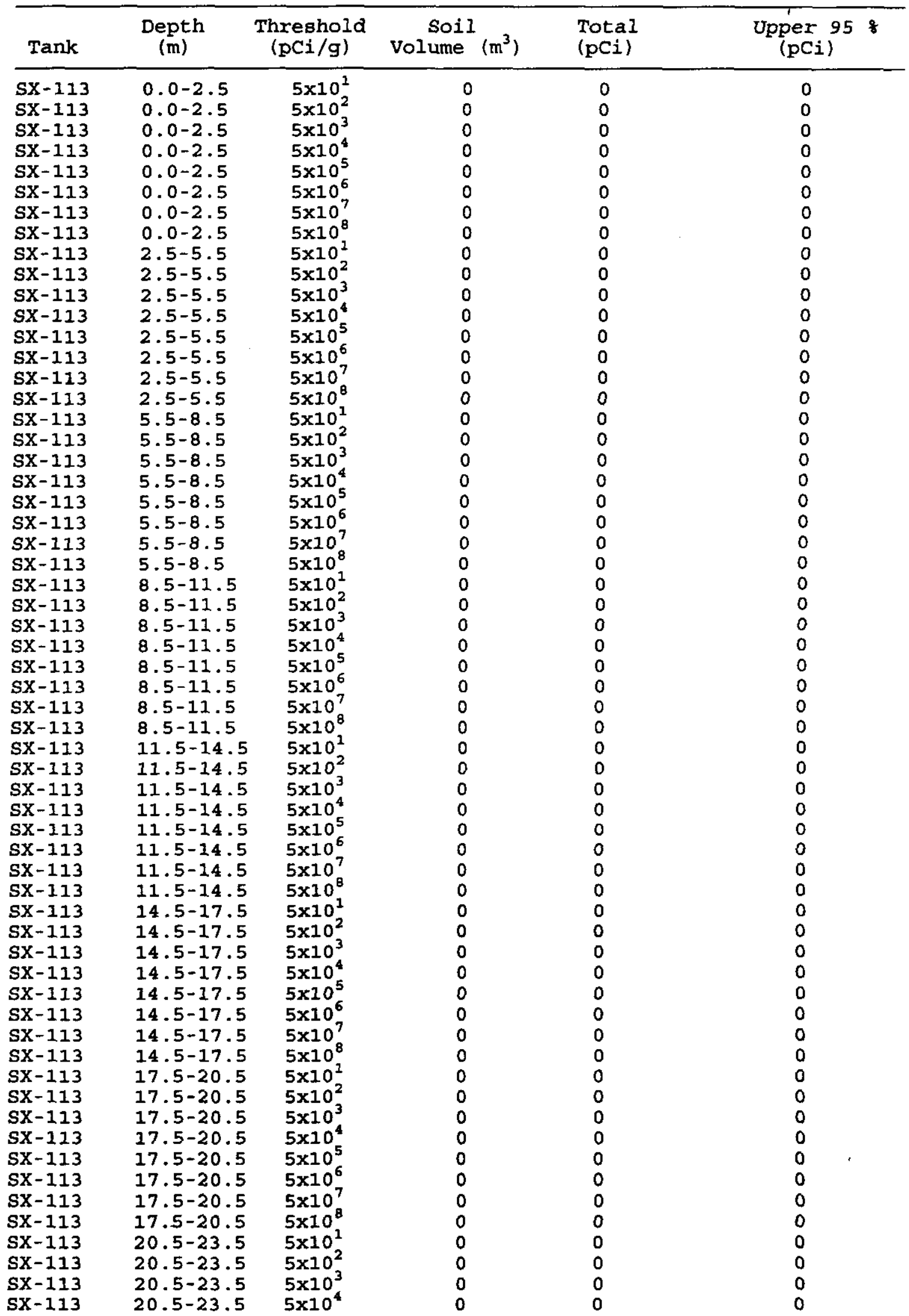


Table 14. Continued.

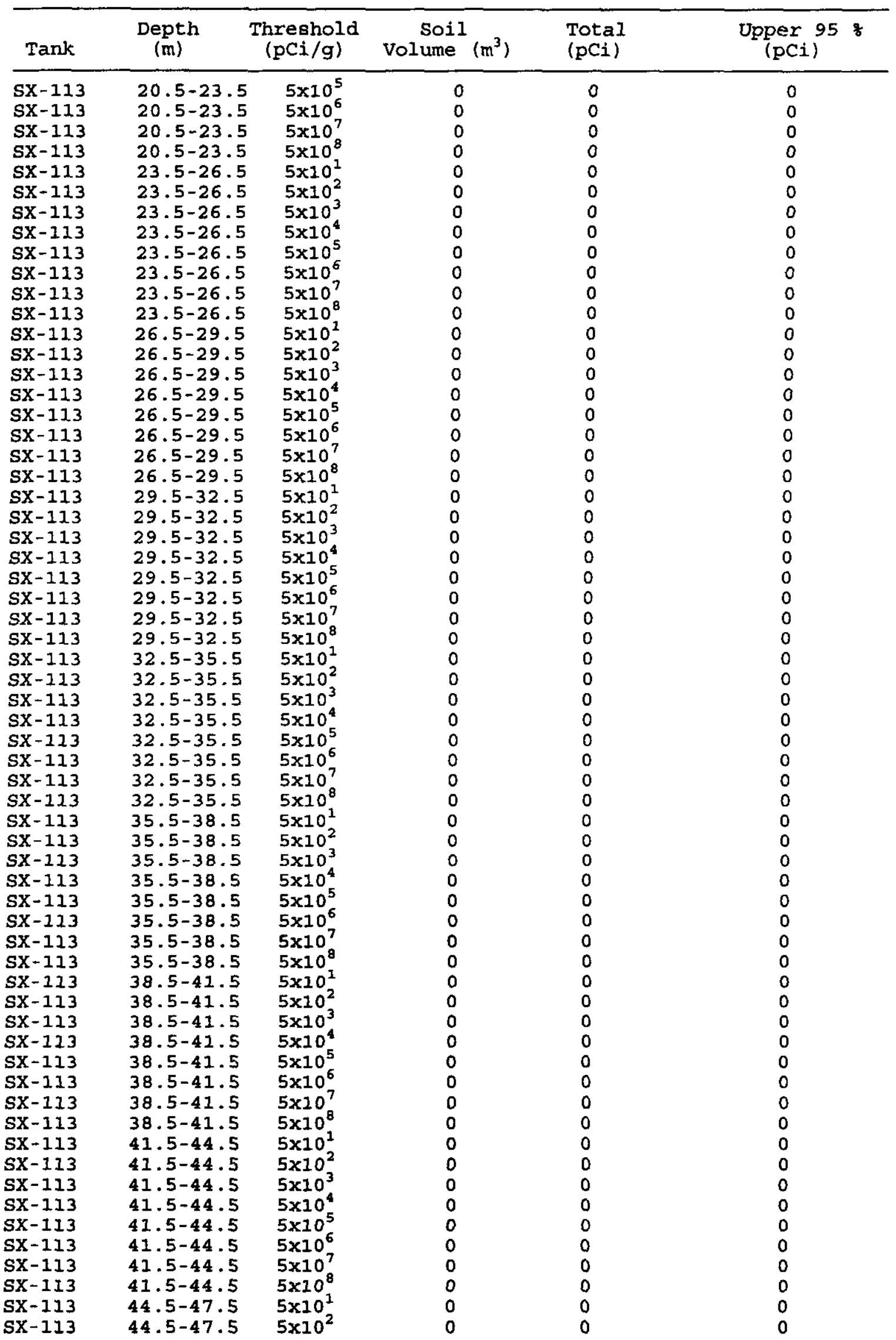


HNF-5782 Rev. 0

Table 14. Continued.

\begin{tabular}{cccccc}
\hline Tank & $\begin{array}{c}\text { Depth } \\
(\mathrm{m})\end{array}$ & $\begin{array}{c}\text { Threshold } \\
(\mathrm{pCi} / \mathrm{g})\end{array}$ & $\begin{array}{c}\text { Soil } \\
\text { Volume }\end{array}$ & $\begin{array}{c}\text { Total } \\
\text { (pCi) }\end{array}$ & $\begin{array}{c}\text { Upper } 95 \% \\
(\text { pCi) }\end{array}$ \\
\hline SX-113 & $\mathbf{4 4 . 5 - 4 7 . 5}$ & $5 \times 10^{3}$ & 0 & 0 & 0 \\
SX-113 & $\mathbf{4 4 . 5 - 4 7 . 5}$ & $5 \times 10^{4}$ & 0 & 0 & 0 \\
SX-113 & $\mathbf{4 4 . 5 - 4 7 . 5}$ & $5 \times 10^{5}$ & 0 & 0 & 0 \\
SX-113 & $\mathbf{4 4 . 5 - 4 7 . 5}$ & $5 \times 10^{6}$ & 0 & 0 & 0 \\
SX-113 & $\mathbf{4 4 . 5 - 4 7 . 5}$ & $5 \times 10^{7}$ & 0 & 0 & 0 \\
SX-113 & $\mathbf{4 4 . 5 - 4 7 . 5}$ & $5 \times 10^{8}$ & 0 & 0 & 0 \\
SX-113 & $47.5-50.5$ & $5 \times 10^{1}$ & 0 & 0 & 0 \\
SX-113 & $47.5-50.5$ & $5 \times 10^{2}$ & 0 & 0 & 0 \\
SX-113 & $47.5-50.5$ & $5 \times 10^{3}$ & 0 & 0 & 0 \\
SX-113 & $47.5-50.5$ & $5 \times 10^{4}$ & 0 & 0 & 0 \\
SX-113 & $47.5-50.5$ & $5 \times 10^{5}$ & 0 & 0 & 0 \\
SX-113 & $47.5-50.5$ & $5 \times 10^{6}$ & 0 & 0 & 0 \\
SX-113 & $47.5-50.5$ & $5 \times 10^{7}$ & 0 & 0 & \\
SX-113 & $47.5-50.5$ & $5 \times 10^{8}$ & 0 & 0 & 0 \\
\hline
\end{tabular}


Table 15. SX-114 inventory of soil volumes, total activities and upper 95\% confidence limit, exceeding 8 activity thresholds over 17 depth increments.

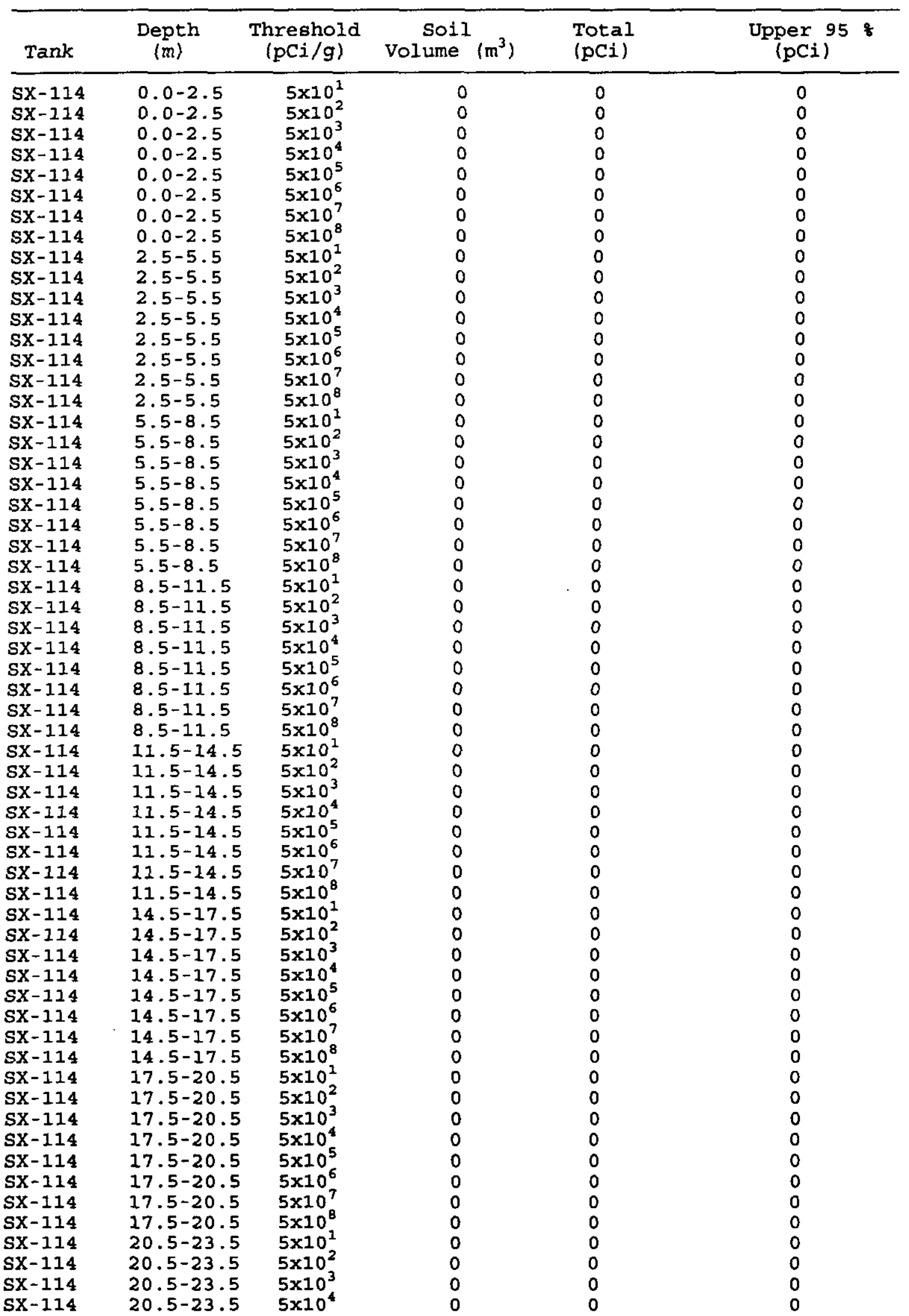


Table 15. Continued.

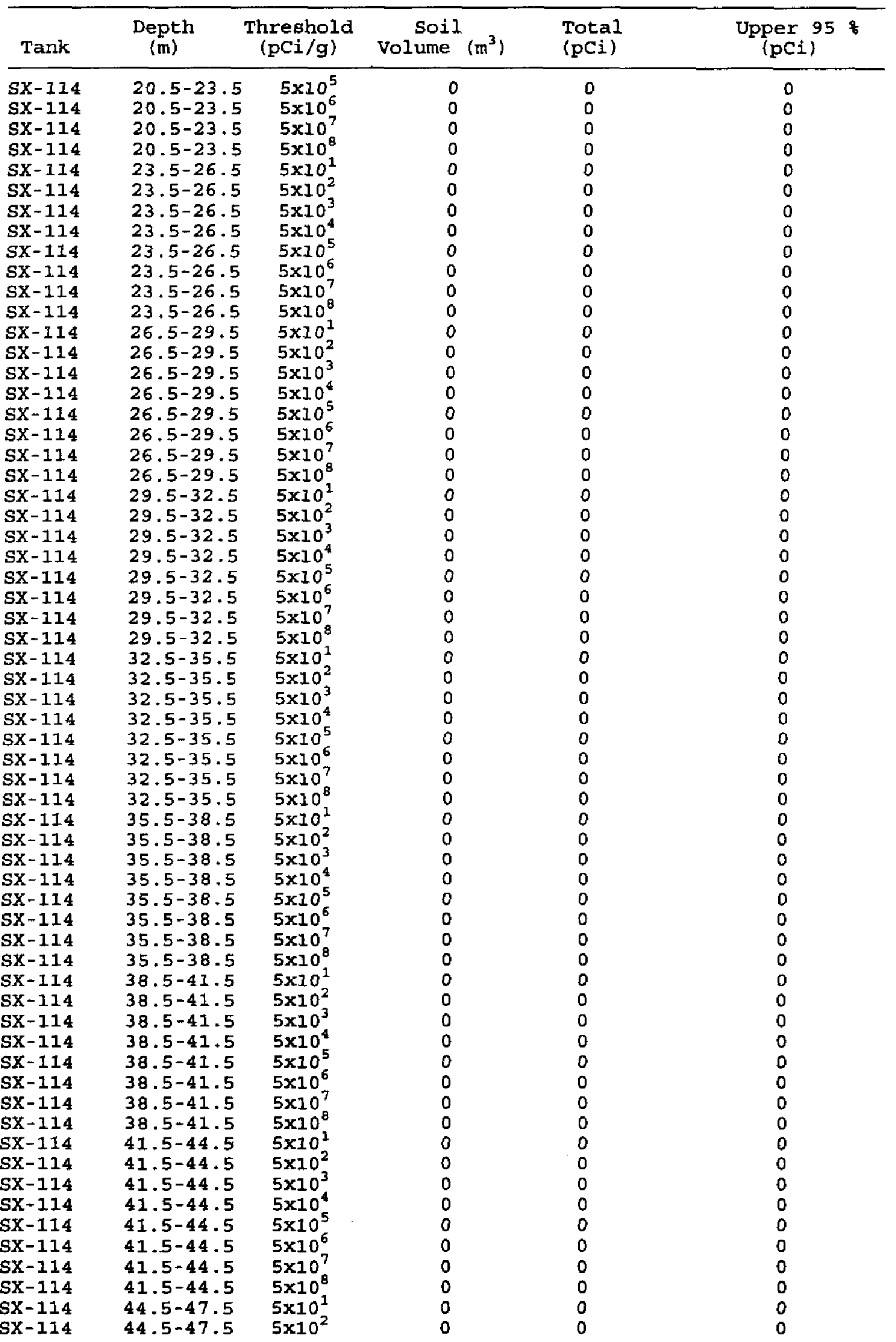


HNF-5782 Rev. O

Table 15. Continued.

\begin{tabular}{|c|c|c|c|c|c|}
\hline Tank & $\begin{array}{l}\text { Depth } \\
\text { (m) }\end{array}$ & $\begin{array}{c}\text { Threshold } \\
(\mathrm{pCi} / \mathrm{g})\end{array}$ & $\begin{array}{c}\text { Soil } \\
\text { Volume }\left(\mathrm{m}^{3}\right)\end{array}$ & $\begin{array}{l}\text { Total } \\
\text { (pCi) }\end{array}$ & $\begin{array}{l}\text { Upper } 95 \\
\text { (pCi) }\end{array}$ \\
\hline$s \mathrm{X}-114$ & $44.5-47.5$ & $5 \times 10^{3}$ & 0 & 0 & 0 \\
\hline $5 x-114$ & $44.5-47.5$ & $5 \times 10^{4}$ & 0 & 0 & 0 \\
\hline $5 x-114$ & $44.5-47.5$ & $5 \times 10^{5}$ & 0 & 0 & 0 \\
\hline$s x-114$ & $44.5-47.5$ & $5 \times 10^{6}$ & 0 & 0 & 0 \\
\hline $5 x-114$ & $44.5-47.5$ & $5 \times 10^{7}$ & 0 & 0 & 0 \\
\hline $5 X-114$ & $44.5-47.5$ & $5 \times 10^{8}$ & 0 & 0 & 0 \\
\hline $5 x-114$ & $47.5-50.5$ & $5 \times 10^{1}$ & 0 & 0 & 0 \\
\hline $5 x-114$ & $47.5-50.5$ & $5 \times 10^{2}$ & 0 & 0 & 0 \\
\hline $5 x-114$ & $47.5-50.5$ & $5 \times 10^{3}$ & 0 & 0 & 0 \\
\hline$s x-114$ & $47.5-50.5$ & $5 \times 10^{4}$ & 0 & 0 & 0 \\
\hline sX-114 & $47.5-50.5$ & $5 \times 10^{5}$ & 0 & 0 & 0 \\
\hline $5 x-114$ & $47.5-50.5$ & $5 \times 10^{6}$ & 0 & 0 & 0 \\
\hline$s x-114$ & $47.5-50.5$ & $5 \times 10^{7}$ & 0 & 0 & 0 \\
\hline $5 x-114$ & $47.5-50.5$ & $5 \times 10^{8}$ & 0 & 0 & 0 \\
\hline
\end{tabular}


Table 16. Sx-115 inventory of soil volumes, total activities and upper 95 confidence limit, exceeding 8 activity thresholds over 17 depth increments.

\begin{tabular}{|c|c|c|c|c|c|}
\hline Tank & $\underset{(m)}{\text { Depth }}$ & $\begin{array}{l}\text { Threshold } \\
(\mathrm{pCi} / \mathrm{g})\end{array}$ & $\begin{array}{l}\text { Soil } \\
\text { Volume }\left(\mathrm{m}^{3}\right)\end{array}$ & $\begin{array}{l}\text { Total } \\
\text { (pCi) }\end{array}$ & $\underset{\text { UpCi) }}{\text { Upper } 95}$ \\
\hline$s x-115$ & $0.0-2.5$ & $5 \times 10^{1}$ & 0 & 0 & 0 \\
\hline$s x-115$ & $0.0-2.5$ & $5 \times 10^{2}$ & 0 & 0 & 0 \\
\hline$S X-115$ & $0.0-2.5$ & $5 \times 10^{3}$ & 0 & 0 & 0 \\
\hline$s x-115$ & $0.0-2.5$ & $5 \times 10^{4}$ & 0 & 0 & 0 \\
\hline$s x-115$ & $0.0-2.5$ & $5 \times 10^{5}$ & 0 & 0 & 0 \\
\hline$S X-115$ & $0.0-2.5$ & $5 \times 10^{6}$ & 0 & 0 & 0 \\
\hline$s x-115$ & $0.0-2.5$ & $5 \times 10^{7}$ & 0 & 0 & 0 \\
\hline$s x-115$ & $0.0-2.5$ & $5 \times 10^{8}$ & 0 & 0 & 0 \\
\hline$s x-115$ & $2.5-5.5$ & $5 \times 10^{1}$ & 0 & 0 & 0 \\
\hline$s x-115$ & $2.5-5.5$ & $5 \times 10_{2}^{2}$ & 0 & 0 & 0 \\
\hline$s x-115$ & $2.5-5.5$ & $5 \times 10^{3}$ & 0 & 0 & 0 \\
\hline$s x-115$ & $2.5-5.5$ & $5 \times 10^{4}$ & 0 & 0 & 0 \\
\hline$s x-115$ & $2.5-5.5$ & $5 \times 10^{5}$ & 0 & 0 & 0 \\
\hline$s x-115$ & $2.5-5.5$ & $5 \times 10^{6}$ & 0 & 0 & 0 \\
\hline$s x-115$ & $2.5-5.5$ & $5 \times 10^{7}$ & 0 & 0 & 0 \\
\hline$s X-115$ & $2.5-5.5$ & $5 \times 10^{8}$ & 0 & 0 & 0 \\
\hline sx-115 & $5.5-8.5$ & $5 \times 10^{1}$ & 0 & 0 & 0 \\
\hline$s x-115$ & $5.5-8.5$ & $5 \times 10^{2}$ & 0 & 0 & 0 \\
\hline $5 x-115$ & $5.5-8.5$ & $5 \times 10^{3}$ & 0 & 0 & 0 \\
\hline$s x-115$ & $5.5-8.5$ & $5 \times 10^{4}$ & 0 & 0 & 0 \\
\hline$S x-115$ & $5.5-8.5$ & $5 \times 10^{5}$ & 0 & 0 & 0 \\
\hline $5 x-115$ & $5.5-8.5$ & $5 \times 10^{6}$ & 0 & 0 & 0 \\
\hline$s x-115$ & $5.5-8.5$ & $5 \times 10^{7}$ & 0 & 0 & 0 \\
\hline$s x-115$ & $5.5-8.5$ & $5 \times 10^{8}$ & 0 & 0 & 0 \\
\hline$s x-115$ & $8.5-11.5$ & $5 \times 10^{1}$ & 0 & 0 & 0 \\
\hline$s x-115$ & $8.5-11.5$ & $5 \times 10_{2}^{2}$ & 0 & 0 & 0 \\
\hline$s x-115$ & $8.5-11.5$ & $5 \times 10^{3}$ & 0 & 0 & 0 \\
\hline$s x-115$ & $8.5-11.5$ & $5 \times 10^{4}$ & 0 & 0 & 0 \\
\hline$s x-115$ & $8.5-11.5$ & $5 \times 10^{5}$ & 0 & 0 & 0 \\
\hline$s x-115$ & $8.5-11.5$ & $5 \times 10^{6}$ & 0 & 0 & 0 \\
\hline$S x-115$ & $8.5-11.5$ & $5 \times 10^{7}$ & 0 & 0 & 0 \\
\hline$s x-115$ & $8.5-11.5$ & $5 \times 10^{8}$ & 0 & 0 & 0 \\
\hline $5 x-115$ & $11.5-14.5$ & $5 \times 10^{1}$ & 0 & 0 & 0 \\
\hline$S x-115$ & $11.5-14.5$ & $5 \times 10^{2}$ & 0 & 0 & 0 \\
\hline$s x-115$ & $11.5-14.5$ & $5 \times 10^{3}$ & 0 & 0 & 0 \\
\hline$s x-115$ & $11.5-14.5$ & $5 \times 10^{4}$ & 0 & 0 & 0 \\
\hline$s x-115$ & $11.5-14.5$ & $5 \times 10^{5}$ & 0 & 0 & 0 \\
\hline$s x-115$ & $11.5-14.5$ & $5 \times 10^{6}$ & 0 & 0 & 0 \\
\hline $5 X-115$ & $11.5-14.5$ & $5 \times 10^{7}$ & 0 & 0 & 0 \\
\hline$s x-115$ & $11.5-14.5$ & $5 \times 10^{8}$ & 0 & 0 & 0 \\
\hline$s x-115$ & $14.5-17.5$ & $5 \times 10^{1}$ & 0 & 0 & 0 \\
\hline$S x-115$ & $14.5-17.5$ & $5 \times 10^{2}$ & 0 & 0 & 0 \\
\hline$s x-115$ & $14.5-17.5$ & $5 \times 10^{3}$ & 0 & 0 & 0 \\
\hline$s x-115$ & $14.5-17.5$ & $5 \times 10^{4}$ & 0 & 0 & 0 \\
\hline$s x-115$ & $14.5-17.5$ & $5 \times 10^{5}$ & 0 & 0 & 0 \\
\hline$s x-115$ & $14.5-17.5$ & $5 \times 10^{6}$ & 0 & 0 & 0 \\
\hline$s x-115$ & $14.5-17.5$ & $5 \times 10^{7}$ & 0 & 0 & 0 \\
\hline$s x-115$ & $14.5-17.5$ & $5 \times 10^{8}$ & 0 & 0 & 0 \\
\hline$s x-115$ & $17.5-20.5$ & $5 \times 10^{1}$ & 305 & $8.20107 E+11$ & $3.27623 \mathrm{E}+12$ \\
\hline $5 x-115$ & $17.5-20.5$ & $5 \times 10^{2}$ & 97 & $7.63569 \mathrm{E}+11$ & $3.13041 E+12$ \\
\hline$s x-115$ & $17.5-20.5$ & $5 \times 10^{3}$ & 24 & $6.11761 E+11$ & $2.68844 E+12$ \\
\hline$s x-115$ & $17.5-20.5$ & $5 \times 10^{4}$ & 0 & 0 & 0 \\
\hline$s x-115$ & $17.5-20.5$ & $5 \times 10^{5}$ & 0 & 0 & 0 \\
\hline $5 x-115$ & $17.5-20.5$ & $5 \times 10_{7}^{6}$ & 0 & 0 & 0 \\
\hline$s x-115$ & $17.5-20.5$ & $5 \times 10^{7}$ & 0 & 0 & 0 \\
\hline$s x-115$ & $17.5-20.5$ & $5 \times 10^{8}$ & 0 & 0 & 0 \\
\hline$s x-115$ & $20.5-23.5$ & $5 \times 10^{1}$ & 505 & $3.31327 E+12$ & $1.44906 \mathrm{E}+13$ \\
\hline$s x-115$ & $20.5-23.5$ & $5 \times 10^{2}$ & 192 & $3.22672 \mathrm{E}+12$ & $1.42725 E+13$ \\
\hline$S X-115$ & $20.5-23.5$ & $5 \times 10^{3}$ & 58 & $2.86767 E+12$ & $1.32741 E+13$ \\
\hline sx-115 & $20.5-23.5$ & $5 \times 10^{4}$ & 10 & $1.89946 \mathrm{E}+12$ & $9.95216 \mathrm{E}+12$ \\
\hline
\end{tabular}


Table 16. Continued.

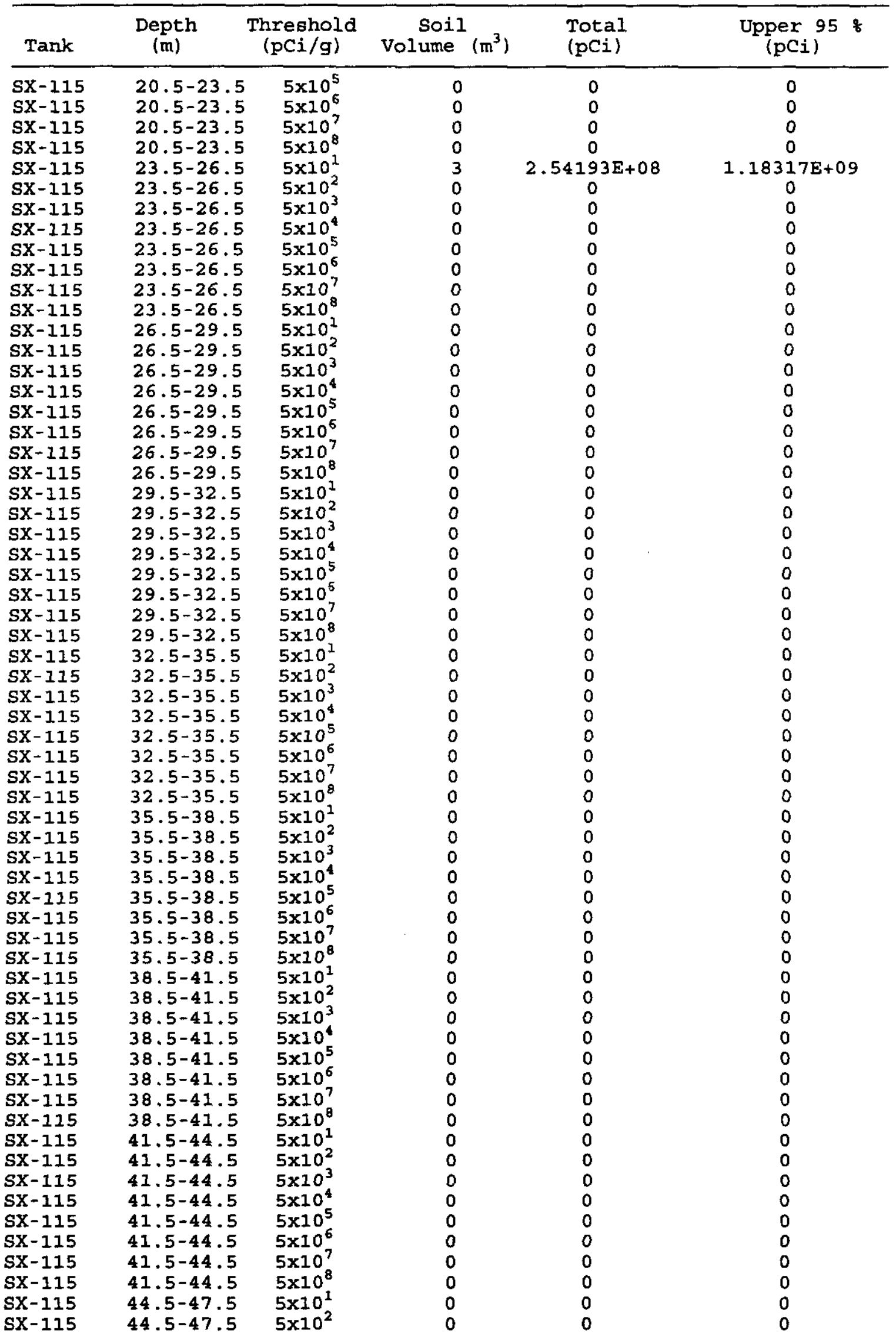


Table 16. Continued.

\begin{tabular}{cccccc}
\hline Tank & $\begin{array}{c}\text { Depth } \\
(\mathrm{m})\end{array}$ & $\begin{array}{c}\text { Threshold } \\
(\mathrm{pCi} / \mathrm{g})\end{array}$ & $\begin{array}{c}\text { Soil } \\
\text { Volume }\end{array}\left(\mathrm{m}^{3}\right)$ & $\begin{array}{c}\text { Total } \\
(\mathrm{pCi})\end{array}$ & $\begin{array}{c}\text { Upper } 95 \text { \% } \\
(\mathrm{pCi})\end{array}$ \\
\hline SX-115 & $44.5-47.5$ & $5 \times 10^{3}$ & 0 & 0 & 0 \\
SX-115 & $44.5-47.5$ & $5 \times 10^{4}$ & 0 & 0 & 0 \\
SX-115 & $44.5-47.5$ & $5 \times 10^{5}$ & 0 & 0 & 0 \\
SX-115 & $44.5-47.5$ & $5 \times 10^{6}$ & 0 & 0 & 0 \\
SX-115 & $44.5-47.5$ & $5 \times 10^{7}$ & 0 & 0 & 0 \\
SX-115 & $44.5-47.5$ & $5 \times 10^{8}$ & 0 & 0 & 0 \\
SX-115 & $47.5-50.5$ & $5 \times 10^{1}$ & 0 & 0 & 0 \\
SX-115 & $47.5-50.5$ & $5 \times 10^{2}$ & 0 & 0 & 0 \\
SX-115 & $47.5-50.5$ & $5 \times 10^{3}$ & 0 & 0 & 0 \\
SX-115 & $47.5-50.5$ & $5 \times 10^{4}$ & 0 & 0 & 0 \\
SX-115 & $47.5-50.5$ & $5 \times 10^{5}$ & 0 & 0 & 0 \\
SX-115 & $47.5-50.5$ & $5 \times 10^{6}$ & 0 & 0 & 0 \\
SX-115 & $47.5-50.5$ & $5 \times 10^{7}$ & 0 & 0 & 0 \\
SX-115 & $47.5-50.5$ & $5 \times 10^{8}$ & 0 & 0 & 0 \\
\hline
\end{tabular}



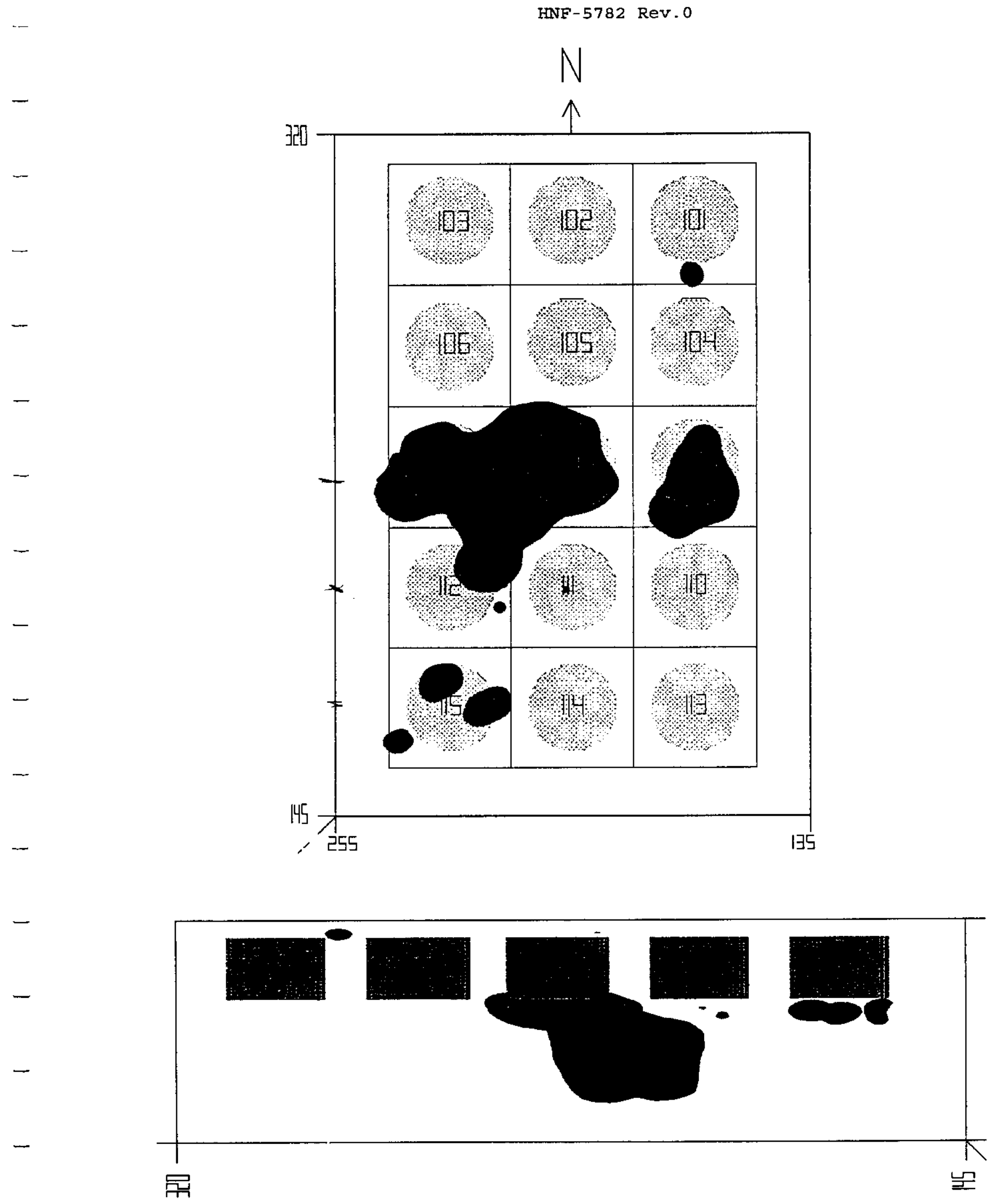

Figure 1. SX kriging point predictions exceeding $5 \times 10^{1} \mathrm{pCi} / \mathrm{g}$ from a top and west view. 
HNF-5782 Rev.0
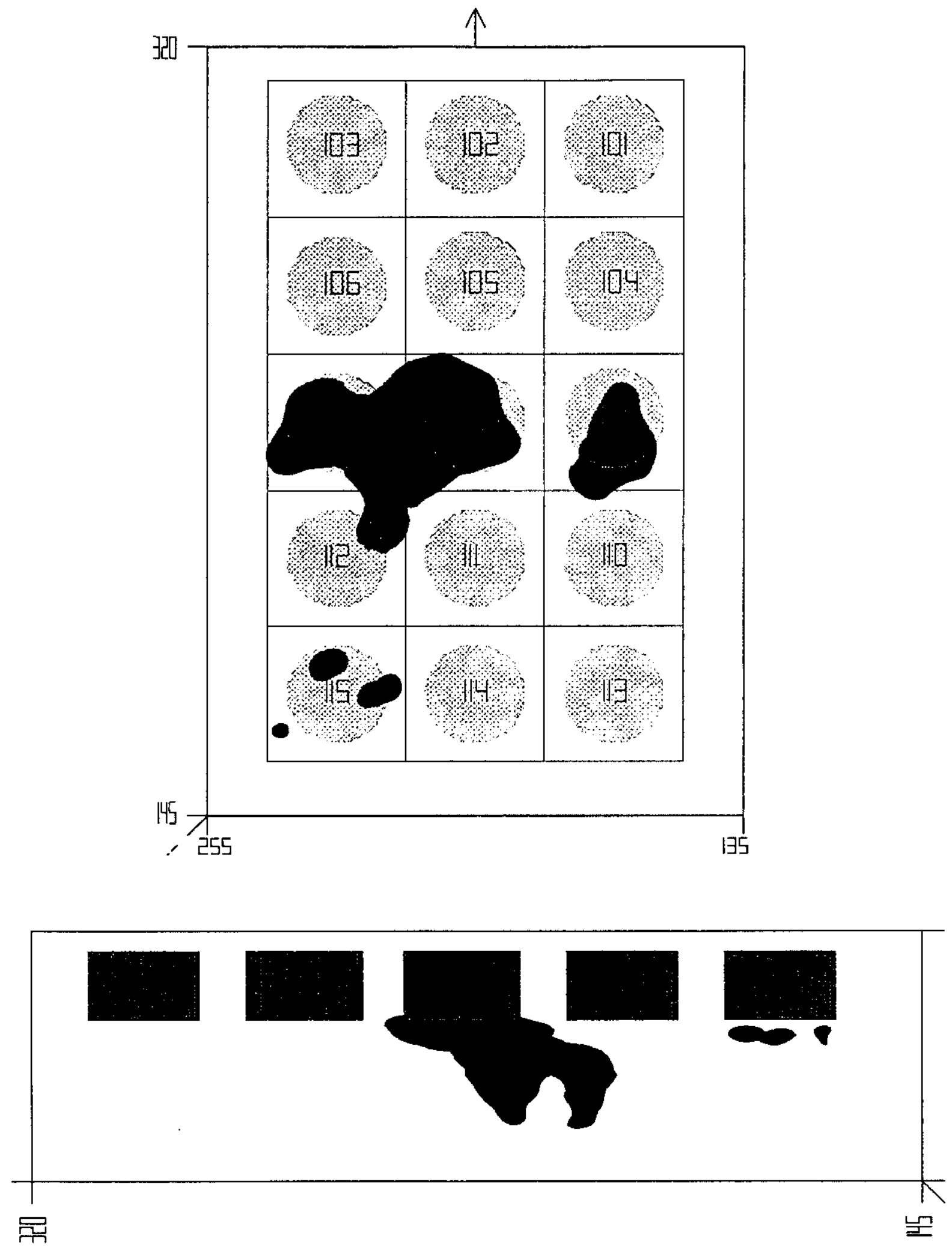

Figure 2. SX kriging point predictions exceeding $5 \times 10^{2} \mathrm{pCi} / \mathrm{g}$ from a top and west view. 

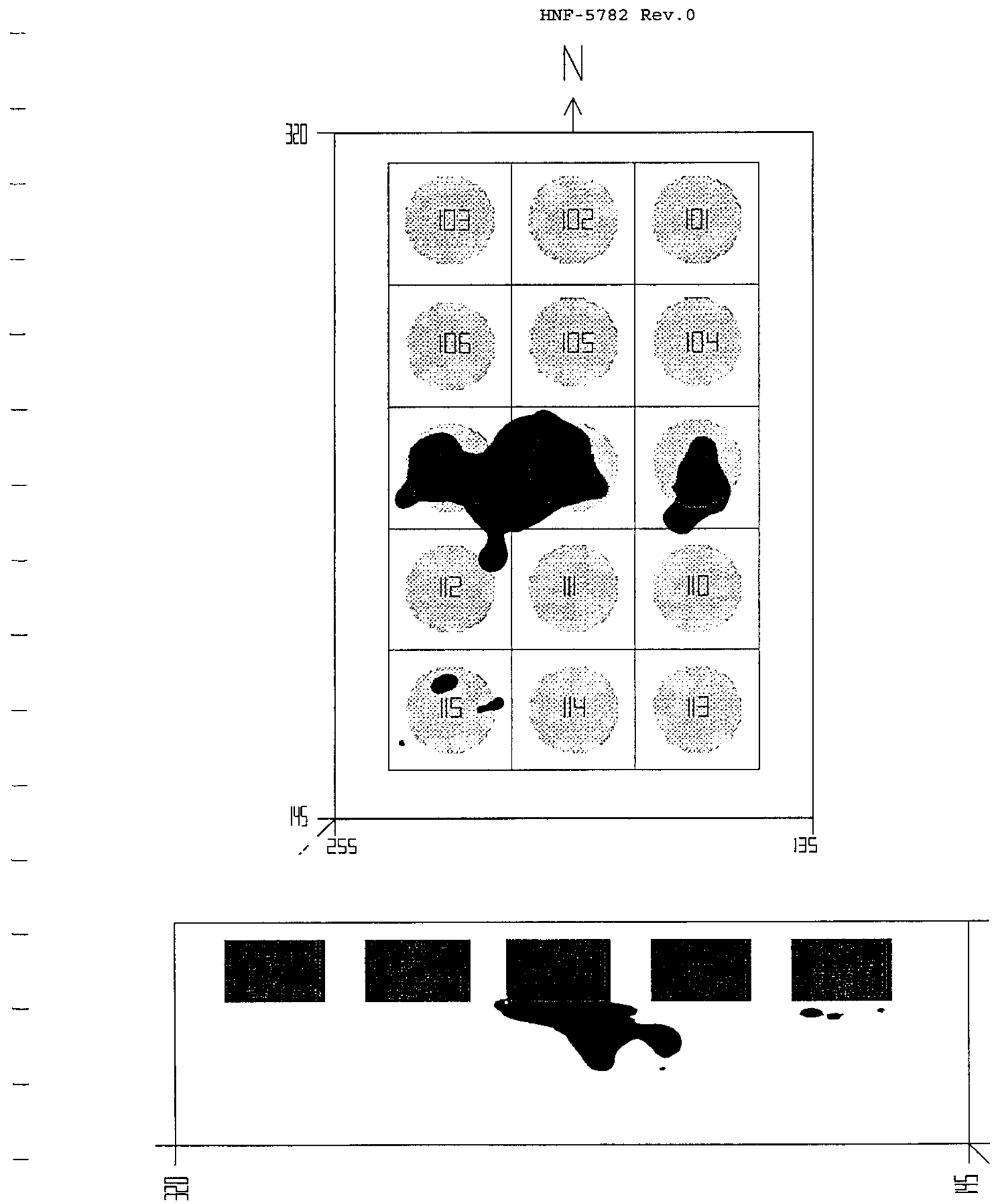

Figure 3. SX kriging point predictions exceeding $5 \times 10^{3} \mathrm{pCi} / \mathrm{g}$ from a top and west view. 

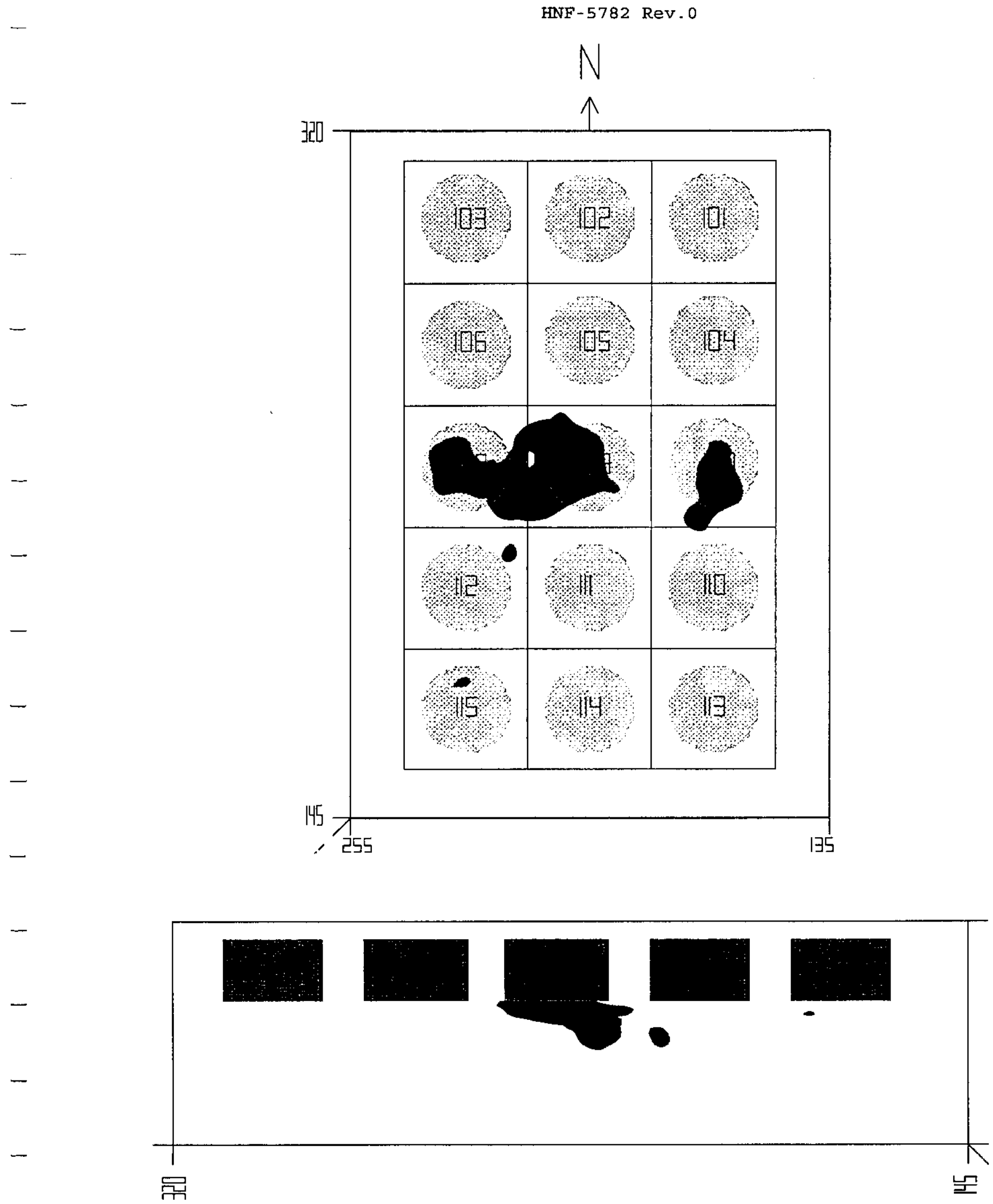

Figure 4. SX kriging point predictions exceeding $5 \times 10^{4} \mathrm{pCi} / \mathrm{g}$ from a top and west view. 

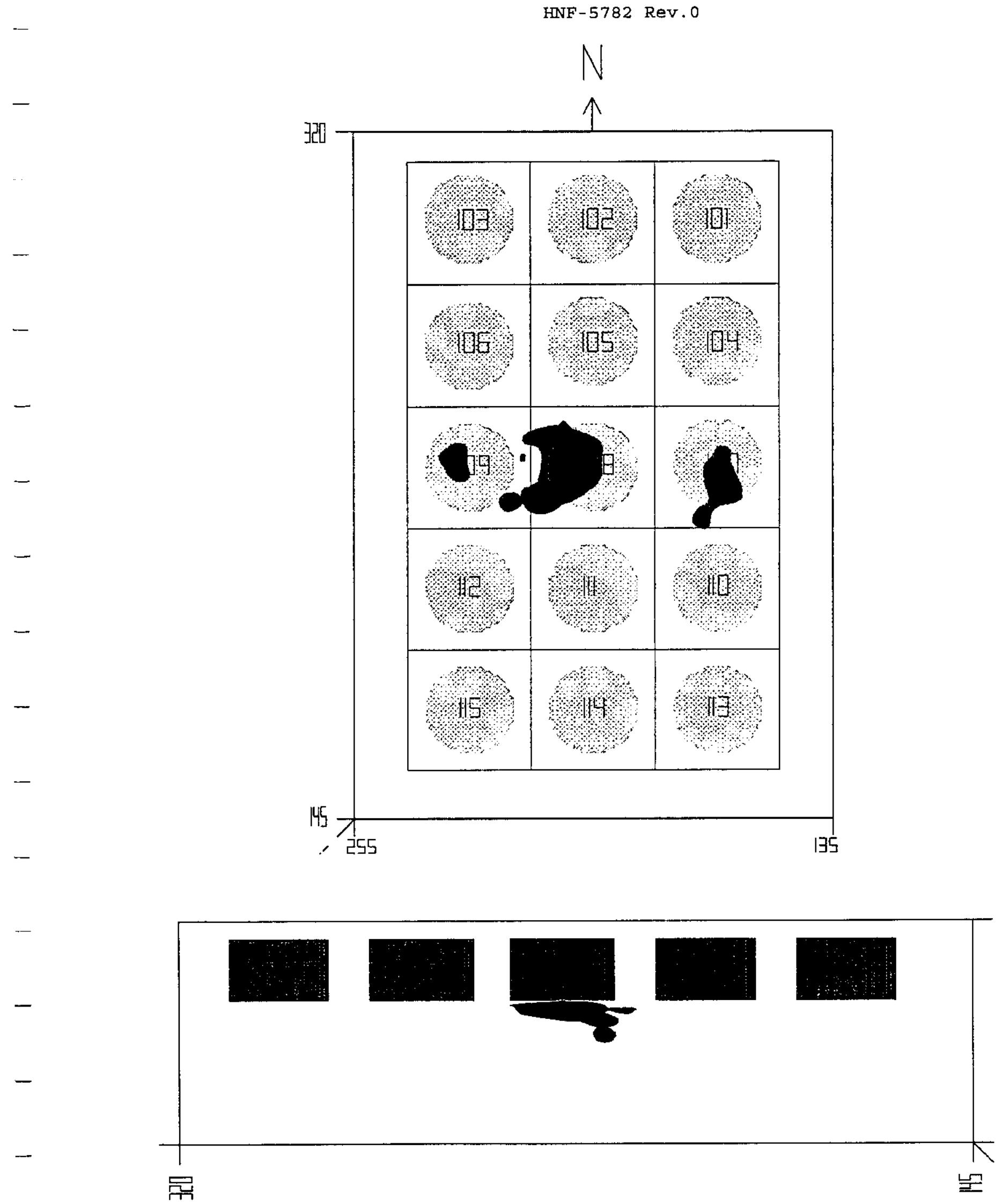

Figure 5. SX kriging point predictions exceeding $5 \times 10^{5} \mathrm{pCi} / \mathrm{g}$ from a top and west view. 

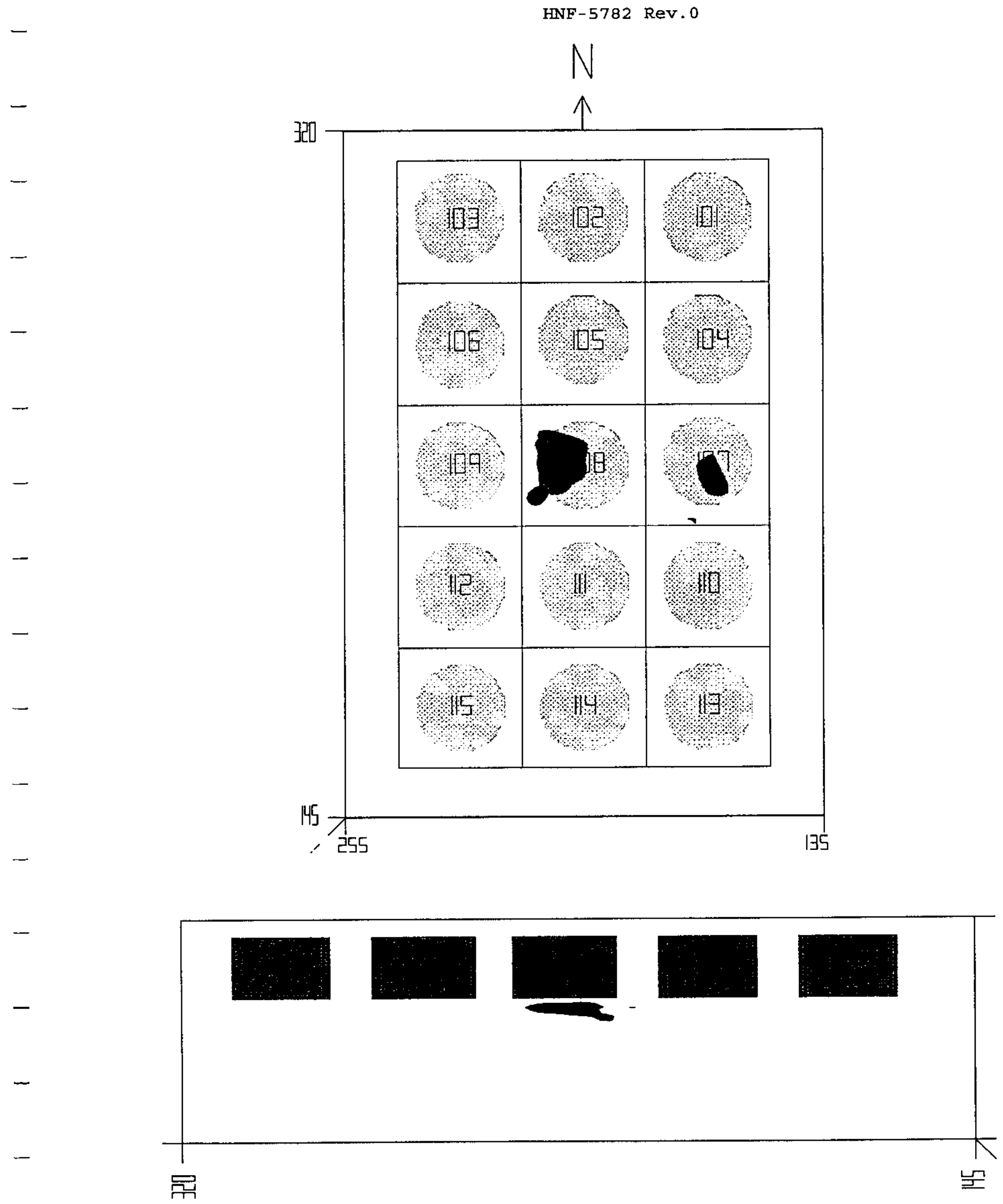

Figure 6. SX kriging point predictions exceeding $5 \times 10^{6} \mathrm{pCi} / \mathrm{g}$ from a top and west view. 

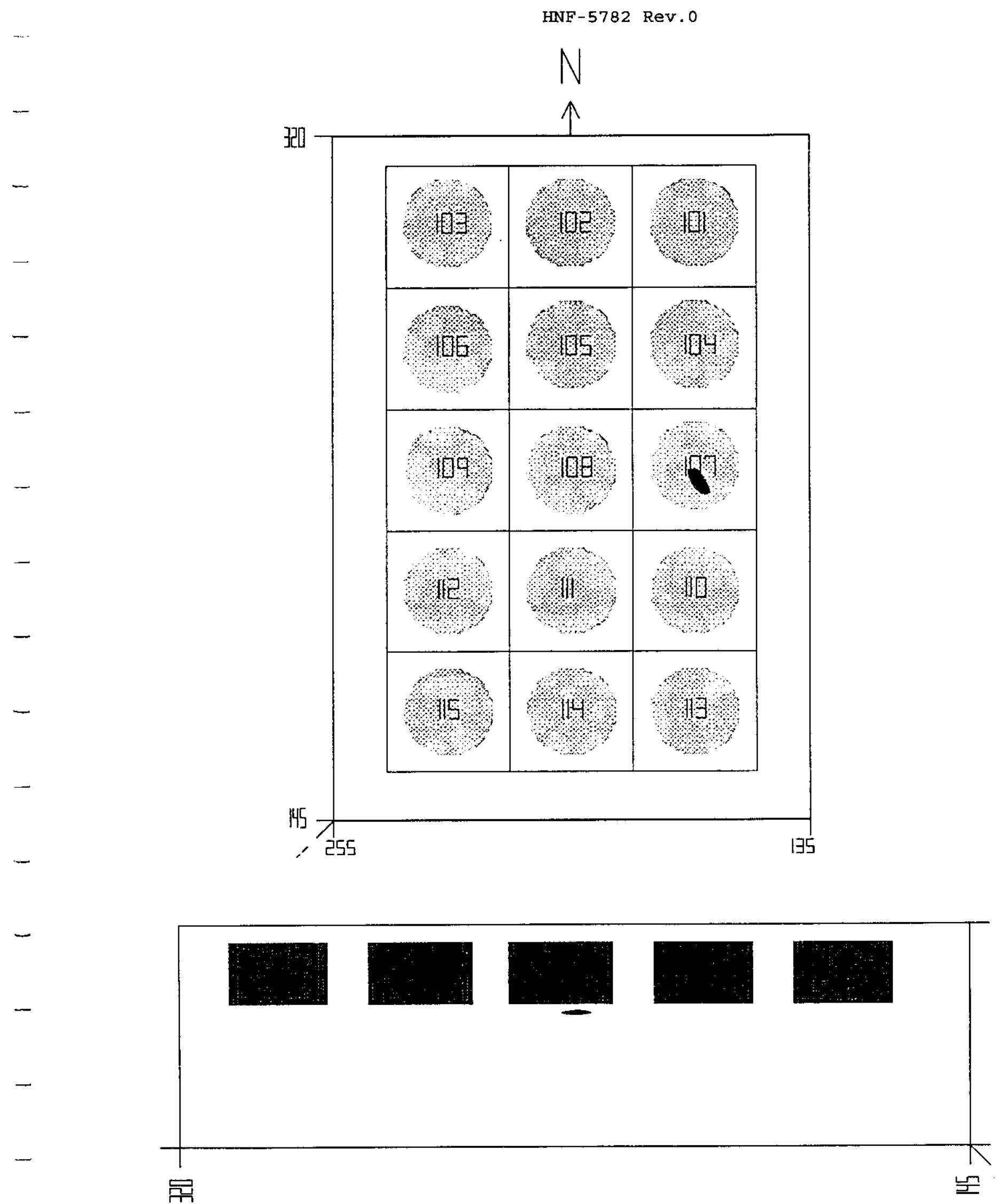

Figure 7. SX kriging point predictions exceeding $5 \times 10^{7} \mathrm{pCi} / \mathrm{g}$ from a top and west view. 